\title{
Investigating resource competition in cereal-legume intercropping systems
}

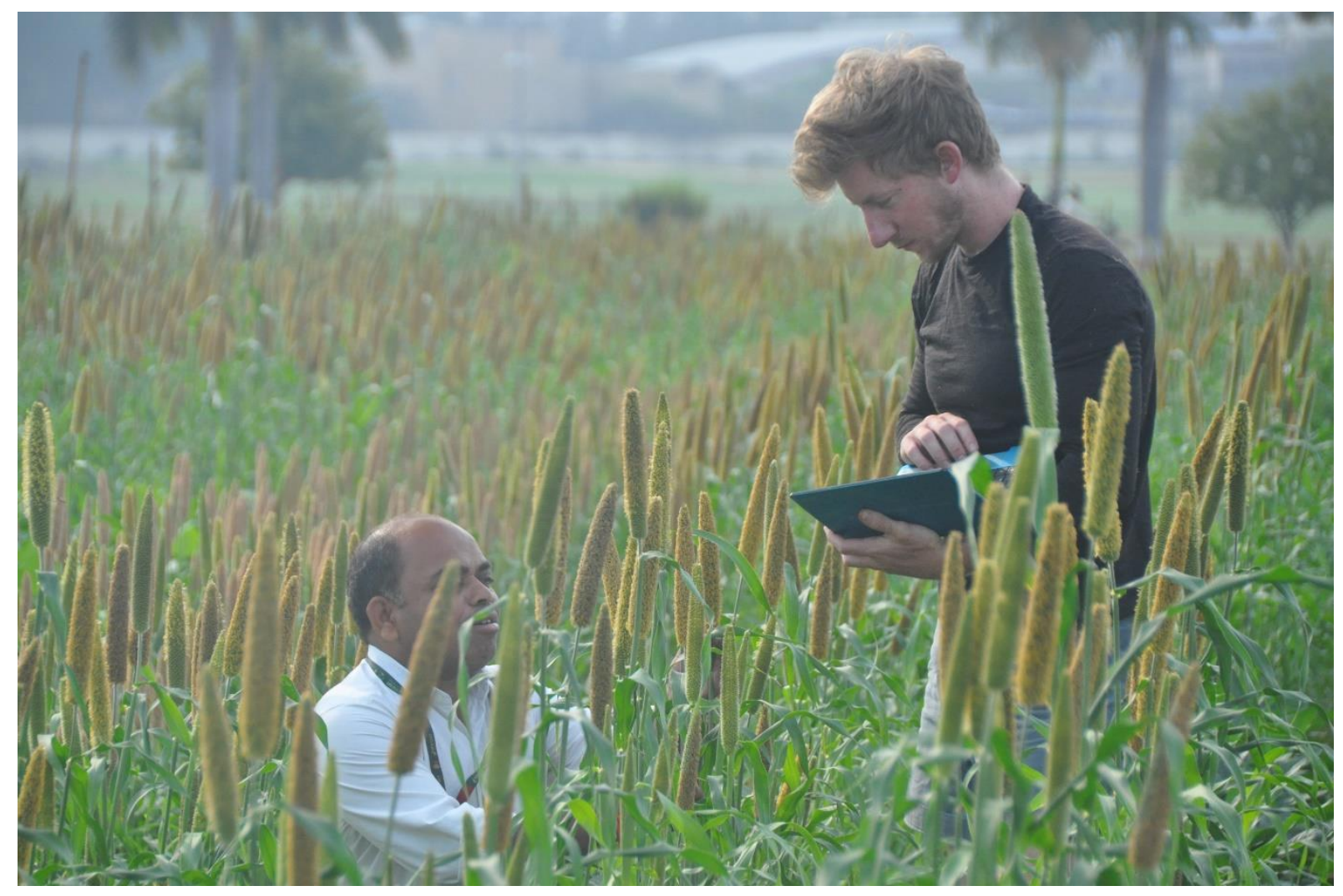

\author{
PhD Dissertation \\ William C.D. Nelson \\ Universität Göttingen \\ 2020
}




\title{
Investigating resource competition in cereal-legume intercropping systems
}

\author{
Dissertation \\ William C.D. Nelson \\ Degree in the International $\mathrm{PhD}$ Program for \\ Agricultural Sciences in Göttingen (IPAG) \\ Faculty of Agricultural Sciences \\ Georg-August-University Göttingen, Germany
}




\author{
By William C.D. Nelson \\ Born in Croydon, London, England \\ Submitted in Göttingen, January 2019 \\ Revised in Göttingen, September 2020
}

D7

1. First supervisor: Prof. Dr. Anthony M. Whitbread

2. Co-supervisor: Prof. Dr. Reimund P. Rötter

3. Third examiner: Prof. Dr. Johannes Isselstein

Defence date: 08.02.2019 
Cover photo credit: Karina Schell, 2015. 


\section{Content}

\section{Chapter One}

\section{Introduction}

$\begin{array}{lll}1.1 & \text { Intercropping } & 1\end{array}$

1.2 Processed based crop modelling 3

$1.3 \quad$ Field experimentation and model improvement 5

$\begin{array}{lll}1.4 & \text { Objectives and summary } & 6\end{array}$

$\begin{array}{lll}1.5 & \text { Structure of } \mathrm{PhD} \text { thesis }\end{array}$

1.6 References 8

\section{Chapter Two}

Testing pearl millet and cowpea intercropping systems under high temperatures

$\begin{array}{lll}2.1 & \text { Introduction } & 14\end{array}$

$\begin{array}{lll}2.2 .1 & \text { Study site } & 15\end{array}$

$\begin{array}{ll}\text { 2.2.2 Climate conditions during the trial periods } & 16\end{array}$

2.2.4 Plant and soil sampling 20

$\begin{array}{lll}2.2 .5 & \text { Data analysis } 20\end{array}$

2.3 Results 21

2.3.1 Grain yield and sequential biomass accumulation 21

$\begin{array}{lll}\text { 2.3.2 } & \text { LER of yield } & 28\end{array}$

2.3.3 Soil moisture at full maturity \& light interception 30

2.4 Discussion 31

2.4.1 Cropping system performance 31

2.4.2 Cropping system responses to water treatment 33

2.4.3 Plant density 34

$\begin{array}{lll}2.5 & \text { Conclusion } & 35\end{array}$

2.6 Acknowledgements 36

2.7 References 36

2.8 Appendix 39

$\begin{array}{lll}2.8 .1 & \text { Sequential biomass harvests } & 39\end{array}$

2.8.2 Leaf area index - light interception 41

$\begin{array}{lll}2.8 .3 & \text { Solar radiation } & 43\end{array}$

$2.9 \quad$ ANOVA results 44

\section{CHAPTER THREE}

Crop model based exploration of the mechanisms underlying pearl millet-cowpea intercropping performance

$\begin{array}{lll}3.1 & \text { Introduction } & 46\end{array}$ 
$\begin{array}{lll}3.2 & \text { Materials and Methods } & 48\end{array}$

$\begin{array}{lll}3.2 .1 & \text { Study region } & 48\end{array}$

3.2.2 Model testing 48

$3.3 \quad$ Results $\quad 55$

3.3.1 Model validation $\quad 55$

3.3.2 Simulation experiment: sensitivity analysis of plant height 61

3.4 Discussion 63

3.4.1 Model performance $\quad 64$

3.4.2 Model improvement $\quad 65$

3.4.3 Understanding the mechanisms underlying pearl millet-cowpea intercropping performance: a case study for plant height $\quad 67$

$\begin{array}{lll}3.4 .4 & \text { Conclusion } & 67\end{array}$

$\begin{array}{lll}3.5 & \text { Acknowledgements } & 68\end{array}$

$\begin{array}{lll}3.6 & \text { References } & 68\end{array}$

\section{CHAPTER FOUR}

What determines a productive winter bean-wheat genotype combination for intercropping in central Germany?

$\begin{array}{lll}4.1 & \text { Introduction } & 73\end{array}$

$\begin{array}{lll}4.2 & \text { Materials and methods } & 75\end{array}$

$\begin{array}{lll}\text { 4.2.1 Site conditions } & 75\end{array}$

$\begin{array}{lll}\text { 4.2.2 Genetic material and experimental design } & 76\end{array}$

$\begin{array}{lll}\text { 4.2.3 Plant and soil sampling } & 78\end{array}$

$\begin{array}{lll}\text { 4.2.4 Data analysis } & 79\end{array}$

$\begin{array}{lll}4.3 & \text { Results } & 80\end{array}$

$\begin{array}{llr}4.3 .1 & \text { Yield } & 80\end{array}$

4.3.2 Physiological traits: leaf area index, plant height and lodging 84

$\begin{array}{lll}\text { 4.3.2 } & \text { Soil water and nitrogen } & 87\end{array}$

$\begin{array}{lll}4.4 & \text { Discussion } & 88\end{array}$

4.4.1 Winter Wheat-bean intercrop performance $\quad 89$

4.4.2 Traits characteristics, resource competition, and implications for breeding 90

4.4.3 Perspectives for winter bean-wheat intercropping 92

$\begin{array}{lll}4.5 & \text { Conclusion } & 94\end{array}$

$\begin{array}{lll}4.6 & \text { References } & 94\end{array}$

$\begin{array}{lll}4.7 & \text { Appendix } & 99\end{array}$

\section{ChaPTER Five}

\section{General discussion}

$\begin{array}{lll}5.1 & \text { Challenges of intercropping } & 101\end{array}$

$\begin{array}{lll}5.2 & 103\end{array}$ 
5.3 Field experimentation for crop model improvement

5.4 Winter bean case study: modelling winter faba bean in northern Germany initial challenges and perspectives

$\begin{array}{lll}\text { 5.4.1 Introduction } & 106\end{array}$

$\begin{array}{lll}\text { 5.4.2 Materials and methods } & 107\end{array}$

$\begin{array}{lll}\text { 5.4.3 Preliminary results and discussion } & 107\end{array}$

$\begin{array}{ll}5.4 .4 \quad \text { Concluding remarks } & 110\end{array}$

$\begin{array}{lll}5.5 & \text { Future crop model applications in intercropping } & 111\end{array}$

5.6 Challenges of developing a modelling framework for intercropping across

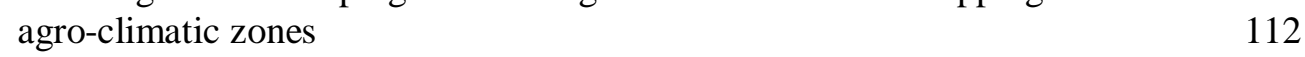

$\begin{array}{lll}5.7 & \text { Conclusions } & 117\end{array}$

$\begin{array}{lll}5.8 & \text { References } & 118\end{array}$

SUMMARY

ACKNOWLEDGEMENTS 


\section{Chapter One}

\section{Introduction}

\subsection{Intercropping}

Intercropping is the practice of growing two or more crops in close proximity (Andrews and Kassam, 1976). Although terminology differs throughout the literature, with terms such as 'mixed cropping' or 'mixtures' being used, this study will refer to the cultivation practice as intercropping. The cultivation of a single crop species is also referred to as a 'sole crop', which is sometimes referred to as 'pure' in some studies (Vandermeer, 1992). Intercropping is a prominent practice in low-input agricultural systems, and has been used for centuries throughout the world up until the $20^{\text {th }}$ century with the on-set of agricultural intensification (Borlung, 2000; Geno and Geno, 2001). The increased use of mechanised practices, such as harvesting and the application of fertilisers increased the efficiency of sole crop production (Lithourgidis et al., 2011). However, such cropping strategies have not been enjoyed without negative consequences on environmental health, which has encouraged an increase in the interest of more sustainable systems where under certain circumstances external resources are not available or are restricted (Tscharntke et al., 2012). While consumer preferences, agricultural and trade policies need to be in favour of multispecies systems for them to prosper, agricultural research has made continuous efforts to understand the mechanisms behind them (Keating and Carberry, 1993; Morris and Garrity, 1997; Tusbo et al., 2005; Nelson et al., 2018).

The major advantages of intercropping cited are the increment in higher production per unit land without additional input (such as mineral fertiliser) and increased buffering against stresses and plant production difficulties (Altieri, 1999; Malezieux et al., 2009). Rusinamhodzi et al. (2012) reported more than three times the financial gain when intercropping maize and pigeon pea compared to sole maize in smallholder systems in Mozambique. A main disadvantage however is the product not being 'pure' but mixed, which can have a lower marketability in some places. Mixed crop management also presents challenges for the current mechanised systems, i.e. separating products, which either requires increased labour or special machinery.

Intercropping is traditionally used in low-input smallholder systems because of poor plant population, where farmers hope to capitalise on niches, i.e. the space left between the initial plantings. This is known as additive intercropping, where the space between crop rows is filled with an intercrop (Hauggaard-Nielsen et al., 2006; Snaydon, 1991). Another 
common system sees alternate rows of, for example, a sole cereal stand, replaced by companion crop rows (usually a legume), known as replacement intercropping, as seen in Nelson et al. (2018). Intercrop systems not only consist of row-based structures, but are also cultivated as strips, whereby multiple rows, of for example a cereal, are followed by multiple rows of a companion crop (Li et al., 2006). Sun et al. (2018) also present successful intercropping of the forage legume alfalfa with maize, highlighting the fact that systems (grassland and arable in this case) can also be mixed. This study focuses on arable, single row cereal-legume intercrop cultivation.

The use of leguminous plant species as part of any intercrop system can be beneficial for low-input systems, due to the ability of legumes to fix nitrogen (Jensen, 1996; Xiao et al., 2004). The mechanisms behind positive mixing effects are strongly hypothesised. The symbiosis with rhizobia is of particular interest, as cereal-legume intercropping is seen to be especially promising (Li et al., 2006; Xiao et al., 2004; Senbayram et al., 2008; Blum, 2009). Hauggaard-Nielsen and Andersen (2000) and Li et al. (2006) explain how differences in timing between component crops, spatial pattern and the acquisition and use of light, water and nutrients leads to improved resource use efficiency through crop mixtures. Scientific evidence and arguments that promote intercropping systems focus on numerous factors, such as increasing input costs, a decrease in the availability of energy, nitrogen, phosphorous, and agrochemicals that can be connected with climate variability and environmental damage (Newton et al., 2009; Randers, 2012; Tilman et al., 2002). The resource use efficiency of intercrop systems does not solely refer to nutrients, but encapsulates factors such as water use, and space, be that above- (light) or below-ground (root) (Keating and Carberry, 1993; Morris and Garrity, 1993; Chimonyo et al., 2016a; Streit et al., 2018). In low-input systems in particular, intercropping is also said to better defend stands against weeds, plant pathogens and pests, due to canopy coverage and the benefits associated with increased biodiversity (Altieri, 1995; Finckh, 2008; Gronle and Boehm, 2012).

A major challenge for agricultural production in the coming decades is to increase productivity from existing production sites. To do so, resources such as light, water, nutrients and labour need to work as efficiently as possible to realise eco-efficient and resilient crop production systems (Keating et al., 2010). In a recent review on the acceleration of genetic gains in legumes, Varshney et al. (2018) stress the importance of precision when designing plant breeding programmes, and highlight the importance of approaching agricultural challenges from a systems perspective. The development of successful intercrop systems is therefore likely to be achieved via a similar method, looking 
at specific conditions and certain crop combinations, planting diverse crop mixtures of various types with varying attributes (Malézieux et al., 2009). Indeed, Li et al. (2006) highlight the importance of crop combinations for intercropping, as some can be more beneficial than others.

The yield advantage gained via intercropping is referred to as the 'mixing effect' (Hof and Rauber, 2003) with land equivalent ratios (LER) higher than one indicating superiority of inter- over sole cropping (Willey, 1979; cf. Pretzch and Schuetze, 2009). Land equivalent ratios were reported to be higher than one in $60 \%$ of 344 surveyed cases by Hof and Rauber (2003). Similarly, Paulsen and Schochow (2007) found LER to be higher than one for 50 of 76 arable land mixtures. On average, mixing effects seem to be positive, with a large variation between cases. This opens up options to exploit favourable interactions between specific component crops (Lithourgidis et al., 2011; Kremen and Miles, 2012). With the above-mentioned examples in mind, while intercropping interactions proved favourable in general, there are clearly some scenarios that do not result in higher overall yields. Hence, intercropping is not always seen as a convincing option for farmers. Processes determining intercropping performance need to be far better understood before it is seen as a conceivable option. An improved understanding would allow for the selection of specific crop combinations, at a genotype level, along with densities and other management options. Intercropping is a highly sophisticated system and has the potential, with an advanced understanding, to be managed with precision, like many modern monoculture systems. While field experiments can be financially demanding, they are crucial if we are to make advancements. Linking crop simulation models (CSM) and field experiments presents itself as an effective method of dealing with the overwhelming variety of intercropping combinations to be tested, and could help guide field-based research (Reynolds et al., 2018; Rötter et al., 2018b).

\subsection{Processed based crop modelling}

While a range of process based crop models exists (Table 1), the Agricultural Production Systems Simulator (APSIM) is widely used has been chosen for this study. The model was and continues to be developed by the Australian Production Systems Research Unit (APSRU), which is a collaborative group made up of CSIRO and Queensland State Government agencies, having started in 1991. While different models vary in terms of the description of certain processes, they simulate plant growth, which is divided by the various organs, such as stem, leaves, and roots on a daily basis. The development of plants is divided into growth stages, such as emergence, juvenile, flowering, grain filling, and maturity. A 
water balance and a nitrogen module enables APSIM (among other models) to assess such limitations. Crop modules for APSIM, for example cowpea (Robertson et al., 2002), have been tested against field observations, which are documented, and can be found within the model and online (Table 1). Limitations of APSIM include stresses from nutrients other than nitrogen, as well as pests and diseases, although considerable efforts on the latter have been initiated (Savary et al., 2018).

The APSIM model consists of a modular framework and is therefore suitable for a range of purposes, such as climate change assessments (Asseng et al., 2014), and ideotyping for plant breeding programmes (Rötter et al., 2015; He et al., 2018). The modular nature of models like APSIM enables knowledge from various disciplines to be brought together and integrated (Mao et al., 2015). This was a particularly important part of this study in terms of the experiments conducted in Germany as part of the IMPAC ${ }^{3}$ project, which will be discussed in more detail later. The APSIM model is particularly popular, in part, due to its user friendly interface. Simple simulation experiments can be conducted without the need for computer engineering skills and its use is often combined with field-based experimentation. The extent of model development has mainly explored monoculture cereals, such as wheat, barley, maize, and rice, due to, but not exclusively, economic importance, and data being more readily availabile compared to that of other systems.

Sustainable intensification strategies often promote the use of legumes (Franke et al. 2018; van Loon, et al., 2018), as well as multispecies systems under various scenarios (Altieri, 2004; Masvaya et al., 2017). Consequently, modelling communities have started looking into the integration of legumes in current systems, exploring niches (Sennhenn et al., 2017), and highlighting yield gaps and potential improvement strategies (Hajjarpoor et al., 2018). While research on sole legume systems is well-established, intercropping is becoming increasingly important, in line with global sustainability agendas and movements (Mao et al., 2015; Chimonyo et al., 2016b). Studies that combine modelling and intercropping are however rare (Carberry et al., 1996), highlighting the unique scientific contribution offered by this thesis. With legume demand increasing to compliment cereal production (Varshney et al., 2018), intercropping presents itself as an obvious opportunity to exploit and play a key role in global legume integration programmes.

The availability and competition for resources plays a major role in determining the circumstances under which optimal efficiencies are achieved (Sennhenn et al., 2017), especially in multispecies systems. Such traits are however often difficult to measure in the field alone, and so crop modelling has become a useful tool with which to understand the 
interactions between environment, phenotype and genotype in cropping systems (Hammer et al., 2010).

Table 1: Common process based crop models.

\begin{tabular}{|c|c|c|c|}
\hline Full name & Abbreviation & Reference & Link \\
\hline $\begin{array}{l}\text { Agricultural Production } \\
\text { Systems sIMulator }\end{array}$ & APSIM & $\begin{array}{l}\text { Holzworth et al., } \\
2014\end{array}$ & $\underline{\text { www.apsim.info }}$ \\
\hline $\begin{array}{l}\text { Simulateur mulTIdisciplinaire } \\
\text { pour les Cultures Standard }\end{array}$ & STICS & $\begin{array}{l}\text { Brisson et al., } \\
2003\end{array}$ & www.paca.inra.fr \\
\hline $\begin{array}{l}\text { Decision Support System for } \\
\text { Agrotechnology Transfer }\end{array}$ & DSSAT & Jones et al., 2003 & $\underline{\text { www.dssat.net }}$ \\
\hline CropSyst & CropSyst & $\begin{array}{l}\text { Stöckle, Donatelli } \\
\text { and Nelson, } 2003\end{array}$ & $\begin{array}{l}\text { www.sites.bsyse. } \\
\text { wsu.edu/CS_Suite_4 }\end{array}$ \\
\hline World Food Studies & WOFOST & de Wit et al., 2019 & www.wofost.wur.nl \\
\hline
\end{tabular}

\subsection{Field experimentation and model improvement}

Crop modelling can play an important role in the development of food production systems (Reynolds et al., 2018), but the inclusion of field experimentation must be a key part of this process (Rötter et al., 2018b). Crop modelling has achieved great merits over the past decade in particular through joint international efforts such as the Agricultural Model Intercomparison and Improvement Project (AgMIP: Rosenzweig et al., 2013) and Modelling European Agriculture with Climate Change for food Security (MACSUR: Hoffmann et al., 2018; Rötter et al., 2018b). These projects linked climate, crop, and economic modelling communities to collaborate on food security and sustainability based projections. Output examples include yield gap assessments (Hoffmann et al., 2018) and the use of multi-model ensembles (MME), which are reported to offer more robust information than single models (Asseng et al., 2014; Rodrigues et al., 2019; Rötter et al., 2012b). As a recent example of legume based crop model research, Hajjarpoor et al. (2018) reported that Indian chickpea production has the potential to produce $40 \%$ more than currently achieved under standard management practices, highlighting the way in which modelling experiments can guide and shape future research. While a large amount of modelling work has been done since 2010, mainly looking at drought and heat stress, future modelling research looks to focus on the use of empirical evidence to improve CSMs, as well as the development of more holistic, integrated approaches that combine several tools to help 
deliver genetic gains (Varshney et al., 2018). Whitbread et al. (2017) showed that fieldmeasured soil water was indeed better suited to parameterise the APSIM crop model than common laboratory methods, emphasising the importance of field-derived data. The connection between targeted field experimentation and CSMs orientates itself around specific and well-designed experiments on certain crop impacts of given scenarios, such as drought for instance, as well as broadening the range of crops researched (Rötter et al., 2018a). Crop simulation models can be used to guide field trials, which in turn, give feedback to the models and the specific questions posed. The need for more robust food production systems in the face of climate variation (Trnka, et al., 2014) calls for improved agricultural management and the development of suitable genetic material (Rötter et al., 2015); two aspects of crop production and CSM improvement that this thesis investigates.

\subsection{Objectives and summary}

Within the above-described topics, this $\mathrm{PhD}$ thesis has the following objectives:

i. Develop our understanding of GxExM interactions of intercrop systems through looking at detailed data sets comprised of grain yield and biomass harvests as well as plant physiological traits.

ii. Evaluate model accuracy and identify knowledge gaps that specify areas of APSIM that need improvement.

iii. Discuss the interrelation between using field experimentation to improve CSMs, and CSMs for the identification, definition, and development of field trial design, as well as questions surrounding agricultural systems.

To address these objectives two cereal-legume intercropping trials were conducted, one in semi-arid India, and the other in Germany under temperate conditions. The crop cultivars used suited the climate in question, i.e. pearl millet and cowpea in India, and wheat and faba bean in Germany. The synergy between the trials was based on the experimentation with sole and intercrop systems, assessing the impacts of traits on both systems, as well as some additional management-based variations. Experimental set-up differed between the Indian and German trials to add a more defined focus to each site. The trial in India was conducted in the off-season and exposed to high temperatures and little to no precipitation. This trial was irrigated with three different treatments, as well as using two different sowing densities. Only one genotype for each crop was used in this trial, which spanned two years, being sown around the beginning of February and harvested three to four months later 
(around May). The German trial took place under rain-fed conditions over three years, covering two different sites in central Germany, and included the use of eight bean genotypes and three wheat varieties. Both of these crops were winter crops, sown around October and harvested in August the following year. This experiment investigated the interactions between the various genetic combinations, assessing which bean and wheat traits are responsible and more preferable for intercropping and why. In both experiments, intercrop stands were sown simultaneously. Once the field trial data sets had been analysed, the data was used as input for the CSM APSIM.

\subsection{Structure of $\mathrm{PhD}$ thesis}

This thesis is divided into five chapters. The first, introduces the scientific motivation and background of the overall research objectives. Chapter two, three, and four consist of a collection of research results written in the form of journal articles, of which chapter two is published. Chapters three and four have been submitted and are under review by peer reviewed journals. The final chapter, chapter five, briefly brings the conclusions of the previous chapters together and discusses the overall research objectives.

i. Chapter two, published in Field Crops Research as:

Nelson, W.C.D., Hoffmann, M.P., Vadez, V., Rötter, R.P., Whitbread, A.M., 2018.

Testing pearl millet and cowpea intercropping systems under high temperatures. F. Crop. Res. 217, 150-166. doi: 10.1016/j.fcr.2017.12.014.

ii. Chapter three, submitted and under review as:

Nelson, W.C.D., Hoffmann, M.P., Vadez, V., Rötter, R.P., Koch, M., Whitbread, A.M. (under review). Crop model based exploration of the mechanisms underlying pearl millet-cowpea intercropping performance. Understanding the mechanisms underlying pearl millet-cowpea intercropping performance: what can crop modelling teach us?

iii. Chapter four, submitted and under review as:

W.C.D. Nelson \& D.J. Siebrecht-schöll, M.P. Hoffmann, R.P. Rötter, A.M. Whitbread, W. Link (under review). What determines a productive winter beanwheat genotype combination for intercropping in central Germany? 


\subsection{References}

Altieri, M. A., 1995. Agroecology: the science of sustainable agriculture. Westview Press, 433pp. doi: 10.1007/BF02345332.

Altieri, M. A., 1999. The ecological role of biodiversity in agroecosystems. Agriculture, Ecosystems \& Environment 74, 19-31. doi: 10.1016/S0167-8809(99)00028-6.

Altieri, M.A., 2004. Linking ecologists and traditional farmers in the search for sustainable agriculture. Front Ecol Environ 2004; 2 (1): 35-42. doi: 10.2307/3868293.

Andrews, D.J., Kassem, A.H., 1976. The importance of multiple cropping in increasing world food supply. American Society of Agronomy, Crop Science Society of America, and Soil Science Society of America: 1-10.

Asseng, S., Ewert, F., Martre, P., Rötter, R. P., Lobell, D. B., Cammarano, D., Kimball, B. A., Ottman, M. J., Wall, G. W., White, J. W., Reynolds, M. P., Alderman, P. D., Prasad, P.V.V., Aggarwal, P. K., Anothai, J., Basso, B., Biernath, C., Challinor, A. J., De Sanctis, G., Doltra, J., Fereres, E., Garcia-Vila, M., Gayler, S., Hoogenboom, G., Hunt, L. A., Izaurralde, R. C., Jabloun, M., Jones, C. D., Kersebaum, K. C., Koehler, A-K., Müller, C., Naresh Kumar, S., Nendel, C., O’Leary, G., Olesen, J. E., Palosuo, T., Priesack, E., Eyshi Rezaei, E., Ruane, A. C., Semenov, M. A., Shcherbak, I., Stöckle, C., Stratonovitch, P., Streck, T., Supit, I., Tao, F., Thorburn, P. J., Waha, K., Wang, E.,Wallach, D., Wolf, J., Zhao, Z., Zhu, Y., 2014. Rising temperatures reduce global wheat production. Nature Climate Change, vol. 5, February 2015. doi: 10.1038/nclimate2470.

Blum, A., 2009. Effective use of water (EUV) and not water-use efficiency (WUE) is the target of crop yield improvement under drought stress. Field Crops Research. 112: 11-123. doi: 10.1016/j.fcr.2009.03.009.

Brisson, N., Gary, C., Justes, E., Roche, R., Mary, B., Ripoche, D., Zimmer, D., Sierra, J., Bertuzzi, P., Burger, P., Bussière, F., Cabidoche, Y.M., Cellier, P., Debaeke, P., Gaudillère, J.P., Hénault, C.H., Maraux, F., Seguin, B., Sinoquet, H., 2003. An overview of the crop model STICS. Eur. J. Agron. 18:309-332. doi: 10.1016/S11610301(02)00110-7.

Carberry, P. S., Adiku, S. G. K., McCown, R. L., Keating, B. A. 1996. Application of the APSIM cropping systems model to intercropping systems. In: Ito O., Johansen, C., Adu-Gyamfi, J., Katayama, K., Kumar Rao, J. V. D., and Rego, T. J. (Eds), 1996. Dynamics of Roots and Nitrogen in Cropping Systems of the Semi-Arid Tropics. Japan International Research Center for Agricultural Sciences, 637-48.

Chimonyo, V.G.P., Modi, A.T., Mabhaudhi, T., 2016a. Water use and producivity of a sorghum-cowpea-bottle gourd intercrop system. Agricultural Water Management 165 (2016) 82-96. doi: 10.1016/j.agwat.2015.11.014.

Chimonyo, V.G.P., Modi, A.T., Mabhaudhi, T., 2016b. Simulating yield and water use of a sorghum-cowpea intercrop using APSIM. Agric. Water Manag. 177, 317-328. doi: 10.1016/j.agwat.2016.08.021.

Craufurd, P.Q., Vadez, V., Jagadish, S.V.K., Prasad, P.V.V., Zaman-Allah, M., 2011. Crop science experiments designed to inform crop modeling. Agric. Forest Meteorol. Vol. 170, 15 March 2013, Pages 8-18. doi: 10.1016/j.agrformet.2011.09.003. 
Dalgleish, N., and Foale, M., 1998. Soil matters - Monitoring soil water and nutrients in dryland farming. Agricultural Production Systems Research Unit Toowoomba, Queensland, Australia.

Finckh, M.R., 2008. Integration of breeding and technology into diversification strategies for disease control in modern agriculture. European Journal of Plant Pathology 121, 399-409. doi: 10.1007/s10658-008-9273-6.

Franke, A.C., van den Brand, G.J., Vanlauwe, B., Giller, K.E., 2018. Sustainable intensification through rotations with grain legumes in Sub-Saharan Africa: A review. Agriculture, Ecosystems and Environment 261 (2018) 172-185. doi: 10.1016/j.agee.2017.09.029.

Geno, L.M., Geno, B.J., 2001. Polyculture production: principles, benefits and risks of multiple cropping land management systems for Australia: a report for the rural industries research and development corporation. Rural Industries Research and Development Corporation.

Gronle, A., and H. Boehm, 2012. Does a pea-cereal intercropping under shallow ploughing compensate for the higher weed growth compared to deep ploughing in organic farming, Julius-Kuhn-Archiv, 434, 2012243.

Hajjarpoor, A., Vadez, V., Soltani, A., Gaur, P., Whitbread, A., Babu, D.S., Gumma, M.K., Diancoumba, M., Kholová, J., 2018. Characterisation of the main chickpea cropping systems in India using a yield gap analysis approach. Field Crops Research 223 (2018) 93-104. doi: 10.1016/j.fcr.2018.03.023.

Hauggaard-Nielsen, H., Ambus, P, Jensen, E. S., 2001. Temporal and spatial distribution of roots and competition for nitrogen in pea-barley intercrops - a field study employing 32P technique. Plant \& Soil 236, 63-74. doi: 10.1023/A:1011909414400.

Hauggaard-Nielsen, H., Anderson, M.K., Jornsgaard, B., Jensen, E.S., 2006. Density and relative frequency effects on competitive interactions and resource use in pea-barley intercrops. Field Crops Res. 95, 256-267. doi: 10.1016/j.fcr.2005.03.003.

Hammer, G. L., van Oosterom, E., McLean, G., Chapman, S. C., Broad, I., Harland, P., and Muchow, R. C., 2010. Adapting APSIM to model the physiology and genetics of complex adaptive traits in field crops. Journal of Experimental Botany 61, 21852202. doi: $10.1093 / \mathrm{jxb} / \mathrm{erq} 095$.

He, W., Yang, J.Y., Qian, B., Drury, C.F., Hoogenboom, G., He, P., Lapen, D., Zhou, W., 2018. Climate change impacts on crop yield, soil water balance and nitrate leaching in the semiarid and humid regions of Canada. PLOS ONE, Nov. 16, 2018. doi: 10.1371/journal.pone. 0207370 .

Hoffmann, M.P., Haakana, M., Asseng, S., Höhn, J.G., Palosu, T., Ruiz-Ramos, M., Fronzek, S., Ewert, F., Gaiser, T., Kassie, B.T., Paff, K., Rezaei, E.E., Rodriguez, A., Semenov, M., Srivastava, A.K., Stratonovitch, P., Tao, F., Chen, Y., Rötter, R.P., 2018. How does inter-annual variability of attainable yield affect the magnitude of yield gaps for wheat and maize? An analysis at ten sites. Agricultural Systems 159 (2018) 199-208. doi: 10.1016/j.agsy.2017.03.012.

Holzworth, D.P., Huth, N.I., Peter, G., Zurcher, E.J., Herrmann, N.I., McLean, G., Chenu, K., van Oosterom, E.J., Snow, V., Murphy, C., Moore, A.D., Brown, H., Whish, J.P.M., Verrall, S., Fainges, J., Bell, L.W., Peake, A.S., Poulton, P.L., Hochman, Z., Thorburn, P.J., Gaydon, D.S., Dalgliech, N.P., Rodriguez, D., Cox, H., Chapman, 
S., Doherty, A., Teixeira, E., Sharpe, J., Cichota, R., Vogeler, I., Li, F.Y., Wang, E., Hammer, G.L., Robertson, M.J., Dimes, J.P., Whitbread, A.M., Hunt, J., van Rees, H., McClelland, T., Carberry, P.S., Hargreaves, J.N.G., MacLeod, N., McDonald, C., Harsdorf, J., Wedgwood, S., Keating, BA., 2014. APSIM - Evolution towards a new generation of agricultural systems simulation. Environmental Modelling \& Software. Vol. 62, December 2014, p. 327-350. doi: 10.1016/j.envsoft.2014.07.009.

Hof, C., and R. Rauber, 2003: Growing crop mixtures in organic farming. Published by National Program for Organic farming at Federal Institute for Agriculture and Human Nutrition, Bonn and Goettingen, 55 pages; ISBN 3-00-011733-4).

Jensen, E.S., 1996. Rhizodeposition of $\mathrm{N}$ by pea and barley and its effect on soil $\mathrm{N}$ dynamics. Soil Biol Biochem 28.1:65-71. doi: 10.1016/0038-0717(95)00116-6.

Jones, J., Hoogenboom, G., Porter, C., Boote, K., Batchelor, W., Hunt, L., Wilkens, P., Singh, U., Gijsman, A., Ritchie, J., 2003. The DSSAT cropping system model. Eur. J. Agron. 18, 235-265. doi: 10.1016/S1161-0301(02)00107-7.

Keating, B.A. and Carberry, P.S., 1993. Resource capture and use in intercropping: solar radiation. Field Crops Research, 34 (1993) 273-301. doi: 10.1016/03784290(93)90118-7.

Keating, B. A., Carberry, P.S., Bindraban, P.S., Asseng, S., Meinke, H., Dixon, J., 2010. Eco-efficient agriculture: concepts, challenges and opportunities. Crop Science 50, 109-119. doi: 10.2135/cropsci2009.10.0594.

Kremen, C., and A. Miles, 2012. Ecosystem services in biologically diversified versus conventional farming systems: benefits, externalities, and trade-offs. Ecology and Society 17(4), 40. doi: 10.5751/ES-05035-170440.

Li, L., Sun, J.H., Zhang, F., Guo, T., Bao, X., Smith, F.A., Smith, S.E., 2006. Root distribution and interactions between intercropped species. Oecologia 147, 280-290. doi: 10.1007/s00442-005-0256-4.

Lithourgidis, A.S., Dordas, C.A., Damalas, C.A., Vlachostergios, D.N., 2011. Annual intercrops: an alternative pathway for sustainable agriculture. Review article. Australian Journal of Crop Science 5, 369-410.

van Loon, M.P., Deng, N., Grassini, P., Rattalino Edreira, J.I., Wolde-meskel, E., Baijukya, F., Marrou, H., van Ittersum, M.K., 2018. Prospect for increasing grain legume crop production in East Africa. European Journal of Agronomy 101 (2018) 140-148. doi: 10.1016/j.eja.2018.09.004.

Malezieux, E., Crozat, Y., Dupraz, C., Laurans, M., Makowski, D., Ozier-Lafontaine, H., Rapidel, B., de Tourdonnet, S., Valantin-Morison, M., 2009. Mixing plant species in cropping systems: concepts, tools and models. A review. Agronomy for Sustainable Development 29, 43-62. doi: 10.1051/agro:2007057.

Mao, LL., Zhang, LZ., Zhang, SP., Evers, J.B., van der Werf, W., Wang, JJ., Sun, HQ., Su, ZC., Spiertz, H., 2015. Resource use efficiency, ecological intensification and sustainability in intercropping systems. Journal of Integrative Agriculture 2015, 14(8): 1542-1550. doi: 10.1016/S2095-3119(15)61039-5.

Masvaya, E.N., Nyamangara, J., Descheemaker, K., Giller, K.E., 2017. Is mazie-cowpea intercropping a viable option for smallholder farms in the risky environments of 
semi-arid southern Africa? Field Crops Research 209 (2017) 73-87. doi: 10.1016/j.fcr.2017.04.016.

Morris, R.A., Garrity, D.P., 1993. Resource capture and utilisation in intercropping. Field Crops Research 34, 303-317. doi: 10.1016/0378-4290(93)90119-8.

Nelson, W.C.D., Hoffmann, M.P., Vadez, V., Rötter, R.P., Whitbread, A.M., 2018. Testing pearl millet and cowpea intercropping systems under high temperatures. F. Crop. Res. 217, 150-166. doi: 10.1016/j.fcr.2017.12.014.

Newton, A.C., Begg, G.S. and J.S. Swanston, 2009. Deployment of diversity for enhanced crop function. Review Article. Annals of Applied Biology 154, 309-322. doi: 10.1111/j.1744-7348.2008.00303.x.

Paulsen, H. M., and M. Schochow, 2007. Yields of mixed cropping systems with oil crops (in German). In: Paulsen, H. M., and M. Schochow (eds), 2007: Mixed cropping with oil crops as a tool to increase the area productivity in organic farming - nutrient supply, weed suppression, pest and disease and product quality (in German). Institute for Organic Farming, FAL, Trenthorst (currently at Johann Heinrich von Thuenen-Institute). Pp. 13-32. http://orgprints.org/13217

Pretzsch, H., and G. Schuetze, 2009. Transgressive overyielding in mixed compared with pre stands of Norway spruce and European beech in Central Europe: evidence on stand level and explanation on individual tree level. Eur. J. Forst. Res. 128, 183-204.

Randers, J., 2012. A Global Forecast for the next forty years, 2052. A report to the Club of Rome. Commemorating the 40th Anniversary of the Limits to Growth. Chelsea Green Publishing.

Reynolds, M., Kropff, M., Crossa, J., Koo, J., Kruseman, G., Milan, A.M.m Rutkoski, J., Schulthess, U., Balwinder-Singh, Sonder, K., Tonnang, H., and Vadez, V., 2018. Role of modelling in International Crop Research: Overview and some case studies. Agronomy 2018, 8, 291; doi: 10.3390/agronomy8120291.

Robertson, M.J., Carberry, P.S., Huth, N.I., Turpin, J.E., Probert, M.E., Poulton, P.L., Bell, M., Wright, G.C., Yeates, S.J., Brinsmead, R.B., 2002. Simulation of growth and development of diverse legume species in APSIM. Aust. J. Agric. Res. 53, 429-446. doi: 10.1071/AR01106.

Rodrigues, A., Ruiz-Ramos, M., Palosuo, T., Carter, T.R., Fronzek, S., Lorite, I.J., Ferrise, R., Pirttioja, N., Bindi, M., Baranowski, P., Buis, S., Cammarano, D., Chen, Y., Dumont, B., Ewert, F., Gaiser, T., Hlavinka, P., Hoffmann, H., Höhn, J.G., Jurecka, F., Kersebaum, K.C., Krzyszak, J., Lana, M., Mechiche-Alami, A., Minet, J., Montesino, M., Nedel, C., porter, J.R., Ruget, F., Semenov, M.A., Steinmetz, Z., Stratonovitch, P., Supit, I., Tao, F., Trnka, M., de Wit, A., Rötter, R.P., 2019. Implications of crop model ensembels size and componsition for estimate of adaptation effects and agreement of recommendations. Agricultural and Forest Meteorology 264 (2019) 351-362 doi: 10.1016/j.agrformet.2018.09.018.

Rosenzweig, C., Jones, J., Hatfield, J.L., Ruane, A.C., Boote, K.J., Thorburn, P., Antle, J.M., Nelson, G.C., Porter, C., Janssen, S., Asseng, S., Basso, B., Ewert, F., Wallach, D., 2013. The Agricultural Model Intercomparison and Improvement Project (AgMIP): Protocols and pilot studies. Agricultural and Forest Moeterology 170 (2013) 166-182. doi: 10.1016/j.agrformet.2012.09.011. 
Rötter, R.P., Palosuoa, T., Kersebaum, K.C., Angulo, C., Bindi, M., Ewert, F., Ferrise, R., Hlavinka, P., Moriondo, M., Nendel, C., Olesen, J.E., Patil, R.H., Ruget, F., Takáč, J., Trnka, M., 2012. Simulation of spring barley yield in different climatic zones of Northern and Central Europe: a comparison of nine crop models. Field Crops. Res. 133,23-36. doi: 10.1016/j.fcr.2012.03.016.

Rötter, R.P., Tao, F., Höhn, J.G., Palosuo, T., 2015. Use of crop simulation modelling to aid ideotype design of future cereal cultivars. Journal of Experimental Botany, vol. 66, issue 12, 1 June 2015, p. 3463-3476. doi: 10.1093/jxb/erv098.

Rötter, R.P., Appiah, M., Fichtler, E., Kersebaum, K.C., Trnka, M., Hoffmann, M.P., 2018a. Linking modelling and experimentation to better capture crop impacts of agronomic extremes - A review. Field Crops Research. Volume 221, 15 May 2018, p. 142-156. doi: 10.1016/j.fcr.2018.02.023.

Rötter, R.P., Hoffmann, M.P., Koch, M., Müller, C., 2018b. Progress in modelling agricultural impacts of and adaptations to climate change. Curr. Opin. Plant Biol. doi: 10.1016/j.pbi.2018.05.009.

Rusinamhodzi, L., Corbeels, M., Nyamangara, J., Giller, K.E., 2012. Maize-grain legume intercropping is an attractive option for ecological intensification that reduces climatic risk for smallholder farmers in central Mozambique. Field Crops Research 136 (2012) 12-22. doi: 10.1016/j.fcr.2012.07.014.

Savary, S, Nelson, A.D., Djurle, A., Esker, P.D., Sparks, A., Amorim, L., Filho, A.B., Caffi, T., Castilla, N., Garrett, K., McROberts, N., Rossi, V., Yuen, J., Willocquet, L., 2018. Concepts, approaches, and avenues for modelling crop health and crop losses. European Journal of Agronomy 100 (2018) 4-18. doi: 10.1016/j.eja.2018.04.003.

Senbayram M., Dixon L., Goulding K.W.T., and Bol R. 2008. Long-term influence of manure and mineral nitrogen applications on plant and soil ${ }^{15} \mathrm{~N}$ and ${ }^{13} \mathrm{C}$ values from the Broadbalk Wheat Experiment. Rapid Communication in Mass Spectrometry. 22, 1735-1740. doi: 10.1002/rcm.3548.

Sennhenn, A., Njaruni, D.M.G., Maas, B.L., and Whitbread, A.M., Exploring niches for short-season grain legumes in semi-arid eastern Kenya - coping with the impacts of climate variability. Frontiers in plant science. doi: 10.3389/fpls.2017.00699.

Snaydon, R.W., 1991. Replacement or additive designs for competition studies. J. Appl. Ecol. 28, 930-946. doi: 10.2307/2404218.

Stöckle, C., Donatelli, M., Nelson, R., 2003. CropSyst, a cropping systems simulation model. Eur. J. Agron. 18. 289-304. doi: 10.1016/S1161-0301(02)00109-0.

Streit, J. Meinen, C., Nelson, W.C.D., Siebrecht-Schöll, D., Rauber, R., 2018. Above- and belowground biomass in a mixed cropping system with eight novel winter faba bean genotypes and winter wheat using FTIR spectroscopy for root species discrimination. Accepted by Plant and Soil. doi: 10.1007/s11104-018-03904-y.

Sun, T., Li, Z., Wu, Q., Sheng, T., Du, M., 2018. Effects of alfalfa intercropping on crop yield, water use efficiency, and overall economic nebefit in the Corn Belt of Northeast China. Field Crops Research 216 (2018) 109-119. doi: 10.1016/j.fcr.2017.11.007. 
Tilman, D., K.G. Cassman, P.A. Matson, R. Naylor, and S. Polasky, 2002. Agricultural sustainability and intensive production practices. Nature 418, 671-677. doi: 10.1038/nature01014.

Trnka, M., Rötter, R.P., Ruiz-Ramos, M., Kersebaum, K.C., Olesen, J.E., Zalud, Z., Semenov, M.A., 2014. Adverse weather conditions for European wheat production will become more frequent with climate change. Nature Climate Change 4, 637-643. doi: $10.1038 /$ nclimate2242.

Tscharntke, T., Clough, Y., Wagner, T. C., Jackson, L., Motzke, I., Perfecto, I., Vandermeer, J., Whitbread, A., 2012. Global food security, biodiversity conservation and the future of agricultural intensification. Biol Conserv 151:53-59. doi: 10.1016/j.biocon.2012.01.068.

Tsubo, M., Walker, S., Ogindo, H.O., 2005. A simulation model of cereal-legume intercropping systems for semi-arid regions I. Model development. F. Crop. Res. 93 (2005) 10-22. doi: 10.1016/j.fcr.2004.09.002.

Vandermeer, J., 1992. The ecology of intercropping. Cambridge University Press, Cambridge.

Varshney, R.K., Thundi, M., Pandey, M.K., Tardieu, F., Ojiewo, C., Vadez, V., Whitbread, A.M., Siddique, K.H.M., Nguyen, H.T., carberry, P.S., and Bergvinson, D., 2018. Accelerating genetic gains in legumes for the development of prosperous smallholder agriculture: integrating genomics, phenotyping, systems modelling and agronomy. Journal of Experimental Botany, Vol. 69, No. 13 pp. 3293-3312, 2018. doi: $10.1093 / \mathrm{jxb} / \mathrm{ery} 088$.

Willey, R. W., 1979: Intercropping - Its importance and research needs. Part 1: Competition and yield advantages. Field Crop Abstracts 32, 1-10.

de Wit, A., Boogaard, H., Fumagalli, D., Janssen, S., Knapen, R., van Kraalingen, D., Supit, I., ver der Wijngaart, R., van Diepen, K., 2019. 25 years of WOFOST cropping systems model. Agricultural Systems. 168 (2019) 154-167. doi: 10.1016/j.agsy.2018.06.018.

Xiao, J.B., Li, L., Zhang, F.S., 2004. Effect of root contact on interspecific competition and $\mathrm{N}$ transfer between wheat and faba bean using direct and indirect $15 \mathrm{~N}$ techniques. Plant \& Soil 262, 45-54. doi: 10.1023/B:PLSO.0000037019.34719.0d. 


\section{Chapter Two}

\section{Testing pearl millet and cowpea intercropping systems under high temperatures ${ }^{1}$}

\subsection{Introduction}

Intercropping is an important crop production strategy for smallholder farmers, as it can lead to productivity improvements per unit of land when compared with those of sole cropping systems (Vandermeer, 1989). For instance, Rusinamhodzi et al. (2012) presented an example of this where intercropping maize with pigeonpea led to more than a threefold increase in financial return compared with sole maize on smallholder farms in Mozambique. Explanations for the benefits of intercrop systems are typically related to at least one of the following three factors (Brooker et al., 2015): First, complementary use of resource niches, especially in terms of the different rooting behaviour of crops. As an example, intercropping has been found to enhance root-length density in subsoil (Schröder and Köpke, 2012). Secondly, the combination of different crops can result in better system protection against pests and diseases. A classic example is the widely promoted 'push-pull' system in eastern Africa (Cook et al., 2007). Thirdly, intercropping leads to the development of a more complex canopy structure that can help to generate a more favourable micro-climate, which could potentially reduce soil moisture evaporation (Harris et al., 1987; Tsubo et al., 2004). Harris et al. (1987) presented an interesting example for this third factor based on sorghum/groundnut intercropping experiments conducted on the ICRISAT Research Station, Patancheru, India. Increases in groundnut pod weight per plant were found in intercropped stands, especially under drought conditions, which were to some extent due to shading and cooling effects of sorghum on groundnut.

Recent studies have highlighted areas of India that have become increasingly drought-prone, leading to a decline in cereal production (Nath et al., 2017). Intercropping could therefore be an interesting option for farming in dryland areas with large variability in precipitation, resulting in potentially high climate-induced risk. Observations show and climate models project a higher frequency of extreme weather events, such as heat waves, droughts, or heavy rains, causing reductions in crop yields and putting food security under further strain (Coumou and Rahmstorf, 2012; Rummukainen, 2012).

Climate models project that large areas of the sub-tropics, including the Indian subcontinent in particular, will experience drying through precipitation decline (Chadwick,

\footnotetext{
${ }^{1}$ This chapter has been published as Nelson, W.C.D., Hoffmann, M.P., Vadez, V., Rötter, R.P., Whitbread, A.M., 2018. Testing pearl millet and cowpea intercropping systems under high temperatures. F. Crop. Res. 217, 150-166.p. Res. 217, 150-166. doi: 10.1016/j.fcr.2017.12.014.
} 
2016; He and Soden, 2016), highlighting the need for robust, climate smart crop production strategies.

Experimentation under controlled conditions, such as in climate chambers and greenhouses, could offer valuable insights into stress physiology and plant reactions in relation to a variety of high temperature and limited water supply scenarios. However, it is arguably difficult to properly test more complex strategies like intercropping under controlled conditions. With this in mind, a pearl millet/cowpea intercropping trial was conducted within the dry (Rabi) season, which typically runs from October to March. The trial ran from January to May over two years in Telangana, India. Little to no precipitation during the growth period and high temperatures of up to $42.2{ }^{\circ} \mathrm{C}$ - compared with observed maximum temperatures of $36.5^{\circ} \mathrm{C}$ during the main (Kharif) cropping season (taken from a period of July to October, 1980 to 2010) - mimic harsher climate conditions. Intercrop performance is, to a large extent, determined by resource competition between plants and therefore cropping density. Relatively low densities are often used in low rainfall regions (Dadson et al., 2005) due to better performance and lower risk, for example through the requirement of less seed in comparison to higher density stands. We doubled the locally used density ( $60 \mathrm{~cm}$ between row spacing, known as low density in this experiment) to have a comparable high density treatment. Finally, we controlled water supply to quantify the amount needed to achieve reasonable yields independent of cropping system (sole vs intercrop) and density. A fundamental aim of the experiment was to identify cropping system adaptation strategies for harsher climate conditions than those of the current key cropping seasons.

\subsubsection{Study site}

The trial was conducted at the ICRISAT Research Station, Patancheru, India (17.25 degrees N, 78.05 degrees E, Altitude: $545 \mathrm{~m}$ ). The climate of the region is semi-arid tropical with annual rainfall averaging $910 \mathrm{~mm}$ (taken from a period of 1980-2010). The year is divided into five climatic seasons: a dry season (January to March, $37 \mathrm{~mm}$ ), a pre-rainy season (April to May, $56 \mathrm{~mm}$ ), a rainy season (June and September, $681 \mathrm{~mm}$ ), a post-rainy season (October to November, $127 \mathrm{~mm}$ ), and a post-rainy dry season (December, $5 \mathrm{~mm}$ ) (Virmani and Reddy, 1982; ICRISAT-India, Patancheru Weather Station Records 19802010). Our field trials were conducted across two seasons. Planting took place in late January/early February, and harvesting in early May. Both experiments were conducted on the same piece of land, of which the characteristics, according to Bhattacharyya et al. 
(2016), were as follows: $79.3 \%$ sand, $6.4 \%$ silt, and $14.3 \%$ clay, with organic carbon in the top soil at 0.55 and the $\mathrm{pH} 6-7$.

\subsubsection{Climate conditions during the trial periods}

The daily mean temperature over the trial period in 2015 was $26.1{ }^{\circ} \mathrm{C}$, with $39.6{ }^{\circ} \mathrm{C}$ (Julian day 123) and $11^{\circ} \mathrm{C}$ (Julian day 35) the maximum and minimum daily temperatures, respectively. In 2016, the daily mean temperature was $29.7^{\circ} \mathrm{C}$ over the trial period, with $42.2{ }^{\circ} \mathrm{C}$ (Julian day 112) and $14.8^{\circ} \mathrm{C}$ (Julian day 49) the maximum and minimum daily temperatures, respectively. Information on daily temperatures (max. and min.), rainfall and irrigation, and solar radiation is shown in Figures 1, 2, and 15 (appendix), respectively.

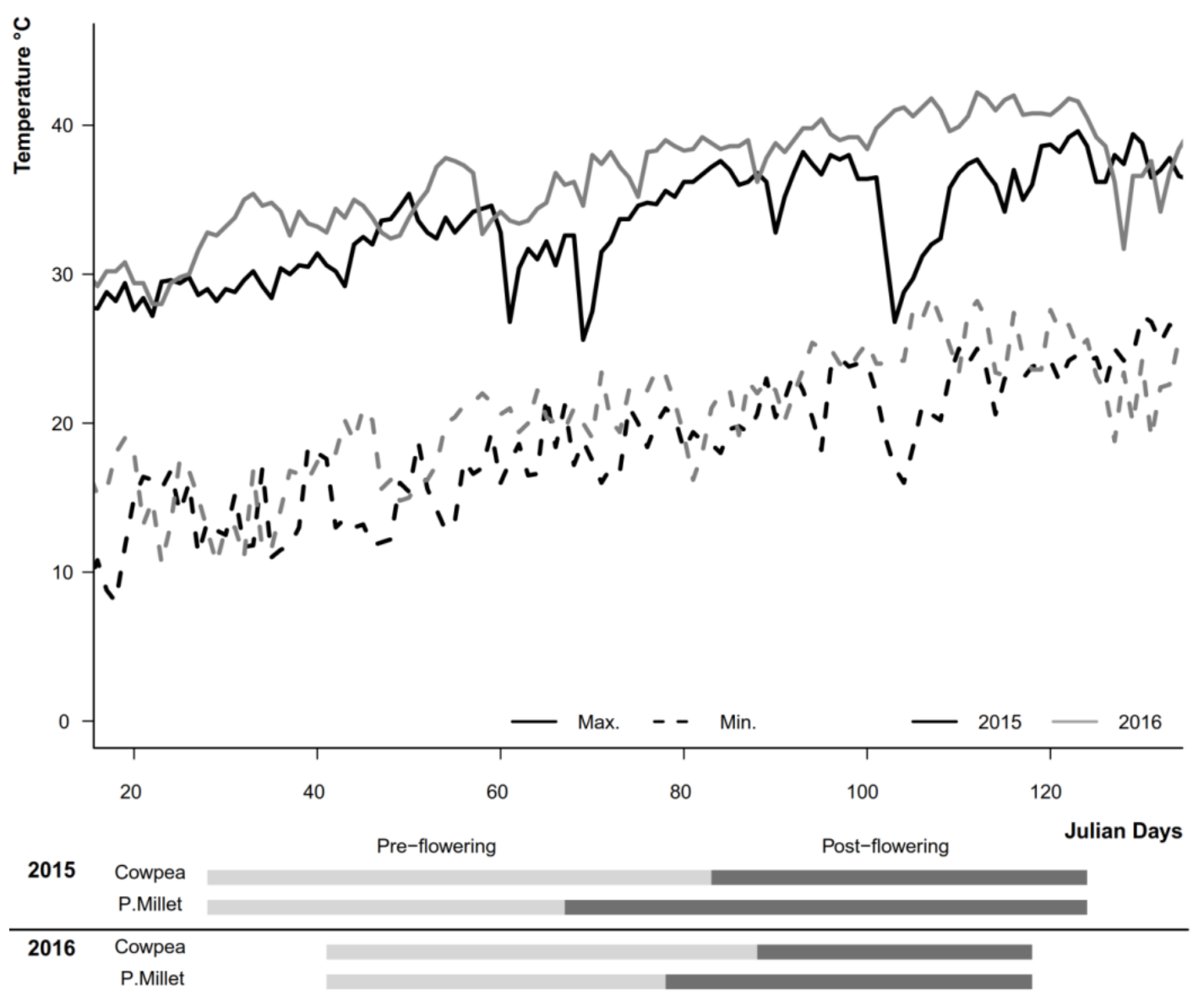

Figure 1. Daily maximum and minimum temperature and physiology timeline 2015 and 2016. Solid lines represent the daily maximum temperatures and dashed lines the minimum. Development phases of both cowpea and pearl millet are presented for both years separately. Horizontal bars filled in light grey (below the plot) represent the time from germination to the completion of flowering of both crops. The following grain/pod filling to final harvest stage is shown through the dark grey bars. 


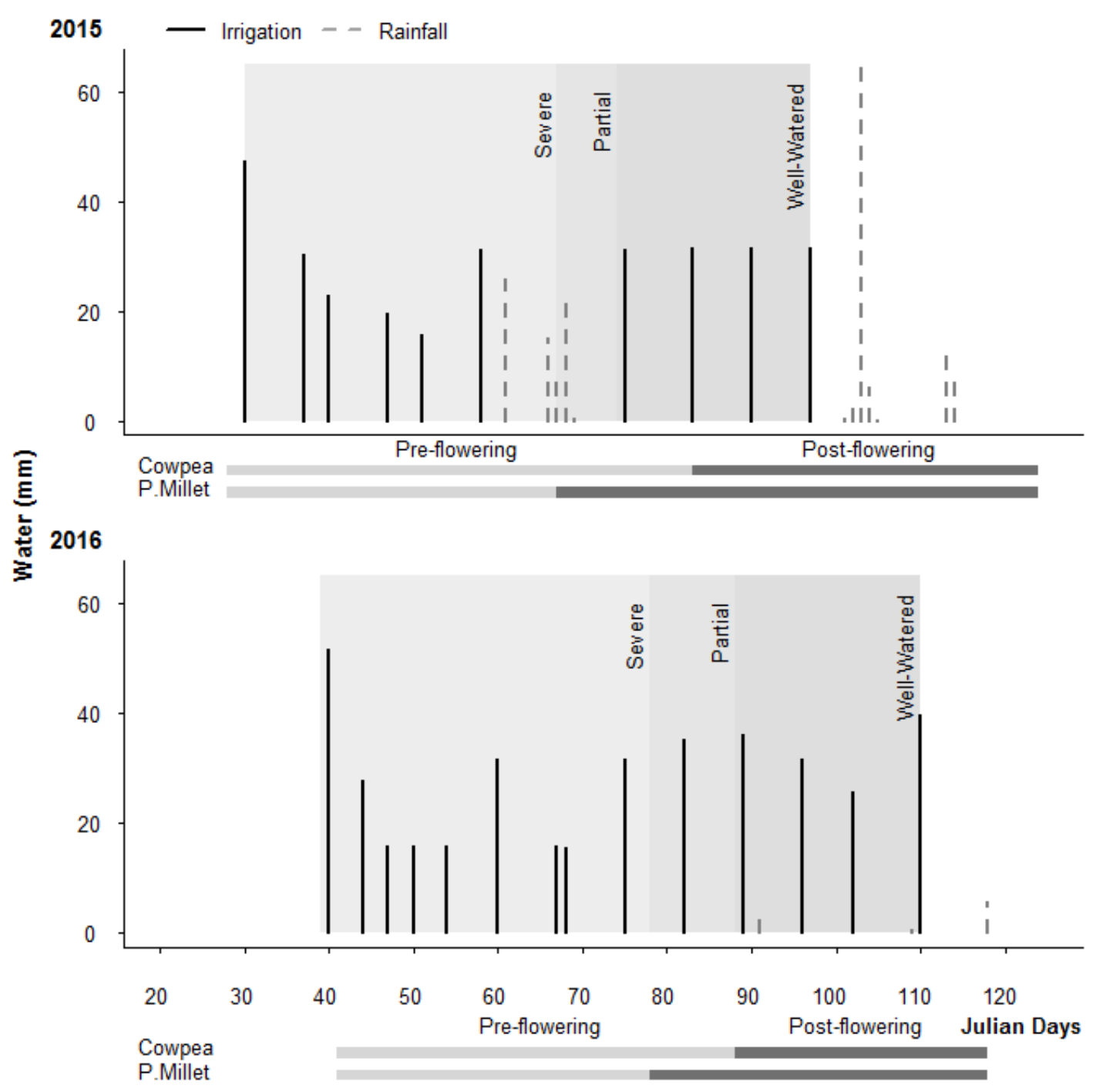

Figure 2. Water supply and physiology timeline 2015 and 2016. Vertical bars represent the amount and type of water supplied to each treatment. Solid bars represent irrigation water applied, and dashed lines in light grey represent precipitation. The large blocks of grey (in three different shades) represent the days, from and to, in which the irrigation treatments were applied. The treatments were, Severe stress, Partial stress, and Well-watered. Horizontal bars filled in light grey (below each plot) represent the time from germination to the completion of flowering of both crops. The following grain/pod filling to final harvest stage is shown through the dark grey bars.

The experiment was set-up as a split-split plot design. Three cropping systems were grown within each density: sole pearl millet, sole cowpea, and intercropped pearl millet and cowpea (Figure 3). Each plot type (three irrigation treatments, two densities, two systems, and two crops) had four replicates, which led to a total of 72 plots. Two low density pearl millet border rows (1.8 metres across) were planted between each irrigation treatment to minimise border effects.

All plots were irrigated using drip irrigation on a weekly basis. The mean weekly irrigation application was $28 \mathrm{~mm}$ in both years. Three irrigation treatments were applied 
once every Monday morning, according to the following: severe stress (317 $\mathrm{mm}$ in 2015 and $267 \mathrm{~mm}$ in 2016 total water supply; this treatment stopped water supply as pearl millet flowered), partial stress (348 mm in 2015 and $334 \mathrm{~mm}$ in 2016 total water supply; this treatment stopped water supply as cowpea flowered), and well-watered (442 $\mathrm{mm}$ in 2015 and $399 \mathrm{~mm}$ in 2016 total water supply). Irrigation supply was conducted taking rainfall events into account. If it rained the day before the planned irrigation, the following morning's irrigation supply was reduced by the amount of rain the experimental site received to ensure comparability between the two years.

Consequentially, within each irrigation treatment two densities were sown of all cropping systems (as described above): low density at 17 plants $/ \mathrm{m}^{2}$ (60 $\mathrm{cm}$ between row spacing), and high density at 33 plants $/ \mathrm{m}^{2}$ (30 $\mathrm{cm}$ between row spacing) - within row spacing was $10 \mathrm{~cm}$ throughout. 
(a)

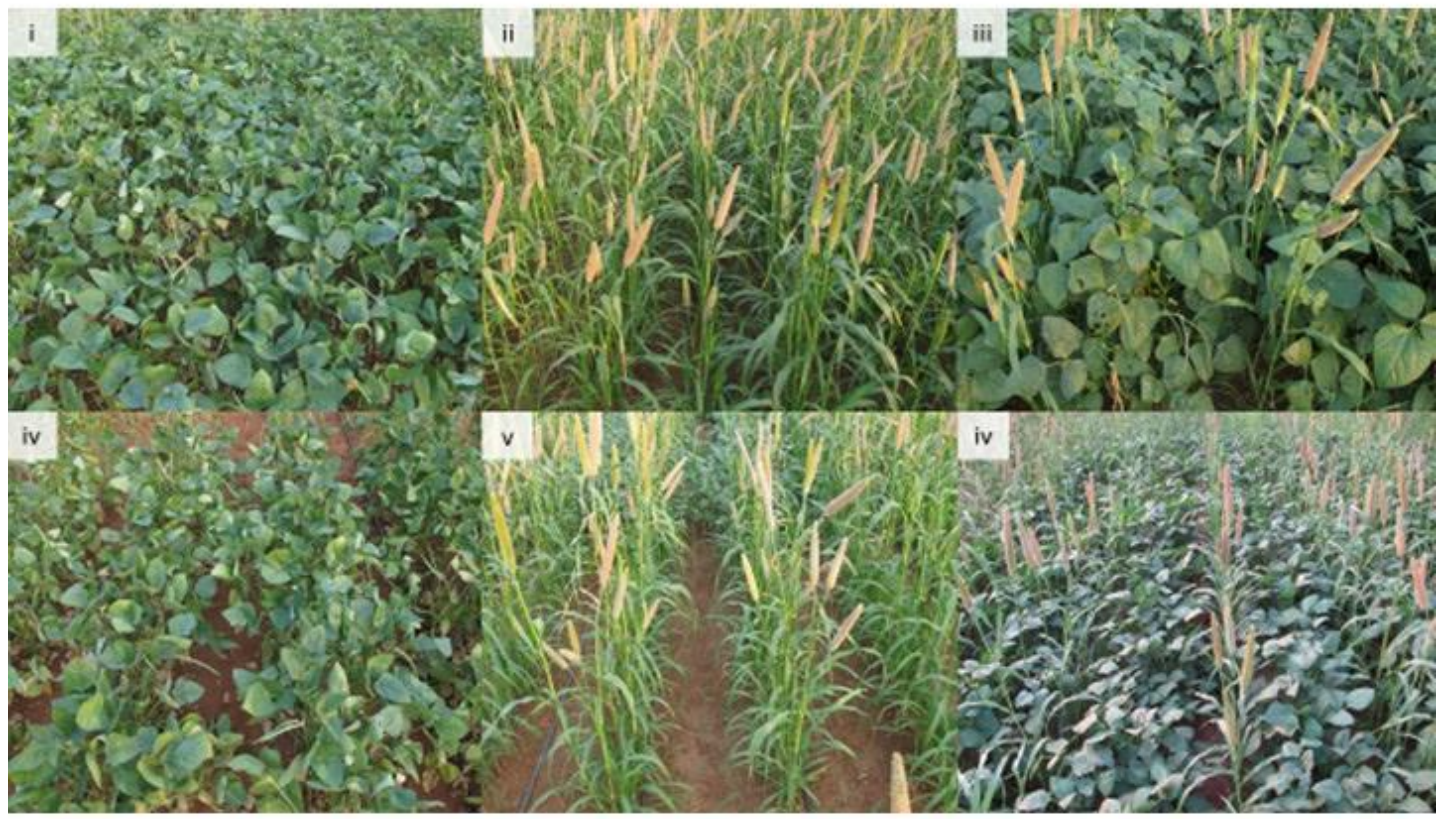

(b)
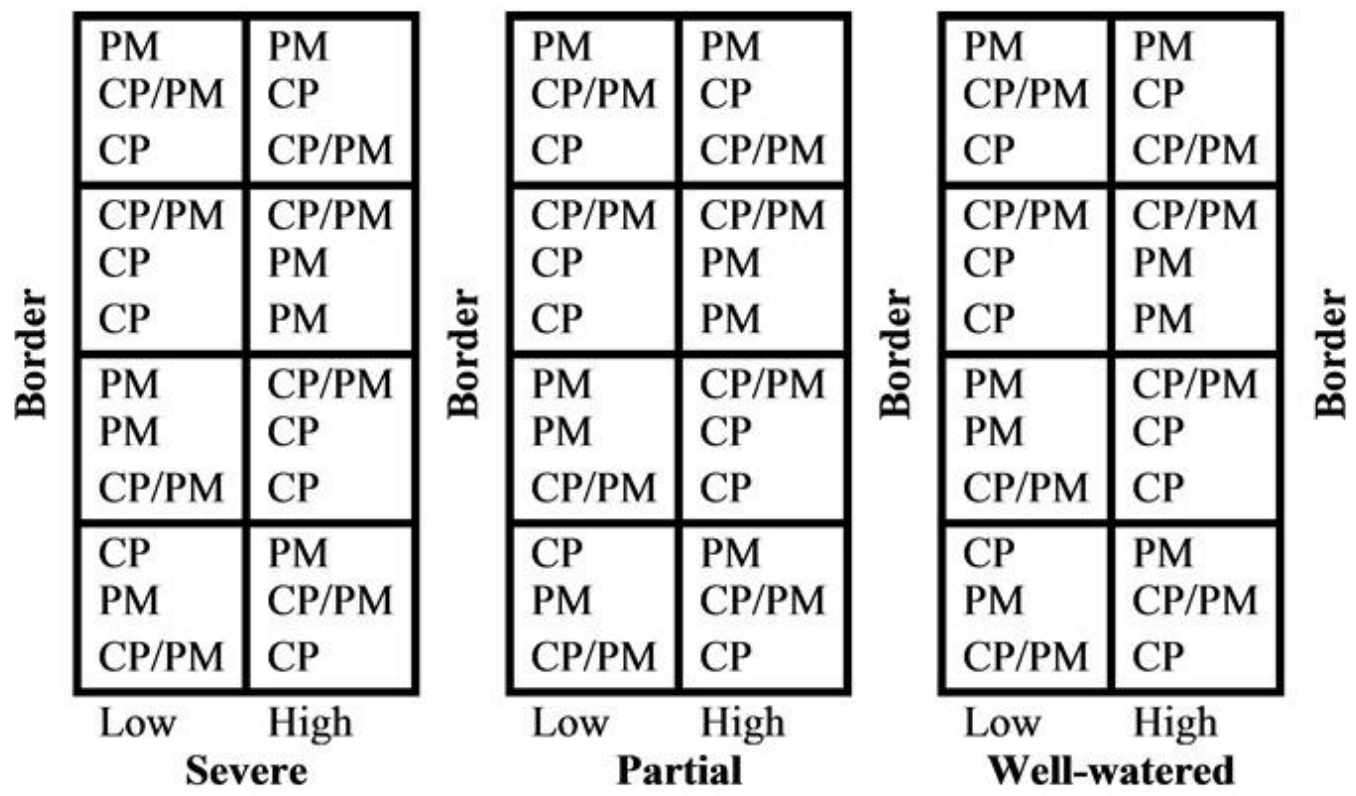

Figure 3. Plot type (a) and experimental design (b). (i) High density sole cowpea, (ii) High density sole pearl millet, (iii) High density pearl millet and cowpea intercropping, (iv) Low density sole cowpea, (v) High density sole pearl millet, and (vi) Low density pearl millet and cowpea intercropping. Part two (b) of the figure illustrates how the experiments were set-up, highlighting treatment (Severe stress, Partial stress, Wellwatered), densities (Low, High), plot type (PM=pearl millet sole, $C P=$ cowpea sole, and $C P / P M=$ cowpea and pearl millet intercropping). Substantial borders were used so that irrigation applications did not mix. 
Sowing was conducted by hand on 30/01/2015 and 02/02/2016. An erect forage cowpea cultivar (Russian Giant), and short pearl millet hybrid cultivar (H77/833-2, ICRISAT breeding programme) were used. These two cultivars were chosen as they are commonly used in the region as a cover crop (cowpea) and a popular hybrid grain crop (pearl millet). Soil was fertilised with $100 \mathrm{~kg} \mathrm{ha}^{-1}$ of Di-Ammonium Phosphate (DAP $=18 \%$ $\mathrm{N}+46 \% \mathrm{P} 2 \mathrm{O} 4$ ) before sowing, as well as $100 \mathrm{~kg} \mathrm{ha}^{-1}$ of urea nitrogen to pearl millet as a top dressing once plots were well established.

\subsubsection{Plant and soil sampling}

Sequential and final biomass harvests were conducted by hand at pearl millet flowering, cowpea flowering as well as two weeks after the cowpea flowering harvest (Figure 11 and 12 appendix). With $50 \mathrm{~cm}$ borders at each end (length ways within the row), harvests consisted of $50 \mathrm{~cm}$ of biomass of every plot row, except one border row on either side of the plot. These harvests involved scanning the leaves of four individual plants per plot to obtain the leaf area (data not presented here), as well as dried biomass weights of plant parts separated into leaf, stem, flower, and pod (cowpea) or tiller (pearl millet).

The only difference between the 2015 and 2016 seasons was that plots, and therefore sample size, were larger in 2016. In 2015, each plot was $5 \mathrm{~m}$ long and $2.4 \mathrm{~m}$ wide. In 2016, each plot was $5 \mathrm{~m}$ long and $3 \mathrm{~m}$ wide. One metre in length for all rows, excluding the two outer most rows (border rows), was used for the final harvest sample.

Pearl millet plants were threshed and cowpea pods opened to obtain the true yield of each plot before being weighed. The remaining biomass was dried in ovens at $60{ }^{\circ} \mathrm{C}$ for 48 hours and weighed.

Leaf Area Index (LAI - Figure 13 and 14 appendix) was calculated using an AccuPAR LP-80 to measure potential (above canopy) and actual (below canopy/on the soil surface) light interception for each plot. LAI was measured on a weekly basis and three repetitions were made in three different sections of each plot. Soil samples were taken one day before sowing and one day after the final harvest by hand so water use could be assessed. These were weighed directly in the field, dried in ovens at $105^{\circ} \mathrm{C}$ for 48 hours and weighed. Sampling was detailed so it can be effectively used to calibrate crop simulation models.

\subsubsection{Data analysis}

Yield and biomass data was subjected to a split-split block analysis of variance (ANOVA). Main plots were defined by irrigation (severe stress, partial stress, well-watered) and split according to density (low and high). Within the densities, plots were split further 
by system type: sole pearl millet, sole cowpea, and intercropped pearl millet and cowpea. The response variables used for the statistical analysis were yield and harvest index; the explanatory variables that were tested for interactions were system, treatment, density, and year (Table 1 and 2 appendix). Homogeneity of variance was tested visually and transformed when necessary in order to conform to the requirements of ANOVA. For significant differences $(\mathrm{p}>0.05)$, the post-hoc Tukey test was used. The analysis was run for each year (2015 and 2016) separately. The open source software R was used to conduct the analysis and create the figures for this study.

A method for assessing the efficiency of intercropping over sole cropping is to use a ratio, such as the land equivalent ratio (LER) (Willey, 1979). This is the area under sole cropping compared with the area under intercropping required to yield equal amounts at the same level of management. The LER is a common approach to assess the land use advantage of intercropping (Rao and Willey, 1980):

$$
L E R=\operatorname{LER}_{a}+\operatorname{LER}_{b}=\frac{I_{a}}{S_{a}}+\frac{I_{b}}{S_{b}}
$$

$I_{a}$ and $I_{b}$ are the yields for each crop in the intercrop system, and $S_{a}$ and $S_{b}$ are the yields for each of the sole crops. $L_{E R}$ and $L E R_{b}$ are the partial LER values for each species. An LER value higher than 1.0 indicates that there is a land use advantage for intercropping.

Partial land equivalent ratio (pLER) refers to the separate parts of the LER equation. Intercropping with two crops such as pearl millet and cowpea is comprised of two pLER values (pearl millet and cowpea), which are added to give the total LER value. Partial land equivalent ratio values are used to assess the contribution of each crop towards total LER and are more detailed in terms of land use assessment.

\subsection{Results}

\subsubsection{Grain yield and sequential biomass accumulation}

We found certain patterns, which, however, fundamentally differed by year. In 2015 , irrespective of plant density, yields increased with irrigation: at low density sole pearl millet yields increased from below $1,000 \mathrm{~kg} \mathrm{ha}^{-1}$ with low irrigation (severe stress treatment) to above $2,000 \mathrm{~kg} \mathrm{ha}^{-1}$ with high irrigation (well-watered treatment), and at high density from above $1,000 \mathrm{~kg} \mathrm{ha}^{-1}$ to more than $2,500 \mathrm{~kg} \mathrm{ha}^{-1}$ with high irrigation (Figure 4). Interestingly, the pattern could only be seen slightly in the case of intercropped pearl millet at low density, 
where yields remained below $1,500 \mathrm{~kg} \mathrm{ha}^{-1}$. The only case in which an increase in water supply significantly improved pearl millet intercrop yield was between partial and wellwatered, low density stands in 2015 , with average yields of $920 \mathrm{~kg} \mathrm{ha}^{-1}$ and $1,350 \mathrm{~kg} \mathrm{ha}^{-1}$ respectively (Figure 4). Intercropping pearl millet with cowpea simultaneously, i.e. with the same sowing date, reduced pearl millet yield significantly in all cases except for severe, low density stands in 2015.

Cowpea yields, however, presented a different pattern, whereby yields were not affected by system (intercrop and sole) except for under the well-watered treatments in both densities in 2015 (Figure 5).

In the 2016 season, more significant differences could be found between severe and partial treatment stands, in comparison to those found between partial and well-watered (Figure 5). The highest cowpea yields in 2015 were found in sole, well-watered, low density stands with an average yield of $1,150 \mathrm{~kg} \mathrm{ha}^{-1}$ (Figure 5). This was the only instance in which sole cowpea out yielded its intercrop counterpart, which yielded an average of $600 \mathrm{~kg} \mathrm{ha}^{-1}$ (Figure 5). In terms of system performance, pearl millet yielded significantly more as a sole crop in every case across both years, except for one instance in 2015 at low density under the severe treatment (Figure 4). Differences in system performance between the years occurred for cowpea. In 2016 the partial treatment yielded almost as well as under the wellwatered treatment, at both low and high density, which was not the case in 2015 (Figure 5). In the 2016 season, more significant differences could be found for cowpea between severe and partial treatment stands (Figure 5). 

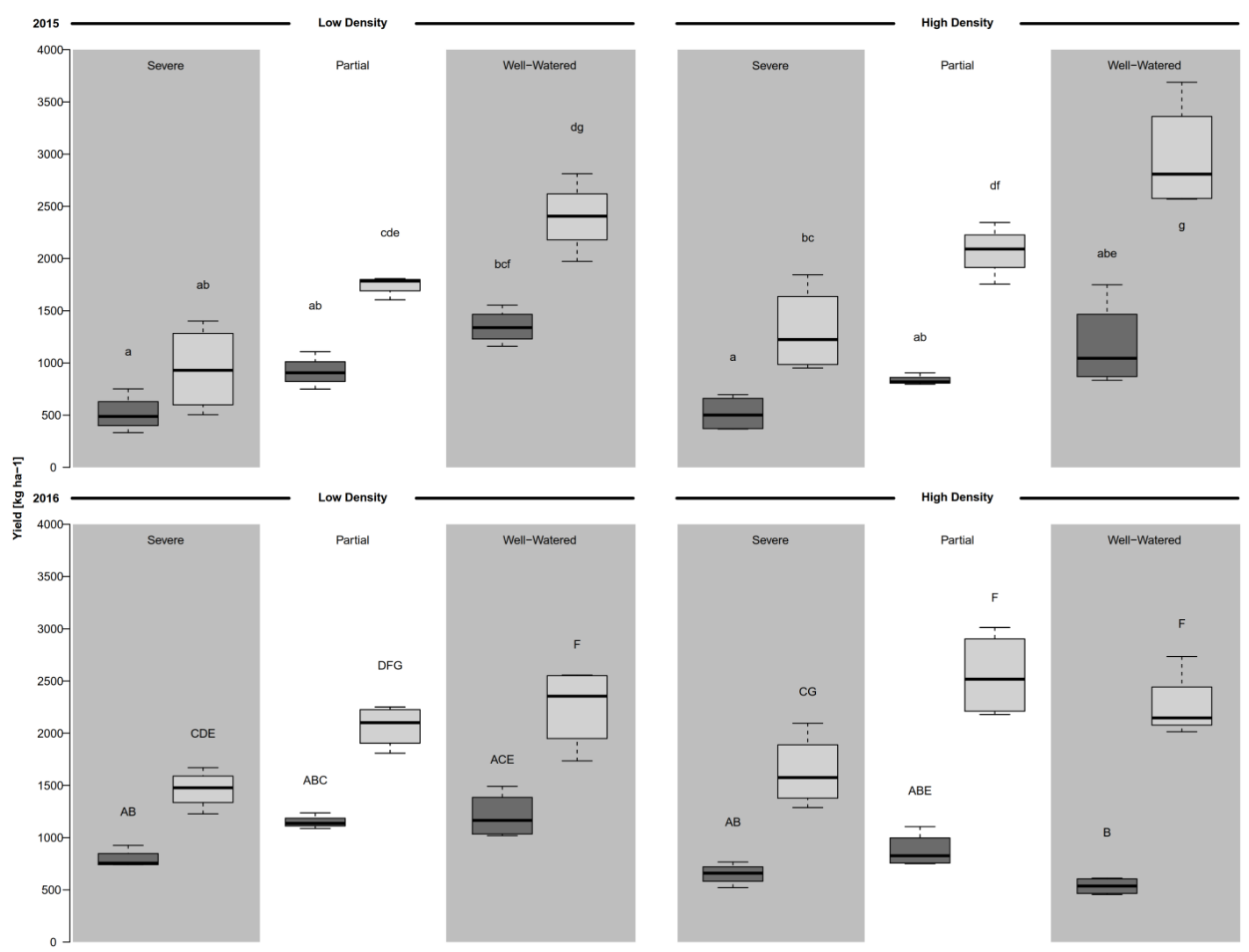

Figure 4. Pearl Millet Yield 2015 and 2016. The top half of the figure illustrates yield data from 2015, and bottom half that of 2016. This is the same for density, with low density results on the left-hand side of the figure and high density on the right. Treatments are shown in order of the amount of water applied, with severe receiving the least water to the left, followed by partial, and well-watered to the right of each plot respectively. Dark grey boxes represent the yields of intercropped plots and light grey boxes those of sole cropped plots. The three horizontal lines indicate the $75 \%$ percentile (up), median (solid line across boxes) and $25 \%$ percentile yield (bottom); the upper and bottom bars outside the boxes show the maximum and minimum values respectively. Significant differences are shown through lower and upper case letters for 2015 and 2016, respectively. 

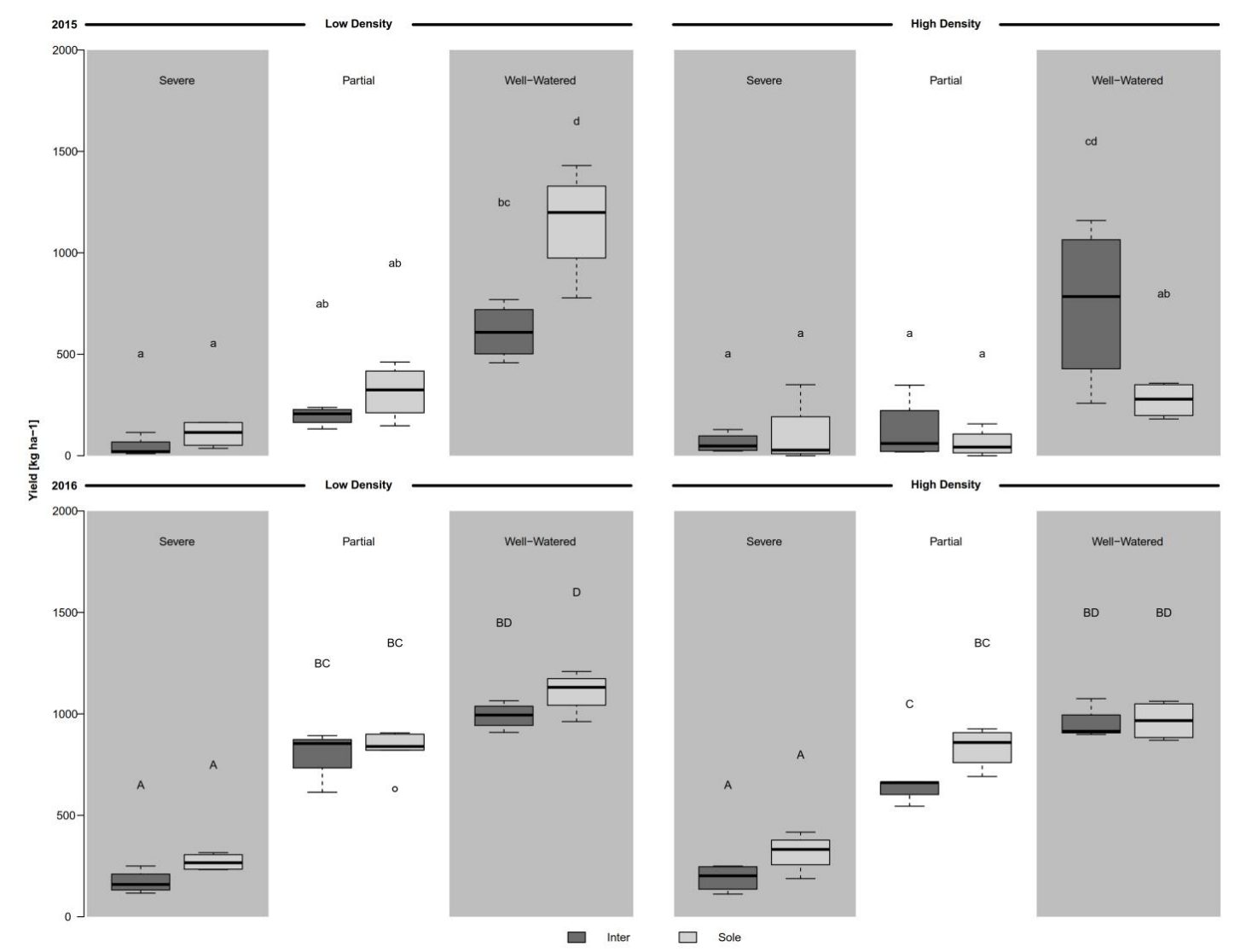

Figure 5. Cowpea Yield 2015 and 2016. The top half of the figure illustrates yield data from 2015, and bottom half that of 2016. This is the same for density, with low density results on the left-hand side of the figure and high density on the right. Treatments are shown in order of the amount of water applied, with severe receiving the least water to the left, followed by partial, and well-watered to the right of each plot respectively. Dark grey boxes represent the yields of intercropped plots and light grey boxes those of sole cropped plots. The three horizontal lines indicate the $75 \%$ percentile (up), median (solid line across boxes) and $25 \%$ percentile yield (bottom); the upper and bottom bars outside the boxes show the maximum and minimum values respectively. Significant differences are shown through lower and upper case letters for 2015 and 2016, respectively.

In 2015, pearl millet HI ratios increased significantly between severe and wellwatered treatments across densities and systems, but not in 2016, where HI remained equal within densities (Figure 6). In all but one instance (2016, sole pearl millet, partial treatment) high density stands had significantly lower HI ratios in 2016 (Figure 6). Pearl millet yields across densities in 2016 were equal in all instances but one (well-watered intercrop stands, Figure 4). Lower HI for pearl millet at high density in 2016 reflected the increased biomass in comparison to yield at this density (Figure 6). While pearl millet yield was dramatically reduced when intercropped, there were no significant differences in HI between systems in both years (Figure 6). The presence of cowpea reduced the total production of the entire pearl millet plant, and not just the plant's ability to produce grain. 
Significantly higher cowpea HI ratios were found under well-watered as opposed to severe treatments in both years and densities, except under high density in 2015 (Figure 7). These findings emulated yield results (Figure 5) and showed biomass and grain production were affected in the same way. In general, HI ratios for both pearl millet and cowpea were significantly reduced by density in 2016 (Figure 6 and 7). Yield results showed no significant differences between crops in terms of density (Figure 4 and 5).

In terms of vegetative biomass, pearl millet produced more than cowpea. The 2015 data set (Figure 11 appendix) clearly shows high density sole pearl millet stands produced more biomass compared with those at low density - this was the case for all treatments in 2015: 3,520 $\mathrm{kg} \mathrm{ha}^{-1}$ and 4,990 $\mathrm{kg} \mathrm{ha}^{-1}$ (severe low and high density); 5,260 $\mathrm{kg} \mathrm{ha}^{-1}$ and 5,890 $\mathrm{kg} \mathrm{ha}^{-1}$ (partial low and high density); and 5,280 $\mathrm{kg} \mathrm{ha}^{-1}$ and 7,110 $\mathrm{kg} \mathrm{ha}^{-1}$ (well-watered low and high density).

The same pattern was also found with sole cowpea, but to a lesser extent when compared with sole pearl millet: 2,260 kg ha-1 and 2,820 kg ha-1 (severe low and high density); 3,860 $\mathrm{kg} \mathrm{ha}^{-1}$ and 4,250 $\mathrm{kg} \mathrm{ha}^{-1}$ (partial low and high density); and 5,860 kg ha ${ }^{-1}$ and 6,200 $\mathrm{kg} \mathrm{ha}^{-1}$ (well-watered low and high density). 


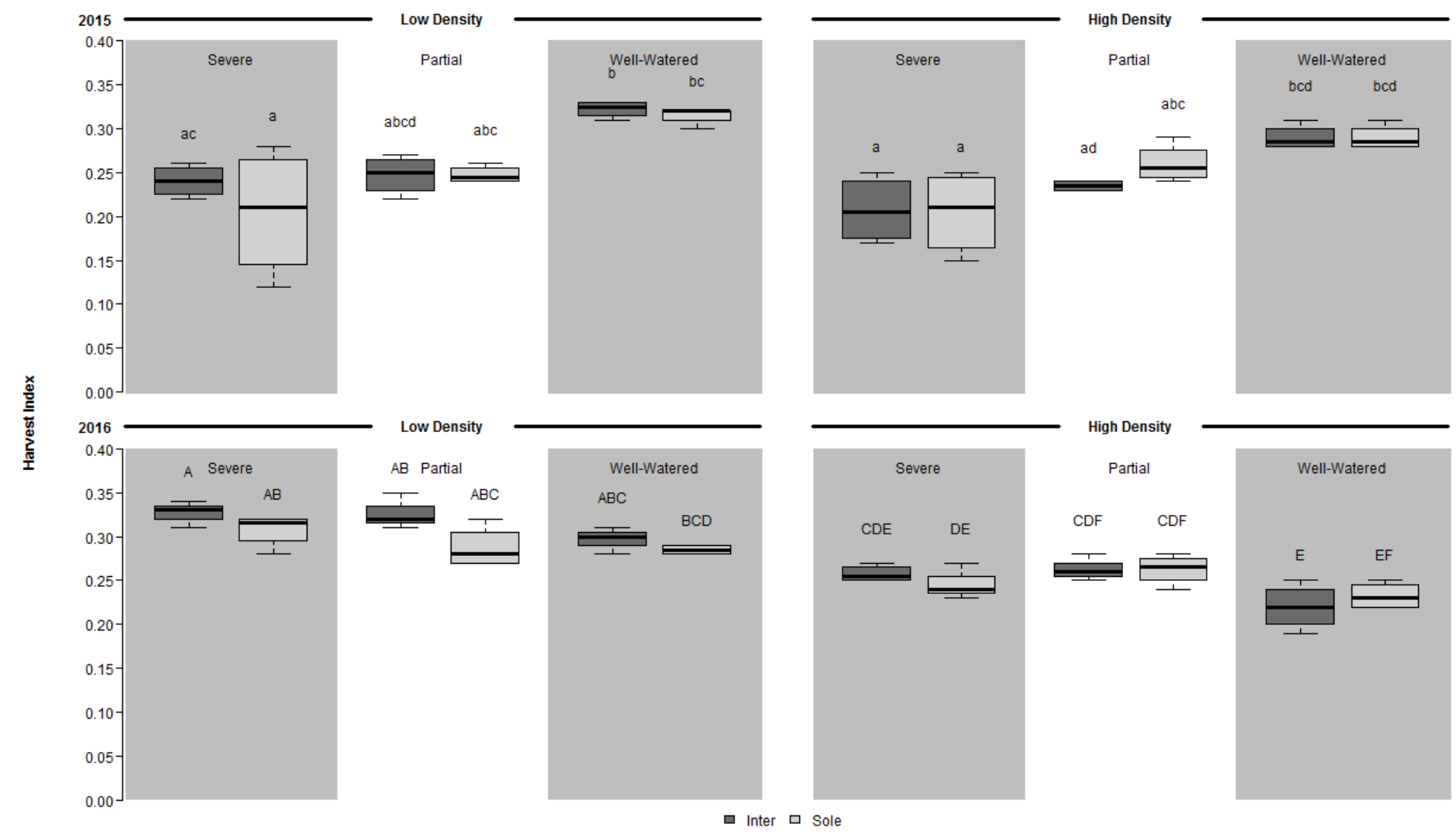

Figure 6. Harvest Index for Pearl Millet. The top half of the figure illustrates HI data from 2015, and bottom half that of 2016. This is the same for density, with low density results on the left-hand side of the figure and high density on the right. Treatments are shown in order of the amount of water applied, with severe receiving the least water to the left, followed by partial, and well-watered to the right of each plot respectively. Dark grey boxes represent the HI values of intercropped plots and light grey boxes those of sole cropped plots. The three horizontal lines indicate the $75 \%$ percentile (up), median (solid line across boxes) and $25 \%$ percentile yield (bottom); the upper and bottom bars outside the boxes show the maximum and minimum values respectively. Significant differences are shown through lower and upper case letters for 2015 and 2016, respectively. 


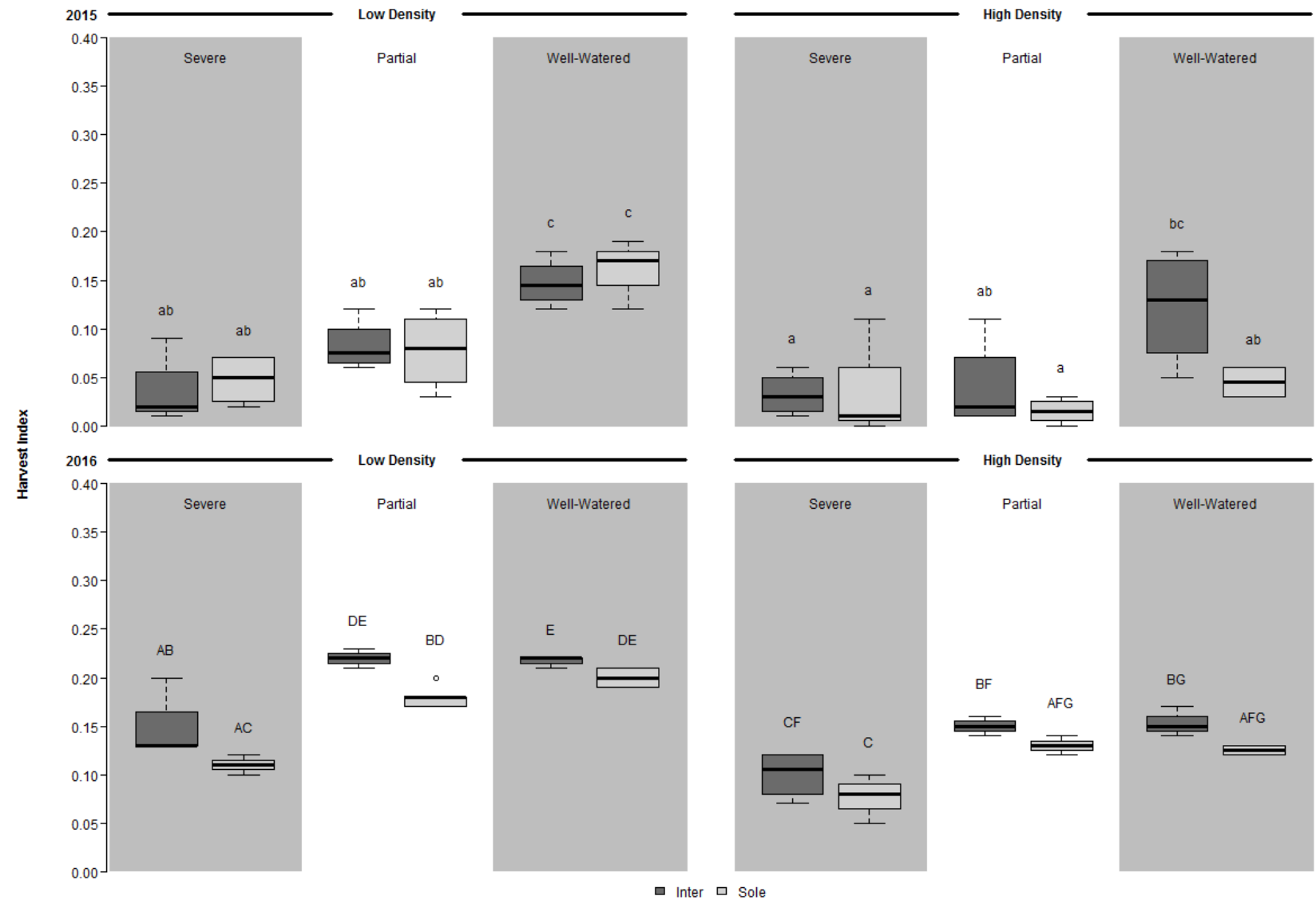

Figure 7. Harvest Index for Cowpea. The top half of the figure illustrates HI data from 2015, and bottom half that of 2016. This is the same for density, with low density results on the left-hand side of the figure and high density on the right. Treatments are shown in order of the amount of water applied, with severe receiving the least water to the left, followed by partial, and well-watered to the right of each plot respectively. Dark grey boxes represent the HI values of intercropped plots and light grey boxes those of sole cropped plots. The three horizontal lines indicate the 75\% percentile (up), median (solid line across boxes) and $25 \%$ percentile yield (bottom); the upper and bottom bars outside the boxes show the maximum and minimum values respectively. Significant differences are shown through lower and upper case letters for 2015 and 2016, respectively. 


\subsubsection{LER of yield}

Partial land equivalent ratio values varied between years (Figure 8), largely due to the 2015 high density sole cowpea yields cultivated under partial and well-watered treatments, for which the yields were 56.5, 157.2, 28.5, and 0 (partial), and 181.2, 357.7, 215.5, and $342.2 \mathrm{~kg} \mathrm{ha}^{-1}$ (well-watered, Figure 4 and 5).

Partial land equivalent ratios showed that intercropping did not necessarily perform better under stress. High density stands under the severe stress treatment had two of the lowest values, with 0.9 and 1.0 in 2015 (severe low density), and 1.2 and 1.0 in 2016 (severe high density, Figure 8). As a comparison, well-watered low and high density stands achieved ratios of 1.1 and 3.1 (2015), and 1.4 and 1.2 (2016, Figure 8).

Figure 8 illustrates the necessity to assess partial LER values and not just LER totals. Values from 2016 showed well-watered high density stands to have a total LER of 1.2 (Figure 8). From this value, 0.2 is from pearl millet, and 1.0 from cowpea - pearl millet was sacrificed for increased cowpea yield (Figure 8). Mean yields for this example were 966.6 and 950.5 for cowpea, and 2,260 and $535 \mathrm{~kg} \mathrm{ha}^{-1}$ for pearl millet, for sole and intercropped stands (Figure 8). 


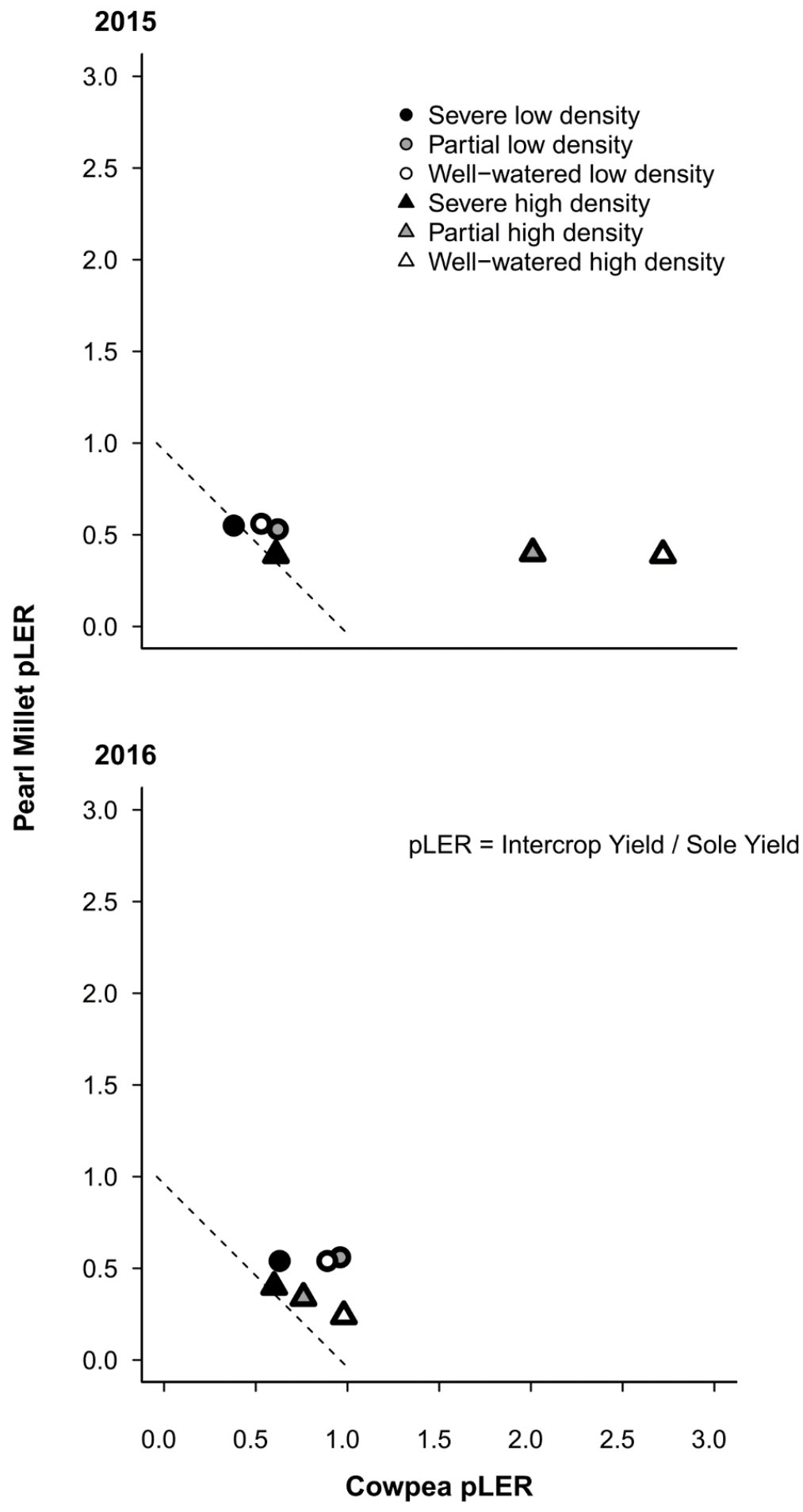

Figure 8. Partial land equivalent ratio (pLER) of cowpea fodder and pearl millet grain for intercropping patterns at high and low density and under three different irrigation treatments (severe stress, partial stress, and well-watered) over two years of experimentation, 2015 and 2016. Each symbol represents an average pLER value from four replicates of the different density and water regimes. The black line indicates a total LER value of one. 


\subsubsection{Soil moisture at full maturity \& light interception}

Soil moisture within both of the top two layers $(0-15 \mathrm{~cm}$ and $15-30 \mathrm{~cm})$ in 2015 under the severe treatment showed high density plots retained more water than low density plots across all systems (Figure 9). Complementary to this were the higher LAI values of high density plots across all systems under the severe treatment by Julian day 78, which captured the full flowering periods of both pearl millet and cowpea crops (Figure 13 appendix). Interestingly, there were larger differences in LAI, i.e. ground cover, between low and high density sole cowpea and intercrop stands, but not between those of sole pearl millet (Figure 13 and 14 appendix). Higher LAI values in both years (Figure 13 and 14) linked well with higher soil moisture values in 2015 , particularly under the severe irrigation treatment (Figure 9 and 10).

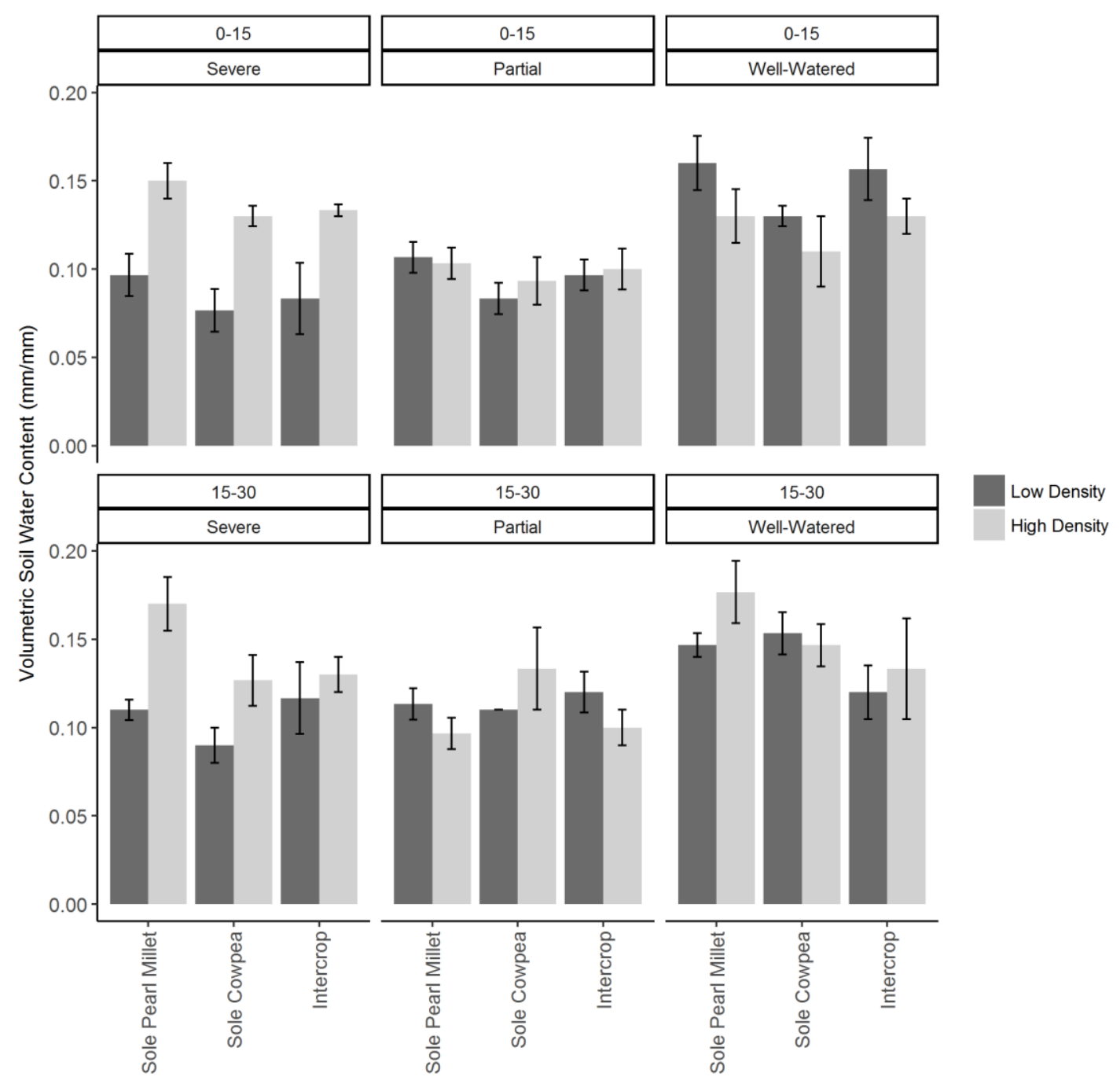

Figure 9. Full maturity volumetric soil water content $(\mathrm{mm} / \mathrm{mm})$, layers $0-15 \mathrm{~cm}$ and $15-30 \mathrm{~cm}, 2015$. The effect of cropping system and density on soil moisture directly after the final harvest in 2015. The bars represent the mean soil moisture, along with standard deviation whiskers. 


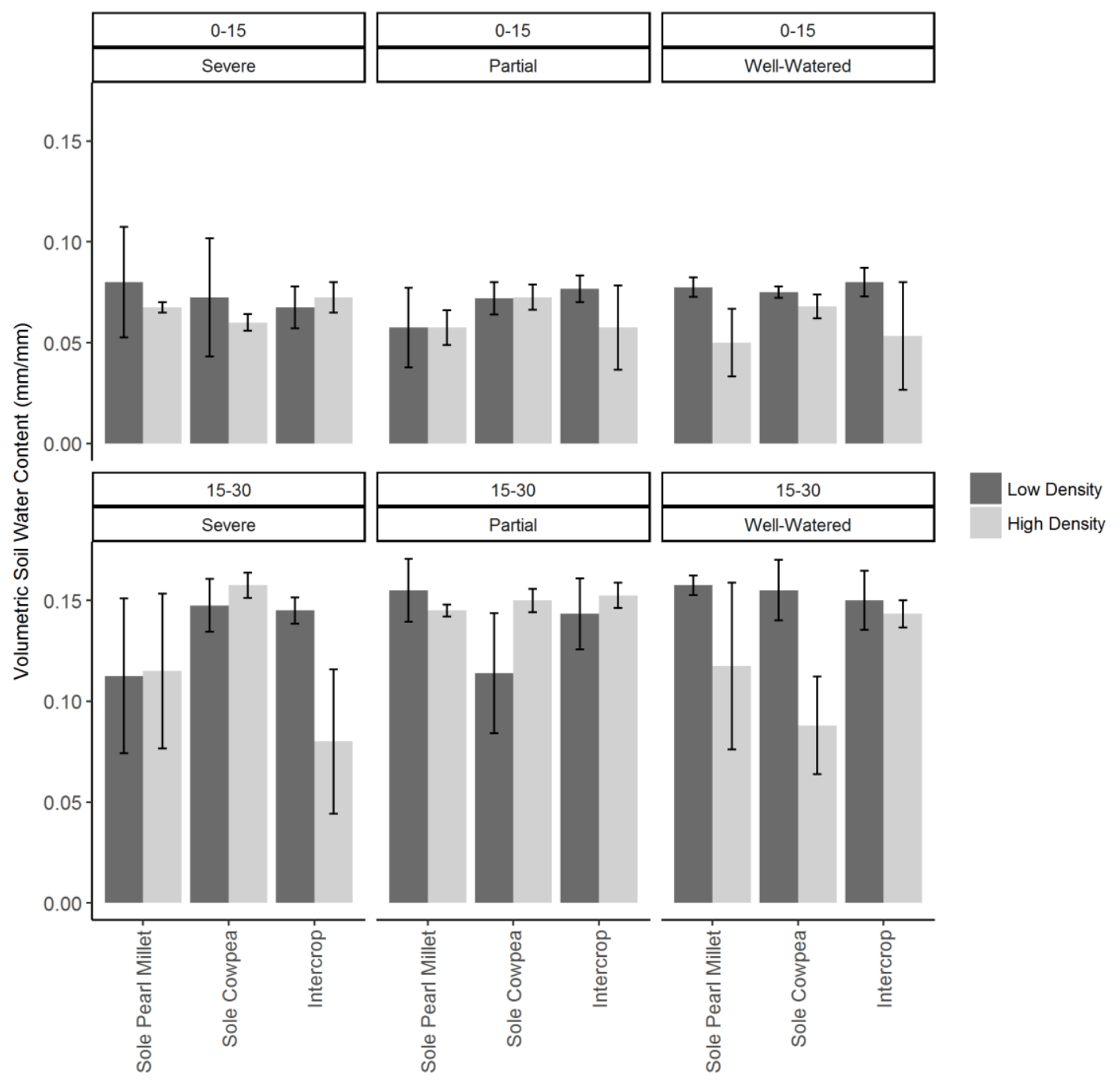

Figure 10. Full maturity volumetric soil water content $(\mathrm{mm} / \mathrm{mm})$, layers $0-15 \mathrm{~cm}$ and $15-30 \mathrm{~cm}, 2016$. The effect of cropping system and density on soil moisture directly after the final harvest in 2016. The bars represent the mean soil moisture, along with standard deviation whiskers.

\subsection{Discussion}

\subsubsection{Cropping system performance}

Under extreme temperature conditions, as found in the off-season (from January to May, 2015 and 2016) at the semi-arid site in Telangana, India, under field conditions, intercropping did not prove to be a suitable adaptation strategy. Pearl millet grown as a sole crop produced significantly higher yields with almost $1,650 \mathrm{~kg} \mathrm{ha}^{-1}$ with high irrigation over both years and densities compared with stands where it was intercropped with cowpea (Figure 4). Cowpea yields were not consistently affected by the system. Our findings were in-line with those of previous studies that showed the simultaneous sowing of pearl millet and cowpea intercropped stands lead to pearl millet yield reductions (Mohammed et al., 2008; Ntare, 1989; Ntare, 1990; Terao et al., 1997). As described by Zegada-Lizarazu et al. (2006), water-use in this specific system was heavily influenced by the system in the form 
of competition from cowpea. Root studies confirmed that competition between these two crops in particular was greatest when planted simultaneously, as they shared the same root zone (Terao et al., 1997). Singh (1997) explained how pearl millet yield was reduced, as simultaneous planting with cowpea reduced its ability to develop deep roots. If cowpea is sown two weeks after pearl millet, it could be dominated by the already developed pearl millet root system and therefore suffer yield reductions. A suggested solution is to plant two rows alternately, for example with four rows of cowpea and two rows of pearl millet. This aims to allow the cereal to penetrate zones under rows of other cereal plants, reducing competition with cowpea roots, which could help compensate for the fact that pearl millet roots do not grow directly beneath their own plant (Terao et al., 1997). Reddy et al. (1992) found no pearl millet yield reduction when cowpea was sown one week after pearl millet, which supports the above-mentioned strategy if pearl millet is of considerable importance to the farmer.

Mohammed et al. (2008) found cowpea yield to decrease by $47 \%$ when intercropped with pearl millet, the difference in trial set-up being that cowpea was sown two weeks after pearl millet. The same study suggested that competitive light interception, i.e. shade from taller crops with more biomass, can heavily impact yield. This builds on the previous work of Blade et al. (1997), who showed consistent, gradual decreases in cowpea yield the later it is planted after pearl millet.

It is important to note that the pearl millet used in this trial was a short variety (in terms of height), which, especially at high density, had a large percentage of its leaves overshadowed by intercropped cowpea, illustrated in Figure 3, 1c, which shows that almost only the pearl millet panicles grew taller than the intercropped cowpea. The reduction in pearl millet yield in response to intercropping with cowpea was therefore related to light (aboveground biomass), and water (below-ground biomass), which enforces the work of Terao et al., (1997), who stressed the importance of system architecture. The timing of shade development has also been found to be of great importance (Walker, 2015). Leaf area index was captured at plot level in this study. However, in order to understand the canopy architecture of intercrop plots and the impact of shade, more detailed LAI data collection could help with the understanding of such systems in their entirety. This could include recording the light intercepted by the taller of the intercropped species alone, which in some instances casts shade over the lower canopy of the shorter intercropped species.

Land equivalent ratio inconsistencies (Figure 5) highlight the complexity of analysing and understanding crop production systems, which forces us to assess the relevance of such ratios. When assessing intercropping systems, it was difficult to find 
trends through ratios, and it was necessary to look into the details. For instance, 2015 LER total values of 2.4 (high density partial) and 3.1 (high density well-watered) suggest intercropping was far more efficient than sole cropping (Figure 8) - comparable values in 2016 vary. Further investigation into partial LER and actual yield values showed a very different result (Reddy et al., 1992).

Clearly, when looking at LER, it is vital to take into consideration which crops are more preferable for the farmer. For example, pearl millet proved to be a stable crop that produced reliable yields. The same cannot be said for cowpea however due to its sensitivity to climate variation. The use of LER for data interpretation must therefore be done with caution, as high LER values (above 1.0), indicating the intercrop system in question is more productive than sole equivalents, is clearly not a good measure of yield productivity, nor is it supposed to be. As Prins and Wit (2005) argued, LER is too simple and may not be useful when analysing intercropping systems, in particular when crops show high elasticity and variance. The variability in LER across various systems was clearly a sign that a more developed understanding of the factors responsible is needed ( $\mathrm{Yu}$ et al., 2015). The literature, as well as the results in this study, so far showed LER to be inconsistent. It is therefore important that the specificity of the farming situation, i.e. the usefulness of each component within the relevant cultural and social setting, is emphasised when interpreting LER as part of field trial analysis.

\subsubsection{Cropping system responses to water treatment}

Water supply was a key factor in the determination of yields, but not the most limiting one in all cases. Sole pearl millet responded to increased water supply to an extent, but not consistently past the partial irrigation treatment. Of particular interest is that there were no differences between intercropped pearl millet at treatment and density levels within each year, except for in 2015 at low density between partial and well-watered treatments (Figure 4). This indicated that intercropped pearl millet suffered from competition with cowpea more than from water stress. Studies have argued that the water sources of pearl millet can be changed by the presence of a cowpea intercrop able to 'out compete' the cereal for water. This reaction is said to be due to the presence of cowpea forcing pearl millet to rely on more recently supplied water - be that precipitation or irrigation (Zegada-Lizarazu et al., 2006). However, if this were the case, well-watered intercropped pearl millet should have performed better as water supply increased, which it did not. With this in mind, it seems cowpea outcompeted pearl millet for root space more than anything else. The cereal's reduction in performance when intercropped was not found when cowpea planting was 
delayed by two weeks. The response was similar when pearl millet is intercropped with other legumes (Zegada-Lizarazu et al., 2005). The strongest change in terms of water supply for both pearl millet and cowpea inter and sole crop stands was observed between severe to partial treatments. Here, it seems the irrigation water supply of $350 \mathrm{~mm}$ in 2015 and 330 $\mathrm{mm}$ in 2016 (partial water stress) was sufficient. Any additional supply of water led to a diminishing return.

\subsubsection{Plant density}

Spatial arrangement of course also influences competition dynamics and yield stability can vary under different types of intercropping systems, be they made up of singular or multiple rows (Dapaah et al., 2003; Mohammed et al., 2008). This highlights the importance of defining the aims of a system prior to assessing its performance. Mohammed et al. (2008) found that pearl millet-cowpea intercropping systems could be enhanced by cultivating two pearl millet rows next to four cowpea rows. In our study, under intercropping, while the presence of simultaneously sown cowpea reduced pearl millet yield, a system effect, density did not play an important role in terms of yield production. However, yield is of course not the only arable cultivation product. Vegetative biomass can be used as animal feed, vegetables for human consumption, and straw input for soil organic matter build-up. There is therefore strong competition for biomass, especially in lowresource systems, as found in many semi-arid regions. With this is mind, density clearly played an important role in terms of vegetative biomass production (Figure 11 and 12 appendix), where high density pearl millet in particular produced higher yields compared with when sown at low density. Craufurd (2000) found a strong density response with intercrop yields, whereby cowpea yield decreased as pearl millet density increased. Craufurd (2000) went on to explain that intercrop yields were dominated by cereals, which was not the case in our study, and was probably due to the relay aspect of the experiments reported on in which cowpea was sown seven days or more after pearl millet, giving the cereal an advantage. Another possible interpretation is that of a cowpea genotype effect on the pearl millet line used in intercropping. The cowpea line that was used is routinely used as a fallow crop, rather than for grain, indicated by poor harvest index ratios. Being a genotype with inherently high foliage could have been part of the reason for depressed intercropped pearl millet yields. The fact that we used a short pearl millet variety clearly played an important role in cowpea's ability to shade the intercropped pearl millet, especially when sown at high density, as well as the above-described competition for soil 
resources. Mao et al. (2014) found higher plant densities led to crops with excessive vegetative growth, which supports our findings for pearl millet and cowpea in 2016, as the HI is reduced with increased density (Figure 6 and 7).

Significantly equal HI ratios for pearl millet are in-line with the findings of Muchow (1989), who observed that although more water supply increased sole pearl millet HI values, the effect was not significant. The decline in pearl millet HI at high density (Figure 6) in combination with significantly equal yields over density (Figure 4) highlights the higher level of grain-yield efficiency that comes from low density cultivation. As density was the only influential factor in terms of pearl millet HI, it is clear that the provision of sufficient space is important to achieve pearl millet's yield potential. Of course, only one pearl millet genotype was tested and more work would be needed to test the possibility of genotype-bydensity interactions. This also showed that when pearl millet was under stress, the entire plant was affected i.e. biomass and yield production. The fact that water deficits have little influence on pearl millet $\mathrm{HI}$ further emphasised the stability and reliability of the crop as suitable for farmers in semi-arid regions, particularly with climate variation and instability in mind. Cowpea on the other hand showed a great deal more variation. Higher HI values were found at low density, and as water supply increased. The over-riding output of HI values from both crops in intercropped and sole stands was that low density planting was more preferable (60 $\mathrm{cm}$ between row spacing), be it as an inter- or sole crop system.

\subsection{Conclusion}

The off-season experiment showed that the cultivation of both pearl millet and cowpea under extreme heat was possible. Intercropping, at least when simultaneously planted, did not improve yield productivity, despite LER values above one, and reduced the performance of pearl millet. The provision of supplemental water through drip irrigation increased yields of both crops, but more so for cowpea of which yields were low across treatments and years as well as being sensitive to water supply and seasonal climate variation. Pearl millet on the other hand, proved to be well-adapted to high temperatures and limited water supply. The locally practiced low density (60 $\mathrm{cm}$ between row spacing) was the most efficient in terms of seed supply and yield output, whereas biomass production was higher when sown at high density. The most effective drip irrigation water supply in terms of grain yield was made up of around $340 \mathrm{~mm}$ (partial stress water application mean over the two years) divided over and applied once a week up until 48 DAS (mean length of partial stress irrigation in 2015 and 2016). As we have shown, the off-season can be used effectively to test strategies under climatic conditions that may shift into key cropping 
seasons. Our observations suggest that there may be opportunities to develop intercropping options for farmers, even under harsher conditions. Two key aspects that require further research include: (i) broader testing of genetic material of both pearl millet and cowpea as part of intercropping systems, and (ii) investigation of whether delayed planting of cowpea would reduce the negative effect on pearl millet grain yield when intercropped.

\subsection{Acknowledgements}

We are grateful for the help of the field and laboratory staff from the Systems Analysis for Climate Smart Agriculture (SACSA) team at ICRISAT Hyderabad, India, for hosting the trial. WCDN receives support from the IMPAC ${ }^{3}$ project, funded by the German Federal Ministry of Education and Research, grant number 031A351A.

MPH and RPR receive support from the 'Limpopo Living Landscapes' project within the SPACES programme (grant number 01LL1304A) funded by the German Federal Ministry of Education and Research (http://www.bmbf.de/en/).

AMW acknowledges the CGIAR Research Program Climate Change, Agriculture and Food Security (CCAFS) for funding his time.

VV acknowledges the CGIAR Research Programs Grain Legumes and CRP Dryland Cereals.

\subsection{References}

Bhattacharyya, T., Wani, S.P., Pal, D.K., Sahrawat, K.L., Pillai, S., Nimje, A., Telpande, B., Chandran, P., Chaudhury, S., 2016. Special section: soil and water management ICRISAT, India soils: yesterday, today and tomorrow 110.

Brooker, R.W., Jones, H.G., Paterson, E., Watson, C., Brooker, R.W., Bennett, A.E., Cong, W., Daniell, T.J., George, T.S., Hallett, P.D., Hawes, C., Iannetta, P.P.M., Jones, H.G., Karley, A.J., Li, L., Mckenzie, B.M., 2015. Improving intercropping: a synthesis of research in agronomy, plant physiology and ecology. New Phytol. 205, 107-117. doi: 10.1111/nph.13132.

Chadwick, R., 2016. Precipitation: Sub-tropical drying explained. Nat. Clim. Chang. doi: $10.1038 /$ nclimate 3167.

Cook, S.M., Khan, Z.R., Pickett, J.A., 2007. The use of push-pull strategies in integrated pest management. Annu. Rev. Entomol. 52, 375-400. doi: 10.1146/annurev.ento.52.110405.091407.

Coumou, D., Rahmstorf, S., 2012. A decade of weather extremes. Nat. Clim. Chang. 2, 491496. doi: 10.1038/Nclimate1452.

Craufurd, P.Q., 2000. Effect of plant density on the yield of sorghum-cowpea and pearl millet-cowpea intercrops in northern Nigeria. Exp. Agric. 36, 379-395. doi: $10.1017 /$ S0014479700003124. 
Dadson, R.B., Hashem, F.M., Javaid, I., Joshi, J., Allen, A.L., Devine, T.E., 2005. Effect of water stress on the yield of cowpea (Vigna unguiculata L. Walp.) genotypes in the Delmarva Region of the United States. J. Agron. Crop Sci. 191, 210-217. doi: 10.1111/j.1439-037X.2005.00155.x.

Dapaah, H.K., Asafu-Agyei, J.N., Ennin, S.A., Yamoah, C., 2003. Yield stability of cassava, maize, soya bean and cowpea intercrops. J. Agric. Sci. 140, 73-82. doi: $10.1017 /$ S0021859602002770.

Harris, D., Natarajan, M., Willey, R., 1987. Physiological basis for yield advantage in a sorghum/groundnut tntercrop exposed to drought. F. Crop. Res. 17, 259-272. doi: $10.1016 / 0378-4290(87) 90040-2$.

He, J., Soden, B.J., 2016. A re-examination of the projected subtropical precipitation decline. Nat. Clim. Chang. 1, 1-6. doi: 10.1038/nclimate3157.

Mao, L., Zhang, L., Zhao, X., Liu, S., van der Werf, W., Zhang, S., Spiertz, H., Li, Z., 2014. Crop growth, light utilization and yield of relay intercropped cotton as affected by plant density and a plant growth regulator. F. Crop. Res. 155, 67-76. doi: 10.1016/j.fcr.2013.09.021.

Mohammed, I.B., Olufajo, O.O., Singh, B.B., Oluwasemire, K.O., Chiezey, U.F., 2008. Productivity of Millet / Cowpea Intercrop as Affected by Cowpea Genotype and Row Arrangement. World J. Agric. Sci. 4, 818-824.

Muchow, R.C., 1989. Comparative productivity of maize, sorghum and pearl millet in a semi-arid tropical environment II. Effect of water deficits. F. Crop. Res. 20, 207219. doi: 10.1016/0378-4290(89)90080-4.

Nath, R., Nath, D., Li, Q., Chen, W., Cui, X., 2017. Impact of drought on agriculture in the Indo-Gangetic Plain, India. Adv. Atmos. Sci. 34, 335-346. doi: 10.1007/s00376016-6102-2.

Ntare, B.R., 1989. Evaluation of cowpea cultivars for intercropping with pearl millet in the Sahelian zone of West Africa. F. Crop. Res. 20, 31-40. doi: 10.1016/03784290(89)90021-X.

Ntare, R., 1990. Intercropping morphologically different cowpeas with pearl millet in a short season environment in the Sahel. Expl Agric. 26, 41-47.

Prins, U., Wit, J. De, 2005. Intercropping cereals and grain legumes: a farmers perspective. F. Crop. Res. 24-25.

Reddy, K.C., Visser, P., Buckner, P., 1992. Pearl millet and cowpea yields in sole and intercrop systems, and their after-effects on soil and crop productivity. F. Crop. Res. 28, 315-326. doi: 10.1016/0378-4290(92)90017-4.

Rusinamhodzi, L., Corbeels, M., Nyamangara, J., Giller, K.E., 2012. Maize-grain legume intercropping is an attractive option for ecological intensification that reduces climatic risk for smallholder farmers in central Mozambique. F. Crop. Res. 136, 1222. doi: 10.1016/j.fcr.2012.07.014.

Schröder, D., Köpke, U., 2012. Faba bean (Vicia faba L.) intercropped with oil crops - a strategy to enhance rooting density and to optimize nitrogen use and grain production? F. Crop. Res. 135, 74-81. doi: 10.1016/j.fcr.2012.07.007. 
Singh, B.B., D.R. Mohan Raj, K.E. Dashiell, and L.E.N.J. (eds. )., 1997. Advances in cowpea research. Copublication Int. Inst. Trop. Agric. Japan Int. Res. Cent. Agric. Sci. (JIRCAS). UTA, Ibadan, Niger. 375.

Tsubo, M., Ogindo, H.O., Walker, S., 2004. Yield Evaluation of Maize-Bean Intercropping in a Semi-Arid Region of South Africa. African Crop Sci. J. 12, 351-358. doi: 10.4314/acsj.v12i4.27897.

Virmani, S.M., Reddy, S.J., 1982. Rainfall probability estimates for selected locations of semi-arid india. Crops.

Walker, S., 2015. Shade Effects on Phaseolus vulgaris L. Intercropped with Zea mays L. under Well-Watered Conditions 176, 168-176. doi: 10.1111/j.1439037X.2004.00089.x.

Yu, Y., Stomph, T.J., Makowski, D., van der Werf, W., 2015. Temporal niche differentiation increases the land equivalent ratio of annual intercrops: A metaanalysis. F. Crop. Res. 184, 133-144. doi: 10.1016/j.fcr.2015.09.010.

Zegada-Lizarazu, W., Izumi, Y., Iijima, M., 2006. Water Competition of Intercropped Pearl Millet with Cowpea under Drought and Soil Compaction Stresses. Plant Prod. Sci. 9, 123-132. doi: 10.1626/pps.9.123.

Zegada-Lizarazu, W., Niitembu, S., Iijima, M., 2005. Mixed planting with legumes modified the water source and water use of pearl millet. Plant Prod. Sci. 8, 433-440. doi: $10.1626 / p p s .8 .433$. 


\subsubsection{Sequential biomass harvests}

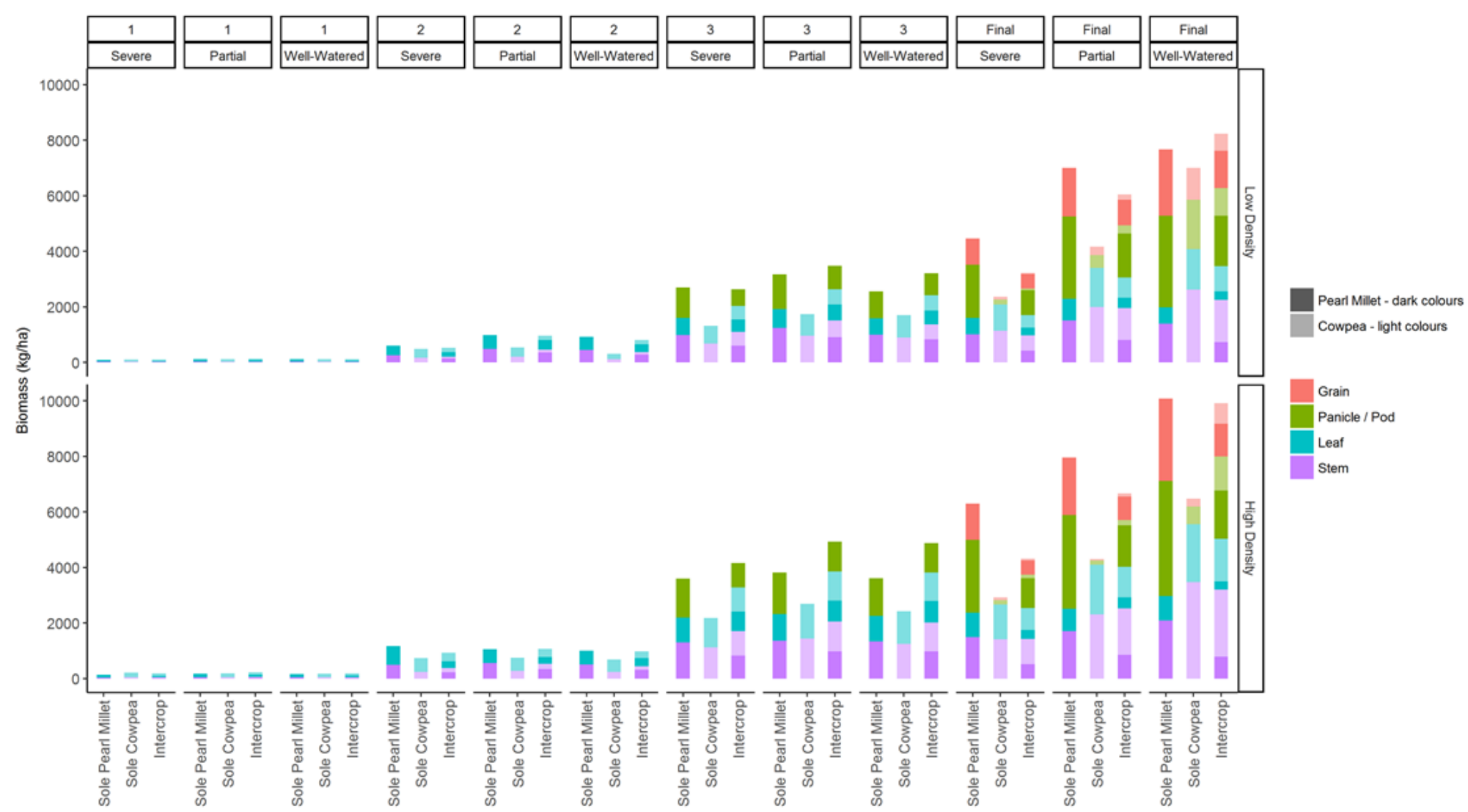

Figure 11. Biomass accumulation over time - four separate harvests in 2015, split into Julian day. The biomass of each plant part is given a different colour, as indicated in the legend. Pearl millet plant parts are represented by the darker shades of the colours in the legend, and cowpea by those that are lighter. Biomass growth of low density plots is shown in the upper most time series, that of high density below. 


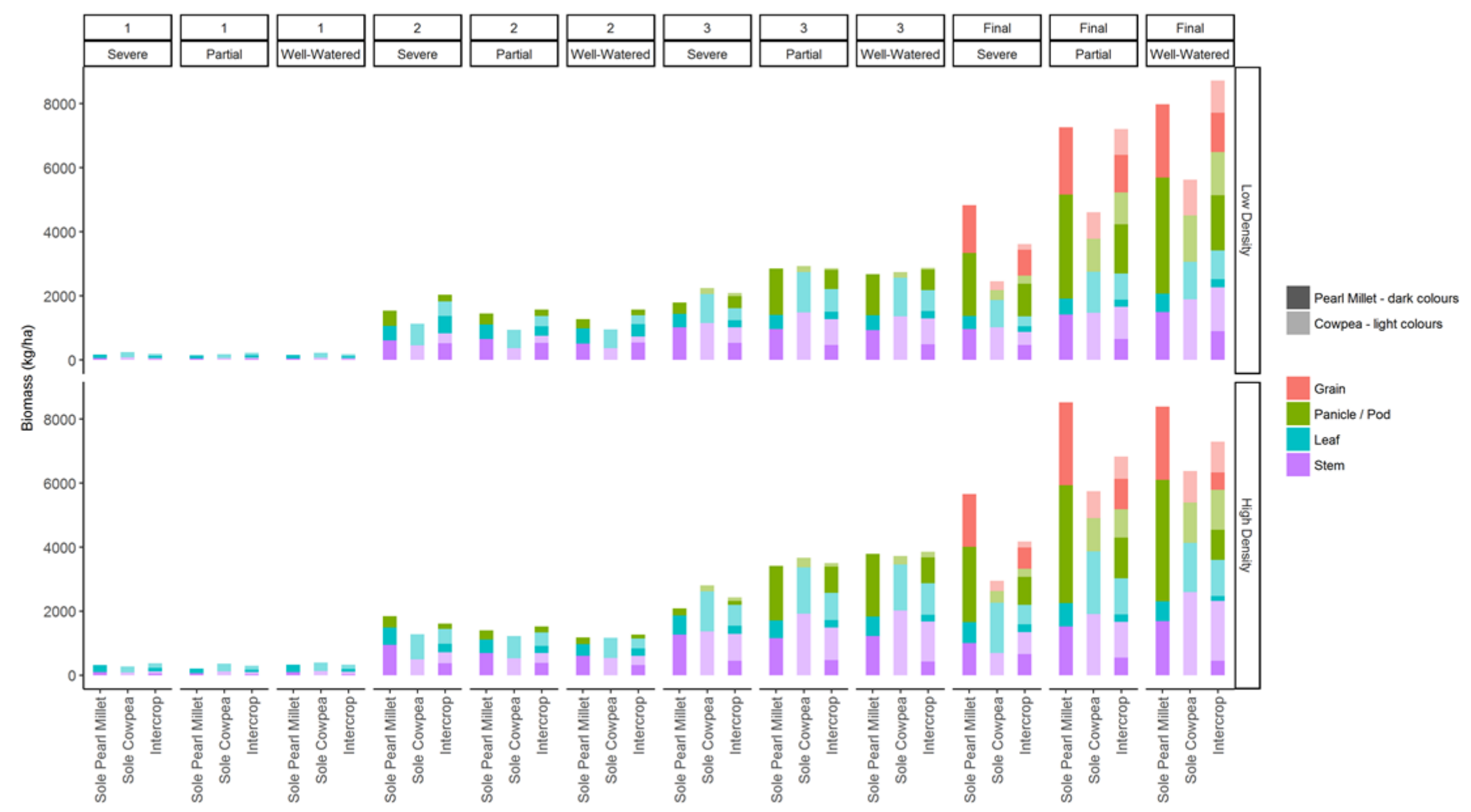

Figure 12. Biomass accumulation over time-four separate harvests in 2016. 


\subsubsection{Leaf area index - light interception}

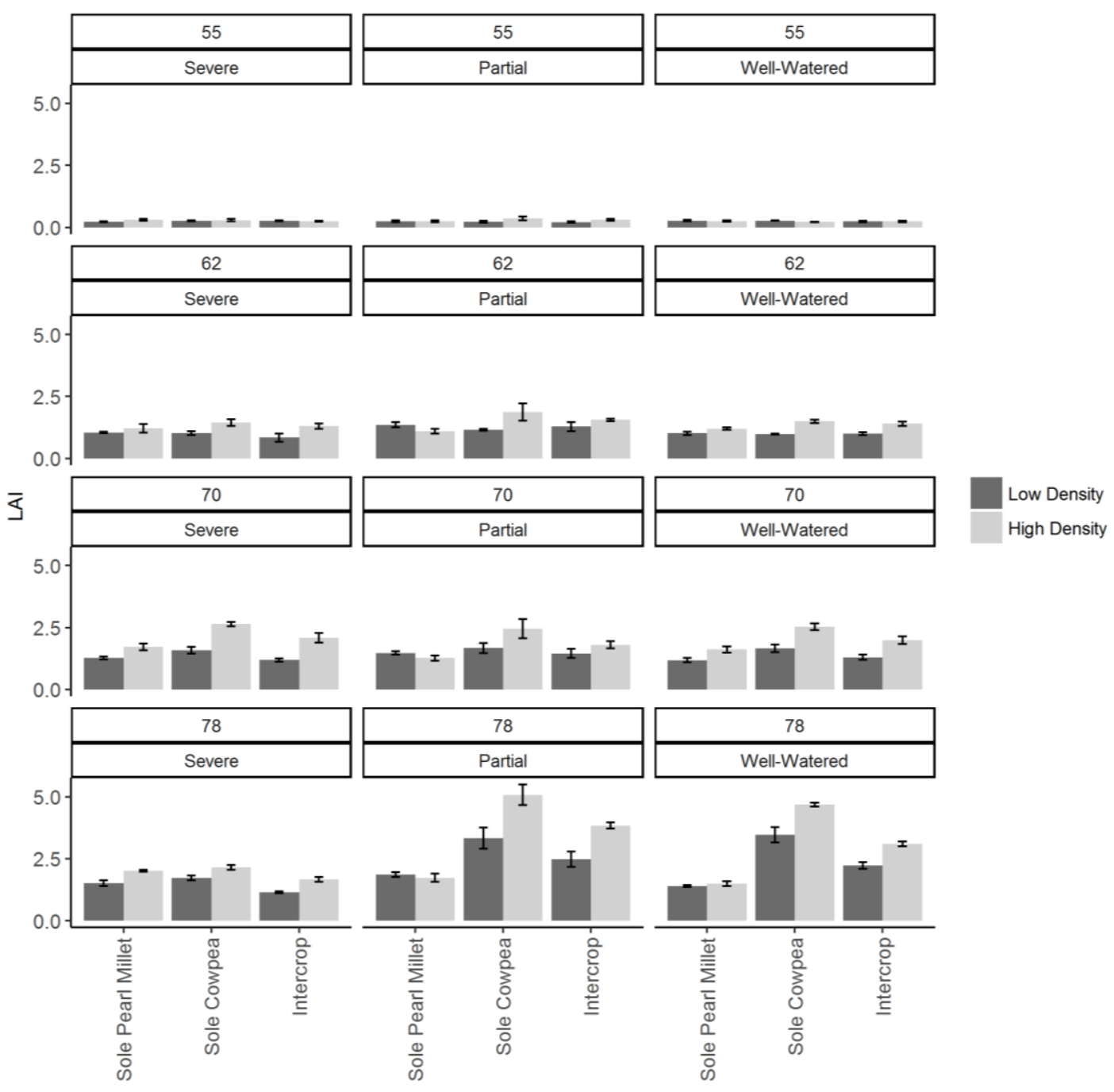

Figure 13. Leaf Area Index over four dates (Julian day) in 2015, with standard error bars across treatments. Densities are indicated via the shade of grey used, low density (dark grey), and high density (light grey). The measurements shown capture the end of flowering for both crops. 


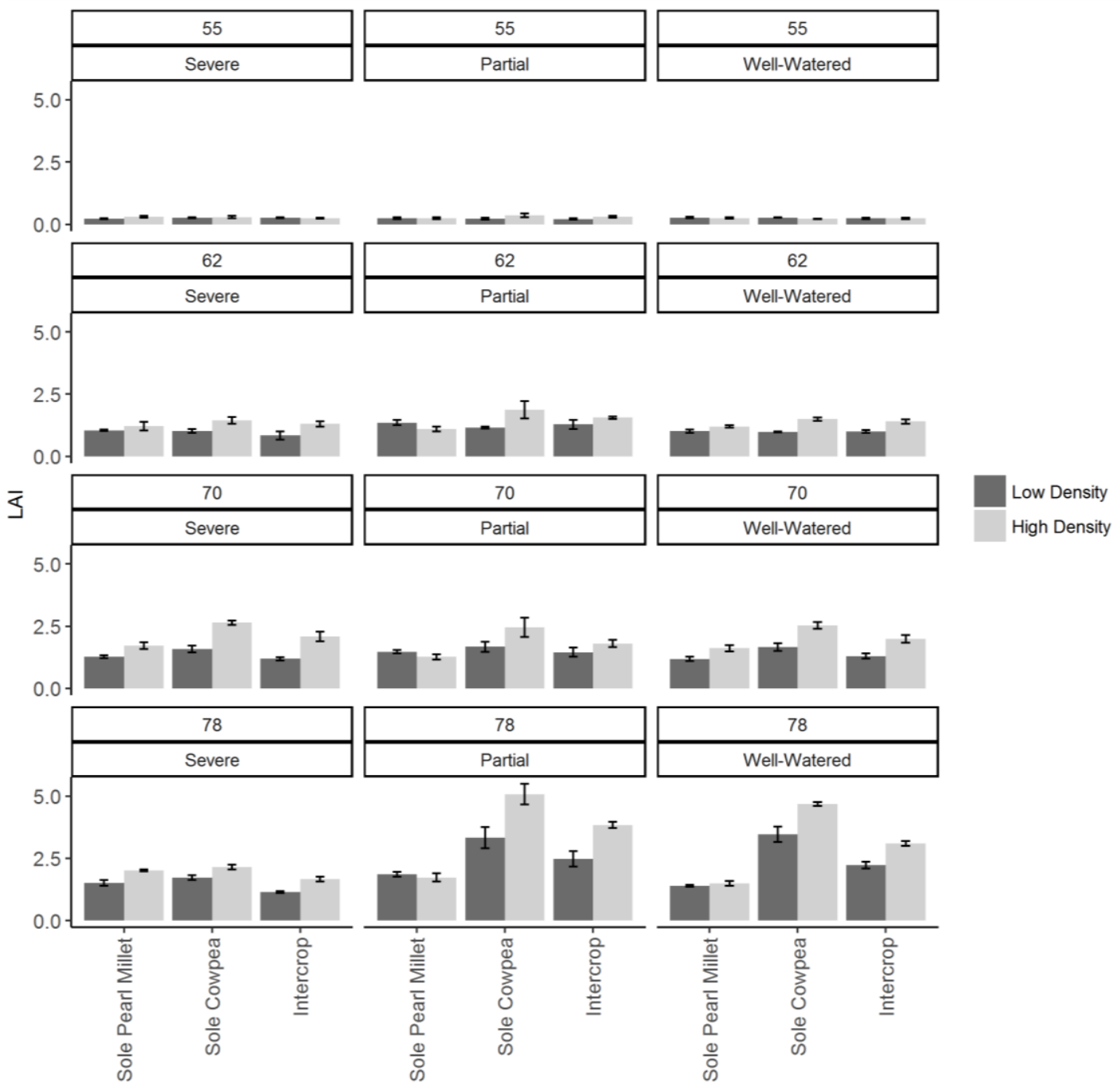

Figure 14. Leaf Area Index over four dates (Julian day) in 2016. The measurements shown capture the end of flowering for both crops. 


\subsubsection{Solar radiation}

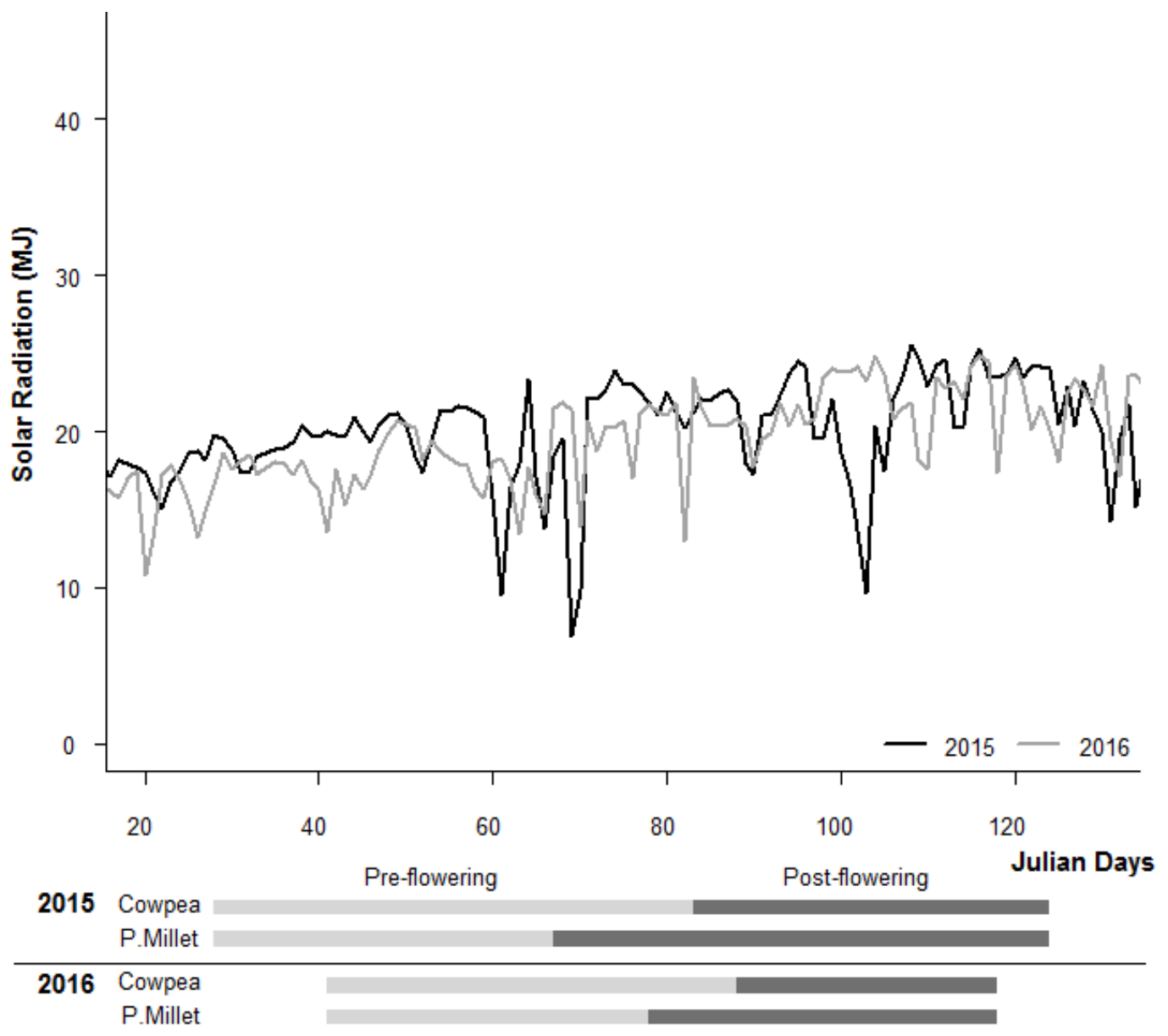

Figure 15. Solar Radiation and physiology timeline 2015 and 2016. Solid lines represent the daily solar radiation, black 2015, and grey 2016 (MJ). Development phases of both cowpea and pearl millet are presented for both years separately. Horizontal bars filled in light grey (below the plot) represent the time from germination to the completion of flowering of both crops. The following grain/pod filling to final harvest stage is shown through the dark grey bars. 


\subsection{ANOVA results}

Table A1: Results of ANOVA on the effects of System, Treatment, Density, and Year and their interactions on cowpea and pearl millet yield.

\begin{tabular}{|c|c|c|c|c|c|c|}
\hline Cowpea & Df & Sum Sq & Mean Sq & F value & $\operatorname{Pr}(>\mathrm{F})$ & \\
\hline System & 1 & 159226 & 159226 & 8.6194 & 0.0044621 & $* *$ \\
\hline Treatment & 2 & 7690426 & 3845213 & 208.155 & $<2.2 \mathrm{e}-16$ & $* * *$ \\
\hline Density & 1 & 280267 & 280267 & 15.1718 & 0.0002175 & $* * *$ \\
\hline Year & 1 & 2994224 & 2994224 & 162.0879 & $<2.2 \mathrm{e}-16$ & $* * *$ \\
\hline System:Treatment & 2 & 6056 & 3028 & 0.1639 & 0.8491271 & \\
\hline System:Density & 1 & 231849 & 231849 & 12.5508 & 0.0006996 & $* * *$ \\
\hline Treatment:Density & 2 & 252561 & 126281 & 6.836 & 0.0019132 & $* *$ \\
\hline System:Year & 1 & 28812 & 28812 & 1.5597 & 0.215759 & \\
\hline Treatment:Year & 2 & 743289 & 371645 & 20.1184 & 1.15E-07 & $* * *$ \\
\hline Density:Year & 1 & 118583 & 118583 & 6.4193 & 0.0134659 & * \\
\hline System:Treatment:Density & 2 & 405760 & 202880 & 10.9826 & $6.87 \mathrm{E}-05$ & $* * *$ \\
\hline System:Treatment:Year & 2 & 3581 & 1790 & 0.0969 & 0.9077529 & \\
\hline System:Density:Year & 1 & 284511 & 284511 & 15.4016 & 0.0001967 & $* * *$ \\
\hline Treatment:Density:Year & 2 & 69409 & 34704 & 1.8787 & 0.160206 & \\
\hline System:Treatment:Density:Year & 2 & 189724 & 94862 & 5.1352 & 0.008226 & $* *$ \\
\hline Residuals & 72 & 1330044 & 18473 & & & \\
\hline \multicolumn{7}{|l|}{ Pearl Millet } \\
\hline System & 1 & 28793523 & 28793523 & 376.4765 & $<2.2 \mathrm{e}-16$ & $* * *$ \\
\hline Treatment & 2 & 10422097 & 5211048 & 68.1347 & $<2.2 \mathrm{e}-16$ & $* * *$ \\
\hline Density & 1 & 66016 & 66016 & 0.8632 & 0.356 & \\
\hline Year & 1 & 73470 & 73470 & 0.9606 & 0.33036 & \\
\hline System:Treatment & 2 & 1955820 & 977910 & 12.7862 & $1.81 \mathrm{E}-05$ & $* * *$ \\
\hline System:Density & 1 & 1764901 & 1764901 & 23.0762 & $8.40 \mathrm{E}-06$ & $* * *$ \\
\hline Treatment:Density & 2 & 172106 & 86053 & 1.1251 & 0.33032 & \\
\hline System:Year & 1 & 136020 & 136020 & 1.7785 & 0.1866 & \\
\hline Treatment:Year & 2 & 2601677 & 1300838 & 17.0085 & $9.23 \mathrm{E}-07$ & $* * *$ \\
\hline Density:Year & 1 & 338778 & 338778 & 4.4295 & 0.03886 & * \\
\hline System:Treatment:Density & 2 & 147092 & 73546 & 0.9616 & 0.3872 & \\
\hline System:Treatment:Year & 2 & 106978 & 53489 & 0.6994 & 0.50029 & \\
\hline System:Density:Year & 1 & 10044 & 10044 & 0.1313 & 0.71813 & \\
\hline Treatment:Density:Year & 2 & 277264 & 138632 & 1.8126 & 0.1707 & \\
\hline System:Treatment:Density:Year & 2 & 57063 & 28531 & 0.373 & 0.68997 & \\
\hline Residuals & 71 & 5430193 & 76482 & & & \\
\hline \multicolumn{7}{|l|}{---} \\
\hline Signif. codes: $0^{\prime * * * \prime} 0.001$ & '* & ${ }^{* \prime} 0.011^{\prime}$ & ${ }^{* \prime} 0.05^{\prime}$ & . $0.1^{\prime}$ & $' 1$ & \\
\hline
\end{tabular}


Table A2: Table A2: Results of ANOVA on the effects of System, Treatment, Density, and Year and their interactions on cowpea and pearl millet harvest index.

\begin{tabular}{lrllllll} 
Cowpea & Df & Sum Sq & Mean Sq & F value & Pr(>F) & \\
\hline System & 1 & 159226 & 159226 & 8.619 & 0.004462 & $* *$ \\
Treatment & 2 & 7690426 & 3845213 & 208.155 & $<2 \mathrm{e}-16$ & $* * *$ \\
Density & 1 & 280267 & 280267 & 15.172 & 0.000217 & $* * *$ \\
Year & 1 & 2994224 & 2994224 & 162.088 & $<2 \mathrm{e}-16$ & $* * *$ \\
System:Treatment & 2 & 6056 & 3028 & 0.164 & 0.849127 & \\
System:Density & 1 & 231849 & 231849 & 12.551 & 0.0007 & $* * *$ \\
Treatment:Density & 2 & 252561 & 126281 & 6.836 & 0.001913 & $* *$ \\
System:Year & 1 & 28812 & 28812 & 1.56 & 0.215759 & \\
Treatment:Year & 2 & 743289 & 371645 & 20.118 & $1.15 \mathrm{E}-07$ & $* * *$ \\
Density:Year & 1 & 118583 & 118583 & 6.419 & 0.013466 & $*$ \\
System:Treatment:Density & 2 & 405760 & 202880 & 10.983 & $6.87 \mathrm{E}-05$ & $* * *$ \\
System:Treatment:Year & 2 & 3581 & 1790 & 0.097 & 0.907753 & \\
System:Density:Year & 1 & 284511 & 284511 & 15.402 & 0.000197 & $* * *$ \\
Treatment:Density:Year & 2 & 69409 & 34704 & 1.879 & 0.160206 & \\
System:Treatment:Density:Year & 2 & 189724 & 94862 & 5.135 & 0.008226 & $* *$ \\
Residuals & 72 & 1330044 & 18473 & & & \\
\hline
\end{tabular}

\begin{tabular}{|c|c|c|c|c|c|c|}
\hline \multicolumn{7}{|l|}{ Pearl Millet } \\
\hline System & 1 & 159226 & 159226 & 8.619 & 0.004462 & $* *$ \\
\hline Treatment & 2 & 7690426 & 3845213 & 208.155 & $<2 \mathrm{e}-16$ & $* * *$ \\
\hline Density & 1 & 280267 & 280267 & 15.172 & 0.000217 & $* * *$ \\
\hline Year & 1 & 2994224 & 2994224 & 162.088 & $<2 \mathrm{e}-16$ & $* * *$ \\
\hline System:Treatment & 2 & 6056 & 3028 & 0.164 & 0.849127 & \\
\hline System:Density & 1 & 231849 & 231849 & 12.551 & 0.0007 & $* * *$ \\
\hline Treatment:Density & 2 & 252561 & 126281 & 6.836 & 0.001913 & $* *$ \\
\hline System:Year & 1 & 28812 & 28812 & 1.56 & 0.215759 & \\
\hline Treatment:Year & 2 & 743289 & 371645 & 20.118 & $1.15 \mathrm{E}-07$ & $* * *$ \\
\hline Density:Year & 1 & 118583 & 118583 & 6.419 & 0.013466 & * \\
\hline System:Treatment:Density & 2 & 405760 & 202880 & 10.983 & $6.87 \mathrm{E}-05$ & $* * *$ \\
\hline System:Treatment:Year & 2 & 3581 & 1790 & 0.097 & 0.907753 & \\
\hline System:Density:Year & 1 & 284511 & 284511 & 15.402 & 0.000197 & $* * *$ \\
\hline Treatment:Density:Year & 2 & 69409 & 34704 & 1.879 & 0.160206 & \\
\hline System:Treatment:Density:Year & 2 & 189724 & 94862 & 5.135 & 0.008226 & $* *$ \\
\hline Residuals & 72 & 1330044 & 18473 & & & \\
\hline \multicolumn{7}{|l|}{--} \\
\hline Signif. codes: $0^{\prime * * * \prime} 0.001$ & ‘* & $*^{* \prime} 0.01$ & ‘*’ 0.05 & $\because 0.1$ & "1 1 & \\
\hline
\end{tabular}




\section{Chapter Three}

\section{Crop model based exploration of the mechanisms underlying pearl millet-cowpea intercropping performance ${ }^{2}$}

\subsection{Introduction}

Intercropping is promoted as a promising option in particular for low-input smallholder systems (Brooker et al., 2015). Traditionally, intercropping is used in such systems because of low plant population, where farmers hope to capitalise on niches, i.e. the space left between the initial plantings. A common system sees alternate rows of, for example, a sole crop cereal stand, replaced by companion crop rows (usually a legume), known as replacement intercropping, as seen in Nelson et al. (2018). It is argued that by using two different species important resources such as water and nutrients can be used complementarily (Brooker et al., 2015). However, it is clear that using intercropping as a silver bullet across regions and scenarios does not work, as crop performance depends on management, germplasm, site-specific environmental and socio-economic conditions (Li et al., 2006; Nelson et al., 2018; Rapholo et al., 2019). Consequently, a more site-specific approach to planting practices and fertiliser use is needed. However, optimisation of cultivar choice and management practices is difficult due to the numerous possible interactions with environmental factors. For example, some cereal-legume intercropping systems might delay the sowing of the legume component to encourage cereal growth dominance, known as relay intercropping (Brooker et al., 2015). However, the added labour required to sow a second time, as well as the increased weed management needed due to a gap in sowing, are factors that must be considered when designing such systems (Rapholo et al., 2019). Future intercropping systems could aim to take advantage of genotypic differences within species for adaptation to intercropping, which could allow for more efficient management through simultaneous sowing. Further investigation is therefore needed to determine the traits of cultivar ideotypes for specific production situations (Rötter et al., 2015). It is currently unclear which traits are needed for productive intercropping systems.

The challenges stated above suggest that field-based experimentation may be too time-consuming and costly to address the many potential climate and managementbased scenarios associated with such systems, as well as providing too little information on the mechanisms of intercrop growth dynamics. Process-orientated modelling has evolved

\footnotetext{
${ }^{2}$ This chapter is under review as Nelson, W.C.D., Hoffmann, M.P., Vadez, V., Rötter, R.P., Koch, M., Whitbread, A.M. (under review). Crop model based exploration of the mechanisms underlying pearl millet-cowpea intercropping performance.
} 
as an option to conduct and evaluate virtual experiments within days as opposed to fieldbased experimentation that requires years. This kind of modelling has limitations however, such as when assessing yield limiting factors, potentially beneficial in intercropping (Rötter et al., 2018). Conducting simulation experiments that systematically vary plant parameters, such as maximum height, phyllochron or temperature requirements for phenological development, can provide valuable information for breeders and farmers, as well as highlight potential areas of model improvement and guide field experimentation (Casadebaig et al., 2016; He et al., 2017; Akinseye et al., 2017).

So far, crop models have rarely been used to evaluate different intercropping practices (Gaudio et al., 2019) - intercrop research so far has in general been largely descriptive (Brisson and Bussiere, 2004; Tsubo et al., 2005). The Agricultural Production systems SIMulator (APSIM; Holzworth et al., 2014), contains a module for intercropping (Carberry et al., 1996), which has been evaluated for sorghum-cowpea intercropping (Chimonyo et al., 2016). While scenario-specific insights have indeed been gained from such work, there is a need to quantify the mechanistic relationships, as the interest in intercropping broadens (Fletcher et al., 2016; Gaudio et al., 2019; Varshney et al., 2018). Plant height is potentially a key trait for intercropping performance, as it contributes towards the determination of shading conditions. While this trait is important in terms of light competition in intercrop simulation scenarios, its effect is not considered in sole crop simulations. The relationship between canopy development and yield in intercropping systems has rarely been explored.

With the potential use of crop modelling for management improvements and genotype interactions in mind, this study had two objectives: (i) the crop model APSIM was evaluated for pearl millet-cowpea intercropping against a detailed field trial data set; (ii) the model was used to systematically explore the effects of interactions between pearl millet (Pennisetum glaucum (L.) and cowpea (Vigna unguiculata (L.)Walp) heights on simulated yields. The simulation experiment aimed to help better understand intercropping limitations and provide insights into the mechanisms of parameters and how they influence cultivar traits and ultimately intercropping performance. Pearl millet-cowpea intercropping was chosen as a common system for dryland smallholder farmers. Pearl millet is a key staple food for dryland regions, and cowpea an important protein source with leaves used as vegetables or fodder (Sennhenn et al., 2017). Model output can be used as the basis for hypotheses to motivate further, more targeted experiments, improve model performance, and ultimately work towards the development of ideotypic intercropping systems (Rötter et al., 2018). 


\subsection{Materials and Methods}

\subsubsection{Study region}

The study took place at the ICRISAT Research Station, Patancheru, India (17.25 ${ }^{\circ}$ $\mathrm{N}, 78.05^{\circ}$ E, Elevation: $545 \mathrm{~m}$ ). The climate of the region is semi-arid tropical with annual rainfall averaging $910 \mathrm{~mm}$ (taken from a period of 1980-2010). The year consists of a dry season (January to March, $37 \mathrm{~mm}$ ), a pre-rainy season (April to May, $56 \mathrm{~mm}$ ), a rainy season (June and September, $681 \mathrm{~mm}$ ), a post-rainy season (October to November, $127 \mathrm{~mm}$ ), and a post-rainy dry season (December, 5mm) (Virmani et al., 1982; ICRISAT-India, Patancheru Weather Station Records 1980-2010). The topsoil was a sandy loam with $79.3 \%$ sand, $6.4 \%$ silt, and $14.3 \%$ clay, with organic carbon in the topsoil at $0.55 \%$ and the $\mathrm{pH} 6$ 7 (Bhattacharyya et al., 2016).

\subsubsection{Model testing}

\subsubsection{APSIM}

The process-based model APSIM (version 7.7) used in this study, with a focus on dryland agriculture (Akinseye et al., 2017; Hoffmann et al., 2018b; Whitbread et al., 2017), was described by Holzworth et al. (2014), and has been widely used (Gaydon et al., 2017; Hoffmann et al., 2018a; Whitbread et al., 2010). The pearl millet model in APSIM (van Oosterom et al., 2001a and b) simulates the growth of the main stem and five tillers per plant separately. Applications are reported in Akponikpè et al. (2011), and O'Leary et al. (2008). The APSIM cowpea model (Robertson et al., 2002) follows the generic APSIM plant description (Wang et al., 2002) and simulates biological nitrogen (N) fixation to meet crop N needs (Chen et al., 2016). Of particular importance is that due to cowpea's ability to fix $\mathrm{N}$ from the air, APSIM assumes, in the case of a lack of mineral $\mathrm{N}$ for plant growth, that any deficit is supplied via fixation. Limitations of $\mathrm{N}$-fixation, such as low phosphorous supply or acidic soils, are ignored (Chen et al., 2016).

Intercropping was simulated using the APSIM Canopy module, whose routines for light interception and competition for water and $\mathrm{N}$ were described by Carberry et al. (1996) and introduces different aboveground layers based on the simulated height of the plant. This enables the modelling of light interception by layer from the tallest stand, with remaining light entering the layer below, determining light competition between intercrop components. Competition for water and $\mathrm{N}$ with intercropping is calculated by daily alternations of the crop that has first access to available resources. This alternation continues until final harvest. It is important to note that the resources available to a crop may differ due to the 
characteristics of that crop, such as rooting depth, soil water extraction capacity, crop lower limit, and $\mathrm{N}$ fixation. Competing intercrops therefore have an indirect impact on one another through the simulated influence of resource availability (Carberry et al., 1996).

\subsubsection{Field data}

The field data used was derived from a trial conducted at the ICRISAT experimental station in the dry seasons of 2015 and 2016 (Nelson et al., 2018). The trials were purposefully conducted during the off-season to ensure complete control of the water supply. The treatments tested were sole crop versus intercrop, 33 versus 17 plants per m-2 (reported as high and low plant-density, respectively), and irrigation for severe stress, partial stress, and well-watered treatments. Intercrop components, pearl millet and cowpea, were sown simultaneously. Cultivars used were Russian Giant for a forage cowpea crop, and a short pearl millet hybrid H77/833-2 (known as HHB 67 in India). Diammonium phosphate (DAP $=18 \% \mathrm{~N}+46 \% \mathrm{P} 2 \mathrm{O} 4)$ was applied at $100 \mathrm{~kg} \mathrm{ha}^{-1}$ before sowing to all plots and urea$\mathrm{N}$ was top-dress applied to pearl millet at $100 \mathrm{~kg} \mathrm{ha}^{-1}$ once plants were well-established. This was done to eliminate $\mathrm{N}$ limitations. Biomass harvests consisting of $500 \mathrm{~mm}$ of biomass of every plot row were done by hand at pearl-millet flowering, cowpea flowering, two weeks after cowpea flowering, and at full maturity with the addition of grain yield. Leaf area index (estimated using an AccuPAR LP-80) on a plot basis, and stem height (cropspecific for intercrop stands) were measured weekly. Soil samples were taken one day before sowing and one day after each biomass harvest using a hand probe so water use could be assessed from 0 to $600 \mathrm{~mm}$ in $150 \mathrm{~mm}$ increments. These were weighed directly in the field, dried in ovens at $60{ }^{\circ} \mathrm{C}$ for 24 hours, followed by $105^{\circ} \mathrm{C}$ for a further 24 hours and weighed. More details can be found in Nelson et al. (2018).

\subsubsection{Model calibration}

APSIM simulations require daily weather data, soil properties, management practices, and cultivar information to be run for specific field trials. Solar radiation, maximum and minimum temperature and precipitation were measured at the experimental station. Information on planting, fertiliser and irrigation practices was collected during the trial. Soil and cultivar data was used to calibrate the model, as explained in detail below. Then, the cowpea and pearl millet sole crop well-watered high plant-density treatments of 2015 were used to derive cultivar specific parameters - these treatments were then excluded from the statistical validation of the model (Figure 1 and 2). Missing soil parameters were 
based on standard values found in the literature. The same model parameterisation was used to simulate the remaining treatments.

Soil parameterisation is especially important for the determination of plant available water holding capacity, defined as the difference between crop lower limit (CLL) and drained upper limit (DUL) (Whitbread et al., 2017). The CLL and DUL were determined according to Dalgliesh et al. (2016). The CLL was determined by positioning rainout shelters over pearl millet and cowpea monoculture stands at flowering and using the volumetric soil water at harvest for crop-specific lower limits (Table 1). Drained upper limit was assessed by drip irrigation wetting of the soil profile (Table 1). Bulk density values were assessed prior to this study. The maximum rates of total water extraction by the crop (KL) were estimated similarly to Dalgliesh et al. (2016) (Table 1).

Table 1. Soil physical properties for the estimated rooting depth, including bulk density (BD), low limit of available soil water for each crop (LL), drained upper limit/ field capacity (DUL), and saturation (SAT). Fraction of plant available water able to be extracted/ day $(K L)$ for each crop and layer (Dalgliesh et al., 2016), and an exploration factor (XF) with 1 for no root growth impediment and 0 if roots cannot penetrate a layer.

\begin{tabular}{|c|c|c|c|c|c|c|c|c|c|c|}
\hline $\begin{array}{l}\text { Dept } \\
(\mathrm{cm})\end{array}$ & $\begin{array}{l}\mathrm{BD} \\
(\mathrm{g} / \mathrm{cc})\end{array}$ & $\begin{array}{l}\text { Air } \\
\text { Dry }\end{array}$ & $\begin{array}{l}\text { Millet } \\
\text { LL } \\
(\mathrm{mm} / \mathrm{mm})\end{array}$ & $\begin{array}{l}\text { Cowpea } \\
\text { LL } \\
(\mathrm{mm} / \mathrm{mm})\end{array}$ & $\begin{array}{l}\text { DUL } \\
(\mathrm{mm} / \mathrm{mm})\end{array}$ & $\begin{array}{l}\text { SAT } \\
(\mathrm{mm} / \mathrm{mm})\end{array}$ & $\begin{array}{l}\text { Millet } \\
\text { KL } \\
\text { (/day) }\end{array}$ & $\begin{array}{l}\text { Millet } \\
\text { XF } \\
(0-1)\end{array}$ & $\begin{array}{l}\text { Cowpea } \\
\text { KL } \\
\text { (/day) }\end{array}$ & $\begin{array}{l}\text { Cowpea } \\
\text { XF } \\
(0-1)\end{array}$ \\
\hline $0-15$ & 1.350 & 0.074 & 0.102 & 0.082 & 0.172 & 0.441 & 0.08 & 1.0 & 0.08 & 1.0 \\
\hline $30-45$ & 1.420 & 0.170 & 0.181 & 0.170 & 0.292 & 0.414 & 0.08 & 1.0 & 0.08 & 1.0 \\
\hline $45-60$ & 1.420 & 0.154 & 0.165 & 0.154 & 0.290 & 0.414 & 0.08 & 1.0 & 0.08 & 1.0 \\
\hline $90-105$ & 1.420 & 0.128 & 0.128 & 0.128 & 0.211 & 0.414 & 0.03 & 1.0 & 0.03 & 1.0 \\
\hline $105-120$ & 1.420 & 0.128 & 0.128 & 0.128 & 0.257 & 0.414 & 0.02 & 1.0 & 0.02 & 1.0 \\
\hline $120-135$ & 1.420 & 0.128 & 0.128 & 0.128 & 0.216 & 0.414 & 0.02 & 1.0 & 0.01 & 0.0 \\
\hline $135-150$ & 1.420 & 0.128 & 0.128 & 0.128 & 0.198 & 0.414 & 0.01 & 1.0 & 0.01 & 0.0 \\
\hline
\end{tabular}

The APSIM Soilwat parameters were set at 4 and $2 \mathrm{~mm}-0.5$ for cona and $\mathrm{u}$ respectively, 73 for the runoff curve number, 88 for the diffusivity constant of water percolation, and 35 for the diffusivity slope under unsaturated conditions, and 0.5 for the SWCON for saturated conditions (Hoffmann et al., 2017; Whitbread et al., 2017). Initial soil water conditions were measured for both years.

The APSIM model's phenological stages are simulated through calculating thermal time (tt, degree days) using base $\left(10^{\circ} \mathrm{C}\right.$ and $\left.10^{\circ} \mathrm{C}\right)$, optimal $\left(33^{\circ} \mathrm{C}\right.$ and $\left.23^{\circ} \mathrm{C}\right)$, and maximum temperatures $\left(47^{\circ} \mathrm{C}\right.$ and $\left.44^{\circ} \mathrm{C}\right)$ for pearl millet and cowpea, respectively, based on empirical data (pearl millet: van Oosterom et al., 2001a and b; and cowpea: Robertson et al., 2002). Pearl millet cultivar HHB 67 was already characterised in APSIM and the characterisation of cowpea cultivar Banjo was used for Russian Giant. Using the trial data, the cultivars were re-parameterised for phenology and canopy development (Table 2). The determination of 
the parameters was done by visually matching model output against observed results of grain yield, biomass, LAI, and plant height (Figure 1, 2 and 3). A key cultivar parameter adapted for pearl millet addressed the height of the plants. In APSIM, actual plant height is a function of the parameters maximum plant height and stem weight. Overall, parameters were set within reasonable ranges found in the literature in order to avoid overfitting the model (see section 3.2.2.1).

Table 2: Cowpea and pearl millet cultivar parameters used for APSIM, highlighting the adaptations made to default APSIM parameters; $t$ t represents the unit thermal time

\begin{tabular}{|c|c|c|c|c|}
\hline APSIM parameter & Description & Unit & Default & Adapted \\
\hline Cowpea & & & Banjo & Russian Giant \\
\hline y_hi_incr & Rate of $\mathrm{HI}$ increase & $0.0164 /$ days & 0.014 & 0.010 \\
\hline y_hi_max_pot & Max. HI & $0-1$ & 0.4 & 0.25 \\
\hline tt_emergence & tt emergence to end juvenile & ${ }^{\circ} \mathrm{C}$ days & 552 & 680 \\
\hline y_tt_flowering & tt flowering to start grain fill & ${ }^{\circ} \mathrm{C}$ days & 100 & 120 \\
\hline y_tt_start_grain_fill & tt to start of grain fill period & ${ }^{\circ} \mathrm{C}$ days & 280 & 390 \\
\hline x_stem_wt & Stem weight & g/plant & $0-15$ & $0-15$ \\
\hline y_height & Plant height & $\mathrm{mm}$ & $0-1000$ & $0-1000$ \\
\hline y_node_app_rate & Node appearance rate & ${ }^{\circ} \mathrm{C}$ days & 50505050 & 40404040 \\
\hline Pearl millet & & & HHB 67 & HHB 67 \\
\hline \multicolumn{5}{|l|}{ Millet main stem } \\
\hline leaf_app_rate1 & tt required to fully emerge & ${ }^{\circ} \mathrm{C}$ days & 62 & 75 \\
\hline leaf_app_rate2 & tt required to fully emerge & ${ }^{\circ} \mathrm{C}$ days & 36.4 & 40.4 \\
\hline head_grain_no_max & Potential grains per head & Grains/head & 2600 & 5200 \\
\hline tt_emerg_to_endjuv & tt emerg. to end of juvenile & ${ }^{\circ} \mathrm{C}$ days & 199.4 & 119.4 \\
\hline tt_flower_to_maturity & tt flower to maturity & ${ }^{\circ} \mathrm{C}$ days & 457 & 610 \\
\hline tt_maturity_to_ripe & tt maturity to harvest & ${ }^{\circ} \mathrm{C}$ days & 1 & 50 \\
\hline y0_const & $\begin{array}{l}\text { Largest leaf area intercept } \\
\text { y-axis regression of the area of the } \\
\text { largest leaf on total leaf number }\end{array}$ & & 7280 & 4280 \\
\hline \multicolumn{5}{|l|}{ Millet tiller 1} \\
\hline leaf_app_rate1 & $\mathrm{tt}$ required to fully emerge & ${ }^{\circ} \mathrm{C}$ days & 62 & 95 \\
\hline leaf_app_rate2 & $\mathrm{tt}$ required to fully emerge & ${ }^{\circ} \mathrm{C}$ days & 36.4 & 80.4 \\
\hline tt_flower_to_maturity & tt flower to maturity & ${ }^{\circ} \mathrm{C}$ days & 457 & 610 \\
\hline tt_maturity_to_ripe & tt maturity to harvest & ${ }^{\circ} \mathrm{C}$ days & 1 & 50 \\
\hline y0_const & $\begin{array}{l}\text { Largest leaf area intercept } \\
\text { y-axis regression of the area of the } \\
\text { largest leaf on total leaf number }\end{array}$ & & 3480 & 1480 \\
\hline \multicolumn{5}{|l|}{ Millet tillers 2, 3, $4 \& 5$} \\
\hline leaf_app_rate1 & tt required to fully emerge & ${ }^{\circ} \mathrm{C}$ days & 62 & 75 \\
\hline tt_flower_to_maturity & tt flower to maturity & ${ }^{\circ} \mathrm{C}$ days & 457 & 610 \\
\hline tt_maturity_to_ripe & tt maturity to harvest & ${ }^{\circ} \mathrm{C}$ days & 1 & 50 \\
\hline y0_const & $\begin{array}{l}\text { Largest leaf area intercept } \\
\text { y-axis regression of the area of the } \\
\text { largest leaf on total leaf number }\end{array}$ & & 3480 & 1570 \\
\hline
\end{tabular}


a
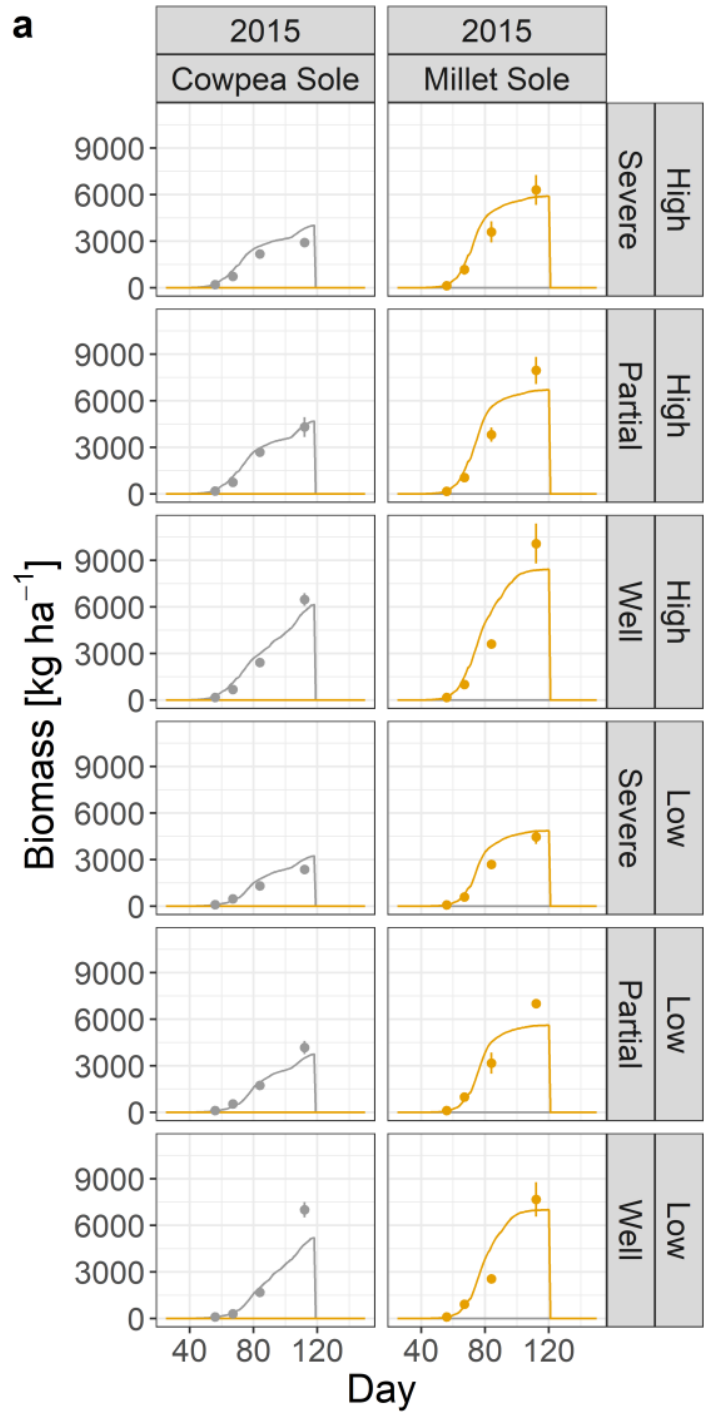

b
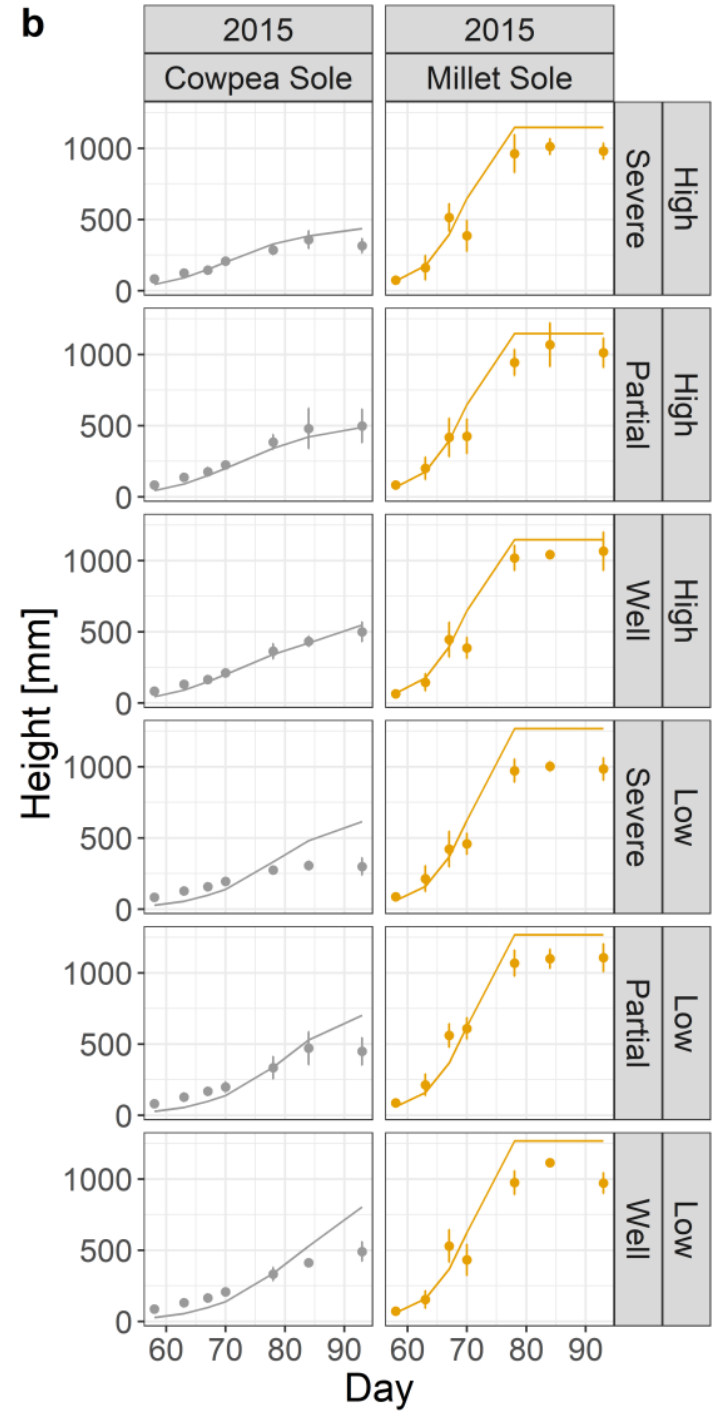

Figure 1. APSIM calibration runs for aboveground biomass (a) and plant height (b) compared simulated lines and observed points throughout the 2015 season for pearl millet and cowpea sole crops in Patancheru. The right-hand side y-axis identifies: high, 33, and low, 17 plants per m-2 planting densities; and weekly irrigation treatments: severe, until pearl millet flowering; partial, until cowpea flowering; and well-watered, until after cowpea flowering. 


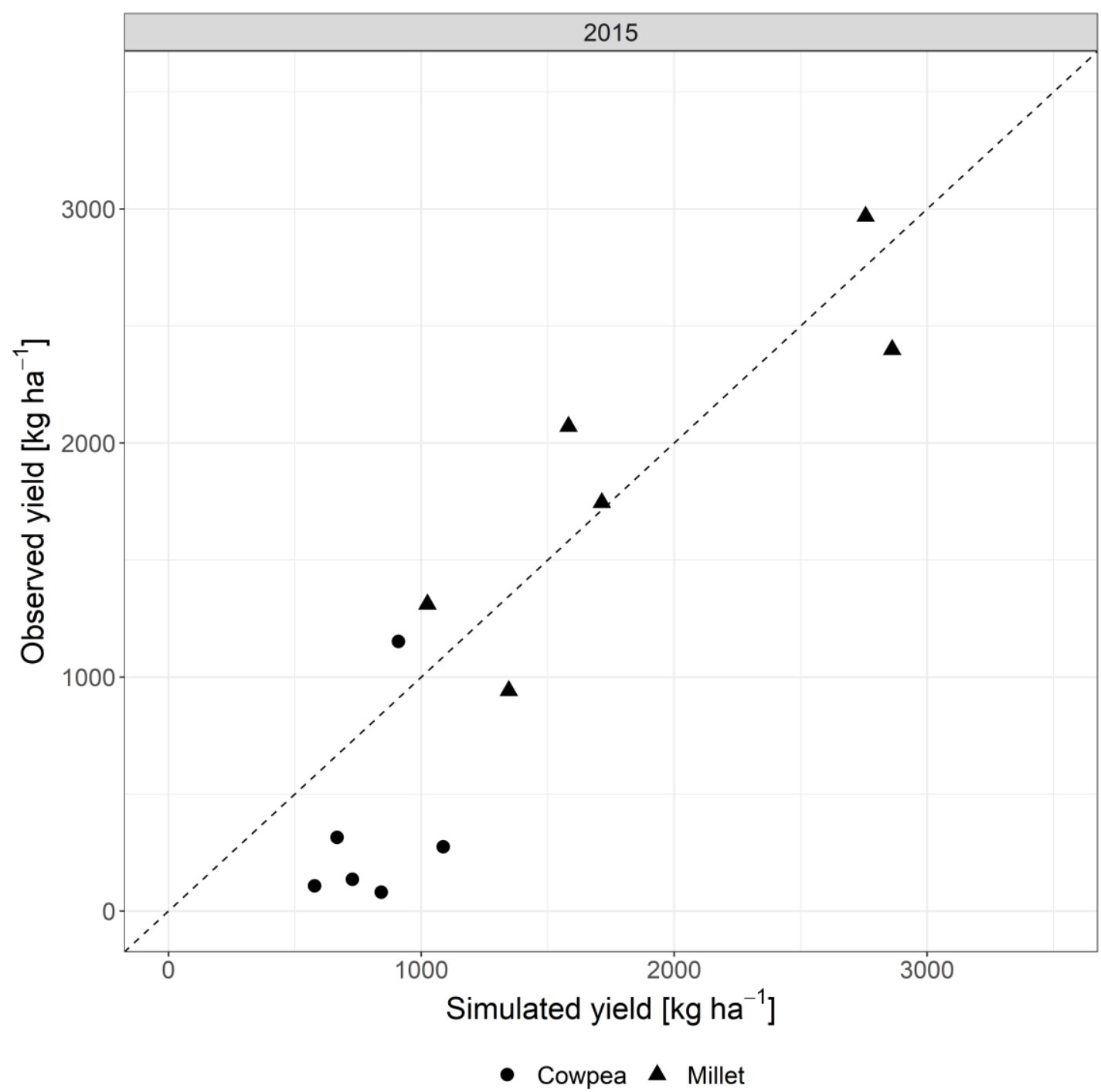

Figure 2. Calibration runs for simulated (x-axis) versus observed (y-axis) grain yield throughout the 2015 season for pearl millet (triangles) and cowpea (circles) sole crops in Patancheru. 


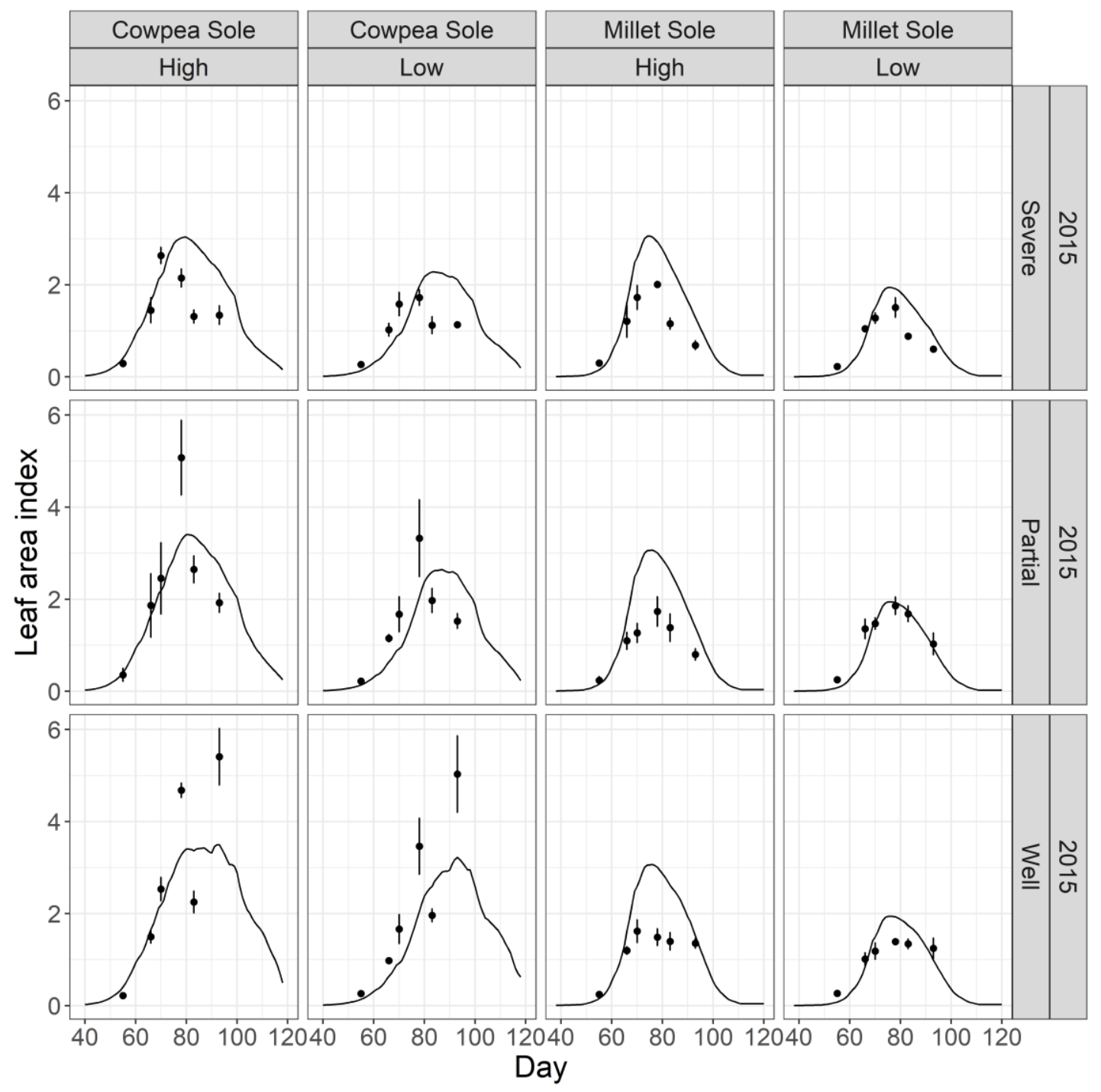

Figure 3. Calibration runs for simulated lines and observed points of LAI throughout the 2015 season for pearl millet and cowpea sole crops in Patancheru. The right-hand side y-axis identifies: 2015, season; and weekly irrigation treatments: severe, until pearl millet flowering; partial, until cowpea flowering; and wellwatered, until two weeks after cowpea flowering. The upper column identifies: cowpea and pearl millet sole crop systems; and high, 33 and low, 17 plants per $m^{-2}$ planting densities.

\subsubsection{Statistical validation}

All treatments besides pearl millet and cowpea sole crops in 2015 were used to validate model performance independently using root mean square error (RMSE), and its normalisation (nRMSE 0-1, the closer to zero is better), model efficiency (EF 0-1, the closer to one the better), and Willmott Index of Agreement (IA 0-1, the closer to one the better) (Hoffmann et al., 2018a). All analyses were done using $\mathrm{R}$ software and the package 'ZeBook' (Wallach et al., 2018) for the statistical validation and ggplot2 for visualisation (Wickham, 2016). 


\subsubsection{Simulation experiment}

The APSIM model was setup for a simulation experiment to explore the effect of the model parameter 'maximum plant height' under different management strategies for pearl millet-cowpea intercropping on grain yield performance. The soil used was the same as the one used in the model validation. The simulation experiment was repeated for 31 years from 1980 to 2010. Simulated rainfall was limited to zero for full control. The sowing date was the 28th of January. The water supply amounts per season and duration after sowing were: $300 \mathrm{~mm}$ during five weeks for severely stressed; $350 \mathrm{~mm}$ over seven weeks for partially stressed; and $500 \mathrm{~mm}$ over nine weeks for well-watered. A plant-density of 33 plants per m-2 with 300 mm between row spacing was compared with 17 plants per m-2 with $600 \mathrm{~mm}$ between row spacing. Within row plant spacing was $100 \mathrm{~mm}$.

Soil water was set at each sowing event to field capacity and the above-described irrigation treatments were applied in addition, as water declined from field capacity. Maximum plant height was systematically varied; for cowpea from 200 to $1000 \mathrm{~mm}$ at intervals of $200 \mathrm{~mm}$, and for pearl millet from 400 to $4000 \mathrm{~mm}$ at intervals of $400 \mathrm{~mm}$. Taking management (two plant-densities and three levels of irrigation) into account, there were 300 simulations

\subsection{Results}

\subsubsection{Model validation}

Willmott Index (IA) values for yield of 0.87 and 0.83 for both crops and pearl millet, respectively, show that the model performed well in terms of capturing growth dynamics and distinguishing treatment effects. Model efficiency was satisfactory for both crops combined at 0.60 , with cowpea yield at 0.22 , and pearl millet yield at 0.46 (Table 3 ). Model accuracy was variable and highly crop specific, as indicated by nRMSE values of 0.44 for both cowpea and pearl millet combined, but with 0.58 and 0.37 for cowpea and pearl millet individually (Table 3). While higher pearl millet yields were captured by the model overall, it seemed to have difficulties reproducing large yields for high plant-density sole crop conditions. Importantly, cowpea yields were still simulated with a RMSE of $322 \mathrm{~kg} \mathrm{ha}^{-1}$, but against a low observed average of $555 \mathrm{~kg} \mathrm{ha}^{-1}$.

While model accuracy was not high for biomass (high relative nRMSE values of around 0.55), the IA emphasised the effectiveness of the model, with $0.91,0.91$, and 0.88 for both crops, pearl millet, and cowpea, respectively (Table 3), which captured the dynamics of 
plant growth. Model efficiency values of $0.68,0.69$, and 0.68 confirmed solid model performance (Table 3).

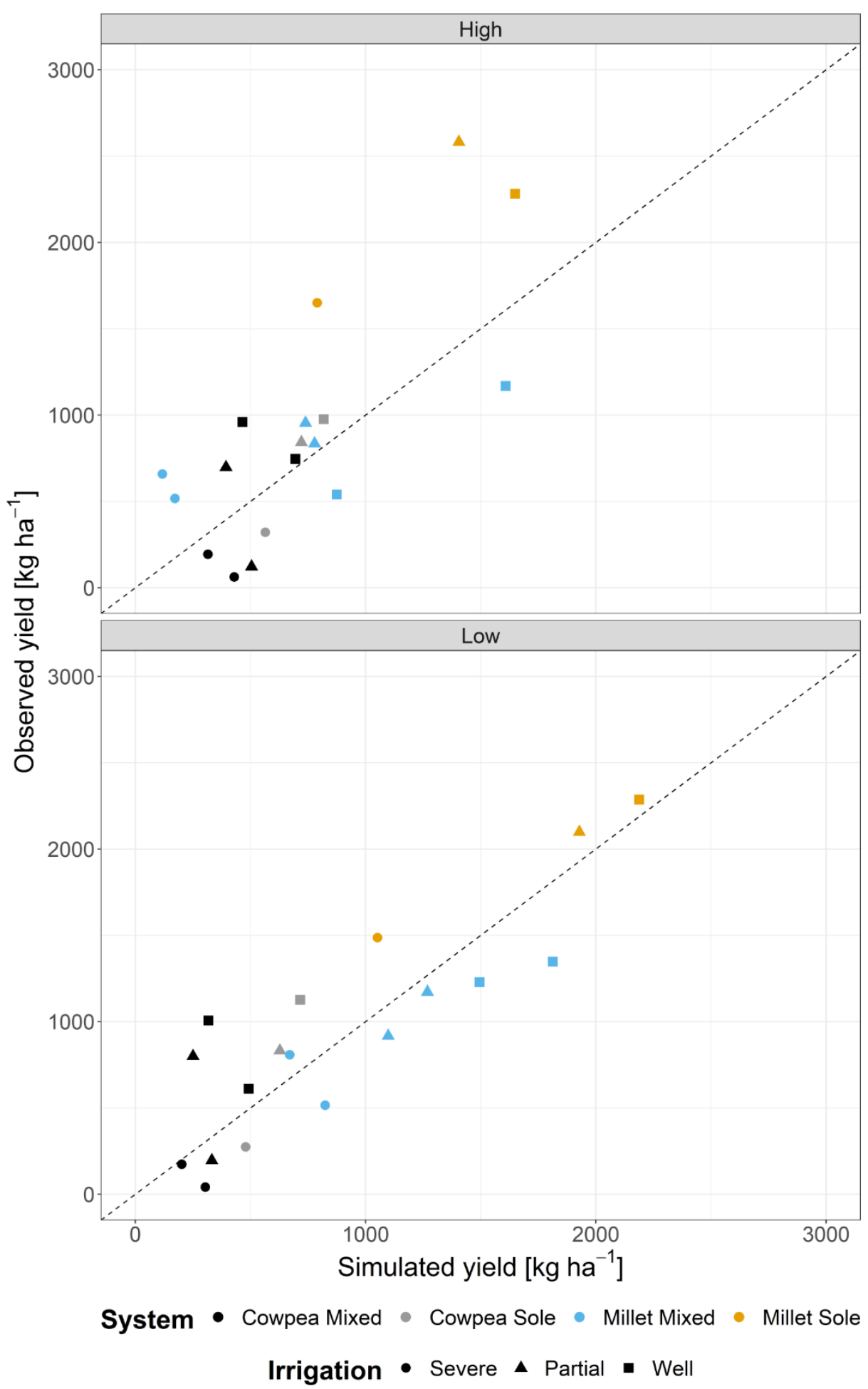

Figure 4. Simulated ( $x$-axis) versus observed (y-axis) grain yield for cowpea and pearl millet sole crops and intercropped stands with high, 33, and low, 17 plants per m-2 planting densities in Patancheru - plots top and bottom respectively. Colours represent the cropping system; and shapes the weekly irrigation treatments: severe, until pearl millet flowering (circles), partial, until cowpea flowering (triangles), and well-watered, until two weeks after cowpea flowering (squares). 
Cowpea biomass yield predictions were particularly accurate under the severe stress treatments at both high and low plant-densities, but worsened over time as water supply increased. This trend can also be seen for pearl millet sole crop in 2016 with both plantdensities. The model clearly simulated the impact of intercropping, and the resource competition that occurs, as pearl millet biomass was lower when intercropped compared to when grown as a sole crop (Figure 5).

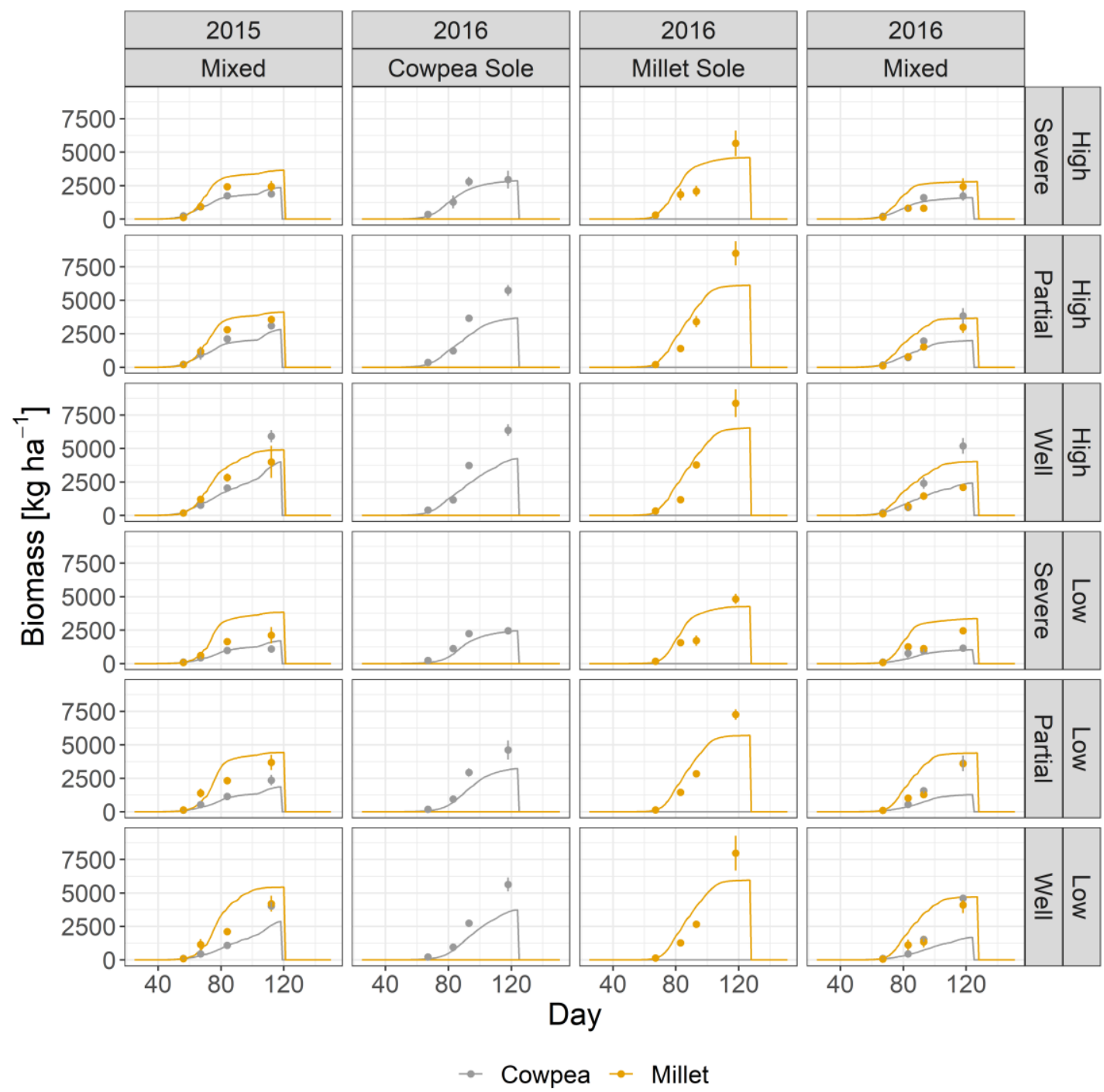

Figure 5. Simulated lines and observed points for biomass over time (Julian days) in Patancheru. Represented treatments, from left to right, are intercropped cowpea and pearl millet 2015, cowpea sole crop 2016, pearl millet sole crop 2016, and intercropped cowpea and pearl millet in 2016. The right-hand side y-axis identifies both high, 33, and low 17 plants per $m^{-2}$ planting densities; and weekly irrigation treatments: severe, until pearl millet flowering, partial, until cowpea flowering, and well-watered, until two weeks after cowpea flowering. 


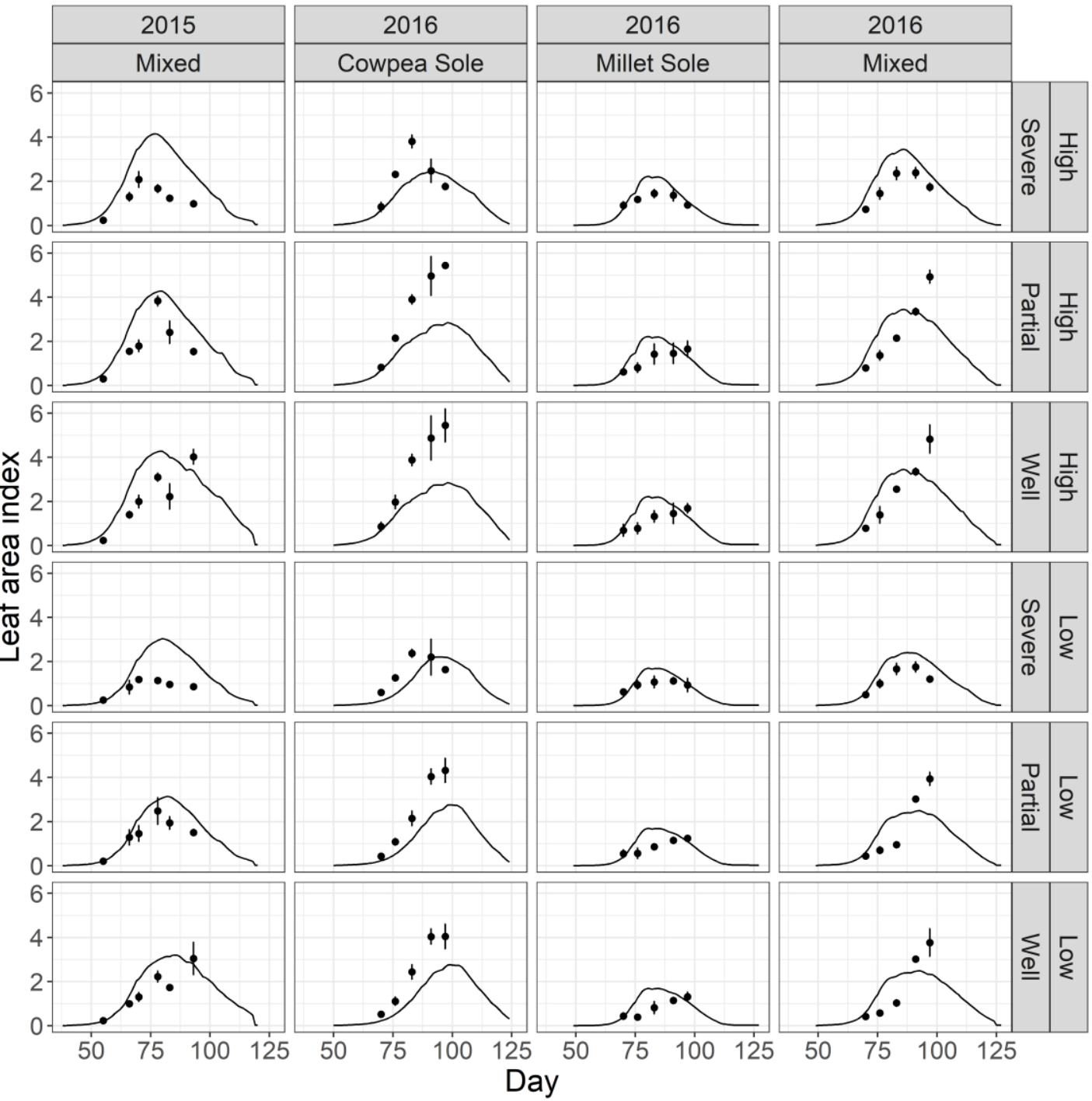

Figure 6. Simulated lines and observed points of the leaf area index shown over time (Julian days) in Patancheru. Represented treatments are intercropped cowpea and pearl millet 2015, cowpea sole crop 2016, pearl millet sole crop 2016, and intercropped cowpea and pearl millet 2016. The right-hand side y-axis identifies both high, 33, and low 17 plants per $m^{-2}$ planting densities; and weekly irrigation treatments: severe, until pearl millet flowering, partial, until cowpea flowering, and well-watered, until two weeks after cowpea flowering. 
Table 3. Model validation: mean observed value, mean simulated value, root mean square error (RMSE), RMSE normalised to the observed mean (nRMSE), Model Efficiency (EF) and the Willmott Index of Agreement (IA).

\begin{tabular}{lllllllll}
\hline Variable & Value & $\mathrm{N}$ & $\begin{array}{l}\text { Mean } \\
\text { obs. }\end{array}$ & $\begin{array}{l}\text { Mean } \\
\text { sim. }\end{array}$ & RMSE & nRMSE & EF & IA \\
\hline Biomass (both crops) & $\mathrm{kg} \mathrm{ha}^{-1}$ & 144 & 1836 & 1872 & 1020 & 0.55 & 0.68 & 0.91 \\
Cowpea biomass & $\mathrm{kg} \mathrm{ha}^{-1}$ & 72 & 1695 & 1215 & 924 & 0.54 & 0.68 & 0.88 \\
Pearl millet biomass & $\mathrm{kg} \mathrm{ha}^{-1}$ & 72 & 1977 & 2528 & 1100 & 0.56 & 0.69 & 0.91 \\
Yield (both crops) & $\mathrm{kg} \mathrm{ha}^{-1}$ & 36 & 918 & 808 & 402 & 0.44 & 0.60 & 0.87 \\
Cowpea yield & $\mathrm{kg} \mathrm{ha}^{-1}$ & 18 & 555 & 479 & 322 & 0.58 & 0.22 & 0.64 \\
Pearl millet yield & $\mathrm{kg} \mathrm{ha}^{-1}$ & 18 & 1280 & 1137 & 469 & 0.37 & 0.46 & 0.83 \\
LAI intercrop stands & - & 66 & 1.72 & 2.37 & 1.10 & 0.64 & 0.06 & 0.75 \\
LAI cowpea sole & - & 30 & 2.59 & 1.61 & 1.32 & 0.51 & 0.28 & 0.75 \\
LAI pearl millet sole & - & 30 & 1.03 & 1.36 & 0.53 & 0.51 & -1.19 & 0.66 \\
Pearl millet height & $\mathrm{mm}_{\text {Cowpea height }}$ & 102 & 567 & 653 & 176 & 0.31 & 0.72 & 0.94 \\
Soil water * & $\mathrm{mm}$ & 102 & 287 & 164 & 154 & 0.54 & 0.07 & 0.75 \\
\hline
\end{tabular}

* Contains measurements from layers 0-150, 150-300, 300-450, and 450-600 mm (see Figure 8).

The dynamics of LAI were simulated well by the model, with an IA value for intercrop stands of 0.75 (Table 3). Simulated LAI was low for cowpea and more accurate for pearl millet (Figure 6). Simulations for sole crop cowpea 2016 for the severe stress, high plant-density treatment captured the effect senescence had on LAI, as values peaked around Julian day 80 and declined as the crop neared maturity. This trend was also seen for the same treatment at the low plant-density, although the values and peaks were not as high. For all sole crop cowpea 2016 treatments, LAI peaks were accurately captured in terms of the stage of the season. There was little difference between observed and simulated partial and well-watered LAI values for all 2016 densities and systems. Simulated intercrop LAI matched observed values especially well for severe stress in 2016 (Figure 6). 


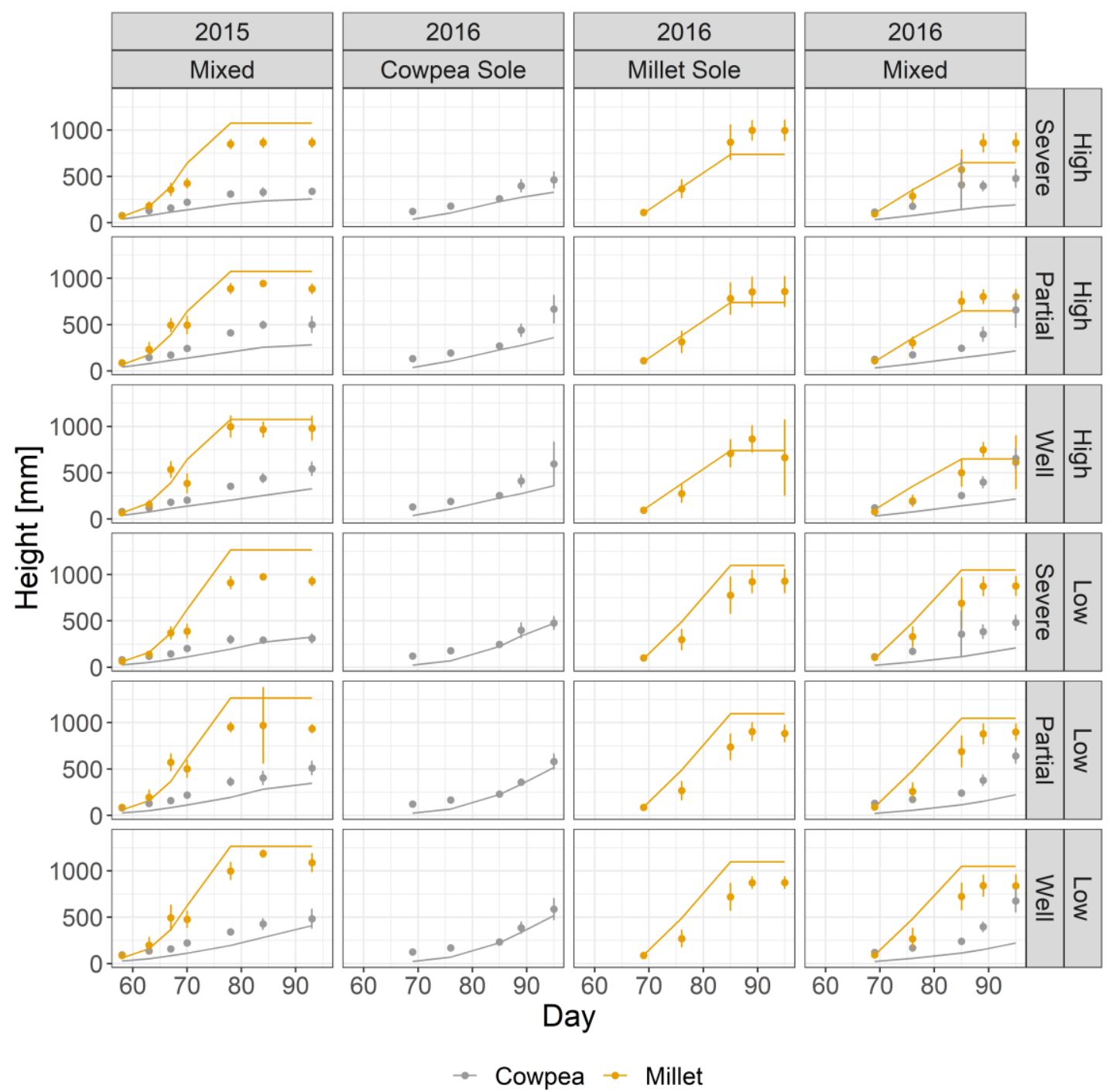

Figure 7. Simulated lines and observed points of the main stem height ( $\mathrm{mm}$ ) shown over time (Julian days) in Patancheru. Represented treatments are intercropped cowpea and pearl millet 2015, cowpea sole crop 2016, pearl millet sole crop 2016, and intercropped cowpea and pearl millet 2016. The right-hand side y-axis identifies both high, 33, and low 17 plants per $m^{-2}$ planting densities; and weekly irrigation treatments: severe, until pearl millet flowering, partial, until cowpea flowering, and well-watered, until two weeks after cowpea flowering.

The model simulated pearl millet stem height accurately with a nRMSE value of 0.31 , EF of 0.72 and a IA value of 0.94 (Table 3). Figure 7 highlights the solid model simulations for both cowpea and pearl millet sole crops. Although in general all treatments were simulated well in this instance, sole crop cowpea 2016 simulations were better at low plant-density towards the end of the season compared to those for high plant-density treatments. For the intercrop treatments in general, the competition from pearl millet was simulated as having a greater impact on cowpea height than observed (Figure 7). With a nRMSE of 0.28 (Table 3), water content trends were clearly well simulated (Figure 8). 


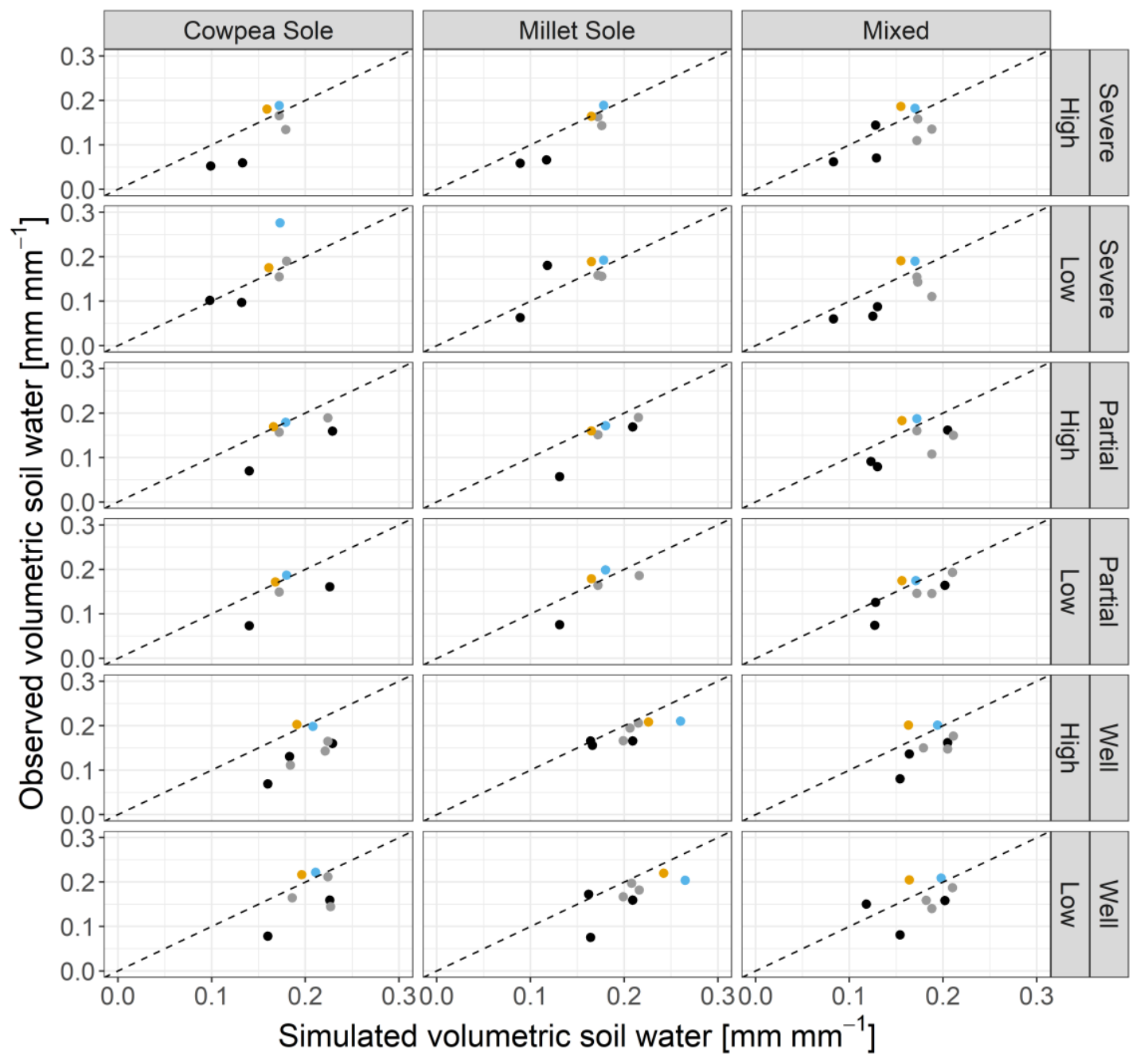

- $0-150 \mathrm{~mm} \cdot 150-300 \mathrm{~mm} \cdot 300-450 \mathrm{~mm} \cdot 450-600 \mathrm{~mm}$

Figure 8. Simulated ( $x$-axis) versus observed (y-axis) volumetric water content of soil water layers 0-150, 150300, 300-450, and 450-600 mm for the experimental site in Patancheru. Represented treatments are cowpea sole crop 2015, pearl millet sole crop 2015, and intercropped cowpea and pearl millet 2016. The right-hand side y-axis identifies both high, 33, and low 17 plants per $m^{-2}$ planting densities; and weekly irrigation treatments: severe, until pearl millet flowering, partial, until cowpea flowering, and well-watered, until two weeks after cowpea flowering.

\subsubsection{Simulation experiment: sensitivity analysis of plant height}

The simulation experiment examined the effects of plant-density, water supply, and varying plant height on sole crop and intercrop pearl millet and cowpea yields. Total yield increased with water supply and maximum pearl millet height, with the highest yield at 2500 $\mathrm{kg} \mathrm{ha}^{-1}$ averaged over 31 simulated years (Figure 9). Yields were slightly higher with low plant-density. 


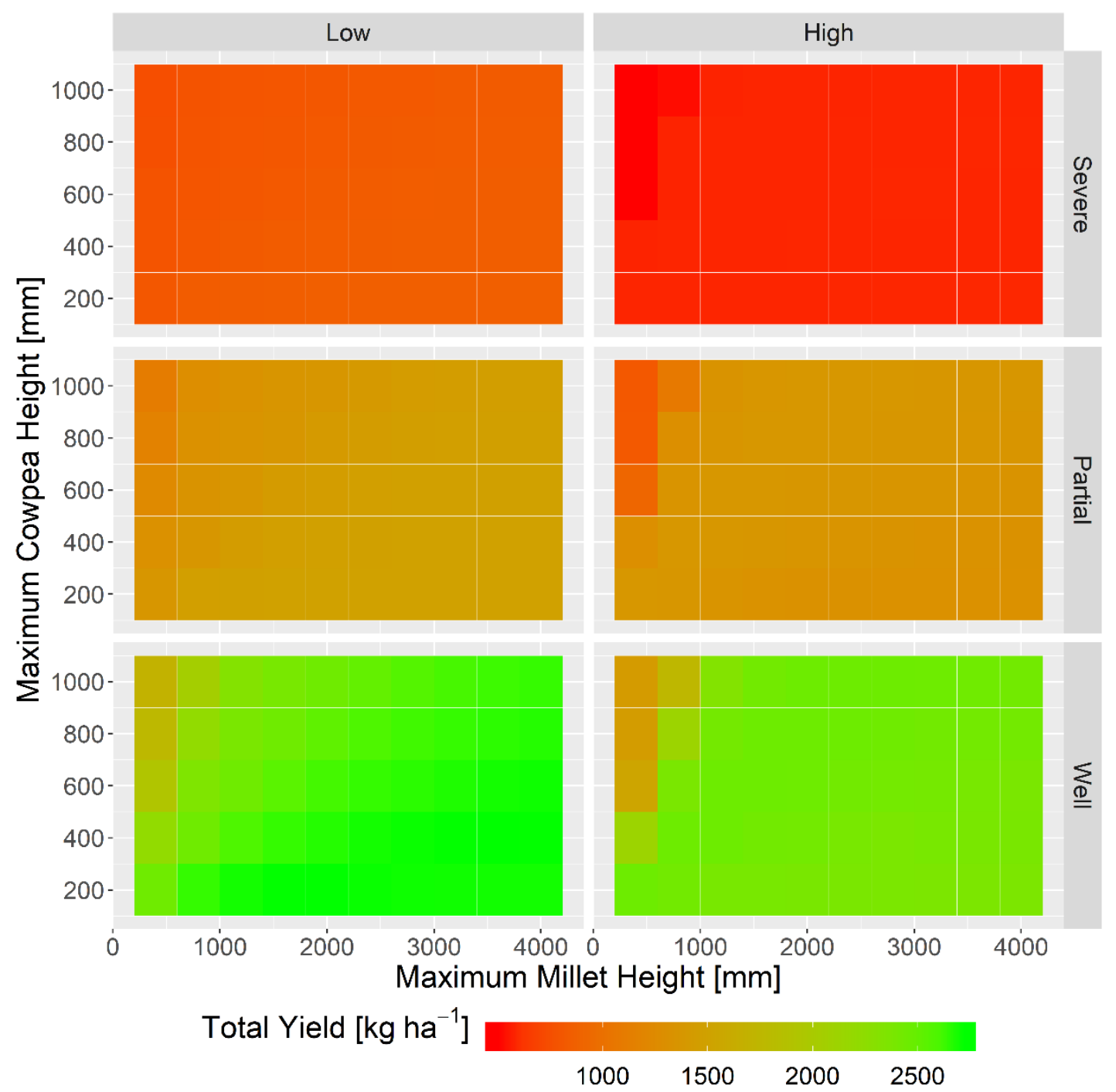

Figure 9. Heat map of total intercrop cowpea plus pearl millet grain yield $\left(\mathrm{kg} \mathrm{ha}^{-1}\right)$ response to maximum pearl millet and cowpea height $(\mathrm{mm})$ for all simulated treatments averaged over a 31-year period. These include low, 17, and high 33 plants per $m^{-2}$ planting densities; and weekly irrigation treatments: severe, until pearl millet flowering, partial, until cowpea flowering, and well-watered, until two weeks after cowpea flowering. Red represents low yield and green high yield.

Pearl millet yield, which increased with water supply and pearl millet plant height in excess of cowpea height, drove total intercrop yield (Figure 9 and 10). Most importantly, the total yield followed pearl millet yield, indicating that pearl millet was the driver of system productivity. Pearl millet yielded substantially higher with increasing water supply. Cowpea yield varied from 500 to $1200 \mathrm{~kg} \mathrm{ha}^{-1}$ and was less affected by treatments than pearl millet. Crucial for higher pearl millet and total yield - in addition to sufficient water supply - was the pearl millet being 100 to $200 \mathrm{~mm}$ taller than the cowpea. 


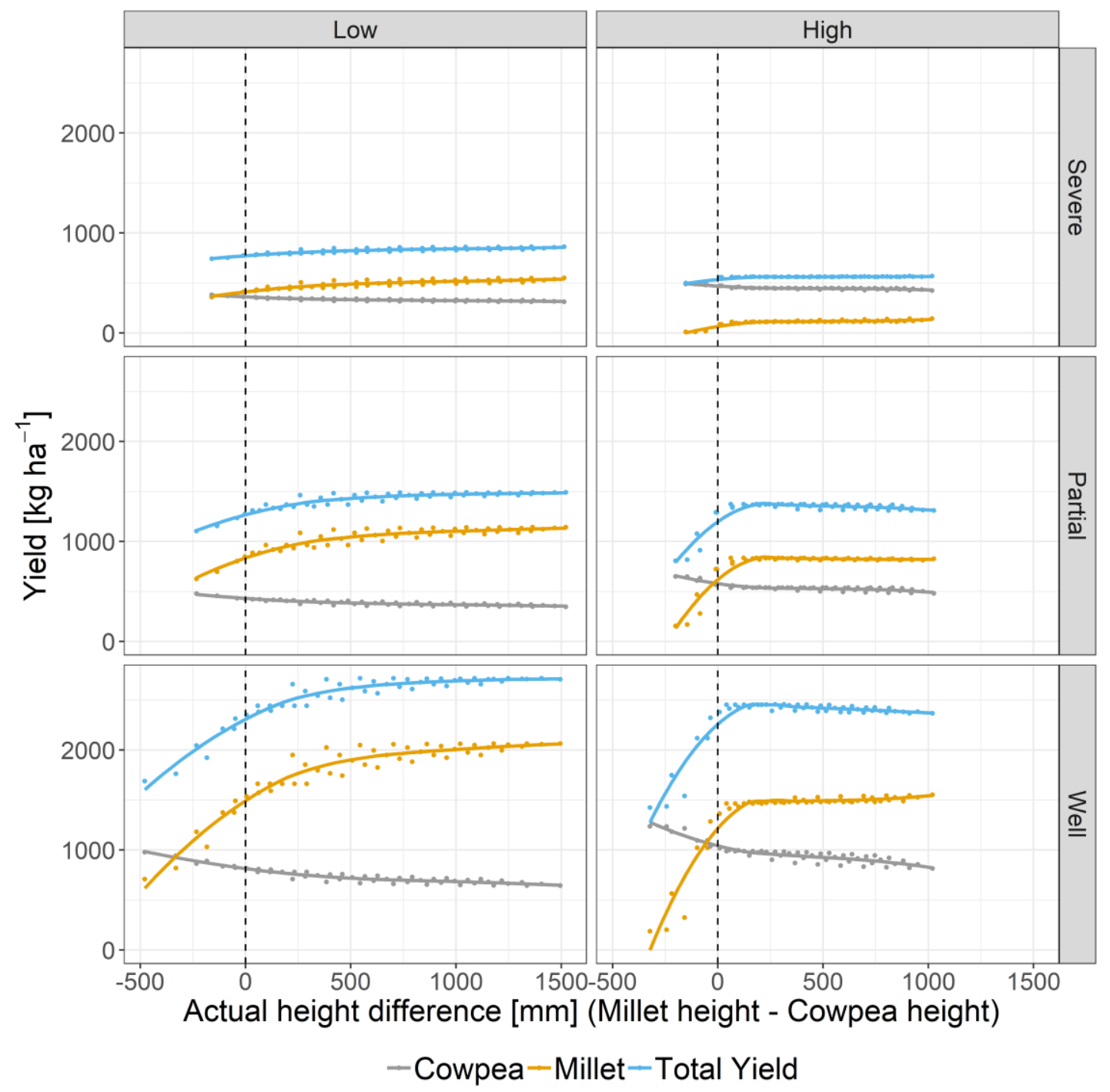

Figure 10. Individual yields ( $\mathrm{kg} \mathrm{ha}^{-1}$ ) of cowpea (grey), pearl millet (orange), and intercrop total yield (blue) for all simulated treatments. These include low, 17, and high 33 plants per $m^{-2}$ planting densities; and weekly irrigation treatments: severe, until pearl millet flowering, partial, until cowpea flowering, and well-watered, until two weeks after cowpea flowering. Each point represents a simulation scenario according to simulated height differences between pearl millet and cowpea. Note: actual height may differ from maximum plant height, as the plant does not achieve maximum height in each simulation, but is the result of stem growth, which is limited by resource supply in a given season. Lines represent the predicted relationship between actual height difference and yield computed by the geom_loess function (Wickham, 2016). The vertical dashed line that runs from 0 to the top of each plot highlights the points at which both intercrop components are the same height and there is ' 0 ' difference between the heights of the two crops.

\subsection{Discussion}

This study evaluated the crop model APSIM for pearl millet-cowpea intercropping, and explored the effect of simulated plant height on pearl millet and cowpea grain yields. Such investigations are part of an overall aim to improve the understanding of intercropping limitations and provide insights into the mechanisms of varied parameters and how they influence cultivar traits and ultimately intercropping performance. 


\subsubsection{Model performance}

Generally, yield dynamics were captured well by APSIM (IA of 0.87 for both crops), but were better captured for pearl millet than cowpea, with values of 0.83 and 0.64 , respectively (Table 3). The poor cowpea simulations inevitably reduced the accuracy of model predictions for intercrop treatments as a whole (Figure 3). Chimonyo et al. (2016) found the cereal component of their cereal-legume intercrop system (sorghum-cowpea) to be more accurately captured by APSIM. This emulates the findings of this study, albeit with a different cereal species, pearl millet. This potentially highlights two things: APSIM, and perhaps crop models in general have largely focussed on cereals in the past; and that legumes, cowpea in particular, can be unstable and highly sensitive to environment and management (Nelson et al., 2018). However, legumes - and multi-species systems - are promoted as important for our landscapes and food production systems (Franke et al., 2018; van Loon et al., 2018; Ngwira et al., 2012), increasing the need for detailed data that will help to accurately develop such models. Nonetheless, intercropping dynamics were generally well captured by APSIM, as both simulated and observed values showed how pearl millet yield and biomass production was compromised through competition from cowpea (Figure 4 and 5). Moreover, this lack of legume stability, and therefore predictability, emphasises the need to quantify scientific findings.

Key to this study is the way the model captured the dynamics of biomass observations, with high IA values at $0.91,0.91$, and 0.88 for both crops, pearl millet, and cowpea, respectively (Table 3). Both cowpea and pearl millet biomass production was lower when intercropped compared to sole crop equivalents (Figure 5). Chimonyo et al. (2016) reported inaccurate cowpea yields and biomass, whereby an over-estimation of yield was linked to an over-estimation of biomass. This study however slightly underestimated cowpea biomass, but more so in the high-water supply treatments (Figure 5). Under severe stress treatments (those that received the least water), at both high and low densities, both crops, but particularly cowpea, were well simulated for biomass development (Figure 5). There was little difference between the partial and well-watered treatments in terms of total water supply. It was therefore not surprising to see similarities between the inaccuracies of partial and well-watered biomass simulations (Figure 5). Clearly, APSIM was unable to capture the boost in above-ground vegetation production at later growth stages (Figure 5). Height was simulated especially well for pearl millet, with nRMSE and IA values of 0.31 and 0.94, respectively (Figure 7 and Table 3). The same can also be argued for cowpea, especially as a sole crop, although there were some deviations for intercropped cowpea height (Figure 7). Observations clearly demonstrated that the cowpea cultivar Russian Giant 
outcompeted the pearl millet more than the model simulated (Figure 5). The model underestimates yield performance of pearl millet high plant-density for sole crop conditions (Figure 4). One reason may be that the model has not been sufficiently tested for the higher densities, which might result in different growth patterns.

Trends found in simulated grain and biomass yields can be partly explained by canopy development. This data set confirmed key insights into cowpea biomass shortfalls (Figure 5), as they were mirrored by the LAI of sole crop cowpea 2016 (Figure 6), but not stem height (Figure 7). However, it should be noted that while cowpea LAI was undersimulated, values were still high and certainly represent a closed canopy, regardless of the poor fit to observations. A comparison with LAI values reported in Chimonyo et al. (2016) highlights inconsistencies, as their sorghum-cowpea intercrop system was over-estimated by $36 \%$ and $15 \%$ for sorghum and cowpea, respectively. However, this was explained by late planting for experiments in 2013/14 that resulted in inadequate photoperiods and growth-suppression (Chimonyo et al., 2016).

Due to the nature of the short growing season, the water treatments partial and wellwatered received similar water supplies (Nelson et al., 2018). Simulations found very little difference between observed values under the partial and well-watered treatments (Figure 5 and 6), which highlights the model's usefulness, albeit inaccurate in the final stages of highwater input systems. Final biomass and grain yield were well-simulated under the severe water deficit stress, agreeing with Chimonyo et al. (2016).

\subsubsection{Model improvement}

While model simulations in this study were reasonable, in particular by capturing intercropping effects, there is room for improvement for the individual modelling of cowpea and pearl millet. Chimonyo et al. (2016) discussed APSIMs leaf area development model as a sigmoidal function of thermal time (Brown et al., 2014) as inconsistent with their findings, which followed more of a power function form. Our study supports this argument for cowpea (Figure 6), which resulted in initial under-estimation, also observed for APSIM wheat (Garrido et al., 2013). While this might not be true for parameters such as height, inaccurate leaf area has knock-on effects in terms of potential radiation capture and therefore biomass and yield production. The simulation of cowpea canopy development is an important area for APSIM improvement (Akinseye et al., 2017) that should be supported due to the ease at which it can be measured in the field. 
Leaf area index measurements illustrate plot-wise canopy cover, but not that of the individual crops when intercropped (Figure 6). While this means no decisive conclusions could be made for the intercropping treatments, as the ratios of cowpea and pearl millet that made up the intercrop LAI could not be quantified, analysis of LAI values for cowpea and pearl millet as sole crops offers insight into the under-estimation of intercrop treatments. Sole crop cowpea simulations were not in-line with observations (Figure 6). In 2016, intercrop simulations versus observations tend to have mirrored whatever happened in the sole crop cowpea treatments (Figure 6), perhaps as cowpea plants typically have a higher LAI compared to pearl millet. This is particularly the case in our study, as the pearl millet cultivar used was bred to be short and should result in a more favourable harvest index (HI). Future experiments could measure the LAI of the pearl millet canopy above the lower cowpea canopy, and the LAI of the cowpea canopy, with measurements just above the soil surface. Although the lowest radiation interception measurements would be influenced by the lower canopy and that of the taller crop, this would offer insight into canopy structures and plant competition for light.

The model showed similar trends across all water treatments and simulations became less accurate as water supply increased (Figure 5 and 6). It is rare to run field trials in hot off-season conditions combined with high water supplies. This could help explain the suboptimal model performance, as such scenarios have rarely been tested, especially for cowpea. Inaccuracies in biomass and LAI in the higher water treatments occurred towards the end of the growing season, where APSIM simulated senescence, contrary to observations (Figure 5 and 6).

The APSIM cowpea model initiates leaf senescence due to age, light competition, water stress, and frost; a fraction of the oldest green leaf dies each day after flowering. Light competition causes leaf area loss with LAI values above 4.0 only - which was not reached for sole crop cowpea treatments - water was well supplied, and there was no frost. Senescence due to age was the only possible cause (Robertson et al., 2002). While this is visible from the model simulations, observations under partial and well-watered irrigation treatments showed no sign of senescence (Figure 6). Age-based senescence is calculated from daily thermal time, which was high in this experiment due to the heat and radiation exposure of the off-season. Its occurrence was in-line with very high temperatures in 2016 (Nelson et al., 2018). While extreme conditions have rarely been tested, it is clearly important for model development when they are to be used to investigate climate variation and temperature rise. In terms of pearl millet, the model underestimated yields for high 
plant-densities (Figure 4), highlighting the need for pearl-millet plant-density experimentation.

\subsubsection{Understanding the mechanisms underlying pearl millet-cowpea intercropping performance: a case study for plant height}

Intercropping dynamics are still not sufficiently understood; a limitation that hampers crop model development. The intercropping module in APSIM is one of the few attempts to use a single point model to simulate intercropping, with few notable exceptions (Brisson and Bussiere, 2004; Chimonyo et al., 2016; Tsubo et al., 2005). Some claim point models are not well suited to model intercropping scenarios, which could benefit from spatially aware 2D or 3D approaches (Gaudio et al., 2019). While the model validation showed that there is still a substantial amount of error in model simulations (Table 3 ), APSIM was able to capture the effect of intercropping in the low yielding environment of the study site with complex production limitations - this may be beyond the capabilities of more complex models. The simulation experiment is a first attempt to quantify the interaction effects of crop specific differences in height on intercropping canopy development and yield performance. This exercise found that when pearl millet was slightly taller than cowpea (100 to $200 \mathrm{~mm}$ ), substantially higher yields ensued - although this was not pronounced under water stress (Figure 10). Additional pearl millet height increases did not result in substantial yield gain. Clearly, the model demonstrated that in order to achieve high total yield, pearl millet must dominate canopy development and should not be shaded by cowpea. However, this simulation-derived hypothesis requires field-based evaluation.

So far, additional height increments were not met with a cost in the model, as it is simply a function of stem weight and maximum height. However, in the real world, taller plants require more assimilates, typically resulting in lower $\mathrm{HI}$ ratios and plants that are increasingly susceptible to lodging. Measuring the allocation of assimilates for different cultivars and evaluating the structural stability of the plant might help to improve its function and parameterisation in APSIM.

\subsubsection{Conclusion}

This study contributes towards quantifying the role of plant height differences in pearl millet-cowpea intercropping systems, providing insightful information for the development of ideotype intercrop systems for farmers. Intercrop yield was led by pearl millet yield, which was maximised under adequate soil water availability when 100 to 200 
$\mathrm{mm}$ taller than cowpea. Cowpea yield was minimally affected by a taller pearl millet intercrop - the cereal must be dominant to optimise total intercrop yield.

Field-based experimentation should further test the impact of light competition on intercrop system performance, potentially implemented genetically through experimentation with cereal-legume genotypes that vary the expression of traits like height, or through management, via plant-density for instance. Crop model performance highlighted the need to run field trials for crop model imporvement in extreme heat scenarios, with special attention paid to leaf dynamics.

\subsection{Acknowledgements}

This study was conducted within the IMPAC3 (grant number 031A351A) funded by the German Federal Ministry of Education.

RPR, MPH, and MK received support from the German Ministry of Education and Research via the 'SALLnet' project (grant number 01LL1802A) within the SPACES2 Program.

AMW acknowledges the CGIAR Research Program Climate Change, Agriculture and Food Security (CCAFS) for funding his time.

VV acknowledges the CGIAR Research Programs Grain Legumes and Dryland Cereals (GLDC) for funding his time.

We are grateful for the help of the field and laboratory staff from the Systems Analysis for Climate Smart Agriculture (SACSA) team at ICRISAT Hyderabad, India, for hosting the trial on which this study is based.

\subsection{References}

Akinseye, F.M., Adam, M., Agele, S.O., Hoffmann, M.P., Traore, P.C.S., Whitbread, A.M. (2017). Assessing crop model improvements through comparison of sorghum (sorghum bicolor L. moench) simulation models: A case study of West African varieties. Field Crop Res. 201, 19-31. doi: 10.1016/j.fcr.2016.10.015.

Akponikpè, P.B.I., Gérard, B., Michels, K., Bielders, C. (2010). Use of the APSIM model in long term simulation to support decision making regarding nitrogen management for pearl millet in the Sahel. Eur. J. Agron. 32, 144-154. doi: 10.1016/j.eja.2009.09.005.

Akponikpè, P.B.I., Minet, J., Gérard, B., Defourny, P., Bielders, C.L. (2011). Spatial fields' dispersion as a farmer strategy to reduce agro-climatic risk at the household level in pearl millet-based systems in the Sahel: A modeling perspective. Agric. For. Meteorol. 151, 215-227. doi: 10.1016/j.agrformet.2010.10.007. 
Bhattacharyya, T., Wani, S.P., Pal, D.K., Sahrawat, K.L., Pillai, S., Nimje, A., Telpande, B., Chandran, P., Chaudhury, S. (2016). Special scetion: Soil and water management ICRISAT, India soils: yesterday, today and tomorrow 110.

Brisson, N., Bussiere, F. (2004). Adaptation of the crop model STICS to intercropping. Theoretical basis and parameterisation. Agronomie 24, 409-421. doi: 10.1051/agro.

Brooker, R.W., Bennett, A.E., Cong, W., Daniell, T.J., George, T.S., Hallett, P.D., Hawes, C., Iannetta, P.P.M., Jones, H.G., Karley, A.J., Li, L., McKenzie, B.M., Pakeman, R.J., Paterson, E., Schöb, C., Shen, J., Squire, G., Watson, C.A., Zhang, C., Zhang, F., Zhang, J., White, P.J. (2015). Improving intercropping: a synthesis of research in agronomy, plant physiology and ecology. New Phytol. 206, 107-117. doi: 10.1111/nph.13132.

Carberry, P. S., Adiku, S. G. K., McCown, R. L., Keating, B. A. (1996). Application of the APSIM cropping systems model to intercropping systems. In: Ito O., Johansen, C., Adu-Gyamfi, J., Katayama, K., Kumar Rao, J. V. D., and Rego, T. J. (Eds), 1996. Dynamics of Roots and Nitrogen in Cropping Systems of the Semi-Arid Tropics. Japan International Research Center for Agricultural Sciences, 637-48.

Casadebaig, P., Zheng, B., Chapman, S., Huth, N., Faivre, R., Chenu, K. (2016). Assessment of the potential impacts of wheat plant traits across environments by combining crop modeling and global sensitivity analysis. PLoS One 11, 1-27. doi: 10.1371/journal.pone.0146385.

Chen, C., Lawes, R., Fletcher, A., Oliver, Y., Robertson, M., Bell, M., Wang, E. (2016). How well can APSIM simulate nitrogen uptake and nitrogen fixation of legume crops? Field Crop Res. 187, 35-48. doi: 10.1016/j.fcr.2015.12.007.

Chimonyo, V.G.P., Modi, A.T., Mabhaudhi, T. (2016). Simulating yield and water use of a sorghum-cowpea intercrop using APSIM. Agric. Water Manag. 177, 317-328. doi: 10.1016/j.agwat.2016.08.021.

Dalgliesh, N., Hochman, Z., Huth, N., Holzworth, D., 2016. Field Protocol to APSoil Characterisations. Version 4. CSIRO, Australia.

Fletcher, A.L., Kirkegaard, J.A., Peoples, M.B., Robertson, M.J., Whish, J., and Swan, A.D. (2016). Prospects to utilise intercrops and crop variety mixtures in mechanised, rainfed, temperate cropping systems. Crop \& Pasture Science, 2016, 67, 1252-1267. doi: 10.1071/CP16211.

Franke, A.C., van den Brand, G.J., Vanlauwe, B., Giller, K.E. (2018). Sustainable intensification through rotations with grain legumes in Sub-Saharan Africa: A review. Agr. Ecosyst. Environ. 261 (2018) 172-185. doi: 10.1016/j.agee.2017.09.029.

Garrido, M., Román, L., Silva, P., Castellaro, G., García de Cortázar, V., Acevedo, E. (2013). Characterization of genetic coefficients of durum wheat (Triticum turgidum L. ssp. durum) 'Llareta-INIA' and 'Corcolén-INIA'. Chilean Journal of Agricultural Research, 73(2). doi: 10.4067/S0718-58392013000200002.

Gaudio, N., Escobar-Gutiérrez, A.J., Casadebaig, P., Evers, J.B., Gérard, F., Louarn, G., Colbach, N., Munz, S., Launay, M., Marrou, H., Barillot, R., Hinsinger, P., Bergez, J.-E., Combes, D., Durand, J.-L., Frak, E., Pagès, L., Pradal, C., Saint-Jean, S., Van Der Werf, W. (2019). Current knowledge and future research opportunities for 
modeling annual crop mixtures. A review. Agron Sustain Dev. 39: 20. doi: 10.1007/s13593-019-0562-6.

Gaydon, D.S., Balwinder-Singh, Wang, E., Poulton, P.L., Ahmad, B., Ahmed, F., Akhter, S., Ali, I., Amarasingha, R., Chaki, A.K., Chen, C., Choudhury, B.U., Darai, R., Das, A., Hochman, Z., Horan, H., Hosang, E.Y., Kumar, P.V., Khan, A.S.M.M.R., Laing, A.M., Liu, L., Malaviachichi, M.A.P.W.K., Mohapatra, K.P., Muttaleb, M.A., Power, B., Radanielson, A.M., Rai, G.S., Rashid, M.H., Rathanayake, W.M.U.K., Sarker, M.M.R., Sena, D.R., Shamim, M., Subash, N., Suriadi, A., Suriyagoda, L.D.B., Wang, G., Wang, J., Yadav, R.K., Roth, C.H. (2017). Evaluation of the APSIM model in cropping systems of Asia. Field Crop Res. 204, 52-75. doi: 10.1016/j.fcr.2016.12.015.

He, D., Wang, E., Wang, J., Lilley, J.M. (2017). Genotype $\times$ environment $\times$ management interactions of canola across China: A simulation study. Agric. For. Meteorol. 247, 424-433. doi: 10.1016/j.agrformet.2017.08.027.

Hoffmann, M.P., Llewellyn, R.S., Davoren, C.W., Whitbread, A.M. (2017). Assessing the potential for zone-specific management of cereals in low-rainfall South-Eastern Australia: Combining on-farm results and simulation analysis. J. Agron. Crop Sci. 203, 14-28. doi: 10.1111/jac.12159.

Hoffmann, M.P., Isselstein, J., Rötter, R.P., Kayser, M. (2018a). Nitrogen management in crop rotations after the break-up of grassland: Insights from modelling. Agric. Ecosyst. Environ. 259, 28-44. doi: 10.1016/j.agee.2018.02.009.

Hoffmann, M.P., Odhiambo, J.O., Koch, M., Ayisi, K., Zhao, G., Soler, A.S., Rötter, R.P. (2018b). Exploring adaptations of groundnut cropping to prevailing climate variability and extremes in Limpopo Province, South Africa. Field Crop Res. 219, 1-13. doi: 10.1016/j.fcr.2018.01.019.

Holzworth, D.P., Huth, N.I., Peter, G., Zurcher, E.J., Herrmann, N.I., McLean, G., Chenu, K., van Oosterom, E.J., Snow, V., Murphy, C., Moore, A.D., Brown, H., Whish, J.P.M., Verrall, S., Fainges, J., Bell, L.W., Peake, A.S., Poulton, P.L., Hochman, Z., Thorburn, P.J., Gaydon, D.S., Dalgliesh, N.P., Rodriguez, D., Cox, H., Chapman, S., Doherty, A., Teixeira, E., Sharp, J., Cichota, R., Vogeler, I., Li, F.Y., Wang, E., Hammer, G.L., Robertson, M.J., Dimes, J.P., Whitbread, A.M., Hunt, J., van Rees, H., McClelland, T., Carberry, P.S., Hargreaves, J.N.G., MacLeod, N., McDonald, C., Harsdorf, J., Wedgwood, S., Keating, B.A. (2014). APSIM - Evolution towards a new generation of agricultural systems simulation. Environ. Model. Softw. 62, 327-350. doi: 10.1016/j.envsoft.2014.07.009.

Li, L., Sun, J.H., Zhang, F., Guo, T., Bao, X., Smith, F.A., Smith, S.E. (2006). Root distribution and interactions between intercropped species. Oecol. 147, 280-290. doi: 10.1007/s00442-005-0256-4.

van Loon, M.P., Deng, N., Grassini, P., Rattalino Edreira, J.I., Wolde-meskel, E., Baijukya, F., Marrou, H., van Ittersum, M.K., 2018. Prospect for increasing grain legume crop production in East Africa. Eur. J. Agron. 101 (2018) 140-148. doi: 10.1016/j.eja.2018.09.004.

Nelson, W.C.D., Hoffmann, M.P., Vadez, V., Roetter, R.P., Whitbread, A.M. (2018). Testing pearl millet and cowpea intercropping systems under high temperatures. Field Crop Res. 217, 150-166. doi: 10.1016/j.fcr.2017.12.014. 
Ngwira, A.R., Aune, J.B., Mkwinda, S. (2012). On-farm evaluation of yield and economic benefit of short term maize legume intercropping systems under conservation agriculture in Malawi. Field Crop Res. 132 (2012) 149-157. doi: 10.1016/j.fcr.2011.12.014.

O'Leary, G.J., Joshi, N.L., Van Oosterom, E.J. (2008). A simulation study of the response of plant-type and nitrogen fertilization on the grain yield of pearl millet. Ann. Arid Zone 47, 121-137.

Rapholo, E., Odhiambo, J.J.O., Nelson, W.C.D., Rötter, R.P., Ayisi, K., Koch, M., Hoffmann, M.P. (2019). Maize-lablab intercropping is promising in supporting the sustainable intensification of smallholder cropping systems under high climate risk in southern Africa. Exp. Agric. 1-14. doi: 10.1017/S0014479719000206.

Robertson, M.J., Carberry, P.S., Huth, N.I., Turpin, J.E., Probert, M.E., Poulton, P.L., Bell, M., Wright, G.C., Yeates, S.J., Brinsmead, R.B. (2002). Simulation of growth and development of diverse legume species in APSIM. Aust. J. Agric. Res. 53, 429-446. doi: 10.1071/AR01106.

Rötter, R.P., Tao, F., Höhn, J.G., Palosuo, T. (2015). Use of crop simulation modelling to aid ideotype design of future cereal cultivars. J. Exp. Bot. 66, 3463-3476. doi: 10.1093/jxb/erv098.

Rötter, R.P., Appiah, M., Fichtler, E., Kersebaum, K.C., Trnka, M., Hoffmann, M.P. (2018). Linking modelling and experimentation to better capture crop impacts of agroclimatic extremes - A review. Field Crops Research, 221, 142-156. doi: 10.1016/j.fcr.2018.02.023.

Sennhenn, A., Njarui, D.M.G., Maass, B.L., Whitbread, A.M. (2017). Exploring Niches for Short-Season Grain Legumes in Semi-Arid Eastern Kenya - Coping with the Impacts of Climate Variability. Front. Plant Sci. 8, 1-17. doi: 10.3389/fpls.2017.00699.

Tsubo, M., Walker, S., Ogindo, H.O. (2005). A simulation model of cereal-legume intercropping systems for semi-arid regions I. Model development. Field Crop Res. 93 (2005) 10-22. doi:10.1016/j.fcr.2004.09.002.

van Oosterom, E.J., Carberry, P.S., O’Leary, G.J. (2001a). Simulating growth, development, and yield of tillering pearl millet. 1. Modelling leaf area profiles on main shoots and tillers. Field Crop. Res. 72, 67-91. doi: 10.1016/S03784290(01)00165-4.

van Oosterom, E.J., Carberry, P.S., Hargreaves, J.N.G., O’Leary, G.J. (2001b). Simulating growth, development, and yield of tillering pearl millet. 2. Simulation of canopy development. Field Crop. Res. 72, 67-91. doi: 10.1016/S0378-4290(01)00165-4.

Varshney, R.K., Thundi, M., Pandey, M.K., Tardieu, F., Ojiewo, C., Vadez, V., Whitbread, A.M., Siddique, K.H.M., Nguyen, H.T., carberry, P.S., and Bergvinson, D. (2018). Accelerating genetic gains in legumes for the development of prosperous smallholder agriculture: integrating genomics, phenotyping, systems modelling and agronomy. Journal of Experimental Botany, 69: 3293-3312. doi: 10.1093/jxb/ery088.

Virmani, S.M., Siva Kumar, M.V.K., and Reddy, S.J. (1982). Rainfall probability estimates for selected locations of semi-arid India. Research Bullitin No. 1, $2^{\text {nd }}$ Edition. 
International Crops Research Institute for the Semi-Arid Tropics ICRISAT Patancheru P.O., Andhra Pradesh 502 324, India.

Wallach, D., Makowski, D., Jones, J.W., Brun, F. (2018). Working with Dynamic Crop Models. Methods, Tools and Examples for Agriculture and Environment. $3^{\text {rd }}$ Edition, Academic Press. ISBN: 9780128117569.

Wang, E., Robertson, M.J., Hammer, G.L., Carberry, P.S., Holzworth, D.P., Meinke, H., Chapman, S.C., Hargreaves, J.N.G., Huth, N.I., McLean, G. (2002). Development of a generic crop model template in the cropping system model APSIM. Eur. J. Agron. 18, 121-140. doi: 10.1016/S1161-0301(02)00100-4.

Whitbread, A.M., Robertson, M.J., Carberry, P.S., Dimes, J.P. (2010). How farming systems simulation can aid the development of more sustainable smallholder farming systems in southern Africa. Eur. J. Agron. 32, 51-58. doi: 10.1016/j.eja.2009.05.004.

Whitbread, A.M., Hoffmann, M.P., Davoren, C.W., Mowat, D., Baldock, J.A. (2017). Measuring and Modeling the Water Balance in Low-Rainfall Cropping Systems. Trans. ASABE 60, 2097-2110. doi: 10.13031/trans.12581.

Wickham, H. (2016). ggplot2, Elegant Graphics for Data Analysis. Springer International Publishing. doi: 10.1007/978-3-319-24277-4. 


\section{Chapter Four}

\section{What determines a productive winter bean-wheat genotype combination for intercropping in central Germany? ${ }^{3}$}

\subsection{Introduction}

Cereal-legume intercropping is seen as one approach that could help achieve a more sustainable agricultural landscape (Fletcher et al., 2016). This is in part due to the potential for higher yields when compared to sole crop equivalents (intercrop performance compared with that of the two sole cropped species on the same area of land) especially when external inputs, such as nitrogen $(\mathrm{N})$ fertilisers are excluded (Bedoussac and Justes, 2010; Malézieux et al., 2009). Intercropping yield advantages are referred to as the 'mixing effect' (HofKautz and Rauber, 2003) or 'overyielding' (Li et al., 2011; Li et al., 2014; Streit et al., 2019) and are typically related to the complementary use of resource niches and tend to be higher under stress (Fargione and Tilmann, 2005; Hector et al., 2002). For example, root length density enhancement (Schröder and Köpke, 2012) might contribute to overyielding, or a complex canopy structure might do so via the establishment of more favourable microclimates that potentially reduce soil moisture evaporation (Tsubo et al., 2004). Cereallegume intercrops are therefore at their most efficient, i.e. have the highest potential for overyielding, in low input environments. A well-known example of such a system is the ancient maize-bean-squash polyculture of Mesoamerica that takes advantage of complimentary canopy development through the establishment of various leaf layers for light interception (Postma and Lynch, 2012). This would suggest that complimentary winter bean-wheat intercropping combinations could be conceptualised by canopy development whereby the faba bean covers the soil, and the wheat grows as a tall erect plant.

Production advantages, be they yield or resource use efficiency based, can also be explained through the notion that two different crop species may not simultaneously compete for the same resources (Hauggaard-Nielsen and Jensen, 2001). Several studies have highlighted the fact that in general, cereals tend to be more reliant on soil inorganic $\mathrm{N}$ (Jensen, 1996) compared to legumes - cereals do not have the alternative N-source that legumes have through symbiosis (Hauggaard-Nielsen et al., 2003). This forces the intercropped legume to rely more than its pure stand on symbiotic N2 fixation to form ammonia (NH3) (Hauggaard-Nielsen and Jensen, 2001).

\footnotetext{
${ }^{3}$ This chapter is under review as W.C.D. Nelson \& D.J. Siebrecht-schöll, M.P. Hoffmann, R.P. Rötter, A.M. Whitbread, W. Link (under review). What determines a productive winter bean-wheat genotype combination for intercropping in central Germany?
} 
For many decades most arable crops have been bred with sole cropping in mind, hence the breeding results may not necessarily be optimal for intercropping (HauggaardNielsen and Jensen, 2001). While research has indeed looked at 'niche complementarity' for spring crops, little information is available for crops sown in autumn, i.e. winter crops (Bedoussac and Justes, 2010). The development of a truly efficient winter intercrop is therefore unique. In a recent review on intercropping, Brooker et al. (2015) argued that plant breeding, and experimentation with crop combinations is likely to have the highest potential to increase the resource-use efficiency of intercrops.

The typical sowing period for legumes like pea or faba bean for northern Europe is spring, especially in Germany and further east where harsher winters prevail (Jensen, Peoples, and Hauggaard-Nielsen, 2010); the main danger for autumn-sown pulses being winter kill (Link, Balko, and Stoddard, 2010). However, research has shown recent success towards more winter-hardy faba bean germplasm (Ali et al., 2016; Arbaoui and Link, 2007; Flores et al., 2012; Landry et al., 2015; Landry et al., 2016). There are many advantages of winter legumes over the spring types, which are mainly sown in spring to avoid frost damage (Flores et al., 2012). Their head start in terms of below-ground biomass development means that substantial growth can be achieved even before spring types have become wellestablished. Autumn-sowing also intends on making better use of the moisture available during the winter months, potentially avoiding drought later in the season - a particular threat for grain yield stability (Flores et al., 2012; Khan et al., 2010).

Intercropping will be judged as successful not only if total grain yield of the intercrop stand is higher than the sole equivalent, but also bearing in mind the complementarity of the two intercropped species. Intercrop complementarity can be determined by improved $\mathrm{N}$ and water use efficiency, as well as above- and below-ground biomass distribution, and is therefore often linked to low input cereal-legume cultivation (Pristeri et al., 2006). The integration of grain legumes, such as faba bean, into such rotations has thus been proven successful when intercropped with wheat (Hof-Kautz et al., 2007; Pristeri et al., 2006). Our study builds on this research and aimed to evaluate the interactions between three winter wheat varieties and eight winter faba bean genotypes (experimental inbred lines) sown as sole and intercrop stands. This is in-line with recent calls for plant breeding programmes to develop crops for specific systems ('system' used as generic term for sole cropping and intercropping) (Varshney et al., 2018). While the overyielding of intercrop stands is wellknown, our study aimed to contribute towards explaining why, i.e. what leads to high overyielding and, more generally, what makes high total grain yield performance of intercrop stands (bean+wheat). This study looked at key agronomic traits, such as leaf area 
index (LAI), and plant height over three seasons of field trials on two separate sites in central Germany with contrastingly different soils.

With the above in mind, the following hypotheses were formulated:

(1) Intercrop stands lead to higher yield compared to sole stand equivalents (higher than the average of the corresponding sole crops).

(2) Intercrops perform better under marginal soil conditions than on soils that offer deeper rooting, and more water and higher $\mathrm{N}$ supply.

(3) There is a genotype effect on the yield performance of the intercrop stands related to canopy development and functional traits.

\subsection{Materials and methods}

\subsubsection{Site conditions}

The field experiment was conducted at two experimental stations of the GeorgAugust-Universität, Göttingen in Niedersachsen, Germany. Reinshof, at $51^{\circ} 29^{\prime} \mathrm{N}, 9^{\circ} 55^{\prime} \mathrm{E}$, at $157 \mathrm{~m}$ above sea level (ASL), and Deppoldshausen at $51^{\circ} 34^{\prime} \mathrm{N}, 9^{\circ} 58^{\prime} \mathrm{E}$ at $342 \mathrm{~m}$ ASL. The general climate can be characterised as maritime to continental, with higher rainfall in the summer months. Annual rainfall averages $630 \mathrm{~mm}$ for the Göttingen area (Deutsche Wetterdienst (DWD, German Weather Service) records 1961-2016). Average annual rainfall during the experimental period (2014-17) was $637 \mathrm{~mm}$ and $592 \mathrm{~mm}$ for Reinshof and Deppoldshausen, respectively (Heshmati et al., 2020).

Field trials were conducted over the course of three seasons, 2014-15, 2015-16 and 2016-17 on the above-mentioned sites. Reinshof is located in a valley and characterised as a Gleyic Fluvisol (WRB). Top soil contained $21 \%$ clay, $11 \%$ sand, and $68 \%$ silt in the Ah horizon. Deppoldshausen is located on a hill where the soil is shallow at 30 to $40 \mathrm{~cm}$ in depth and high in rock content. The marginal soil of this site has an Ah horizon of $25 \mathrm{~cm}$ depth and is characterized as a Calcaric Leptosol. The clay content is higher with $34 \%$ clay, $2 \%$ sand, and $55 \%$ silt (Heshmati et al., 2020). Figure 1 showcases examples of the two soil profiles, Deppoldshausen (i), and Reinshof (ii). 


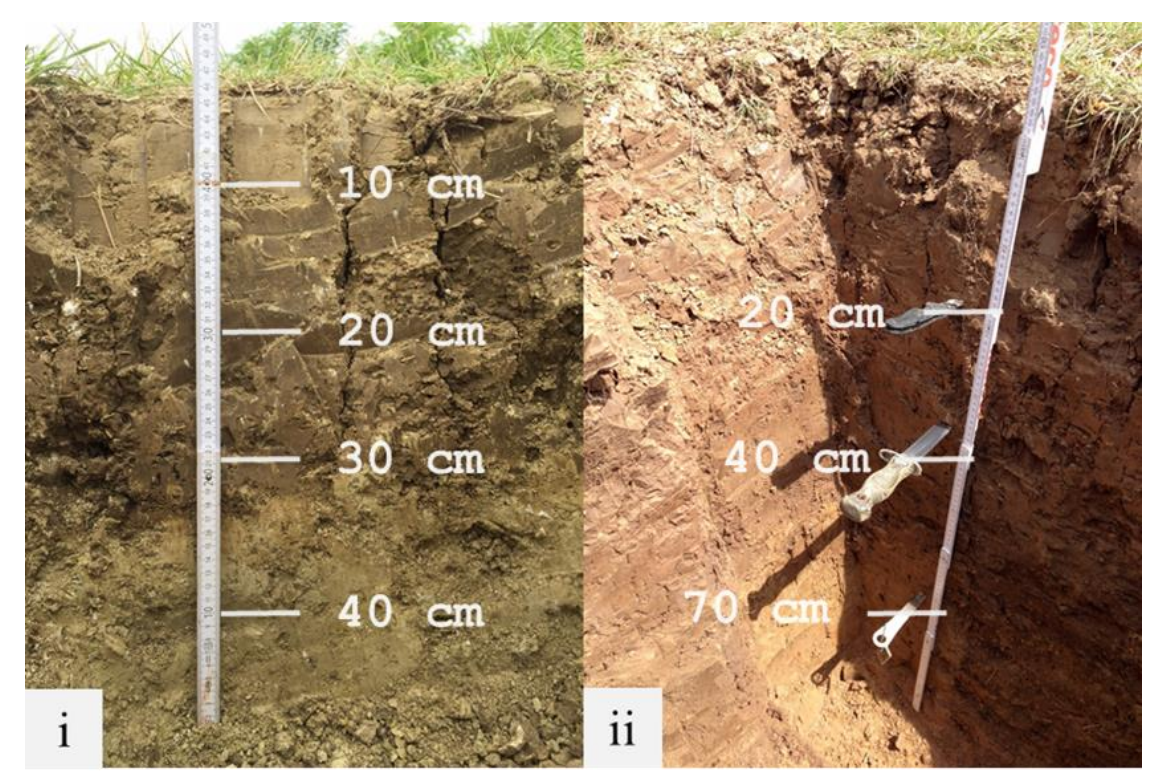

Figure 1. Soil profiles of Deppoldshausen (i) and Reinshof (ii). The ruler within the soil profile pits highlights the shallow (Deppoldshausen, 0-40 cm) and deep (Reinshof, 0-100 cm) characteristics of each soil.

\subsubsection{Genetic material and experimental design}

Eight non-released winter faba bean (Vicia faba L.) genotypes and three released winter wheat (Triticum aestivum L.) varieties were used for this experiment. Winter faba bean genotypes (experimental inbred lines) were chosen from the NPZ (Norddeutsche Pflanzenzucht Hans-Georg Lembke KG, Hohenlieth, Germany) breeding programme and that of the department for Crop Sciences, University of Göttingen (Roth and Link, 2009). They were chosen because of their potential differences in plant height, grain yield, as well as their physiological stage development, such as start of flowering, and time to maturity (Table 1). The three winter wheat varieties were released from European breeding companies that were part of the German Seed Alliance. Genius (Ta1) and Boxer (Ta2) were line varieties, and Hybery (Ta3) a high yielding hybrid variety. These wheat varieties were chosen because of their resistance against major pathogens, such as fusarium and mildew, as well as known further agronomic differences, such as plant height and seed protein content (Bundessortenamt, 2015). 
Table 1. Winter faba bean genotypes included in the experiment with some known characteristics phenotyped prior to the field experiment.

\begin{tabular}{|c|c|c|}
\hline Code & Genotype & Characteristics \\
\hline Vf1 & S_004-1-6 & Medium tall, low tillering, late flowering, medium maturing, high yielding \\
\hline Vf2 & S_062-2-2 & Very short, high tillering, medium early flowering, medium maturing \\
\hline Vf3 & S_069-1-1 & $\begin{array}{l}\text { Very tall, medium tillering, medium late flowering, medium maturing, high } \\
\text { yielding }\end{array}$ \\
\hline Vf4 & S_265-1-1 & Very tall, very high tillering, medium early flowering, medium maturing \\
\hline Vf5 & Hiverna/2-5-1 & $\begin{array}{l}\text { Medium tall, low tillering, medium early flowering, low yielding, pure line } \\
\text { developed from Hiverna (German cv.), superior winter hardiness }\end{array}$ \\
\hline Vf6 & $\begin{array}{l}\text { Côte d'Or/ 1-1- } \\
3\end{array}$ & $\begin{array}{l}\text { Very tall, high tillering, late flowering, late maturing, source of superior winter } \\
\text { hardiness }\end{array}$ \\
\hline Vf7 & $\begin{array}{l}\text { WAB- } \\
\text { Fam157-1-2 }\end{array}$ & Medium tall, low tillering, early flowering, earl maturing, high yielding \\
\hline Vf8 & $\begin{array}{l}\text { WAB-EP98- } \\
267-11\end{array}$ & $\begin{array}{l}\text { Medium tall, medium tillering, late flowering, late maturing, high yielding, } \\
\text { sibling of former cv. Nordica }\end{array}$ \\
\hline
\end{tabular}

For detailed trait assessment, different sets of entries were used due the large size of the experiment and consequential budget constraints. The full set of entries (FSE) included all winter faba bean genotypes and winter wheat varieties grown as sole crops and all 24 intercrop stand combinations between the eight winter faba bean genotypes and three winter wheat varieties. Grain yield is reported from the FSE. The reduced set of entries (RSE) included all winter faba bean genotype sole crop stands and all sole crop stands of one of the winter wheat varieties (Genius, Ta1), as well as all eight intercrop stand combinations. Winter wheat variety Ta1 was chosen to be part of the RSE because of its medium height, high N-uptake capacity, low susceptibility to mildew and rather stable yields (Bundessortenamt, 2015). Winter wheat varieties Ta2 and Ta3 were not included in the RSE. Results for LAI, plant height, and lodging, as well as soil measurements are shown from the RSE stands alone.

The field trials conducted were part of the IMPAC 3 project (https://www.unigoettingen.de/de/528191.html) and set up as a split-plot design with four blocks (replicates), which were further divided into four areas to enable annual rotation. Winter rye was grown on $75 \%$ of the block areas set aside for each season - while rye grain yield was taken from the field, rye straw was tilled into the soil. The main plot factor was defined by the eight 
winter faba bean genotypes and the split-plot factor was defined by the cropping system (sole crop, and intercrop). The eight winter faba bean genotypes and three winter wheat varieties were grown in sole stands and in alternating row intercrop stands. This resulted in 160 stands per site, and therefore 320 plots per season (Siebrecht-Schöll, 2019). Each stand covered a total area of $27 \mathrm{~m} 2$ to allow for various samples and measurements.

In intercrop stands, each of the species was sown at $50 \%$ of its sole stand seed density (replacement or substitutive intercrop design). Faba bean sole stands were sown with 40 seeds per $\mathrm{m} 2$ and wheat sole stands with 320 seeds per m2. Intercrop stands were sown with 20 faba bean seeds per $\mathrm{m} 2$ and with 160 wheat seeds per $\mathrm{m} 2$. The between row distance was $22.5 \mathrm{~cm}$ for all stands - seeds were untreated. Stands were sown with 12 rows.

Bean-wheat intercrop components (intercropped faba bean and wheat seed) were sown simultaneously, along with the equivalent sole crop stands, between the 30th of September and the 29th of October, depending on the season (Table 4 appendix). The last $\mathrm{N}$ fertiliser application took place in 2013 on both sites. The rotation crop prior to this experiment was conventional winter wheat in Reinshof, and oilseed rape in Deppoldshausen. Although crops in this experiment were not fertilised with $\mathrm{N}$, fungicides and insecticides were used when there was a serious threat of crop stand failure. In this instance, all crops were treated. Herbicides were used pre-emergence and manual weeding conducted within the vegetation period.

\subsubsection{Plant and soil sampling}

A combine harvester was employed from the 9th and the 20th of August (Table 4 appendix) to harvest a central stand size of $10.5 \mathrm{~m}^{2}$ consisting of six rows with three buffer rows left at either side of each stand. In addition to this grain yield, crop phenology was monitored using the BBCH scale. Plant height of each species and stand-wise LAI using an AccuPAR LP-80 ceptometer was measured for the RSE (all eight bean genotypes, and the Ta1 wheat variety). Leaf area index was measured four times during the key vegetative production phases in each season, between April to the end of July. Plant height was measured four times within the vegetation period (before flowering, start of flowering, fullflowering, and after flowering of the winter faba beans). The mean of ten representative plants per stand was used for the analysis. Lodging was scored as and when it occurred on a scale of zero to nine, representing no lodging, and severe lodging, respectively. Scores were made per specie per stand - in intercrop stands, bean and wheat were scored separately. Lodging score dates were as follows: 10th of July 2015 (both sites), and the 30th of July for 
Reinshof only (as second scoring date); 27th May 2016 and the 28th of May 2016, Deppoldshausen and Reinshof, respectively; and the 4th of July 2017 (both sites).

Soil sampling for soil water and mineral $\mathrm{N}$ content $\left(\mathrm{N}_{\min }\right)$ was conducted manually at full-flowering and one day after harvest (Table 4 appendix) using a soil auger. Soil samples were only taken in the first and second seasons of experimentation (2014-15 and 2015-16). Due to the nature of the soil profiles at the two sites, soil sample depth differed, going to a depth of 0-90 cm in Reinshof, divided into three $30 \mathrm{~cm}$ layers, and 0-30 $\mathrm{cm}$ in Deppoldshausen (Figure 1). Three soil core samples were taken for each stand sampled and layers mixed in a bucket from which two sub-samples (one for soil water, one for $\mathrm{N}_{\min }$ ) were taken for analysis. Soil water sub-samples were weighed directly in the field, dried in ovens at $105^{\circ} \mathrm{C}$ for $48 \mathrm{~h}$ and weighed, and $\mathrm{N}_{\min }$ sub-samples directly stored in cool boxes before being transported to a soil laboratory for photometric $\mathrm{N}_{\min }$ analysis (Flow Solution III, Alpkem, Wilsonville, Oregon), the $\mathrm{CaCl}_{2}$ method (VDLUFA, 1991). Extractable soil water availability (Figure 9) was calculated using the soil water measurements described above together with the soil-specific lower limit and bulk density values derived from the Niedersächsischen Bodeninformationssystems (Lower Saxony Soil Information Systems, NIBIS: https://www.lbeg.niedersachsen.de/kartenserver).

\subsubsection{Data analysis}

Results were first checked to ensure the normal distribution of the residuals before identifying significant differences between groups. The effects of system (intercrop or sole), site (Reinshof or Deppoldshausen), and genotype on yield and physiological traits were analysed using linear models (R, version 3.4.3; plotted using ggplot2). Data was analysed separately based on fixed effects: system, genotype, and site (dependent on the level of analysis and question). P-values are presented in detail where the following significance

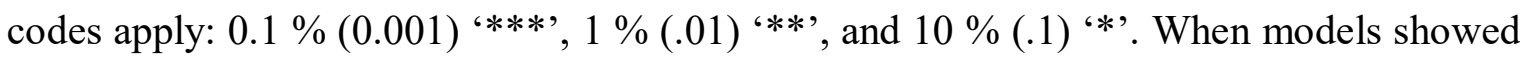
significance, a post-hoc test (Tukey, adjusted for multiple comparisons using the Holm method) was applied to identify differences between groups. For the traits LAI and plant height, maximum values were used for analysis. For example, LAI measurements were taken four times within the vegetative period for each season. The maximum mean values were taken - maximum values among the four time-assessments, per entry and per seasonsite combination, and after calculating means across the four replicates. These maxima were averaged across the three-season experiment - the same applies to plant height and lodging. 


\subsection{Results}

\subsubsection{Yield}

Total yield was significantly higher for intercrop stands compared to sole equivalents in both sites. The highest yields for both intercrop and sole stands were in Reinshof (Figure 2). The difference between intercrop and sole stands, however, was 513 $\mathrm{kg} \mathrm{ha}^{-1}$ greater $(983>470)$ in Deppoldshausen than in Reinshhof; Deppoldshausen is the more marginal site in terms of soil conditions (Table 2; Figure 9).

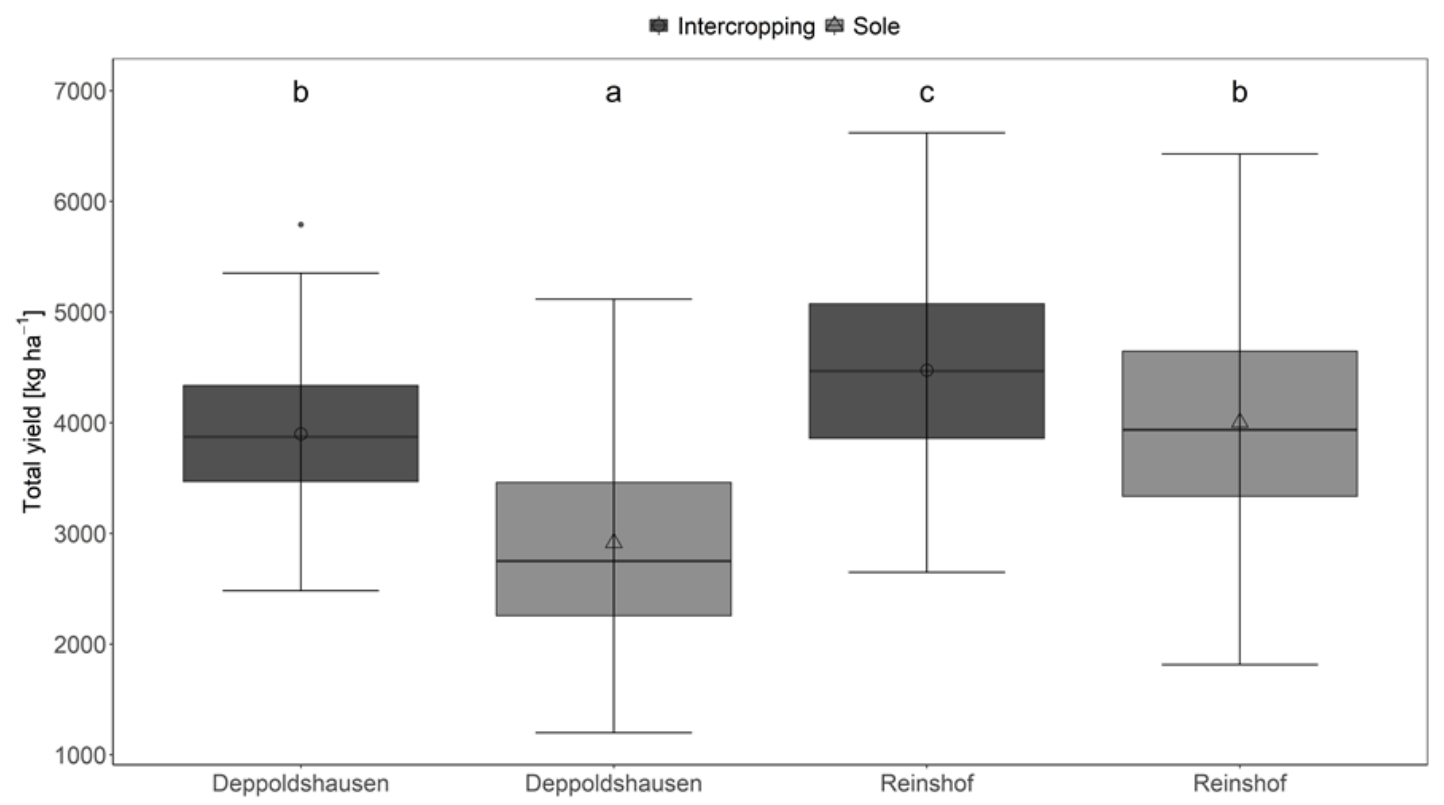

Figure 2. Total intercrop yield (bean+wheat) of all 24 FSE combinations, compared to their equivalent sole stand means for both sites across all three seasons. The three horizontal lines indicate the $75 \%$ percentile (up), median (solid line across boxes) and $25 \%$ percentile yield (bottom); the upper and lower bars outside the boxes show the maximum and minimum values respectively. Significant differences (across all environments) are shown through the lower case letters. The isolated point is an outlier.

Table 2. Within site system differences for yield, means across seasons. The system difference was significant at both sites.

\begin{tabular}{llll}
\hline Site & System & Mean yield $\left(\mathrm{kg} \mathrm{ha}^{-1}\right)$ & System difference $\left(\mathrm{kg} \mathrm{ha}^{-1}\right)$ \\
\hline Deppoldshausen & Intercropping & 3899 & $983 * * *$ \\
Deppoldshausen & Sole & 2916 & \\
\hline Reinshof & Intercropping & 4474 & $470 * * *$ \\
Reinshof & Sole & 4004 & \\
\hline
\end{tabular}

There is an overall trend that the highest total intercrop grain yield (bean+wheat) was associated with high intercrop wheat yield (Figure 4). This is seen at both sites, although to a greater extent and with a high range at Reinshof. The correlation coefficients between total intercrop yield and intercrop wheat yield were $\mathrm{r}=+0.69\left(\mathrm{R} 2=0.47^{* * *}\right)$ at Deppoldshausen and $\mathrm{r}=+0.83(\mathrm{R} 2=0.68 * * *)$ at Reinshof. The highest yielding intercrop 
stand was Vf2-Ta3 in Reinshof $\left(5,324 \mathrm{~kg} \mathrm{ha}^{-1}\right)$, which was only the seventh highest yielding combination in Deppoldhausen (4,057 $\left.\mathrm{kg} \mathrm{ha}^{-1}\right)$. Intercrop combinations Vf7-Ta3 (5,094 kg $\left.\mathrm{ha}^{-1}\right)$ and Vf3-Ta3 (5,021 kg ha $\left.\mathrm{kg}^{-1}\right)$ were second and third in Reinshof, respectively, which also ranked highly in Deppoldshausen in first $\left(4,217 \mathrm{~kg} \mathrm{ha}^{-1}\right)$ and second $\left(4,207 \mathrm{~kg} \mathrm{ha}^{-1}\right)$, respectively. The high-yielding intercrop combinations tended to involve the same bean genotypes, regardless of the wheat variety. Faba bean genotype Vf2 was often part of the highest yielding intercrop stands in Reinshof (Table 3).

Table 3. Yield means across seasons for the top three performing intercrop stands for each of the three wheat varieties in each site. Yields are means of the four blocks. Yields of each intercrop component (i.e., bean yield, wheat yield) are given separately, as well as total intercrop yield (bean+wheat yield). Results are ranked per wheat component (Ta) and site according to total intercrop yield - highest (top), lowest (bottom).

\begin{tabular}{|c|c|c|c|c|}
\hline Site & Combination & Bean only yield & $\begin{array}{l}\text { Wheat only yield } \\
\text { - Mean }\left(\mathrm{kg} \mathrm{ha}^{-1}\right)\end{array}$ & Total intercrop yield \\
\hline Deppoldshausen & Vf7-Ta3 & 2151 & 2066 & 4217 \\
\hline Deppoldshausen & Vf3-Ta3 & 2355 & 1852 & 4207 \\
\hline Deppoldshausen & Vf5-Ta3 & 2043 & 2078 & 4121 \\
\hline Reinshof & Vf2-Ta3 & 1691 & 3633 & 5324 \\
\hline Reinshof & Vf7-Ta3 & 2207 & 2887 & 5094 \\
\hline Reinshof & Vf3-Ta3 & 2196 & 2825 & 5021 \\
\hline Deppoldshausen & Vf3-Ta2 & 2589 & 1474 & 4063 \\
\hline Deppoldshausen & Vf8-Ta2 & 2537 & 1429 & 3966 \\
\hline Deppoldshausen & Vf7-Ta2 & 2496 & 1432 & 3928 \\
\hline Reinshof & Vf3-Ta2 & 2707 & 2010 & 4717 \\
\hline Reinshof & Vf2-Ta2 & 1996 & 2691 & 4687 \\
\hline Reinshof & Vf1-Ta2 & 1993 & 2378 & 4371 \\
\hline Deppoldshausen & Vf2-Ta1 & 2267 & 1664 & 3931 \\
\hline Deppoldshausen & Vf3-Ta1 & 2510 & 1403 & 3913 \\
\hline Deppoldshausen & Vf7-Ta1 & 2583 & 1284 & 3867 \\
\hline Reinshof & Vf2-Ta1 & 2176 & 2337 & 4513 \\
\hline Reinshof & Vf7-Ta1 & 2853 & 1587 & 4440 \\
\hline Reinshof & Vf4-Ta1 & 2453 & 1891 & 4344 \\
\hline
\end{tabular}



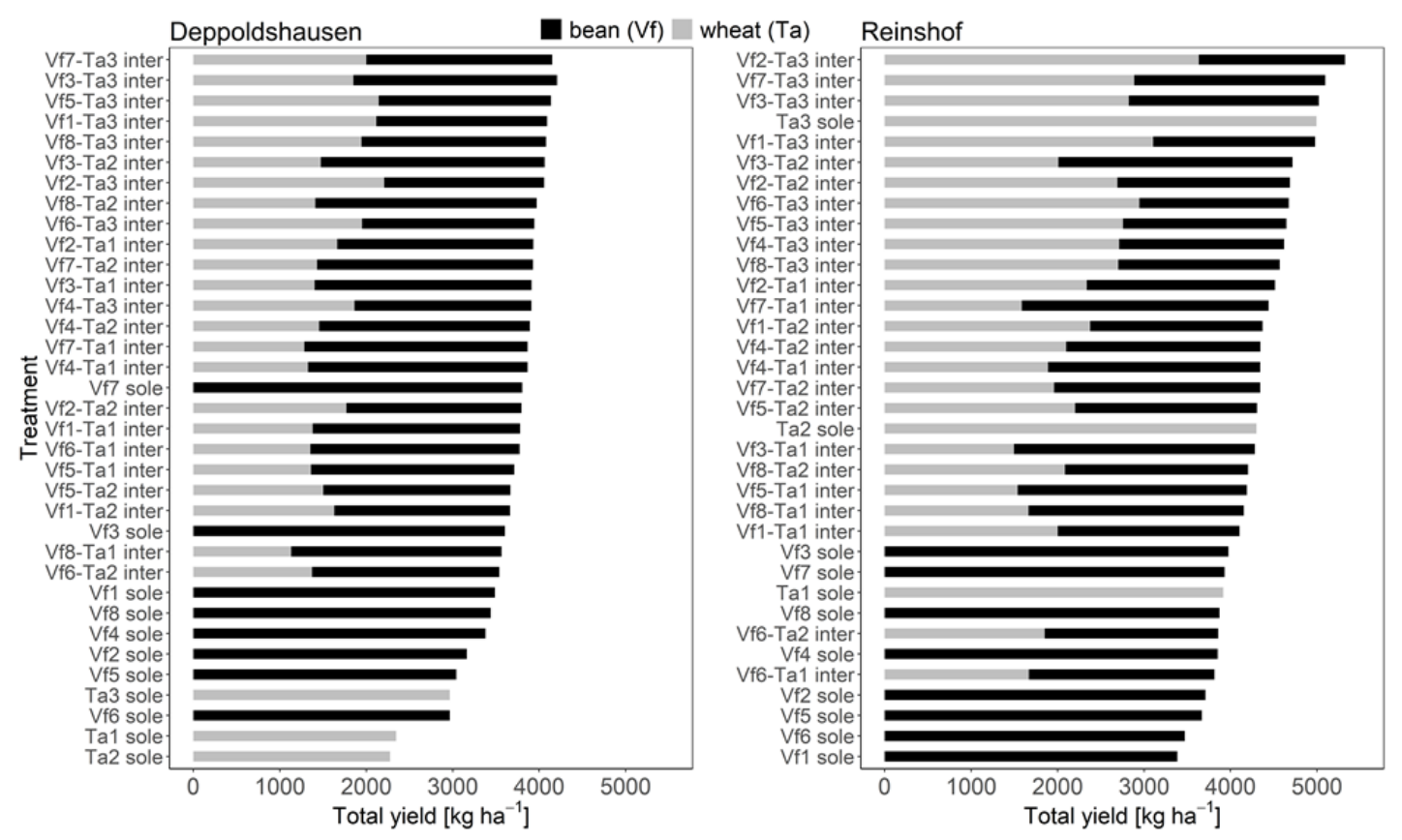

Figure 3. Total yield for each FSE combination for both sites. Total yield is shown from the highest (top) to the lowest (bottom). Bars represent means of four replicates (blocks) across three seasons. For intercrop combinations, the wheat and bean shares of the total intercrop yield are identified through the colours grey and black, respectively.

A slight and insignificant positive association existed between intercropped faba bean yield in Reinshof and the total intercrop yield, if focussing on the mixtures with one wheat variety, i.e. with Ta1, Ta2, or Ta3 (Figure 10 appendix). The correlations were $r=+$ $0.40(\mathrm{R} 2=0.16 ; \mathrm{p}$-value $=0.31), \mathrm{r}=+0.47(\mathrm{R} 2=0.22 ; \mathrm{p}=0.23), \mathrm{r}=+0.19(\mathrm{R} 2=0.03 ; \mathrm{p}$ value $=0.64$ ) when looking at mixtures with Ta1, with Ta2, and with Ta3, respectively. Yet, the correlation became slightly negative, $r=-0.30(\mathrm{R} 2=0.095$; $\mathrm{p}$-value $=0.14)$ when looking across all 24 mixtures (all three wheat varieties together), mainly due to the high yields of wheat variety Ta3 (Figure 10 appendix). This trend was also visible in Deppoldshausen, although to a lesser extent compared to Reinshof. The correlations for Deppoldshausen were $\mathrm{r}=+0.140(\mathrm{R} 2=0.020 ; \mathrm{p}$-value $=0.74), \mathrm{r}=+0.834(\mathrm{R} 2=0.696$ $* *), r=+0.519(\mathrm{R} 2=0.269 ; \mathrm{p}$-value $=0.19)$ when looking at mixtures with Ta1, with Ta2, and with Ta3, respectively. The correlation became slightly negative, $\mathrm{r}=-0.139(\mathrm{R} 2=$ $0.019 ; \mathrm{p}$-value $=0.52$ ) when looking across all 24 mixtures. Note: the terms 'bean only' or 'wheat only' are used to refer to that specific crop's result in the intercrop stand. Bean only yields of intercrop stands were, as expected, negatively correlated with wheat only yields of intercrop stands. Based on the means across replicates, these correlations were, $r=-0.85$ $(\mathrm{R} 2=0.72 * * *)$ and $\mathrm{r}=-0.92(\mathrm{R} 2=0.84 * * *)$ in Deppoldshausen and Reinshof, respectively. Correspondingly, in both sites, increases in the wheat only yields were associated with increased total intercrop yield, with values of $\mathrm{r}=+0.69(\mathrm{R} 2=0.47 * * *)$ 
and $\mathrm{r}=+0.83(\mathrm{R} 2=0.68 * * *)$ for Deppoldshausen and Reinshof, respectively. The positive association between wheat only yield and total intercrop yield was stronger and more consistent than the negative association between bean only yield and total intercrop yield.

High bean only yields at Deppoldshausen were only as high as average bean only yields at Reinshof. High wheat only yields at Deppoldshausen corresponded to below average levels at Reinshof (Figure 4). Total intercrop yield was high when wheat crops were vigorous and beans rather weak.
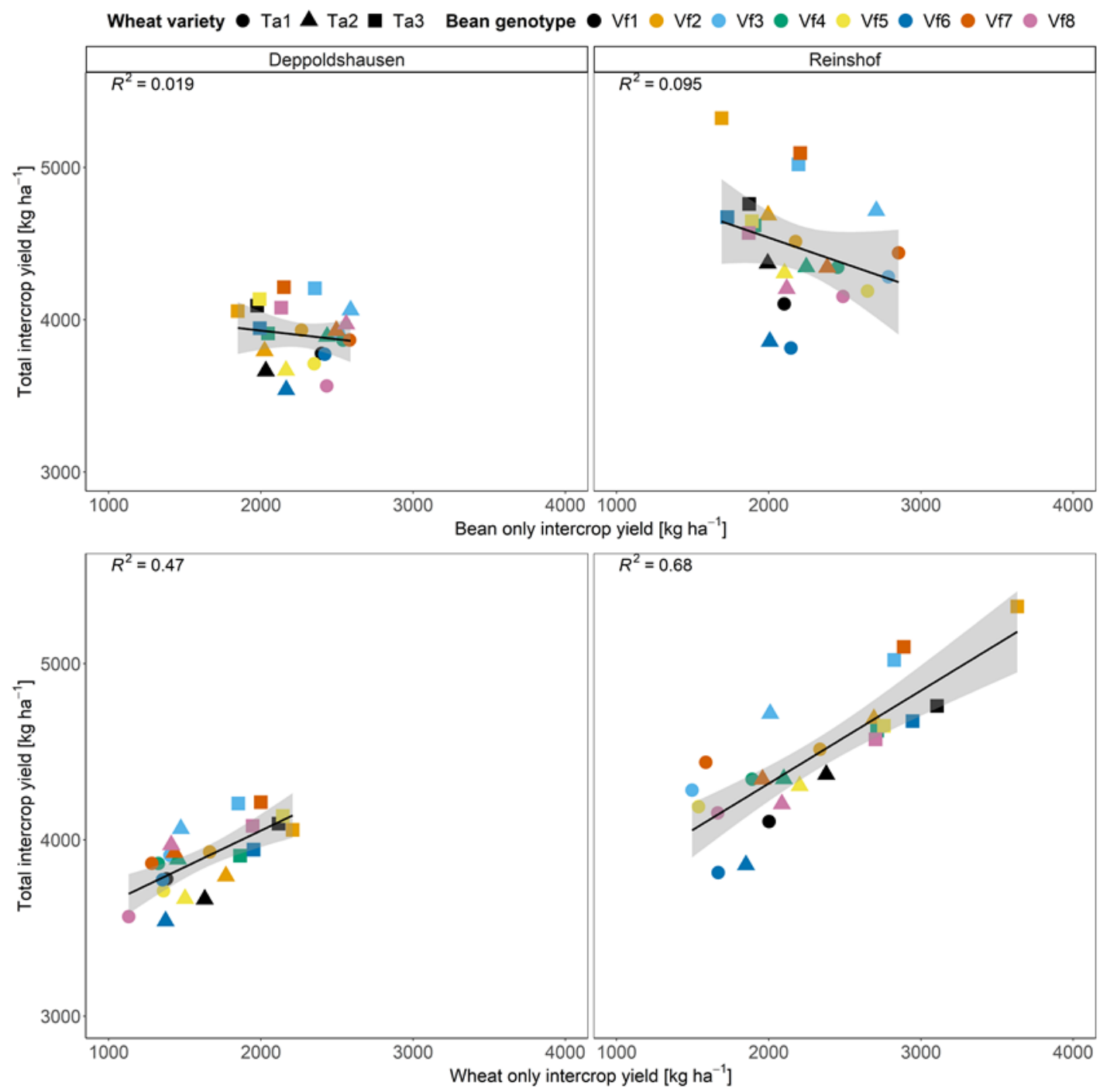

Figure 4. Bean only (top) and wheat only (bottom) yield within intercrop stands and total intercrop (bean+wheat) yield $\left(\mathrm{kg} \mathrm{ha}^{-1}\right)$ for both sites, across all three seasons. Points represent the means of four blocks. While the eight faba bean genotypes are shown through colour, the three wheat varieties they are intercropped with are identified through shapes. 


\subsubsection{Physiological traits: leaf area index, plant height and lodging}

There was a strong positive correlation between the stand-wise intercrop and sole bean LAI values across seasons in both sites, with values of $r=+0.98(R 2=0.96 * *)$ and $r$ $=+0.80(\mathrm{R} 2=0.64 * *)$ for Deppoldshausen and Reinshof, respectively (Figure 5). Leaf area index ranking, i.e. low, medium, and high was the same in Deppoldshausen and Reinshof, although at different levels, i.e. there was a clear site effect, yet little genotype $\mathrm{x}$ site effect. Similar to the pattern of yield (Figure 4), a high intercrop LAI (y-axis) level in Deppoldshausen meant a low intercrop LAI level in Reinshof.

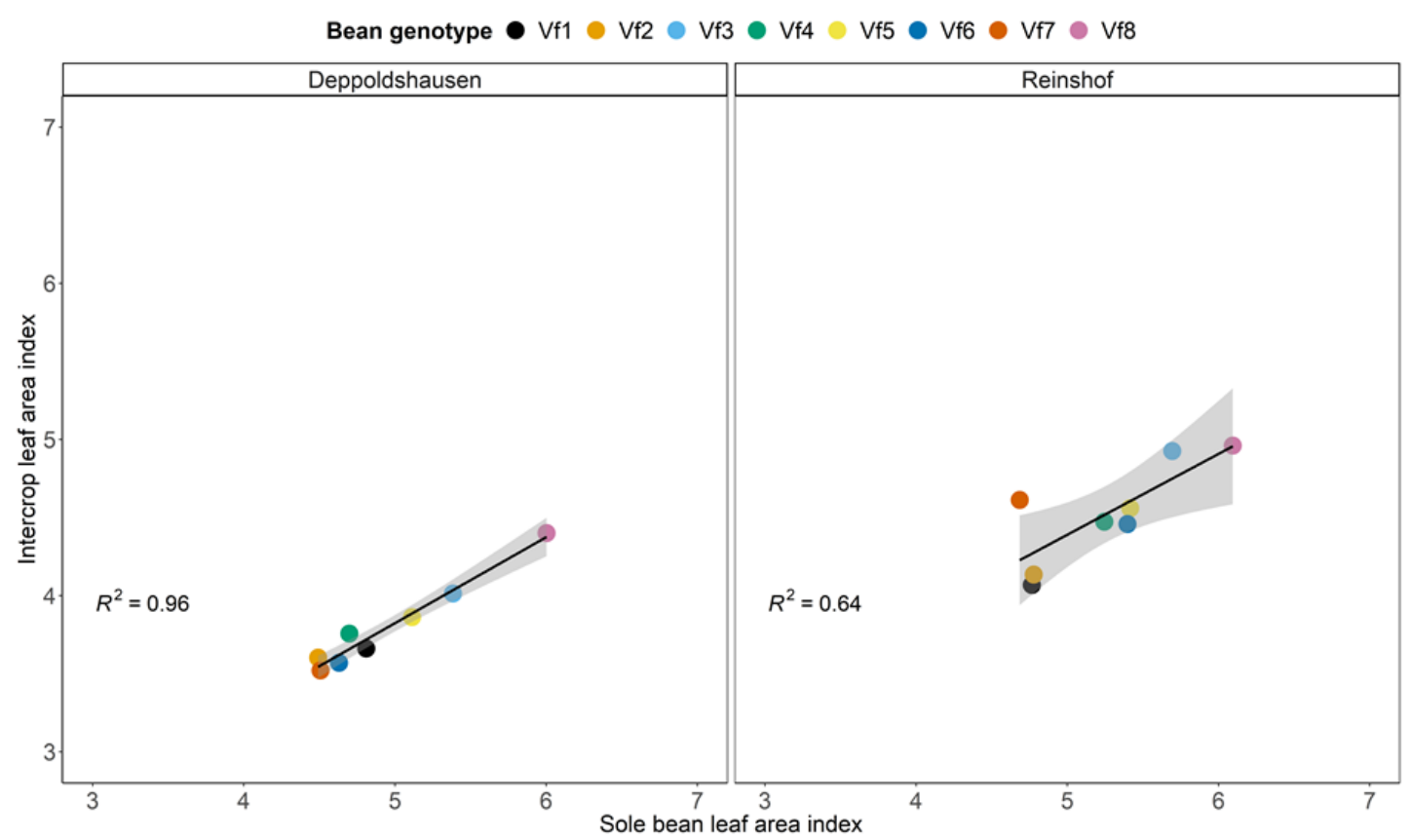

Figure 5. Maximum intercrop (bean+wheat) LAI correlated with maximum sole bean LAI. Leaf area index measurements were taken four times within the vegetative period of each season from four blocks. The points were calculated from the highest (maximum) LAI of those four time points, being specific for each season, and averaged across the three seasons.

In Deppoldshausen, the higher the LAI the lower the total intercrop yield, whereas Reinshof showed no clear tendency (Figure 6). Yield was highest in Reinshof (Vf2-Ta1), albeit with the genotype combination that produced the second lowest LAI in that site. Total intercrop yield in Reinshof did not increase with LAI increments.

Intercrop combination Vf2-Ta1 had one of the lowest LAI values, third in Deppoldshausen and the highest total intercrop yield. The same intercrop combination had the second lowest LAI in Reinshof and again the highest yield (Figure 6). Faba bean genotype Vf2 was the shortest of the eight used. Intercrop combinations that exhibited the lowest LAI therefore achieved the highest total intercrop yields in both sites. 


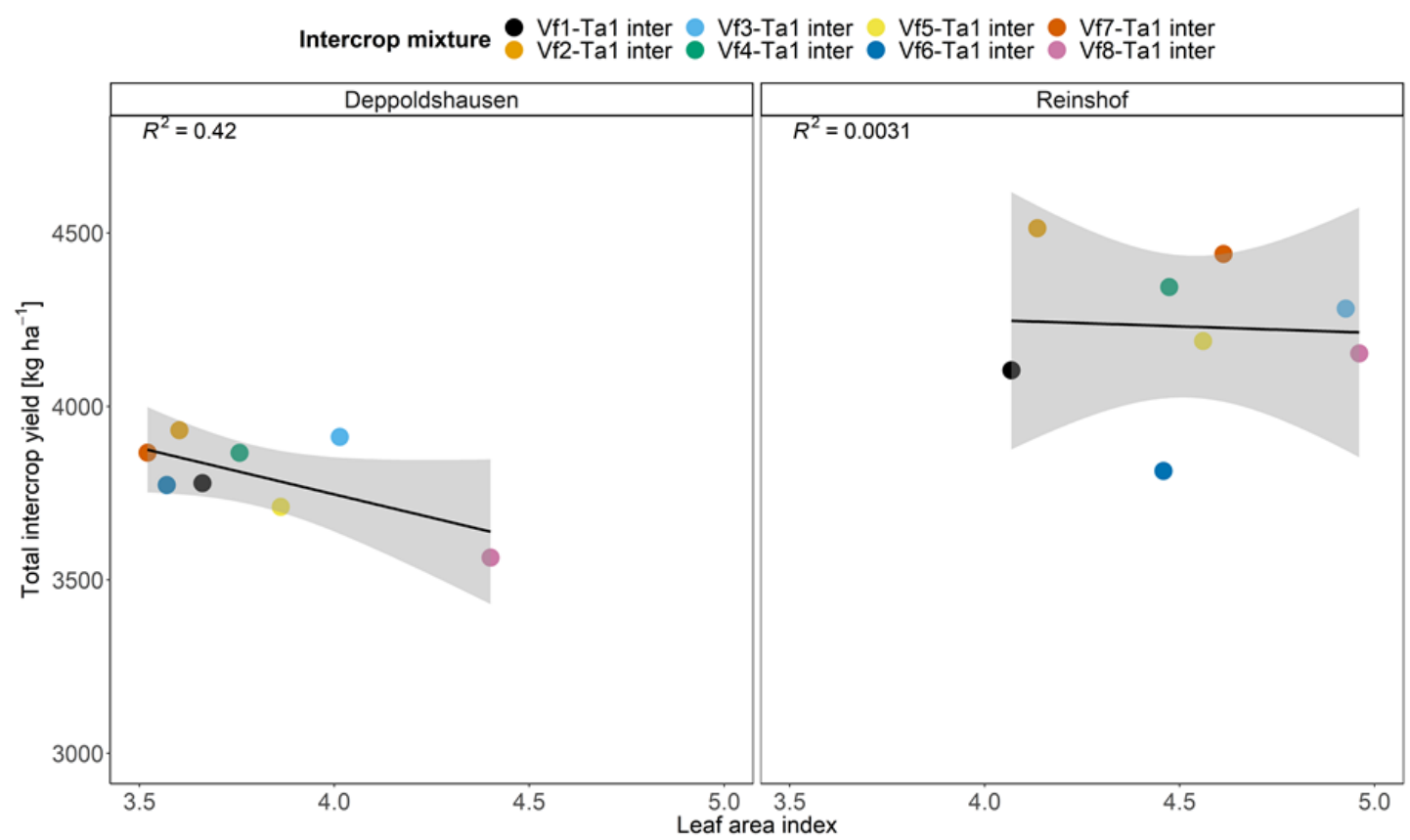

Figure 6. Intercrop (bean+wheat) LAI correlated with the respective total intercrop (bean+wheat) yields. Leaf area index measurements were taken four times within the vegetative period of each season; averages were then taken from the four replicates (blocks). The points represent the highest (maximum) of those means for each season, averaged across the three-season experiment.

Wheat was taller than faba bean in the first season and third season in Deppoldshausen; in Reinshof in the third season only (Figure 7). In the second season, faba beans grew much taller than wheat in both sites, with an average difference of $17 \mathrm{~cm}$ and $29 \mathrm{~cm}$ in Deppoldshausen and Reinshof, respectively. In this season, intercrop combination Vf2-Ta1 was the highest yielding in both sites for total intercrop yield with 4,421 ( $\left.\mathrm{kg} \mathrm{ha}^{-1}\right)$ and 4,461 $\left(\mathrm{kg} \mathrm{ha}^{-1}\right)$ in Deppoldshausen and Reinshof, respectively. This intercrop combination included faba bean genotype Vf2, which was consistently the shortest growing bean in all environments, i.e. these points are consistently the farthest to the right in each stand (Figure 7), indicating that there was the least height difference between the bean and wheat intercrop components.

Wheat yields (squares) were higher than faba bean yields (circles) in season three only, which were also the highest yields out of all seasons of experimentation (Figure 7). 


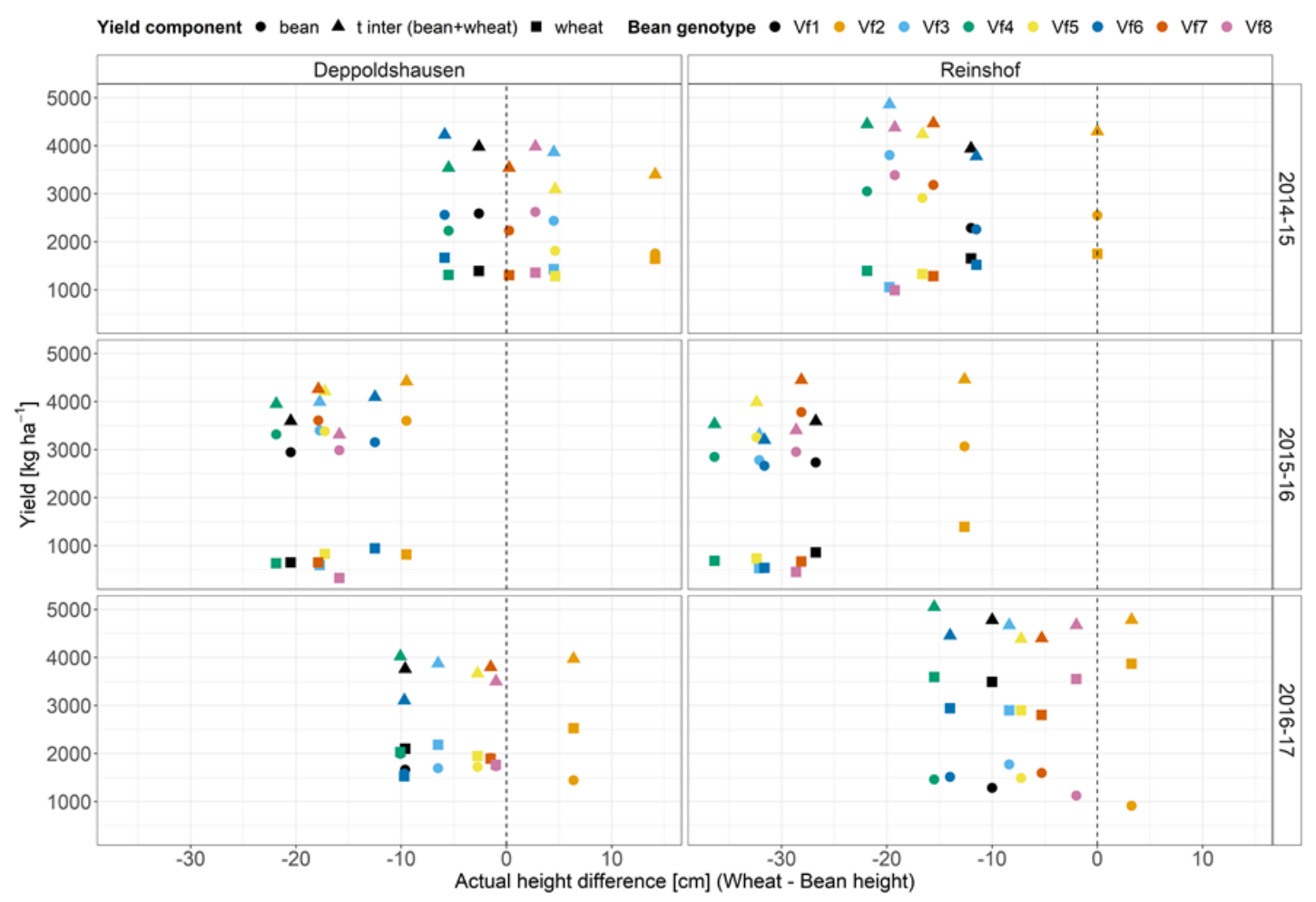

Figure 7. Height difference between intercropped species in relation to the respective intercrop yield components: bean, total intercrop (bean+wheat), wheat. The vertical dashed line at ' $O$ ' indicates zero difference between intercrop species' height within intercrop stands. Points to the right of the dashed line indicate that wheat was taller than bean. Maximum heights were calculated as follows, with the example of bean: bean heights were taken in intercrop stands as means from four blocks, and at four sampling dates. The maximum bean height, used for this figure, was the highest bean height found in each season from the four sampling dates - the same was done for wheat. The height difference plotted is the difference between the maximum bean height minus the maximum wheat height.

The eight faba bean genotypes lodged in the first, and third seasons with average scores of 1.69 and 3.90 (intercrop), and 2.75 and 2.00 (sole) in 2014-15 and 2015-16, respectively. Wheat sole crop stands lodged the least, with averages across all three seasons of 1.67 and 1.06 for wheat variety Ta1 in intercrop and sole crop stands, respectively. The extent of lodging in the first and third seasons did not impact yield.

In the 2015-16 season, the average lodging score for the sole faba bean stands was 4.97 and 6.72 for Deppoldshausen and Reinshof, respectively. Sole faba bean Vf8 lodged the most in both sites with scores of 7.25 and 8.50, respectively (Figure 8). The short growing faba bean Vf2 lodged the least in both sites with scores of 2.25 and 3.25, respectively - lodging scores of Vf2 were not high enough to negatively impact yield. The intercrop stands of these two faba beans lodged, with scores of 1.83 and 2.41 (Vf2), and 4.58 and 7.50 (Vf8), in Deppoldshausen and Reinshof, respectively. The higher scores of faba bean genotype Vf8 caused a reduction of harvestable grain yield.

There was a positive correlation between the canopy height of both intercrop and sole faba bean values and the severity of lodging in both sites, with values of $r=+0.62$ (R2 
$=0.39 * *)$ and $\mathrm{r}=+0.84(\mathrm{R} 2=0.71 * * *)$ for Deppoldshausen and Reinshof, respectively (Figure 8). There was also a positive correlation between the LAI and the severity of lodging in both sites, with values of $\mathrm{r}=+0.85(\mathrm{R} 2=0.73 * * *)$ and $\mathrm{r}=+0.62(\mathrm{R} 2=0.39 *)$ for Deppoldshausen and Reinshof, respectively. As with canopy height, the faba bean genotypes with the lowest and highest lodging scores were similar to those with the lowest and highest LAI values in both sites. High lodging scores of the 2015-16 season were negatively correlated with yield (intercrop and sole), with values of $r=-0.88$ ( $R 2=0.78$ $* * *)$ and $\mathrm{r}=-0.68(\mathrm{R} 2=0.46 * *)$ for Deppoldshausen and Reinshof, respectively.
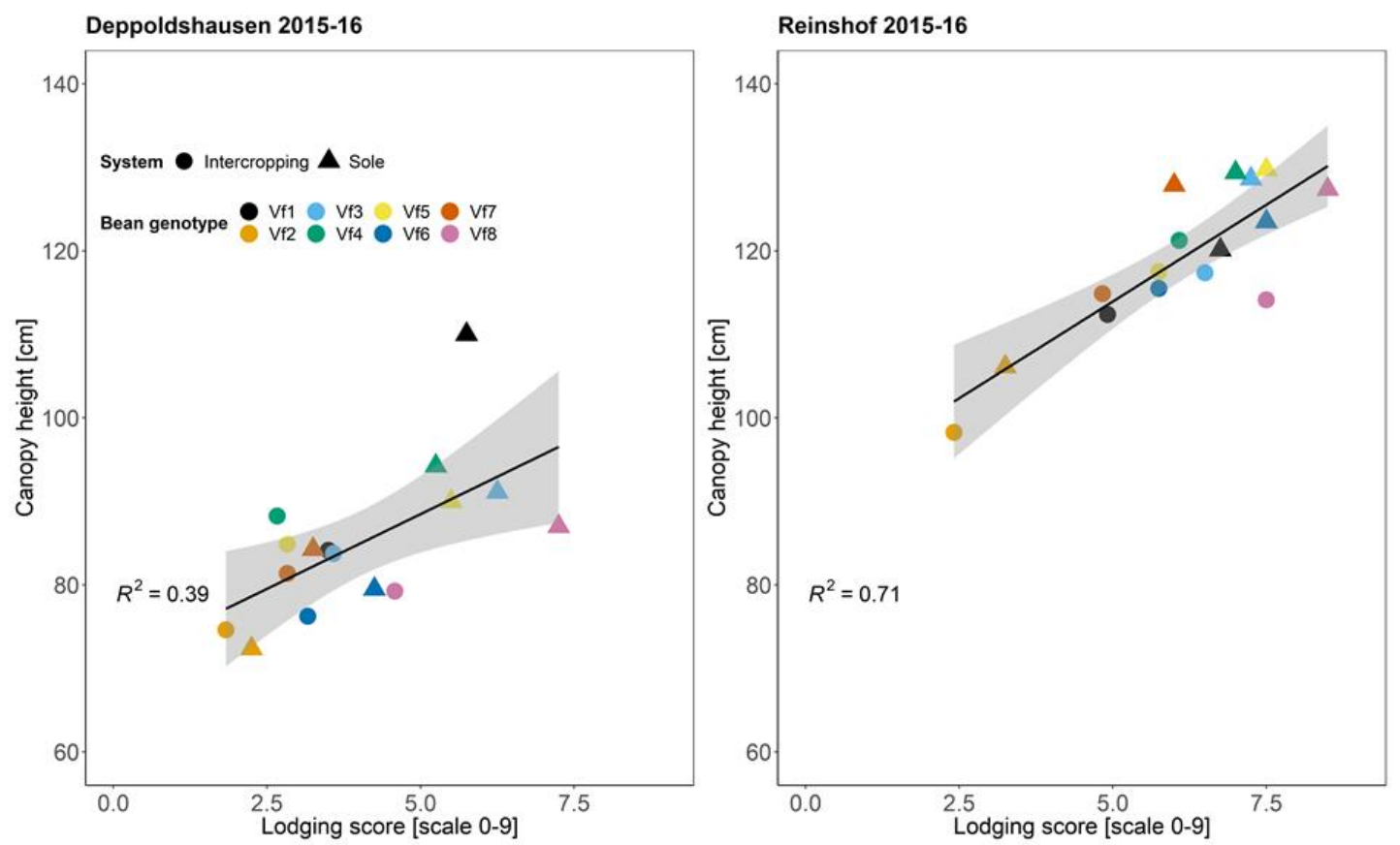

Figure 8. Maximum intercrop (bean+wheat) (circles) and sole bean height (triangles) (cm) correlated with their respective lodging score (scale: $0=$ no lodging; $9=$ full lodging) for both sites (Deppoldshausen and Reinshof) and shown from one season (2015-16). Height measurements were taken four times within the vegetative period from four blocks. The points were calculated from the highest (maximum) height of the four points, and averaged.

\subsubsection{Soil water and nitrogen}

Reinshof had a much higher amount of extractable soil water than Deppoldshausen due to the root zone being three times deeper. Means values at full-flowering were $141 \mathrm{~mm}$ versus $18 \mathrm{~mm}$ and final harvest $158 \mathrm{~mm}$ versus $31 \mathrm{~mm}$ in Reinshof and Deppoldshausen, respectively (Figure 9). Reinshof was clearly the more fertile site in terms of physical and soil chemical properties, as shown by the large bean plants in this site indicated by the traits LAI, plant height, and lodging (Figure 5 to 8). Mineral N content at both sites was higher at harvest time compared to full-flowering - means of 16 increased to $24\left(\mathrm{~kg} \mathrm{ha}^{-1}\right)$, and 10 to 
$15\left(\mathrm{~kg} \mathrm{ha}^{-1}\right)$ in Deppoldshausen and Reinshof, respectively. Mineral N content was higher at both sampling dates in Deppoldshausen compared to Reinshof.
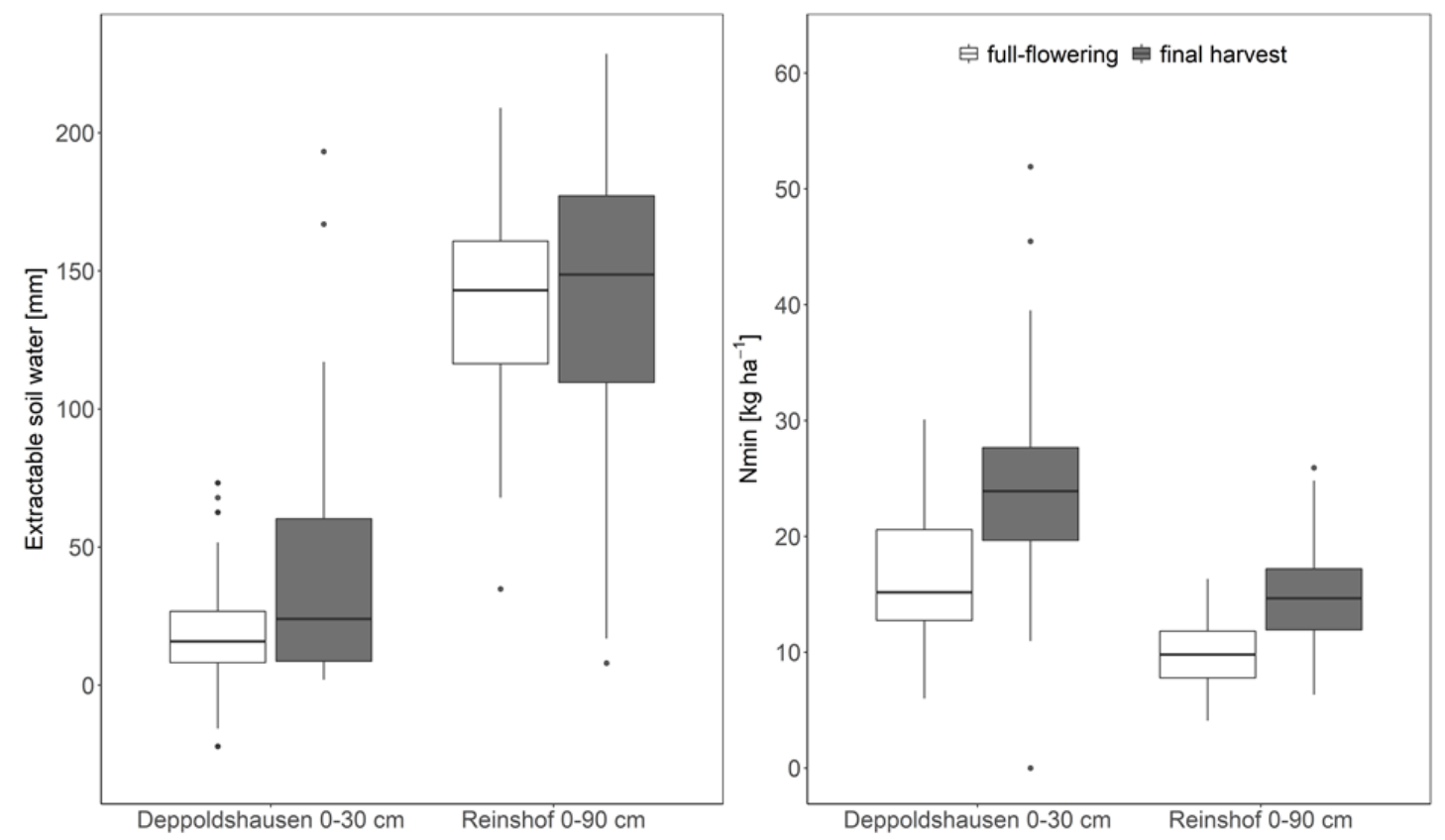

Figure 9. Extractable soil water and $N_{\min }$ content of all intercrop stands at full-flowering and final harvest for two seasons (2014-15 and 2015-16). For each site (Deppoldshausen and Reinshof) and sampling time (at fullflowering and at final harvest) the extractable soil water and $N_{\min }$ content of each layer (0-30, 30-60, and 60$90 \mathrm{~cm}$ ) was summed within each block (replicate), providing four replicate profiles. The three horizontal lines indicate the $75 \%$ percentile (top), median (solid line across boxes) and $25 \%$ percentile yield (bottom); the upper and lower bars outside the boxes extend to the maximum and minimum values respectively. The isolated points are outliers.

\subsection{Discussion}

Intercropping winter bean-wheat is uncommon, in part due to well-established and successful protocols for high-input sole crop agronomy (Fletcher et al., 2016), which is based on the widespread availability of 'affordable' $\mathrm{N}$ fertiliser and therefore the lack of need for legume-based fertility (Peoples et al., 2019). Climate change projections predict mild winters, summer droughts, and in general an unclear future (Rötter et al., 2018). There is therefore a need for more 'tools' and ways in which such unpredictability can be dealt with, encouraging the use of crops like winter faba bean in crop rotations. With agricultural policy advocating for high resource use efficiency and ecological intensification, such winter cereal-legume intercrops are likely to be part of our future agricultural landscapes (Stomph et al., 2020). 


\subsubsection{Winter Wheat-bean intercrop performance}

This study clearly highlighted site-specific magnitudes of overyielding. While intercrops yielded higher compared to sole crops on both sites, the performance difference between the systems in Deppoldshausen was more than double that of Reinshof (Figure 2) - confirming hypothesis one and two of this study. Improved performance in marginal conditions can also be seen across various ecological-systems. Skinner et al. (2004), found the overyielding of grass-clover mixtures to decrease under favourable (weather) conditions compared to normal and dry conditions. Similar responses have also been found with forest species, where mixing species led to overyielding of $66 \%$ on poor sites, $35 \%$ on mediocre sites, and $12 \%$ on fertile sites (Pretzsch, 2013).

Quantification of the intercrop component contributions to total intercrop yield (Figure 3) showed that the highest yielding intercrop stands consisted of more wheat than faba bean. This was especially the case in Reinshof, which had higher amounts of soil water (Figure 8). While it is well-known that wheat performs well with high (comparatively) $\mathrm{N}$ supply (Jensen, 1996; Hauggaard-Nielsen et al., 2003), the two times higher mixture effect of the intercrop stands in Deppoldshausen was partly due to low sole wheat yields, and the comparatively high sole wheat yields in Reinshof (Figure 3). Faba beans were also limited by the soil water content in Deppoldshausen (Figure 9), which led to the development of 'weak bean plants' that did not compete strongly with the wheat, therefore supporting wheat growth (Figure 4). Regardless of the mechanism, the highest total intercrop yields were dependent on the wheat component. Very clearly, the wheat variety with highest wheat only yields was responsible for the high yields of its intercrop stands (Figure 10 appendix). Wheat with lower wheat only intercrop yield allowed for a higher bean only intercrop yield, although this resulted in a lower total intercrop yield. In summary, the gain of bean only intercrop yield allowed due to a weaker wheat did not compensate for the loss of the wheat contribution. In other words, the intercrop stands with the highest bean only intercrop yields (Deppoldshausen: 3,967 $\mathrm{kg} \mathrm{ha}^{-1}$; Reinshof: 4,479 $\mathrm{kg} \mathrm{ha}^{-1}$ - means of top three highest total intercrop yields) were inferior to the intercrop stands with the highest wheat only intercrop yields (Deppoldshausen: 4,095 $\mathrm{kg} \mathrm{ha}^{-1}$; Reinshof: 4,992 $\mathrm{kg} \mathrm{ha}^{-1}-$ means of top three highest total intercrop yields) (Table 5, Figure 10 appendix). Note: this takes into account intercrop stands with any of the three wheat varieties. The larger difference between the abovementioned total intercrop yields between Deppoldshausen and Reinshof $\left(4,095 \mathrm{~kg} \mathrm{ha}^{-1}-\right.$ $3,967 \mathrm{~kg} \mathrm{ha}^{-1}=128 \mathrm{~kg} \mathrm{ha}^{-1} ; 4,992 \mathrm{~kg} \mathrm{ha}^{-1}-4,479 \mathrm{~kg} \mathrm{ha}^{-1}=513 \mathrm{~kg} \mathrm{ha}^{-1}$, respectively) can be attributed to the highest yielding wheat variety Ta3 that was better suited to the more fertile Reinshof site. All of the intercrop stands with the highest wheat only yields included 
wheat variety Ta3, in both sites. Soil characteristics also dictated the extent to which faba bean traits such as LAI, plant height and lodging were expressed. The faba bean genotypes show that the northern European breeding material for winter faba beans is not domesticated and modern enough to limit biomass production under fertile conditions, such as sufficient water availability; this germplasm tends to exaggerate LAI, height and even lodging as environmental conditions allow.

The higher performance of the intercrop stands compared to sole stands on the marginal site highlights an analogy between heterozygosity and the heterotic yield increase of a crop (such as maize) on one side and heterogeneity of an intercropped stand and overyielding on the other. It is well known that heterosis, the heterotic surplus of performance of a hybrid over the mean of its parental inbred lines, is more pronounced under marginal, stressful conditions. The hybrids tend to suffer less under stress than the inbred lines (Abdelmula et al., 1999; Einfeldt et al., 2005). The analogy holds in so far as the overyielding of the intercrops was higher in the marginal, less fertile site. Here, the function of overyielding due to intercropping is based around the increased variation (amount and time span) in use of limited resources, such as water (Figure 9).

\subsubsection{Traits characteristics, resource competition, and implications for breeding}

Leaf area index and biomass values for faba beans showed that they are genetically not capable of reacting to site conditions in an agronomically desirable way (Figure 5). Figure 5 shows an LAI gradient across both sites, with low values in Deppoldshausen, continuing to higher values in Reinshof. Increases in LAI slightly reduced total intercrop yield in Deppoldshausen - albeit minimally - indicating that the LAI - for which faba bean was largely responsible - outcompeted wheat for light (Figure 6). Further development of the canopy led to no clear yield increases in Reinshof. Increases in LAI undoubtedly demand more resources, despite a lack of yield increments. Such patterns of trait expression are not only resource-inefficient, but they are unattractive for farmers who want grain yield, as the lack of predictability makes it difficult to plan. While a meta-analysis of arable crop production found that intercropping across several climatic zones can enhance yield stability compared to that of both respective sole crops, it also found stability to be site-specific (Raseduzzman and Jensen, 2017), which is in agreement with our findings. Moreover, genetic material improvement programmes emphasise the need to develop integrated and multidisciplinary research frameworks that assess optimum GxExM for current and projected scenarios (Palita et al., 2020). These therefore include site and soil (E), as well as 
management aspects such as planting density (M), and must therefore be highly specific. Although cereal-grain legume intercropping is clearly beneficial, it cannot be used as a blanket solution.

It is important to acknowledge the notion that although tall faba beans yielded on average higher than short faba beans, yield differences were minimal (Figure 7). Height per se was therefore not that important for high faba bean yields. Wheat, however, while it did not have to be tall itself, experienced yield reductions the shorter it was in comparison to the faba bean component as part of an intercrop stand. A similar trend was also found by Nelson et al. (2018), where sole cropped pearl millet yields (of a short cultivar) were lower when intercropped with an erect cowpea cultivar. Variation between intercrop and sole crop yields of the pearl millet cultivar used was higher at high compared to low density, i.e. 33 and 17 plants per $\mathrm{m} 2$ respectively (Nelson et al., 2018). Figure 7 highlights the negative impact of a dominant legume well by showing that the lowest intercrop wheat yields were recorded in the second season when intercropped faba beans grew taller than the wheat, in particular in the more fertile site of Reinshof. Indeed, hypothesis three of this study was also confirmed, i.e. there was a genotype effect on the yield performance of the total crop stand, based on canopy development and functional traits. The highest yielding intercrop stands that were assessed in terms of their trait characteristics consisted of Vf2-Ta1. Not only was Vf2 consistently the shortest faba bean genotype, but in Reinshof in particular, the low height of the Vf2 faba bean enabled the wheat to yield $1,394 \mathrm{~kg} \mathrm{ha}^{-1}$ in the second season, compared to the mean of the seven other intercropped wheat yields of $638 \mathrm{~kg} \mathrm{ha}^{-1}$ (Figure 7).

Ultimately, lodging was a main driver of the difference between yield, and harvestable yield for winter faba bean genotypes in this experiment. Although Vf2 may have been part of the highest yielding intercrop combinations in the 2015-16 season, it was mainly due to the fact that these stands were the most harvestable, as they lodged the least (Figure 8). While Vf8 may well have produced more grain, it could not be collected by the combine harvester due to heavy lodging. Lodging score differences between faba bean genotypes, and the mechanically improved standing ability of the intercrop stands markedly influenced the yields of sole faba bean stands and, although to a lesser extent, the yield of the intercrop stands. These differences were expressed to a greater extent on the more fertile site of Reinshof.

Appropriate faba bean genotype selection appears to be less important on marginal soils, as they do not support excessive biomass development that can lead to shading of wheat intercrops and overall stand lodging. On a fertile soil, like that of Reinshof, the use 
of a shorter faba bean (low LAI, low plant height, low tendency to lodge) could ensure good bean and wheat intercrop yields (Figure 3). In the experiment presented, faba bean genotype Vf2 stood out as it expressed some of the lowest LAI values (Figure $5 \& 6$ ), and was the shortest (Figure 7). This genotype was also part of the highest ranked intercrop stands for total yield (bean+wheat) for both sites - although more so in Reinshof - regardless of the wheat variety it was intercropped with (Figure $3 \&$ Table 3). Faba bean genotype Vf2 also lodged the least in all environments (seasons and sites) (data not shown). The second season (2015-16) experienced the most lodging, which led to a yield penalty for the taller beans, therefore favouring the shorter beans (Figure 7). This in turn influenced the yield means across all three seasons (Figure 2), and highlights the lack of faba bean biomass growth stability, and therefore a key challenge for breeders, and farmer adoption.

\subsubsection{Perspectives for winter bean-wheat intercropping}

While a lot has been achieved in faba bean breeding so far, i.e. non-shattering, less lodging genotypes (spring faba beans) (Link, 2009), the lodging in northern European winter bean genotypes, and the traits that contribute towards it, remain key traits that can negatively influence harvestable yield. An optimal scenario for winter bean-wheat intercropping could include a highly fertile site that is able to support high wheat and faba bean yields. However, this study showed that, as judged by the representative set of lines used (Table 1) and based on the standing breeders' knowledge, northern European winter faba beans are not yet sophisticated enough to be grown in such environments and under the management implemented. Where water resources were plentiful, increases in biomass production were not followed by increases in yield, but instead these faba beans outcompeted the intercropped companion wheat for light, and increased the risk of lodging for the entire stand. The successful adoption of winter bean-wheat intercropping must be based on already well-established wheat varieties, such as those used in this experiment. Winter faba bean genotypes should therefore be bred to suit such modern wheat varieties, which have already been bred to be short, mainly to avoid lodging (Damisch and Wiberg, 1991). Breeders could partly substitute breeding shorter faba beans with genotypes that lodge less due to other physiological traits, such as stiffer stems (Sass and Stelling, 1990). Simply breeding for shorter faba beans could lead to lower yields (Link and Stuetzel, 1995), due for example to a reduction in the photosynthetic capacity of a canopy (Peng et al., 2014). Although there is always likely to be some trade-off between yield performance and environmentally influenced stability, it is clearly important to synchronise and harmonise 
genotypic expression with site fertility, especially with the current genetic material available. The linkage between modelling and field experimentation, an inherent part of the overarching IMPAC3 study set-up - within which this field experiment was conducted can support breeding in this respect through ex ante analyses of GxExM interactions (Rötter et al., 2018). Winter hardy faba bean genotypes with high LAI and height with low lodging risk do not currently exist. Crop simulation models (CSM) however, can disentangle traits in silico, such as the lodging-LAI-height syndrome of faba bean, which can allow for better informed breeding.

The application of site-specific knowledge could help farmers and society benefit from winter bean-wheat intercropping, through overyielding (Figure 2 and Table 2), higher grain legume production, leading to less reliance on imports, and increased short- and medium-term ecosystem services - higher $\mathrm{N}_{\min }$ content in the soil, as well as soil organic carbon levels (Hoffmann et al., 2020). A recent study estimated that the increased $\mathrm{N}$ use efficiency of intercropping could reduce fossil-based $\mathrm{N}$ fertiliser by about $26 \%$ on a global scale (Jensen et al., 2020). This is in part due to the legumes being forced - due to competition from a cereal intercrop - to obtain more $\mathrm{N}$ through biological $\mathrm{N}$ fixation compared to when grown as a sole crop.

Winter bean genotypes need to be genetically educated to resist excessive vegetative biomass growth even when conditions allow. The interim-term could see the utilisation of marginal soils as an efficient, site-specific approach to landscape use. Despite the challenges of growing winter faba bean shown through this study, winter bean-wheat intercropping proved a highly productive and resource efficient alternative to sole cropped faba bean and wheat on the marginal site of Deppoldshausen. Key is the thorough exploitation of GxExM interactions for intercrops, and landscape use that incorporates site-specificity, genotypic variation, and adequate farm management. Such an approach would likely increase the adoption of winter intercrops. As Peoples et al. (2019) argue, a thoughtful and thorough reintroduction of legumes into mechanised, temperate farms, through systems such as intercropping is needed. This must include all stakeholders, at least farmers, plant breeders, machinery suppliers, and consumers. While technical barriers and a poor perception of intercrop performance prevents farmer adoption (Lemken et al., 2017), such barriers could surely be overcome by research, mentoring and advice (Stomph et al., 2020). 


\subsection{Conclusion}

While our study has shown that winter bean-wheat intercrop systems are higher yielding under low input management than sole crop equivalents, it also highlighted key traits that are required to ensure high-yielding intercrops. Limited leaf area index, canopy height, and lodging of faba bean are key traits for high performing intercrops. Considering the current available genotypes of winter faba bean, marginal sites are better cultivated with rather vigorous genotypes, while fertile sites require less vigorous ones. This strategy works to ensure good wheat yields as excessive faba bean biomass growth must not out complete wheat for light, or potentially lead to excessive lodging. Winter faba beans should in particular be bred to restrain from excess vegetative biomass development under the more fertile conditions.

\subsection{References}

Abdelmula, A.A., Link, W., von Kittlitz, E., and Stelling, D., 1999. Heterosis and inheritance of drought tolerance in faba bean, Vicia faba L.. Plant Breeding 118, 485-490. U. S. Copyright Clearance Center Code Statement: 0179-9541/99/18060485. doi: 10.1046/j.1439-0523.1999.00411.x.

Ali, M.B.M., Welna, G.C., Sallam, A., Martsch, R., Balko, C., Gebser, B., Sass, O., Link, W., 2016. Association Analysis to Genetically Improve Drought and Freezing Tolerance of Faba Bean (Vicia gaba L.). Crop Science, vol. 56, pp. 1036-1048. doi: 10.2135/cropsci2015.08.0503.

Arbaoui, M. and Link, W., 2007. Effect of hardening on frost tolerance and fatty acid composition of leaves and stems of a set of faba bean (Vicia faba L.) genotypes. Euphytica (2008) 162:211-219. doi. 10.1007/s10681-007-9521-4.

Bedoussac, L., and E., Justes., 2010. The efficiency of a durum wheat-winter pea intercrop to improve yield and wheat grain protein concentration depends on $\mathrm{N}$ availability during early growth. Plant and soil, vol. 330, Issue 1-2, pp. 19-35. doi: 10.1007/s11104-009-0082-2.

Brooker, R.W., Bennett, A.E., Cong, W.F., Daniel, T.J., George, T.S., Hallett, P.D., Hawes, C., Iannetta, P.P.M., Jones, H.G., Karley, A.J., Li, L., McKenzie, B.M., Pakemann, J., Paterson, E., Schöb, C., Shen, J., Squire, G., Watson, C.A., Zhang, C., Zhang, F., Zhang, J., and White, P.J., 2015. Improving intercropping: a synthesis or research in agronomy, plant physiology and ecology. New Phytologist (2015) 206: 107-117. doi: $10.1111 /$ nph. 13132 .

Bundessortenamt (ed.) 2015. Beschreibende Sortenliste, Getreide, Mais, Öl- und Faserpflanzen, Leguminosen, Rüben, Zwischenfrüchte. LandbauVerlagsgesellschaft Hannover, Germany.

Damisch, W. and Wiberg, A., 1991. Biomass Yield - A Topical Issue in Modern Wheat Breeding Programmes. Plant Breeding 107, 11-17. doi: 10.1111/j.14390523.1991.tb00523.x. 
Einfeldt, C.H., Ceccarelli, S., Grando, S., Gland-Zwerger, A., and Geiger, H.H., 2005. Heterosis and mixing effects in barley under drought stress. Plant Breeding 124, 350-355. doi: 10.1111/j.1439-0523.2005.01111.x.

Fargione, J., Tillman, D., 2005. Niche differences in phenology and rooting depth promote coexistence with a dominant C4 bunchgrass. Oecologia 143: 598-606. doi: 10.1007/s00442-005-0010-y.

Fletcher, A.L., Kirkegaard, J.A., Peoples, M.B., Robertson, M.J., Whish, J., and Swan, A.D., 2016. Prospects to utilise intercrops and crop variety mixtures in mechanised, rain-fed, temperate cropping systems. Crop \& Pasture Science, 2016, 67, 1252-1267. doi: $10.1071 / \mathrm{CP} 16211$.

Flores, F., Nadal, S., Solis, I., Winkler, J., Sass, O., Stoddard, F.L., Link, W., Raffiot, B., Muel, F. and Rubiales, D., 2012. Faba bean adaptation in autumn sowing under European climates. Agron. Sustain. Dev. (2012) 32:727-734. doi: 10.1007/s13593012-0082-0.

Hauggaard-Nielsen, H., and Jensen, E.S., 2001. Evaluating pea and barley cultivars for complimentarity in intercropping at different levels of soil $\mathrm{N}$ availability. Field Crops Research 72 (2001) 185-196. doi: 10.1016/S0378-4290(01)00176-9.

Hauggaard-Nielsen, H., Ambus, P., and Jensen, E.S., 2003. The comparison of nitrogen use and leaching in sole cropped versus intercropped pea and barley. Nutrient Cycling in Agroecosystems 65: 289-300. doi: 10.1023/A:1022612528161.

Heshmati, S., Tonn, B., Isselstein, J., 2020. White clover population effects on the productivity and yield stability of mixtures with perennial ryegrass and chicory. Field Crops Research 252 (2020) 107802. doi: 10.1016/j.fcr.2020.107802.

Hector, A., Bazeley-White, E., Loreau, M., Otway, S., and Schmid, B., 2002. Overyielding in grassland communities: testing the sampling effect hypothesis with replicated biodiversity experiments. Ecolo Letters, 5: 502-511. doi: 10.1046/j.14610248.2002.00337.x.

Hoffmann, M.P., Swanepoel, C.M., Nelson, W.C.D., Beukes, D.J., van der Laan, M., Hargreaves, J.N.G., Rötter, R.P., 2020. Simulating medium-term effects of cropping system diversification on soil fertility and crop productivity in southern Africa. European Journal of Agronomy. vol. 119, June. doi: 10.1016/j.eja.2020.126089.

Hof-Kautz, C., and Rauber, R., 2003. Growing crop mixtures in organic farming; in German. Published by the National Program for Organic Farming at the Federal Institute for Agriculture and Human Nutrition, Bonn and Göttingen, 55 pages; ISBN 3-00-011733-4.

Hof-Kautz, C., Hochmuth, C., Schmidtke, K. and Rauber, R., 2007. Wirkung des Gemengeanbaus mit Winterkörnerlegu- minosen sowie der Standraumzuteilung auf Kornertrag und Backqualität von Winterweizen (Effects of intercropping with winter grain legumes and spatial arrangement on grain yield and backing quality of winter wheat). In: Zikeli, S., Claupein, W., Dabbert, S., Kaufmann, B., Müller, T., Valle Zárate, A. (Eds.), Zwischen Tradition und Globalisierung, Beiträge zur 9. Wissenschaftstagung Ökologischer Landbau, Band 1. Universität Hohenheim, Deutschland, pp. 121-124 (in German) http://orgprints.org/10742/.

Jensen, E.S., 1996. Rhizodeposition of $\mathrm{N}$ by pea and barley and its effect on soil $\mathrm{N}$ dynamics. Soil Biol Biochem 28(1):65-71. doi: 10.1016/0038-0717(95)00116-6. 
Jensen, E.S., Peoples, M.B. and Hauggaard-Nielsen, H., 2010. Faba bean cropping systsmes. Field Crops Research. Volume: 115, Number: 3, pp 203-216. doi: 10.1016/j.fcr.2009.10.008.

Jensen, E.S., Carlsson, G., and Hauggaard-Nielsen, H., 2020. Intercropping of grain legumes and cereals improves the use of soil $\mathrm{N}$ resources and reduces the requirement for synthetic gertilizer N: A global-scale analysis. Agronomy for Sustainable Development 40:5. doi: 10.1007/s13593-020-0607-x.

Khan, H.R., Paull, J.G., Siddique, K.H.M., Stoddard, F.L., 2010. Faba bean breeding for drought-affected environments: A physiological and agronomic perspective. Field Crop Res. 115, 279-286. doi: 10.1016/j.fcr.2009.09.003.

Landry, E.J., Lafferty, J.E., Coyne, C.J., Pan, W.L., and Hu, J., 2015. Registration of Four Winter-Hardy Faba Bean Germplasm Lines for Use in Winter Pulse and Cover Crop Development. Journal of Plant registrations 9:367-370 (2015). doi: 10.3198/jpr2014.12.0087crg.

Landry, E.J., Coyne, C.J., McGee, R.J., and Hu, J., 2016. Adaptation of Autumn-Sown Faba Bean Germplasm to Southeastern Washington. Agronomy Journal, Vol. 108, Issue 1. doi: 10.2134/agronj2015.0028.

Lemken, D., Spiller, A., von Meyer-Hoefer, M., 2017. The Case of Legume-Cereal Crop Mixtures in Modern Agriculture and the Transtheoretical Model of Gradual Adoption. Ecological Economics, vol. 137, pp. 20-28. doi: 10.1016/j.ecolecon.2017.02.021.

Li, L., Tilman, D., Lambers, H., and Zhang, F.-S-, 2014. Plant diversity and overyielding: insights from belowground facilitation of intercropping in agriculture. New Phytologist, 203: 63-69. doi: 10.1111/nph.12778.

Li., Q.-Z., Sun, J.-H., Wei, X.-J., Christie, P., Zhang, F.-S., Li, L., 2011. Overyielding and interspecific interactions mediated by nitrogen fertilization in strip intercropping of maize with faba bean, wheat and barley. Plant Soil, 339: 147-161. doi: 10.1007/s11104-010-0561-5.

Link, W. and H. Stützel, 1995. Faba bean. Genetics. In: Diepenbrock, W. and H.C. Becker, (ed). Physiological Potentials for Yield Improvement of Annual Oil and Protein Crops. Advances in Plant Breeding, Vol. 17, Blackwell, Berlin, p. 239 - 278.

Link, W., 2009. Züchtungsforschung bei der Ackerbohne: Fakten und Potentiale. Journal für Kulturpflanzen 61, 341-347. doi: 10.5073/JfK.2009.09.08.

Link, W., Balko, C. and Stoddard, F.L., 2010. Winter hardiness in faba bean: Physiology and breeding. Field Crops Research 115 (2010) 287-296. doi: 10.1016/j.fcr.2008.08.004.

Malézieux E, Crozat Y, Dupraz C., Laurans, M., Makowski, D., Ozier-Lafontaine, H., Rapidel, B., de Tourdonnet, S., Valantin-Morison, M., 2009. Mixing plant species in cropping systems: concepts, tools and models. A review. Agron Sustain Dev Springer Verlag/EDP Sci 29 (1):43-62. doi: 10.1051/agro:2007057.

Nelson, W.C.D., Hoffmann, M.P., Vadez, V., Rötter, R.P., Whitbread, A.M., 2018. Testing pearl millet and cowpea intercropping systems under high temperatures. Field Crops Research 217, 150-166. doi: 10.1016/j.fcr.2017.12.014. 
Palita, P., Kudapa, H. Zougmore, R., Kholova, J., Whitbread A., Sharma M., Varshney, R., 2020. An integrated research framework combining genomics, systems biology, physiology, modelling and breeding for legume improvement in response to elevated $\mathrm{CO} 2$ under climate change scenario. Current Plant Biology. doi: 10.1016/j.cpb.2020.100149.

Peoples, M.B., Hauggaard-Nielsen, H., Huguenin-Elie, O., Jensen, E.S., Justes, E., Williams, M., 2019. Chapter 8 - The Contributions of Legumes to Reducing the Environmental Risk of Agricultureal Production. Agroecosystem Diversity, Reconciling Contemporary Agriculture and Environmental Quality. First Edition, pp. 123-143. doi: 0.1016/B978-0-12-811050-8.00008-X.

Peng, D., Chen, X., Yin, Y., Lu, K., Yang, W., Tang, Y., Wang, Z., 2014. Lodging resistance of winter wheat (Triticum aestivum L.): Lignin accumulation and its related enzymes activities due to the application of paclobutrazol or gibberellin acid. Field Crops Research 157 1-7. doi: 10.1016/j.fcr.2013.11.015.

Postma, J.A. and Lynch, J.P., 2012. Complementarity in root architecture for nutrient uptake in ancient maize/bean and maize/bean/squash polycultures. Annals of Botany 110: 521-534. doi: 10.1093/aob/mcs082.

Pristeri, A., Dahlmann, C., von Fragstein, P., Godding, M.J., Hauggaard-Nielsen, H., Kasyanova, E., and Monti, M., 2006. Yield performance of Faba bean- Wheat intercropping on spring and winter sowing in European organic farming systems. Poster at: Joint Organic Congress, Odense, Denmark, May 30-31, 2006.

Pretzsch, H., 2013. Facilitation and Competition in Mixed-Species Forests Analyzed Along an Ecological Gradient. Nova Acta Leopoldina NF 114, Nr. 391, 159-174.

Raseduzzman, Md. and Jensen, E.S., 2017. Does intercropping enhance yield stability in arable crop production? A meta-analysis. European Journal of Agronomy 91 25-33. doi: 10.1016/j.eja.2017.09.009.

Roth, F., Link, W., 2009. Selektion auf Frosttoleranz von Winterackerbohnen (Vicia faba L.): Methodenoptimierung und Ergebnisse Selection on freezing-tolerance of faba bean (Vicia faba L.): Improvement of methods and results. Lehr- und Forschungszentrum fuer Landwirtschaft, Raumberg-Gumpenstein. 60. Tagung der Vereinigung der Pflanzenzuechter und Saatgutkaufleute Oesterreiches 2009. 31-37.

Rötter, R.P., Appiah, M., Fichtler, E., Kersebaum, K.C., Trnka, M., Hoffmann, M.P., 2018. Linking modelling and experimentation to better capture crop impacts of agroclimatic extremes - A review. Field Crops Research 221 142-156. doi: 0.1016/j.fcr.2018.02.023.

Sass, O., and Stelling, D., 1990. Influence of different plant types on harvestability and yield of faba beans, Vicia faba L. Mutation breeding newsletter No. 35, (p. 44). International Atomic Energy Agency (IAEA): IAEA.

Schröder, D., Köpke, U., 2012. Faba bean (Vicia faba L.) intercropped with oil crops - a strategy to enhance rooting density and to optimize nitrogen use and grain production? Field Crop Res. 135, 74-81. doi: 10.1016/j.fcr.2012.07.007.

Siebrecht-Schöll, D., 2019. Breeding analysis of eight winter faba bean genotypes for mixed cropping with winter wheat, $\mathrm{PhD}$ thesis. http://hdl.handle.net/21.11130/00-17350000-0005-128E-7. 
Skinner, R.H., Gustine, D.L., Sanderson, M.A., 2004. Growth, Water Relations, and Nutritive Value of Pasture Species Mixtures under Moisture Stress. Crop Science, vol. 44, July-August. doi: 44:1361-1369.

Stomph, T., Dordas, C., Baranger, A., de Rijk, J., Dong, B., Evers, J., Gu, C., Li, L., Simon, J., Jensen, E.S., Wang, Q., Wang, Y., Wang, Z., Xu, H., Zhang, C., Zhang, L., Zhang, W.-p., Bedoussac, L., van der Werf, W., 2020. Chapter One - Designing intercrops for high yield, yield stability and efficient use of resources: Are there principles? Advances in Agronomy. Vol. 160, Issue 1, pp. 1-50. doi: 10.1016/bs.agron.2019.10.002.

Streit, J., Meinen, C., Nelson, W.C.D., Siebrecht-Schöll, D., Rauber, R., 2019. Above- and belowground biomass in a mixed cropping system with eight novel winter faba bean genotypes and winter heat using FTIR spectroscopy for root species discrimination. Plant and Soil. doi: 10.1007/s11104-018-03904-y.

Tsubo, M. and Walker, S., 2004. Shade effects of Phaseolus vulgaris L. Intercropped with Zea mays L. under Well-Watered Conditions. Journal of Agronomy \& Crop Science, Vol. 190, 168-176. doi: 10.1111/j.1439-037X.2004.00089.x.

Varshney, R.K., Thundi, M., Pandey, M.K., Tardieu, F., Ojiewo, C., Vadez, V., Whitbread, A.M., Siddique, K.H.M., Nguyen, H.T., Carberry, P.S., and Bergvinson, D., 2018. Accelerating genetic gains in legumes for the development of prosperous smallholder agriculture: integrating genomics, phenotyping, systems modelling and agronomy. Journal of Experimental Botany, Vol. 69, No. 13 pp. 3293-3312, 2018. doi: $10.1093 / \mathrm{jxb} / \mathrm{ery} 088$.

VDLUFA, 1991: Vdlufa Methodenhandbuch Band 1. Die Untersuchung von Böden. 4. Auflage, Vdlufa-Verlag, Darmstadt, Germany. 


\subsection{Appendix}

Table 4. Key dates for all three experimentation seasons.

\begin{tabular}{lllll}
\hline Site & Season & Sowing & Full-flowering & Harvest \\
\hline Reinshof & $2014-15$ & $2014-10-28$ & $2015-05-27$ & $2015-08-10$ \\
Deppoldshausen & $2014-15$ & $2014-10-29$ & $2015-06-04$ & $2015-08-20$ \\
\hline Reinshof & $2015-16$ & $2015-09-30$ & $2016-05-23$ & $2016-08-09$ \\
Deppoldshausen & $2015-16$ & $2015-10-05$ & $2016-06-06$ & $2016-08-16$ \\
\hline Reinshof & $2016-17$ & $2016-10-06$ & $2017-05-29$ & $2017-08-09$ \\
Deppoldshausen & $2016-17$ & $2016-10-11$ & $2017-06-07$ & $2017-08-17$ \\
\hline
\end{tabular}

Table 5. Yield means across seasons for the intercrop stands with the three highest wheat only yields (from top to bottom), followed by the intercrop stands with the three highest bean only yields for each site. Yields are means of the four blocks. Yields of each intercrop component (i.e., bean yield, wheat yield) are given separately, as well as total intercrop yield (bean+wheat yield). Results are ranked according to the yield of the focal crop.

\begin{tabular}{llllll}
\hline Site & Crop focus & Content & $\begin{array}{l}\text { Bean only } \\
\text { yield }\end{array}$ & $\begin{array}{l}\text { Wheat only } \\
\text { yield }\end{array}$ & $\begin{array}{l}\text { Total intercrop } \\
\text { yield }\end{array}$ \\
& & & & & \\
& & & & 2209 \\
& & & & & \\
Deppoldshausen & Wheat & Vf2-Ta3 & 1848 & 2117 & 4057 \\
Deppoldshausen & Wheat & Vf1-Ta3 & 1976 & 4092 \\
Deppoldshausen & Wheat & Vf5-Ta3 & 1991 & 2144 & 4135 \\
Deppoldshausen & Wheat & Mean & 1938 & 2157 & 4095 \\
Reinshof & Wheat & Vf2-Ta3 & 1691 & 3633 & 5324 \\
Reinshof & Wheat & Vf1-Ta3 & 1872 & 3106 & 4977 \\
Reinshof & Wheat & Vf6-Ta3 & 1728 & 2945 & 4674 \\
Reinshof & Wheat & Mean & 1764 & 3228 & 4992 \\
\hline Deppoldshausen & Bean & Vf3-Ta2 & 2589 & 1474 & 4063 \\
Deppoldshausen & Bean & Vf7-Ta1 & 2583 & 1284 & 3867 \\
Deppoldshausen & Bean & Vf8-Ta2 & 2561 & 1411 & 3971 \\
Deppoldshausen & Bean & Mean & 2578 & 1390 & 3967 \\
Reinshof & Bean & Vf7-Ta1 & 2853 & 1587 & 4440 \\
Reinshof & Bean & Vf3-Ta1 & 2786 & 1496 & 4282 \\
Reinshof & Bean & Vf3-Ta2 & 2707 & 2010 & 4716 \\
Reinshof & Bean & Mean & 2782 & 1698 & 4479 \\
\hline
\end{tabular}




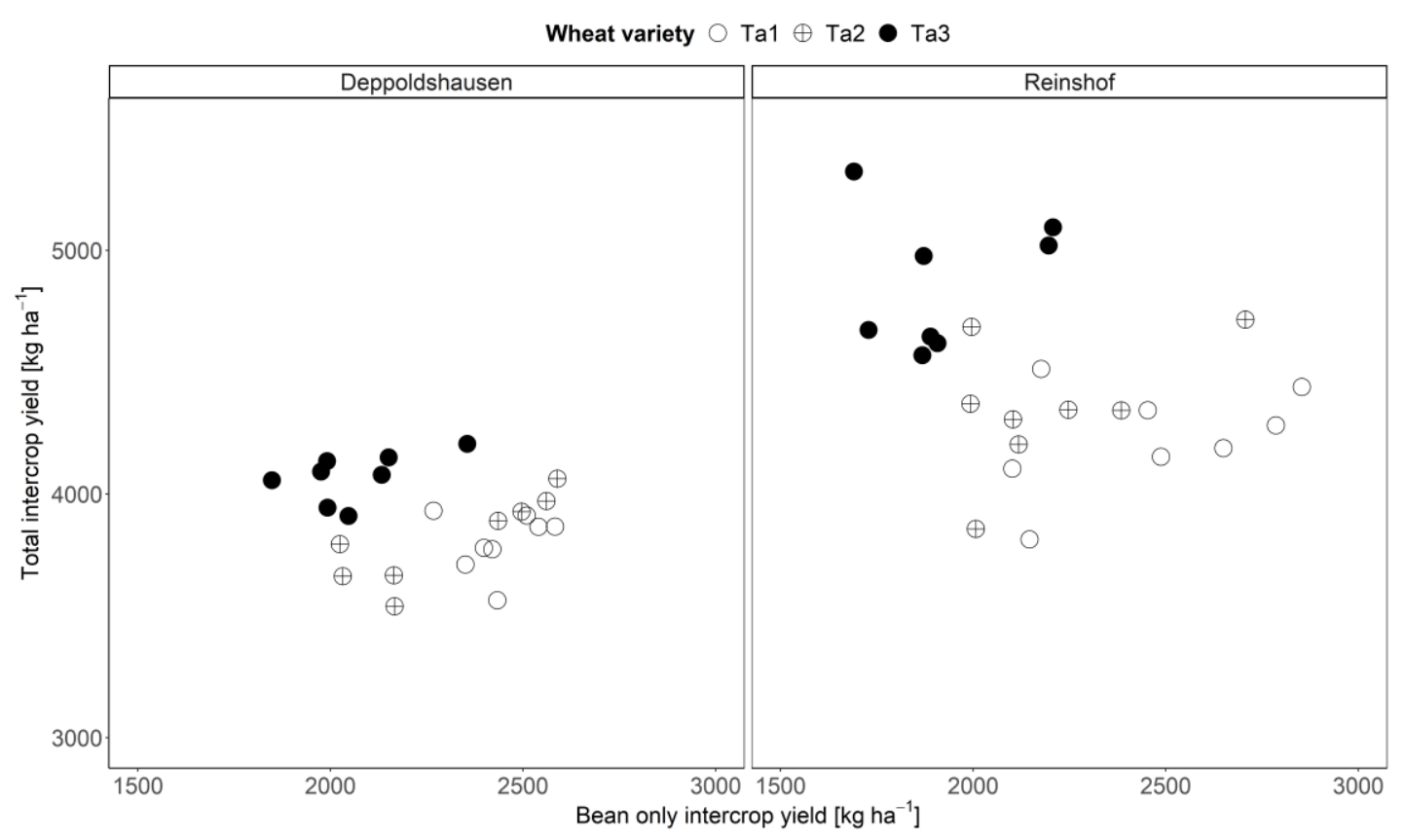

Figure 10. Bean only yield within intercrop stands and total intercrop (bean+wheat) yield ( $\left.\mathrm{kg} \mathrm{ha}^{-1}\right)$ for both sites, across all three seasons. Points represent the means of four blocks. While the eight faba bean genotypes are not shown, the three wheat varieties they are intercropped with are identified through shapes. 


\section{CHAPTER FIVE}

\section{General discussion}

Intercropping is perceived as a sustainable cropping practice to provide both high productivity and resource use efficiency. So far, however, literature mainly reports of case studies limited to few seasons or sites. However, the success of intercropping has been shown to depend on the site-specific exploitation of genotype by environment by management interaction $(\mathrm{GxExM})$. Intercropping is constrained by several factors. While farmers are mainly interested in the cereal components of intercrop systems, which are typically planted as monocultures, they may be reluctant to sacrifice cereal production for 'companion crops', such as legumes. The difficulties in planting and harvesting mixed crops and knowledge gaps in terms of management demands, such as fertiliser or fungicide input, need to be addressed. Moreover, it is clear that intercropping will only be adopted when niches are found in which they can demonstrate their benefits without to be too laborious. A comprehensive quantitative analysis that pin-points and identifies niches based on GxExM is lacking. This $\mathrm{PhD}$ study addresses this by investigating two field trials in different agro-ecological zones. The data collected as part of these trials has been used to evaluate the process-based model APSIM.

\subsection{Challenges of intercropping}

The complexity of intercropping systems makes them challenging to research. The cereal-legume intercrop systems investigated in this study consisted of two canopy layers, with the taller of the two capturing more of the direct solar radiation. While light interception was an important aspect of the intercrop systems studied, measuring it at various layers/ heights was not a core focus of the data collection, highlighting a knowledge gap that must be investigated. The assessment of root systems is also a factor that is rarely considered, due to the time and labour needed, as described by Streit et al. (2018). As discussed in chapter four of this thesis, genotype selection can also be crucial to the success of intercrop combinations, as well as basic management decisions such as the timing of sowing, i.e. whether crops that make up the intercrop system are sown simultaneously, or as relay crops, as was the case in Ngwira et al. (2012) where mucuna was sown six weeks after maize.

An important part of intercropping is the concept of complimentary resource use, whereby different crops require resources, such as nutrients and water, at different times, known as the 'mixing effect' (Hof-Kautz and Rauber, 2003). Bedoussac and Justes (2010) 
found the application of nitrogen only advantageous in winter wheat-pea systems after the pea had flowered, and that application before this hindered $\mathrm{N}_{2}$ fixation of the pea. Indeed, successful intercropping systems require a thorough understanding of such management aspects. Even for low-input smallholder farmers, the benefits of $\mathrm{N}_{2}$ fixation through monoculture legume integration are not straight forward and demand institutional support (van Vugt, Franke and Giller, 2018). While the issues that surround nutrient management could be simplified through the use of cereal-cereal intercropping (Li et al., 2006), it is clear that legumes need to be well integrated into agricultural systems the world over (Sennhenn et al., 2017; Watson et al., 2017; van Loon et al., 2018; Varshney et al., 2018) and should therefore play a key role in the development of future intercropping systems.

As a system, intercropping presents some interesting challenges, especially in an international context. While many of these challenges can be translated directly, for example, from a low-input subsistence system in India to a large farm in Germany, such as cultivar choice and density for instance, some aspects of intercropping differ depending on the scenario. The increased use of mechanised practices in modern agriculture has led to a simplification of system components (Lithourgidis et al., 2011; Vandermeer et al., 1998). While low-input systems may not have harnessed such practices and may be subsistence based, they remain somewhat flexible. Those that cultivate with modern methods however may not be as open to new practices that demand further investment. Integrating legumes into a farming system is often met with some caution, as they are generally seen to be less financially profitable than cereals (Nemecek et al., 2008). With the added requirement and therefore expense of machinery that can simultaneously process multi-species stands, highly mechanised farms may prefer to import legumes (Nemecek et al., 2008; Watson et al., 2017), unless legislation encourages otherwise (Randers, 2012). This has led to the development of integrated assessment frameworks that systematically evaluate sustainable development in agricultural landscapes. They incorporate environmental, economic, and social indicators, and highlight the notion that intercropping is not just a matter of biotic trade-offs (Sattler et al., 2010).

It is well-known that projected global populations are set to increase, which will demand more food production via sustainable means (Tilman et al., 2002; Trnka et al., 2014). As Alston, Beddow and Pardey (2009) show, the 1990s began to experience a clear slowing of yield progress compared to the 30 years that followed the green revolution. The challenges agriculture faces are clearly substantial and they must be met through the adoption of new ideas and technology. This in particular highlights why intercropping could become a modern, mechanised, and intensified system, not just converting marginal to 
productive land, but through efforts to tackle the challenges discussed above. As Fletcher et al. (2017) argue, farmers and machinery manufacturers will find solutions to overcome the challenges, with the knowledge and lessons learned simultaneously extrapolated to lowinput systems. This highlights the importance of work such as that of Hajjarpoor et al. (2018), who through upscaling modelling exercises identify yield gaps that could evoke the attention of the related industries that can support related research and development.

Our agricultural future lies in the culmination of marginal gains, which could consist of Global Positioning System (GPS) devices that allow for accurate inter-row sowing and management of multiple species - previously only manageable as part of the labour intensive systems of subsistence farmers (Robertson et al., 2016). Varshney et al. (2018) confirm the need for precision-based agronomy and use of intuitive computer-based applications. They emphasise the need to breed crops with certain systems and stakeholder demands in mind, as argued in chapter four, which found certain bean genotypes better suited to the intercropping system depending on site slection. This can also be seen in chapters two and three, which show a clear demand for sowing the cowpea intercrop later than the pearl millet to avoid it outcompeting the cereal. A major aspect of genetic gains discussed by Varshney et al. (2018) is the use of specific genetic material and timing certain production stages, and those of potential companion crops with resource availability. This is in particular where crop simulation models (CSM) can be of significant use. Moreover, research needs to develop a full and thorough understanding of intercrop systems and their various forms, which should be achieved through collaborative approaches (Varshney et al., 2018; Reynolds et al., 2018; Rötter et al., 2018a).

\subsection{Modelling intercropping}

Intercropping systems are complex and can vary tremendously depending on the environment in which they are cultivated. Their potential to contribute towards sustainable food security means we must develop efficient ways of assessing potential production. While CSMs should certainly play a key role in such efforts, they need to evolve with research needs and developments, including a range of genetic and environmental scenarios (Fletcher et al., 2017; Rötter et al., 2018a). The detailed empirical data collected as part of this thesis, covering two very different agro-climate zones, exemplifies this and the approach needed to develop CSMs to be able to help shape sustainable food production systems, and in this instance, offer key insights to multispecies systems and resource competition. Indeed, chapter three showed how model simulation performance declined with increased water supply. Simulations were more accurate under water stress, supporting 
the work of Rötter et al. (2018a) who report the majority of related work to focus on drought. Moreover, these insights need to be robust enough to be independent of environmental factors, highlighting the uniqueness of this thesis as key to future work.

Despite the merits of intercropping, it is yet to be fully understood. Various authors have highlighted the complexity that comes with multispecies cultivation, emphasising the notion that intercropping is highly site specific (chapter four), and dependent on environmental and socio-economic conditions (Li et al., 2006; Nelson et al., 2018). While general trends need to be established for framework development, a site- and scenariospecific approach to intercrop management is needed (Varshney et al., 2018), and while traditional experimentation is not sufficient alone, CSM could provide valuable information for plant breeders and farmers, as well as guiding research objectives and areas of improvement (Casadebaig et al., 2016; He et al., 2017; Akinseye et al., 2017). A recent indepth review by Rötter et al. (2018a) emphasised the need for CSMs to broaden their scope in terms of the crops and environmental scenarios they address, as well as being used in close collaboration with empirical studies. A review of empirical studies on the effects of specific weather extremes found the majority of peer reviewed research to focus on three staple crops, wheat (32\%), maize (22\%), and rice (18\%); almost three quarters of all publications (Rötter et al., 2018a). When looking at CSM studies, this figure rose to $89 \%$ for the same three crops (Rötter et al., 2018a).

Empirical intercropping studies that utilise crop models are rare, and while previous investigations have certainly contributed to the development of intercrop models (Tusbo et al., 2005; Brisson, et al., 2004), the topic failed to gather momentum in the past. Interest in intercropping has recently developed due to the need for increased agricultural productivity via sustainable means (Tilman et al., 2002; Trnka et al., 2014), as well as the advances made in CSMs in general. As an example of recent work, Chimonoya et al. (2016) assessed APSIM performance in simulating sorghum-cowpea intercropping systems in South Africa. While they looked at key management options, such as planting date and fertiliser application in relation to yield performance for several sites, detailed physiological information was missing. Brisson et al. (2004) highlighted light interception and root dynamics as key to intercrop model development, and chapters three and four of this thesis clearly support this, as well as demonstrating the importance of leaf and canopy dynamics. Moreover, detailed empirical data is needed to help understand complex systems like intercropping and develop the necessary tools (e.g. CSMs, model frameworks) to counter current and future agricultural challenges. 


\subsection{Field experimentation for crop model improvement}

Despite the scarcity of intercrop modelling studies, lessons can be learned from other modelling exercises. In an extensive review by Rötter et al. (2018a) very few studies were found to have investigated frost in terms of climate extremes, with most research having focused on drought scenarios. Insights from section 5.4 of this general discussion confirm the intricacies of CSM with extreme cold. In addition, chapter three identifies a knowledge gap in terms of modelling well irrigated crops under high temperatures. In a more regionand model-specific study, Gaydon et al. (2017) found APSIM to simulate rice production in several Asian sites well for certain parameters, with room for improvement for others. While APSIM was deemed a useful tool for Asian cropping systems research, conclusions also encouraged empirical research to investigate harsh environments (Gaydon et al., 2017).

This thesis addresses drought to some extent in both of its study sites, India and Germany. While the semi-arid conditions of India may be seen as the more obvious example of drought related research, the motivation behind the cultivation of winter crops in Germany is partly based on climate buffering (Olesen et al., 2011) and the avoidance of short-season spring sown crops - potentially at threat from erratic and variable springsummer conditions. Drought scenarios are also relative to their surrounding environments, which highlights the Deppoldshausen site, with its far shallower soil than that of Reinshof, as a potentially drought-prone location. In relation to below-ground biomass, section ' 5.4 Winter bean case study' confirms the need for the documentation of pre-overwintering plant physiology as crucial to fully understanding this system, as well as the level of snow cover through extremely cold (definition being crop dependent) periods of the season. As discussed in chapter four, the lodging events that occurred in the summer of 2016 highlight an additional aspect of experimentation that could be integrated into CSMs, as it can heavily impact the yield of certain crops (Peake et al., 2014; Vera et al., 2012). This case study is a prime example of how experimentation can be guided by CSMs as well as highlighting the level of detail required to fully understand crop production systems.

The use of CSMs to fully comprehend such systems forces researchers to think differently and ask questions that may not have been posed before. Trnka et al. (2014) conducted simulation experiments that not only highlighted the potentially negative impacts of multiple climate-based stresses on European wheat production, but the importance of developing diverse wheat varieties capable of coping with region- and season-specific threats. This emphasises the relevance of site-specific and precision agriculture for future production systems, as well as how CSMs highlight research gaps and how empirical experimentation can be guided by model generated hypotheses. The relevance of site- 
specific, precision agriculture is emphasised by Robertson et al. (2016) in a detailed assessment on Australian wheat yield improvement. The authors highlight the importance of syncing cultivation sites with appropriate agronomy (including new technology) $\mathrm{x}$ genetic interactions, whereby, for example, plant growth stages match climate windows that in turn minimise crop damage through the avoidance of temperature extremes. Such an approach is also reiterated by a recent review on accelerating genetic gains in legumes by Varshney et al. (2018).

While experimentation can be financially and time demanding, it can be made more goal-oriented and therefore efficient when combined with CSMs. It is strongly argued that model performance is equally dependent on the accuracy of empirical, data (Whitbread et al., 2018), so thorough and high quality data is a pre-requisite to CSM advancement (Carberry et al., 2009; Thornton et al., 2011).

Although CSMs have experienced great success within the last decade, their attention needs to broaden in terms of the crops, systems, and environments they capture. The combination of the two, empirical experimentation and CSMs, has the potential to fill knowledge gaps and streamline agricultural systems of the future (Keating et al., 2010). To add depth and completeness to this thesis and discussion, the following section will assess APSIM simulations of the experimental data presented in chapter four of this thesis.

\subsection{Winter bean case study: modelling winter faba bean in northern Germany - initial challenges and perspectives}

\subsubsection{Introduction}

The application of crop modelling is a tool to explore $\mathrm{GxMxE}$ interactions at various scales (Reynolds et al., 2018). While the majority of work is done testing and developing crop models, this short study presents some of the testing. Although preliminary, this helps to show the process of systematic investigation required for crop modelling studies. There are many interactions and variables that can be changed in a model framework such as APSIM and it is important to understand these aspects in order to guide adjustments efficiently. The green revolution largely aimed to maximise genotype output and modify the environment via management techniques, such as irrigation and fertiliser. While these strategies have been very productive in terms of yields, they do not necessarily focus on resource use efficiency, hence the call for renewed systems that are more eco-efficient (Keating et al., 2010). There is however a shift to improving the genotype and matching the environment and management (Varshney et al., 2018). 
Based on the field trial presented in chapter four of this thesis, this brief case study looks at the simulation of winter faba bean as a sole crop, as an initial attempt to understand the physiology of the crop and its interactions between trait expression and environment. To narrow down our investigation, we focus here on one bean genotype in order to hone in on and uncover these relationships. Little information is available for systems sown in autumn (Bedoussac and Justes, 2010), such as winter faba bean. Link (2010) describes how a major risk for autumn-sown crops is winter kill, although some success has been seen in winter-hardy faba bean germplasm (Arbaoui and Link, 2007; Flores et al., 2012; Landry et al., 2015; Landry et al., 2016). With this in mind, the field trial alone is clearly a unique experiment, enhanced through the use of APSIM.

The development of APSIM has had a strong focus on global drylands (Akinseye et al., 2017; Hoffmann et al., 2018; Whitbread et al., 2018), with limited work in temperate regions. However, the susceptibility of many legume crops to drought, combined with the predicted increases in climate variability (Rötter et al., 2015) has amplified the interest in winter sown crops. Climate buffering capabilities and more advanced biomass growth highlight the need to fully understand these systems. An improved understanding could help the much needed increase of intercropping attractiveness for farmers (Lemken et al., 2017).

\subsubsection{Materials and methods}

Site conditions, field experiment and sampling details can be found in the 'Materials and methods' section of chapter four. To run APSIM (Version 7.7), weather data was recorded and used as input for simulations (Holzworth et al., 2014). The same was done for the relevant soil parameter sections - data taken from soil profiles, as documented in chapter four (Table 1). The ILB1814 faba bean cultivar was chosen from the APSIM database and adapted in terms of phenological parameterisation within reasonable ranges to avoid overfitting the model.

\subsubsection{Preliminary results and discussion}

Initial observations were striking, in that all crops in the 2015-16 season died in January 2016. This was explained by an extreme cold event that occurred with minimum temperatures reaching $-20^{\circ} \mathrm{C}$ (Figure 1). As shown in chapter four, crop death did not occur in reality despite the extreme cold. This acts as an example of how CSM assists in the understanding of system functions. One idea was to simulate the influence snow cover had on crop stands, as a potential parameter that was not measured but could have helped crops 
survive extreme cold through its ability to insulate what lies beneath it. Figure 1 shows the implementation of a simple snow cover model developed by Trnka et al. (2010) called 'snowMAUS', which was tested on around 60 sites throughout Austria at varying altitudes. The model was developed for crop modellers and so requires little weather data input, using only maximum and minimum temperature and precipitation (Trnka et al., 2010). This was based on the premise that even when the air temperature above 0.5 metres of thick snow cover reaches below $-30^{\circ} \mathrm{C}$, the temperature of the soil surface will remain above $-10^{\circ} \mathrm{C}$, which is known to limit crop damage but assist the survival of soil-based pests and diseases (Lamb et al., 1985). As shown in Figure 1, snowMAUS developed around $1.5 \mathrm{~cm}$ of snow cover simultaneous to the extreme cold event. This led to the survival of all crops as illustrated in Figure 2.

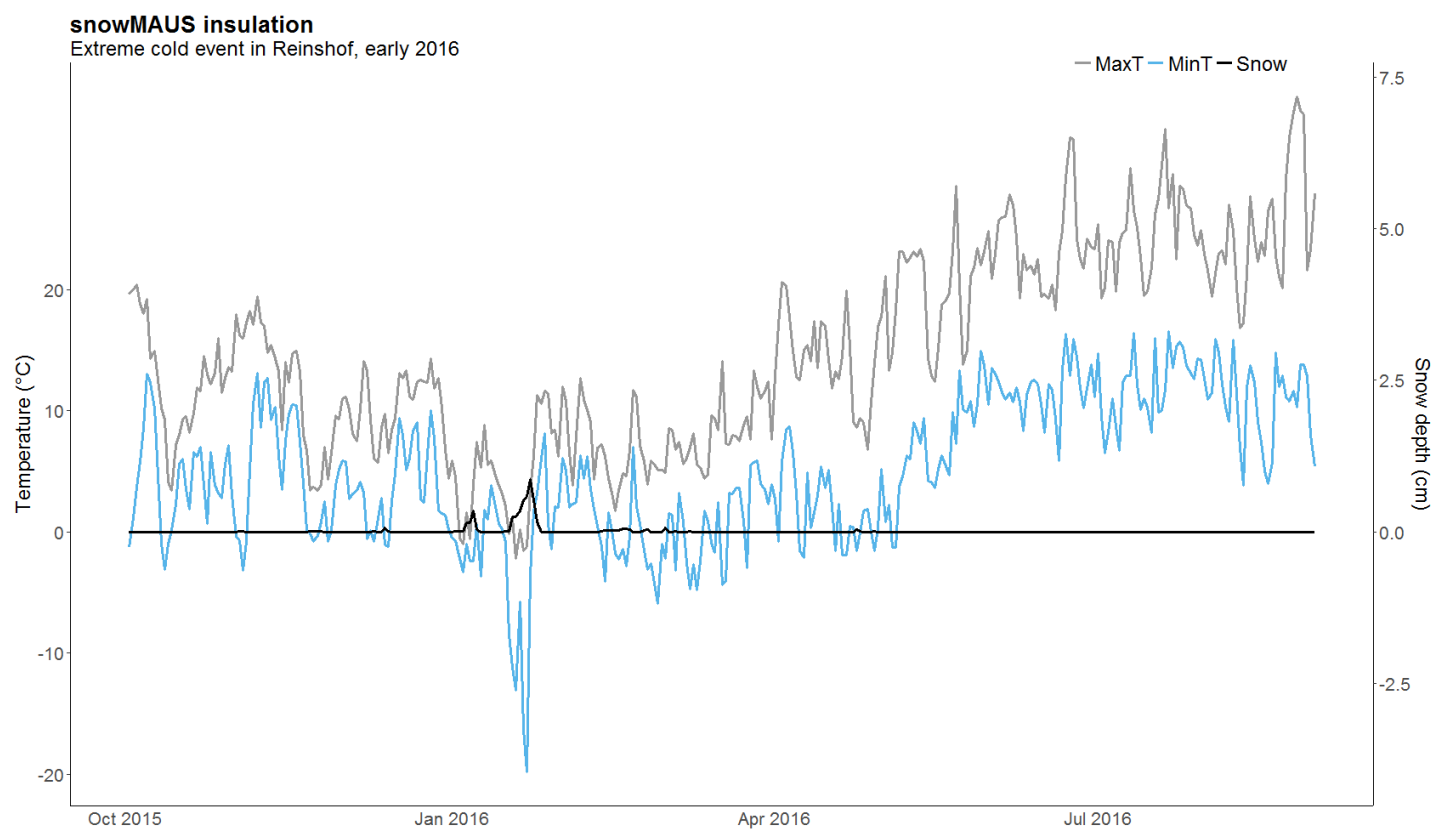

Figure 1. APSIM weather output from October 2015 to the end of July 2016 in Reinshof. Maximum and minimum temperatures $\left({ }^{\circ} \mathrm{C}\right)$ are shown with grey and blue lines, respectively, and use the left $y$-axis. The black line represents the amount of snow build-up $(\mathrm{cm})$ and uses the right y-axis. 


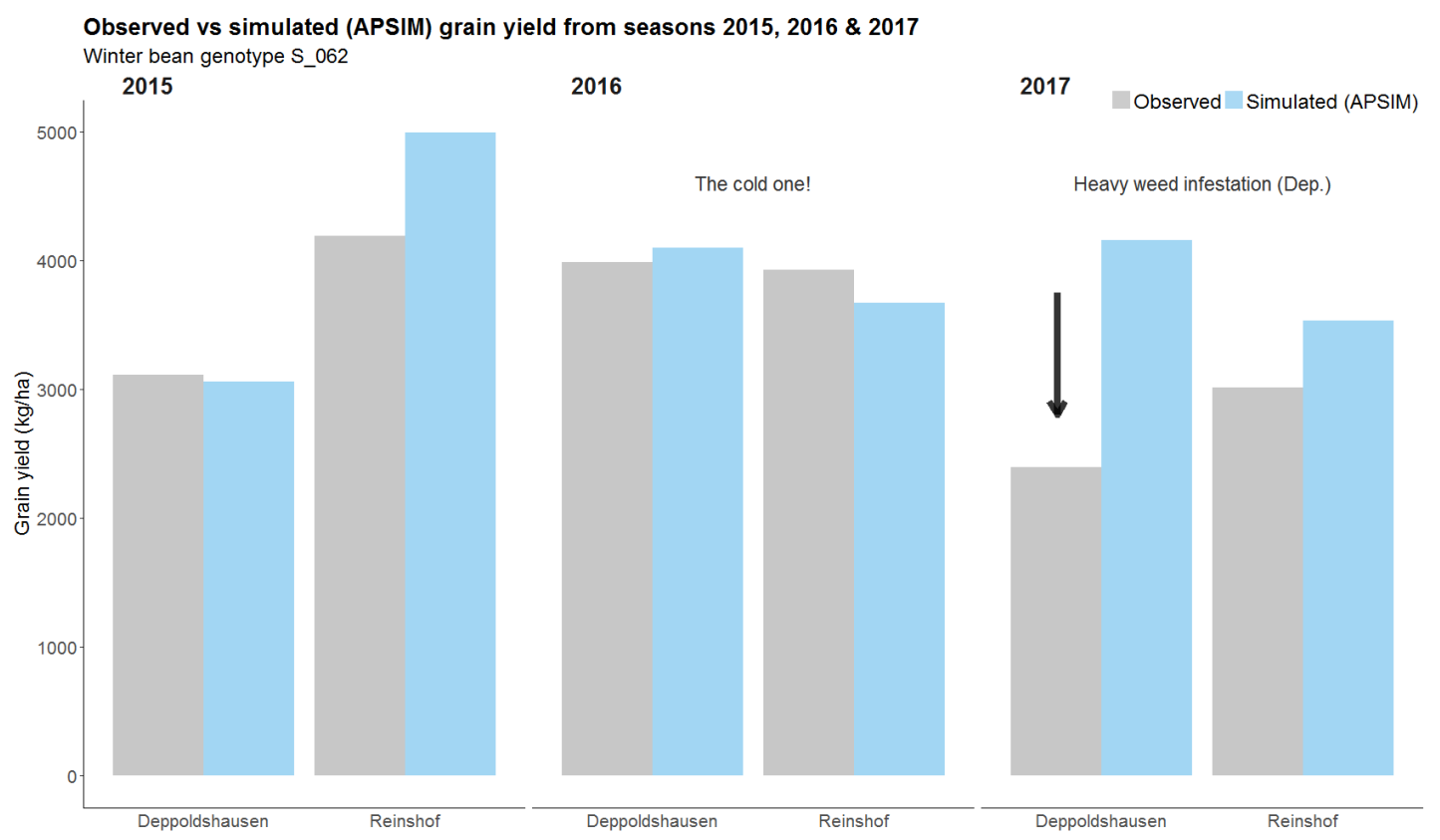

Figure 2. Grain yield $\left(\mathrm{kg} \mathrm{ha}^{-1}\right)$ of winter bean genotype A2 grown as a sole crop for all three seasons and both sites. Grey bars represent the observed yields, and the blue the yields simulated by APSIM. Annotations highlight events that are of interest and importance to the results shown.

Figure 2 shows the grain yields $\left(\mathrm{kg} \mathrm{ha}^{-1}\right)$ of the observed (grey) and simulated (blue) data for each of the three seasons and both IMPAC ${ }^{3}$ experimental field sites, focusing on the Vf2 (S_062) winter bean genotype. Although the original APSIM output experienced death for all crops in the 2015-16 season, the implementation of snowMAUS (Trnka et al., 2010), and subsequent development of insulating snow cover (Figure 1) evidently enabled crops to survive the harsh winter. Although chapter four highlights yield reducing lodging events in 2015-16, it must be noted that the genotype studied here was the one bean genotype that suffered the least from lodging (chapter four). As APSIM does not simulate lodging, the observed versus simulated yields in Figure 2 are therefore justifiable. Observed values in Deppoldshausen, 2016-17 were lower than those simulated by APSIM, due, according to field notes taken throughout the trial, to heavy weed infestations. This highlights the synergy and symbiotic relationship between CSM and empirical data, as both offer different, but key insights into our understanding of the system in question. 


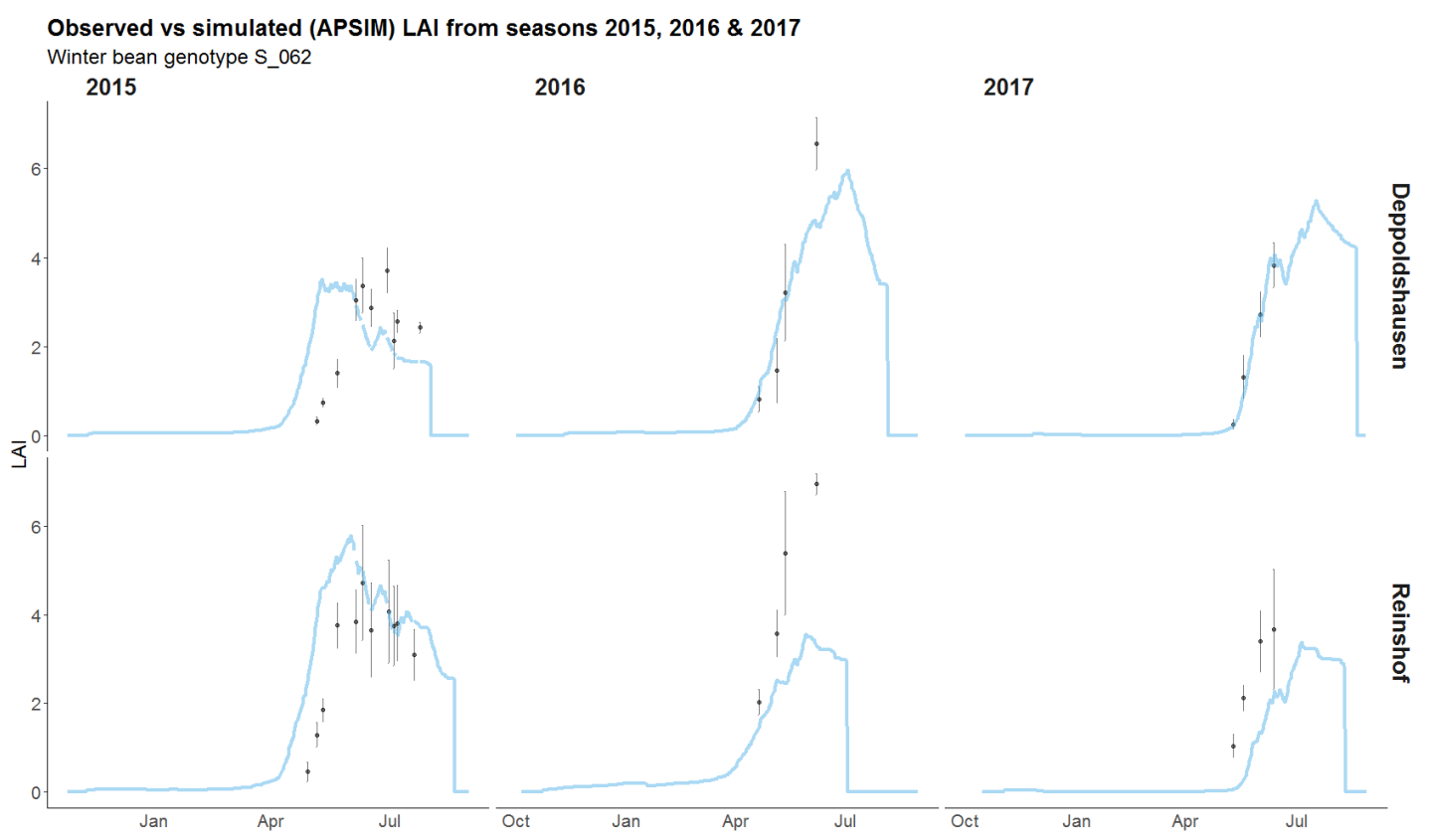

Figure 3. Leaf area index values of winter bean genotype Vf2 (S_062) grown as a sole crop for all three seasons and both sites. Grey points and error bars represent the observed yields, and the blue lines the LAI values simulated by APSIM over time, from April to mid-July of each season.

Figure 3 helps to understand the development of above-ground biomass over time and highlight key differences between seasons, in turn, guiding the next steps of this analysis. While simulated LAI development tends to fit most seasons and sites, observations are a great deal higher in Reinshof in the 2015-16 season (Figure 3). Simulated model output can help to investigate the cause of this yield-gap, uncovering aspects of this system that need to be considered for future experiments.

\subsubsection{Concluding remarks}

This case study demonstrates the need for a systems approach in order to fully comprehend empirical and CSM results and highlights practical examples of the symbiosis involved. While Reynolds et al. (2018) stress the importance of retaining simplicity in crop modelling, the outcome of this brief exercise promotes the documentation of simple but important aspects of field experimentation. The use of the simple snow cover model from Trnka et al. (2010) is also in-line with the recommendation of Reynolds et al. (2018) in retaining simplicity. Parameters to look at in the future are snow cover, lodging frequency and severity, and perhaps the early development of below- and above-ground biomass. Hypotheses would suggest the more developed the biomass before the overwintering period, the more at risk plants are of growing too tall and large in the spring season, leading to a higher chance of lodging. Model parameterisation could also be improved in terms of the insulating effects of snow cover through conducting frost chamber pot experiments. 


\subsection{Future crop model applications in intercropping}

The APSIM model was designed for farming systems, developed to simulate biophysical processes in particular related to climatic risk (Keating et al., 2003). While CSMs remain largely within research communities, the APSIM group continues to push for practical implementation, which is strongly linked to farmers and participatory research, as well as Australian agricultural production (Carberry et al., 2009; Dalgliesh, Foale and McCown, 2009; Hochman et al., 2009; McCown et al., 2009). A recent review on accelerating genetic gains in legumes for the development of smallholder agriculture emphasises the importance of such holistic approaches (Varshney et al., 2018).

The use of CSMs for plant breeding through ideotyping demonstrates their power and usefulness (Semenov et al., 2014; Rötter et al., 2015), and is something plant breeding programmes increasingly recognise as key to enhancing the efficiency of crop improvement programmes (Holzworth et al., 2015). An example of this in practice is seen in APSIMCanola, whereby Lilley et al. (2018) searched for the optimal start of flowering (OSF) considering the climatic stress factors frost, heat, and drought. Motivation came from a combination of observed and simulated yield data that suggested Australian canola production only achieved $50 \%$ of its potential (Lilley et al., 2018). The use of on-farm data and experimental trials, including detailed phenology measurements, led to improvements in the APSIM-Canola module, which was then used to simulate and test innovative strategies (Lilley et al., 2018). This process has resulted in the development of optimal management strategies that include cultivar choice, fertiliser applications, sowing dates and densities, and overall risk reduction (Lilley et al., 2018). This is of particular importance to crop industries such as the one that surrounds canola due to the fast turn-around of cultivars, as well as its economic importance (Lilley et al., 2018).

While the development of robust agricultural systems is imperative, relevance and the integration of research outcomes is key. The importance of connecting empirical experiments with modelling has been discussed, but this connection should also be incorporated into frameworks that consider and guide CSMs. Gaydon et al. (2017) highlight several farming practices that could be empirically investigated in order to improve APSIM, as do the studies presented in this thesis (chapter two; 5.4 of general discussion). However, the importance or relevance of cropping systems is often dependent on institutional and traditional economic and social policies, as well as infrastructure (local and further afield) (Keating et al., 2010), again, highlighting the relevance of holistic approaches to such multifaceted questions (Varshney, et al., 2018). An example of a highly relevant simulation study can be seen in Hajjarpoor et al. (2018), who explore the yield-gaps of Indian chickpea 
cropping systems. Such scaling studies can be challenging, especially when conducted across agro-climatic zones (Ewert et al., 2011), but could act as a robust testing method if intercropping was investigated in the same way.

Cropping systems assessment frameworks have been developed for various purposes, such as integrating legumes into cropping rotations (Reckling et al., 2016), or other agricultural production practices (Sattler et al., 2010). These can, but do not exclusively, include ecological (abiotic and biotic), economic (gross margin), and social (implementation acceptance) aspects. A key premise behind such frameworks is the importance of developing environmentally sustainable options without ignoring the needs of farmers (Sattler et al., 2010; Webber et al., 2014). With this in mind, as well as the abovedescribed need for detailed and thorough empirical data, the future of agricultural systems and related research (including intercropping) calls for collaboration across and within multiple disciplines.

\subsection{Challenges of developing a modelling framework for intercropping across agro- climatic zones}

Although there has been a great deal of CSM applications over the past decade, less emphasis has been put on their improvement (Holzworth et al., 2015), perhaps in part, due to debates over how complex they should be, and uncertainties over collaborative data use. Holzworth et al. (2015) raise the notion that CSMs have become agricultural models that incorporate a plethora of environmental topics spanning multiple disciplines, but a great deal remains to be improved, including the integration of specialty crops (Holzworth et al., 2015) and systems, such as intercropping and the crops studied in this thesis (except for wheat). This is indeed reiterated in the conclusions of Rötter et al. (2018b), who emphasise the progress made for three key cereal crops, wheat, maize, and rice. Rötter et al. (2018b) go on to stress the importance of improving the mechanistic understanding of the environment on plant growth in order to improve CMSs. This thesis discusses the relevance of intercropping and the use of CSMs for two very different case studies. Trends uncovered in these two experiments, especially with the drastically different climate scenarios they encapsulate, could provide reliable parameters on which to base an intercropping model framework. A framework that addresses intercropping as a system, applicable regardless of environment could streamline intercropping research and increase its efficiency. This would undoubtedly be directly transferable to practical applications, such as upscaling experimental findings, and enable intercropping systems to be more agile and risk reducing. 
Kahiluoto et al. (2014) describe how many CSMs are capable of simulating various bio-physical variables, and that they could be used to substantiate general statements concerning the development of resilience. The authors call for the definition of system boundaries and key variables that influence system resilience. The development of such boundaries is certainly a challenge, especially when considering socio-economic variables (Kahiluoto et al., 2014), such as the availability of certain resources, be it financially or land- or time-based for instance. Morton (2007) proposed a framework to study the impacts of climate change on smallholder systems. As an example, this sought to recognise their complexity and high location-specificity and incorporate key stressors on rural livelihoods that affect smallholder crops and animals at the levels of individual fields, bio-physical processes affecting production at a landscape, watershed or community level, as well as the impacts of climate change on human health and livelihoods. Indeed, Webber et al. (2014) state that modellers must be aware that not all technologies are available to all farmers, highlighting the importance of definition and specificity. This is echoed by Rötter et al. (2018b), who stress the need to integrate economic models in order to better reflect and understand production systems.

While a broad and holistic approach to systems development is clearly the way forward, this thesis is only able to look at biotic interactions in intercrop systems. As Savary et al. (2018) discuss, the aim here may be to be as simple as possible, which was their approach in the recently published article investigating the complex topic of modelling plant heath in relation to pests and diseases. This is also in-line with the conclusions of Reynolds et al. (2018), who emphasise the importance of model simplicity. The description of initial frameworks by Webber et al. (2014) is therefore fitting, who describe them as tools to help build research and management capacity, and provide a scientific scaffolding on which to unify scientists and stakeholders and inform land use decisions.

Based on the evidence presented and discussed in thesis, the need for a thorough and comprehensive understanding of intercropping systems is certainly justified, and therefore the development of an intercrop model framework. As Huth et al. (2014) state, modern modelling frameworks enable rapid model development for new agricultural systems, highlighting framework formation as a key method for the progression of intercropping as a topic and risk reducing strategy. Unique to this study is not only the detail at which the field experiments were conducted, but also the combination of two differing environments, semi-arid (India) and temperate (Germany). This offers the opportunity to investigate resource-based drivers, in terms of capture and or efficiency, for intercropping systems across agro-climatic zones, which is something that is demanded by the systems and CSM 
communities (Rötter et al., 2018a). Once a robust framework has been built, it can be integrated into larger, landscape-scale frameworks, incorporating the above-mentioned holistic approaches to tackle the most pressing food security and resource use efficiency questions.

Based on our findings (Table 1), an intercrop model framework must:

1. recognise the complexity and high environmental-specificity of intercropping systems, related to density, sowing date, pest, disease, weed, nutrient, and irrigation management, as well as genotype variation;

2. incorporate resource competition drivers for space and light, i.e. canopy architecture and implications for light interception and competition; belowground competition for water and nutrients closely related to rooting characteristics as well as field-derived soil water parameters;

3. study various climate change impacts separately and combined, such as drought $\mathrm{x}$ heat stress, or drought $\mathrm{x}$ heavy rain as examples (for more information on multiple stress interactions, see Rötter et al., 2018a);

4. incorporate simple models that aide extreme environment simulations (Trnka et al., 2010).

The following table (Table 1) highlights related key findings, research needs, and potential limitations. 
Table 1. Thesis highlights for intercrop model framework development, research needs and limitations.

\begin{tabular}{|c|c|c|c|}
\hline $\begin{array}{l}\text { Related } \\
\text { chapter }\end{array}$ & Key findings & Outlook and research needs & Limitations \\
\hline \multirow[t]{2}{*}{$\begin{array}{l}\text { Chapter } \\
\text { one }\end{array}$} & $\begin{array}{l}\text { Pearl millet and } \\
\text { cowpea production } \\
\text { possible under } \\
\text { extreme heat }\end{array}$ & $\begin{array}{l}\text { Test broad selection of genetic } \\
\text { material, climate extremes and } \\
\text { multiple environmental stress } \\
\text { interactions }\end{array}$ & $\begin{array}{l}\text { Identification of } \\
\text { climate-related stress } \\
\text { resilience needs at a } \\
\text { site-specific scale }\end{array}$ \\
\hline & $\begin{array}{l}\text { Intercropping did } \\
\text { not improve yield } \\
\text { productivity }\end{array}$ & $\begin{array}{l}\text { Test various intercrop } \\
\text { companion sowing dates, and } \\
\text { densities, for their impact on } \\
\text { intercrop performance }\end{array}$ & $\begin{array}{l}\text { Thorough } \\
\text { understanding of } \\
\text { genotype-specific } \\
\text { traits/ growth stages } \\
\text { needed }\end{array}$ \\
\hline \multirow[t]{3}{*}{$\begin{array}{l}\text { Chapter } \\
\text { two }\end{array}$} & $\begin{array}{l}\text { Model performance } \\
\text { declined with } \\
\text { increased water } \\
\text { supply }\end{array}$ & $\begin{array}{l}\text { Further calibrate extreme } \\
\text { scenarios; Measure soil water } \\
\text { dynamics and root exploration } \\
\text { patterns to determine how } \\
\text { various species exploit } \\
\text { available soil nutrients and } \\
\text { water }\end{array}$ & $\begin{array}{l}\text { Field-derived soil data } \\
\text { collection is time } \\
\text { demanding, therefore it } \\
\text { is vital to identify the } \\
\text { key parameters needed }\end{array}$ \\
\hline & \multirow[t]{2}{*}{$\begin{array}{l}\text { Plant height and } \\
\text { leaf dynamics are } \\
\text { crucial }\end{array}$} & $\begin{array}{l}\text { Measure heights and LAI } \\
\text { values for both intercrop } \\
\text { canopies }\end{array}$ & \multirow{2}{*}{$\begin{array}{l}\text { Empirical data } \\
\text { collection financially } \\
\text { and time demanding. A } \\
\text { strategic data- } \\
\text { acquisition plan is } \\
\text { required as part of } \\
\text { experimental design at } \\
\text { all levels }\end{array}$} \\
\hline & & $\begin{array}{l}\text { Expand length of season } \\
\text { captured for biomass } \\
\text { development (early and late } \\
\text { canopy structure, including } \\
\text { senescence) }\end{array}$ & \\
\hline \multirow[t]{4}{*}{$\begin{array}{l}\text { Chapter } \\
\text { three }\end{array}$} & \multirow[t]{2}{*}{$\begin{array}{l}\text { Light competition } \\
\text { dictates dominant } \\
\text { intercrop }\end{array}$} & $\begin{array}{l}\text { Measure heights and LAI } \\
\text { values for both intercrop } \\
\text { canopies }\end{array}$ & \multirow{2}{*}{$\begin{array}{l}\text { Development of time } \\
\text { efficient methodology } \\
\text { that encapsulates } \\
\text { multiple elements of } \\
\text { canopy architecture }\end{array}$} \\
\hline & & $\begin{array}{l}\text { Measure horizontal canopy } \\
\text { spread }\end{array}$ & \\
\hline & $\begin{array}{l}\text { Lodging is a key } \\
\text { risk to winter crops } \\
\text { under high yielding } \\
\text { conditions }\end{array}$ & $\begin{array}{l}\text { Continue documentation of } \\
\text { 'failed'/ poor performing } \\
\text { seasons }\end{array}$ & \multirow[t]{2}{*}{$\begin{array}{l}\text { Need for inter- } \\
\text { disciplinary, } \\
\text { streamlined } \\
\text { methodology }\end{array}$} \\
\hline & $\begin{array}{l}\text { Environmental- } \\
\text { specificity is crucial }\end{array}$ & $\begin{array}{l}\text { Document 'niche climate } \\
\text { parameters', like snow cover }\end{array}$ & \\
\hline
\end{tabular}


As Lüdeling et al. (2016) highlight, key decisions in modelling investigations revolve around which basic processes to retain, and which to ignore. Key to their conclusions is the wide-reaching accessibility of model frameworks, as this could expand related communities, collaboration, and development (Lüdeling et al., 2016). To identify these processes, functional relationships should be identified, which can be pinpointed through sensitivity analyses (Baudron et al., 2015). This could be combined with the development of a conceptual model based on known processes (Muetzelfeldt and Sinclair, 1993). While the above-mentioned methods are valid, the results presented in this thesis proved APSIM's ability to capture the interactions of both intercropping systems with a decent level of accuracy and efficiency (chapter three). With this in mind, an advanced intercrop model framework would be better achieved through identifying and adding the major lessons learned from such detailed intercrop data sets, so that these can enhance the suitability of crop model frameworks in simulating intercropping. Recent research that has made significant advancements on this topic can be seen in the Bispecific Intercrop System WATer Stress dynamic model (BISWAT), a low-data demanding water balance model designed to simulate multi-crop stand dynamics for a range of agro-ecosystems under various conditions (Bertrand et al., 2018). The authors discuss how the lack of data used, which consisted of five contrasting sites, was indeed a drawback that may lead to uncertain representations of processes of minor importance for the situations tested, but may be key for certain scenarios (Bertrand et al., 2018). This highlights the need to first develop an extensive data base covering various crops, genotypes, management strategies (e.g. densities), and environments for the development of a robust and practical intercrop model framework. Bertrand et al. (2018) also stressed the importance of reliable, empirical data, particularly related to soil water, which supports the field work conducted as part of this thesis (chapter two and four).

Essentially, such a model framework must incorporate the drivers behind the definitions of 'intercrop success', which certainly needs to be clearly defined for each scenario. This highlights the need for social and economic model incorporation, or 'linking', as 'intercrop success' can be dictated and defined by natural, economic, or social demands, as well as a combination of them. The identification of these drivers helps answer a key question for intercropping research: under what conditions is intercropping risk reducing or enhancing?

The results of this thesis highlight two highly influential phenological aspects upon which an intercrop model framework can be based, namely canopy height, and LAI, encapsulated in terms of resource use efficiency as radiation capture. Not only are these 
parameters directly linked to risks such as lodging, but their timing and extent of expression dictate the dominance of the intercrop components. This dominance, in turn, can decide whether the intercrop combination is 'successful' or not, which is, as discussed, reliant on factors that are external to biological interactions alone.

\subsection{Conclusions}

An initial objective of this thesis aimed to develop our understanding of GxExM interactions of intercrop systems. This would in turn lead to the ability to determine which conditions enhance intercrop yield productivity, and under which conditions is intercropping more resource use efficient. To investigate this, two intercrop experiments were analysed (chapters two and four), which consisted of detailed data that encompassed typical agronomic aspects such as yield, as well as soil profiles, site-specific climate data, and thorough physiological measurements. This study is somewhat unique, as it attempts to compare a semi-arid (chapter two) and a temperate environment (chapter four).

Through the results of the two experiments, it becomes clear that competition for light is a key resource battle that intercrop companions endure, regardless of environment or specie. This conclusion is supported by the modelling experiment presented in chapter three, which showed how pearl millet and total intercrop yields increased when the cereal was taller than the companion legume intercrop. Field trial observations from chapter four's temperate winter bean-wheat intercrop system emulated the simulation study findings from chapter three, i.e. that total intercrop yield was driven by the cereal, which must be intercropped with a legume that allows it to dominate the canopy and light capture. Additional 'niche measurements' specific to intercrop canopies are key for future investigations and the development GxExM specific intercrop systems. These aim to capture the differences between intercrop component heights and the level of shade cast from the taller to the shorter component, as well as horizontal light competition, especially at early stages of growth.

In addition, this thesis highlights the difficulty of simulating climate extremes, exemplified by the long, winter inclusive season of the German field trial. While APSIM certainly proved reliable for intercrop modelling, the India field-data was easier to simulate, due to the overwintering period and the overall season length of the German experiment (chapter four). Despite this, it is reassuring to report on the success of pragmatic interventions, such as modelling snow cover with basic climate data to overcome this hurdle (5.4 of general discussion). Linked to this is an aspect detailed systems research demands, 
which is the importance of plant development stage timing for resource use efficiency, as well as thorough documentation of plant growth stages.

The final chapter discusses how chapters two, three and four contribute to the need to investigate the interrelations between using field experimentations to improve CSMs, and CSMs for the identification, definition, and development of field trial design. Intercropping research should follow suit in order to be relevant for global agendas, which is pressing due to a renewed interest in the potential of these systems. The future of this area of research must streamline its complexities and incorporate the impacts of various, and perhaps simultaneous environmental and economic influences. A holistic framework is called for, meaning open collaboration, for example knowledge sharing, including the provision of feedback between farmers, natural, economic, and social scientists, as well as an aim to realise a robust understanding of multispecies systems for practical applications.

\section{$5.8 \quad$ References}

Akinseye, F.M., Adam, M., Agele, S.O., Hoffmann, M.P., Traore, P.C.S., Whitbread, A.M., 2017. Assessing crop model improvements through comparison of sorghum (sorghum bicolor L. moench) simulation models: A case study of West African varieties. F. Crop. Res. 201, 19-31. doi: 10.1016/j.fcr.2016.10.015.

Alston, J.M., Beddow, J.M., and Pardey, P.G., 2009. Agricultural Research, Productivity, and Food Prices in the Long Run. Science 325 (5945), 1209-1210. doi: 10.1126/science. 1170451 .

Arbaoui, M. and Link, W., 2007. Effect of hardening on frost tolerance and fatty acid composition of leaves and stems of a set of faba bean (Vicia faba L.) genotypes. Euphytica (2008) 162:211-219. doi: 10.1007/s10681-007-9521-4.

Baudron, F., Delmotte, S., Corbeels, M., Herrera, J.M., Tittonell, P., 2015. Multi-scal tradeoff analysis of cereal residue use for livestock feeding vs. soil mulching in the MidZambezi Valley, Zimbabwe. Agric. Syst. 134. 97-106. doi: 10.1016/j.agsy.2014.03.002.

Bedoussac, L., and Eric, J., 2010. The efficiency of a durum wheat-winter pea intercrop to improve yield and wheat grain protein concentration depends on $\mathrm{N}$ availability during early growth. Plant and soil, vol. 330, Issue 1-2, pp. 19-35. doi: 10.1007/s11104-009-0082-2.

Bertrand, N., Roux, S., Forey, O., Guinet, M., Wery, J., 2018. Simulating plant water stress dynamics in a wide range of bi-specific agrosystems in a region using the BISWAT model. European Journal of Agronomy 99 (2018) 116-128. doi: 10.1016/j.eja.2018.06.001.

Brooker, R.W., Bennett, A.E., Cong, W.F., Daniel, T.J., George, T.S., Hallett, P.D., Hawes, C., Iannetta, P.P.M., Jones, H.G., Karley, A.J., Li, L., McKenzie, B.M., Pakemann, J., Paterson, E., Schöb, C., Shen, J., Squire, G., Watson, C.A., Zhang, C., Zhang, F., Zhang, J., and White, P.J., 2015. Improving intercropping: a synthesis or research in 
agronomy, plant physiology and ecology. New Phytologist (2015) 206: 107-117. doi: 10.1111/nph.13132.

Brisson, N., Bussiere, F., 2004. Adaptation of the crop model STICS to intercropping. Theoretical basis and parameterisation. Agronomie 24, 409-421. doi: 10.1051/agro.

Casadebaig, P., Zheng, B., Chapman, S., Huth, N., Faivre, R., Chenu, K., 2016. Assessment of the potential impacts of wheat plant traits across environments by combining crop modeling and global sensitivity analysis. PLoS One 11, 1-27. doi: 10.1371/journal.pone.0146385.

Carberry, P.S., Hochman, Z., Hunt, J.R., Dalgliesh, N.P., McCown, R.L., Whish, J.P.M., Robertson, M.J., Foale, M.A., Poulton, P.L., and van Rees, H., 2009. Re-inventing model-based decision support with Australian dryland farmers. 3. Relevance of APSIM to commercial crops. Crop \& Pasture Science, 2009, 60, 1004-1056. doi: 10.1071/CP09052.

Chimonyo, V.G.P., Modi, A.T., Mabhaudhi, T., 2016. Simulating yield and water use of a sorghum-cowpea intercrop using APSIM. Agric. Water Manag. 177, 317-328. doi: 10.1016/j.agwat.2016.08.021.

Dalgliesh, N.P., Foale, M.A., and McCown, R.L., 2009. Re-inventing model-based decision support with Australian dryland farmers. 2. Pragmatic provision of soil information for paddock-specific simulation and farmer decision making. Crop \& Pasture Science, 2009, 60, 1031-1043. doi: 10.1071/CP08459.

Ewert, F., van Ittersum, M.K., Heckelei, T., Therond, O., Bezlepkina, I., Andersen, E., 2011. Scale changes and model linking methods for integrated assessment of agrienvironmental systems. Agriculture, Ecosystems and Environment. Volume 142, Issue 1-2, July 2011, Pages 6-17. doi: 10.1016/j.agee.2011.05.016.

Fletcher, A.L., Kirkegaard, J.A., Peoples, M.B., Robertson, M.J., Whish, J., and Swan, A.D., 2017. Prospects to utilise intercrops and crop variety mixtures in mechanised, rain-fed, temperate cropping systems. Crop \& Pasture Science, 2016, 67, 1252-1267. doi: $10.1071 / \mathrm{CP} 16211$.

Flores, F., Nadal, S., Solis, I., Winkler, J., Sass, O., Stoddard, F.L., Link, W., Raffiot, B., Muel, F. and Rubiales, D., 2012. Faba bean adaptation in autumn sowing under European climates. Agron. Sustain. Dev. (2012) 32:727-734. doi: 10.1007/s13593012-0082-0.

Gaydon, D.S., Balwinder-Singh, Wang, E., Poulton, P.L., Ahmad, B., Ahmed, F., Akhter, S., Ali, I., Amarasingha, R., Chaki, A.K., Chen, C., Choudhury, B.U., Darai, R., Das, A., Hochman, Z., Horan, H., Hosang, E.Y., Kumar, P.V., Khan, A.S.M.M.R., Laing, A.M., Liu, L., Malaviachichi, M.A.P.W.K., Mohapatra, K.P., Muttaleb, M.A., Power, B., Radanielson, A.M., Rai, G.S., Rashid, M.H., Rathanayake, W.M.U.K., Sarker, M.M.R., Sena, D.R., Shamim, M., Subash, N., Suriadi, A., Suriyagoda, L.D.B., Wang, G., Wang, J., Yadav, R.K., Roth, C.H., 2017. Evaluation of the APSIM model in cropping systems of Asia. F. Crop. Res. 204, 52-75. doi: 10.1016/j.fcr.2016.12.015.

Hajjarpoor, A., Vadez, V., Soltani, A., Gaur, P., Whitbread, A., Babu, D.S., Gumma, M.K., Diancoumba, M., Kholová, J., 2018. Characterisation of the main chickpea cropping systems in India using a yield gap analysis approach. Field Crops Research 223 (2018) 93-104. doi: 10.1016/j.fcr.2018.03.023. 
He, D., Wang, E., Wang, J., Lilley, J.M., 2017. Genotype $\times$ environment $\times$ management interactions of canola across China: A simulation study. Agric. For. Meteorol. 247, 424-433. doi: 10.1016/j.agrformet.2017.08.027.

Hochman, Z., van Rees, H., Carberry, P.S., McCown, R.L., Gartmann, A., Holzworth, D., van Rees, S., Dalgliesh, N.P., Long, W., Peake, A.S., Poulton, P.L., and McClelland, T., 2009. Re-inventing model-based decision support with Australian dryland farmers. 4. Yield Prophet ${ }^{\circledR}$ helps farmers motitor and manage crops in a variable climate. Crop \& Pasture Science, 2009, 60, 1057-1070. doi: 10.1071/CP09020.

Hof-Kautz, C., and Rauber, R., 2003. Growing crop mixtures in organic farming; in German. Published by the National Program for Organic Farming at the Federal Institute for Agriculture and Human Nutrition, Bonn and Göttingen, 55 pages; ISBN 3-00-011733-4.

Hoffmann, M.P., Odhiambo, J.J.O., Koch, M., Ayisi, K.K., Zhao, G., Soler, A.S., Rötter, R.P., 2018. Exploring adaptations of groundnut cropping to prevailing climate variability and extremes in Limpopo Province, South Africa. F. Crop. Res. 219, 113. doi: 10.1016/j.fcr.2018.01.019.

Holzworth, D.P., Huth, N.I., Peter, G., Zurcher, E.J., Herrmann, N.I., McLean, G., Chenu, K., Oosterom, E.J. Van, Snow, V.O., Murphy, C., Moore, A.D., Brown, H., Whish, J.P.M., Verrall, S., Fainges, J., Bell, L.W., Peake, A.S., Poulton, P.L., Hochman, Z., Thorburn, P.J., Gaydon, D.S., Dalgliesh, N.P., Rodriguez, D., Cox, H., Chapman, S., Doherty, A., Teixeira, E., Sharp, J., Cichota, R., Vogeler, I., Li, F.Y., Wang, E., Hammer, G.L., Robertson, M.J., Dimes, J.P., Whitbread, A.M., Hunt, J., Rees, H. Van, Mcclelland, T., Carberry, P.S., Hargreaves, J.N.G., MacLeod, N., Mcdonald, C., Harsdorf, J., Wedgwood, S., Keating, B.., DeVoil, P.G., van Oosterom, E.J., van Rees, H., 2014. APSIM - Evolution towards a new generation of agricultural systems simulation. Environ. Model. Softw. 62, 327-350. doi: 10.1016/j.envsoft.2014.07.009.

Holzworth, D.P., Snow, V., Janssen, S., Athanasiadis, I.N., Donatelli, M., Hoogenboom, G., White, J.W., Thorburn, P., 2015. Agricultural production systems modelling and software: Current statuts and future prospects., Environmental Modelling \& Software 72 (2015) 276-286. doi: 10.1016/j.envsoft.2014.12.013.

Huth, N.I., Banabas, M., Nelson, P.N., Webb, M.J., 2014. Development of an oil palm cropping systems model: Lessons learned and future directions. July 2014, Environmental Modelling and Software 62:411-419. doi: 10.1016/j.envsoft.2014.06.021.

Kahiluoto, H., Rötter, R., Webber, H., Ewert, F., 2014. The role of modelling in adapting and building the climate resilience of cropping systems. In: Fuhrer, J., Gregory, P. (Eds). Climate Change Impact and Adaptation in Agricultural Systems. CABI.

Keating, B., Carberry, P.S., Hammer, G.L., Probert, M.E., Robertson, M.J., Holzworth, D.P., Huth, N.I., Hargreaves, J.N.G., Meinke, H., Hochman, Z., McLean, G., Verburg, K., Snow, V.O., Dimes, J.P., Silburn, M., Wang, E., Brown, S., Bristow, K.L., Asseng, S., Chapman, S.C., McCown, R.L., Freebairn, D., Smith, C., 2003. An overview of APSIM, a model designed for farming systems simulation. Eur. J. Agron. 18, 267-288. doi: 10.1016/S1161-0301(02)00108-9. 
Keating, B. A., Carberry, P.S., Bindraban, P.S., Asseng, S., Meinke, H., Dixon, J., 2010. Eco-efficient agriculture: concepts, challenges and opportunities. Crop Science 50, 109-119. doi: 10.2135/cropsci2009.10.0594.

Lamb, R.J., Turnock, W.J., Hayhoe, H.N., 1985. Winter survival and outbreaks of Berthaarmy worm, Mamestata configurata (Lepidoptera, Noctuidae) on Canola. Can. Entomol. 17, 727-736. doi: 10.4039/Ent117727-6.

Landry, E.J., Lafferty, J.E., Coyne, C.J., Pan, W.L., and Hu, J., 2015. Registration of Four Winter-Hardy Faba Bean Germplasm Lines for Use in Winter Pulse and Cover Crop Development. Journal of Plant registrations 9:367-370 (2015). doi: 10.3198/jpr2014.12.0087crg.

Landry, E.J., Coyne, C.J., McGee, R.J., and Hu, J., 2016. Adaptation of Autumn-Sown Faba Bean Germplasm to Southeastern Washington. Agronomy Journal, Vol. 108, Issue 1. doi: 10.2134/agronj2015.0028.

Lemken, D., Spiller, A., and von Mayer-Höfer, M., 2017. The case of legume-cereal crop mixtures in modern agriculture and the transtheoretical model of gradual adoption. Ecologial Economics 137 (2017): 20-28. doi: 10.1016/j.ecolecon.2017.02.021.

Li, L., Sun, J.H., Zhang, F., Guo, T., Bao, X., Smith, F.A., Smith, S.E., 2006. Root distribution and interactions between intercropped species. Oecologia 147, 280-290. doi: 10.1007/s00442-005-0256-4.

Link, W., Balko, C. and Stoddard, F.L., 2010. Winter hardiness in faba bean: Physiology and breeding. Field Crops Research 115 (2010) 287-296. doi: 10.1016/j.fcr.2008.08.004.

Lilley, J., Goward, L., Whish, J., Meier, E., McBeath, T., Kirkegaard, J., 2018. APSIMCanola: A physiological context to improve canola agronomy. Conference preceedings: AusCanola 2018, 20th Australian Research Assembly on Brassicas, Perth.

Lithourgidis, A.S., Dordas, C.A., Damalas, C.A., Vlachostergios, D.N., 2011. Annual intercrops: an alternative pathway for sustainable agriculture. Review article. Australian Journal of Crop Science 5, 369-410.

van Loon, M.P., Deng, N., Grassini, P., Rattalino Edreira, J.I., Wolde-meskel, E., Baijukya, F., Marrou, H., van Ittersum, M.K., 2018. Prospect for increasing grain legume crop production in East Africa. European Journal of Agronomy 101 (2018) 140-148. doi: 10.1016/j.eja.2018.09.004.

Lüdeling, E., Smethurst, P.J., Baudron, F., Bayala, J., Huth, N.I., van Noordwijk, M., Ong, C.K., Mulia, R., Lusiana, B., Muthuri, C., Sinclair, F.L., 2016. Field-scale modelling of tree-crop interactions: Challenges and development needs. Agricultural Systems 142 (2016) 51-69. doi: 10.1016/j.agsy.2015.11.005.

McCown, R.L., Carberry, P.S., Hochman, Z., Dalgliesh, N.P., and Foale, M.A., 2009. Reinventing model-based decision support with Australian dryland farmers. 1. Changing intervention concepts during 17 years of action research. Crop \& Pasture Science, 2009, 60, 1017-1030. doi: 10.1071/CP08455.

Morton, J.F., 2007. The impact of climate change on smallholder and subsistence agriculture. PNAS December 11, 2017, vol. 104, no. 50. doi: 10.1073/pnas.0701855104. 
Muetzefeldt, R.I., Sinclair, F.L., 1993. Ecological modelling of agroforestry systems. Agrofor. Abstr. 6 (4), 207-247.

Nelson, W.C.D., Hoffmann, M.P., Vadez, V., Roetter, R.P., Whitbread, A.M., 2018. Testing pearl millet and cowpea intercropping systems under high temperatures. F. Crop. Res. 217, 150-166. doi: 10.1016/j.fcr.2017.12.014.

Nemecek, T., von Richthofen, J.S., Dubois, G., Casta, P., Charles, R. and Pahl, H., 2008. Environmental impacts of introducing grain legumes into European crop rotations. Europ. J. Agronomy 28 (2008) 380-393. doi: 10.1016/j.eja.2007.11.004.

Ngwira, A.R., Aune, J.B., Mkwinda, S., 2012. On-farm evaluation of yield and economic benefit of short term maize legume intercropping systems under conservation agriculture in Malawi. Field Crops Research 132 (2012) 149-157. doi: 10.1016/j.fcr.2011.12.014.

Olesen, J.E., Trnka, M., Kersebaum, K.C., Skjelvag, A.o:, Seguin, B., Peltonen-Sainio, P., Rossi, F., Kozyra, J., Micale, F., 2011. Impacts and adaptation of European crop production systems to climate change. European Journal of Agronomy 34 (2011) 96-112. doi: 10.1016/j.eja.2010.11.003.

Peake, A.S., Huth, N.I., Carberry, P.S., Raine, S.R., Smith, R.J., 2014. Quantifying potential yield and lodging-related yield gaps for irrigated spring wheat in sub-tropical Australia. Field Crops Research 158 (2014) 1-14. doi: 10.1016/j.fcr.2013.12.001.

Randers, J., 2012. A Global Forecast for the next forty years, 2052. A report to the Club of Rome. Commemorating the 40th Anniversary of the Limits to Growth. Chelsea Green Publishing.

Reckling, M., Hecker, J.-M., Bergkvist, G., Watson, C.A., Zander, P., Schläfke, N., Stoddard, F.L., Eory, V., Topp, C.F.E., Marire, J., Bachinger, J., 2016. A cropping system assessment - Evaluating effects of introducing legumes into crop rotations. European Journal of Agronomy 76 (2016) 186-197. doi: 10.1016/j.eja.2015.11.005.

Reynolds, M., Kropff, M., Crossa, J., Koo, J., Kruseman, G., Milan, A.M.m Rutkoski, J., Schulthess, U., Balwinder-Singh, Sonder, K., Tonnang, H., and Vadez, V., 2018. Role of modelling in International Crop Research: Overview and some case studies. Agronomy 2018, 8, 291; doi: 10.3390/agronomy8120291.

Robertson, M., Kirkegaard, J., Rebetzke, G., Llewellyn, R., and Wark, T., 2016. Prospects for yield improvement in the Australian wheat industry: a perspective. Food and Energy Security 2016, 5(2):107-122. doi: 10.1002/fes3.81.

Rötter, R.P., Tao, F., Höhn, J.G., Palosuo, T., 2015. Use of crop simulation modelling to aid ideotype design of future cereal cultivars. J. Exp. Bot. 66, 3463-3476. doi: 10.1093/jxb/erv098.

Rötter, R.P., Appiah, M., Fichtler, E., Kersebaum, K.C., Trnka, M., Hoffmann, M.P., 2018a. Linking modelling and experimentation to better capture crop impacts of agronomic extremes - A review. Field Crops Research. Volume 221, 15 May 2018, p. 142-156. doi: 10.1016/j.fcr.2018.02.023.

Rötter, R.P., Hoffmann, M.P., Koch, M., Müller, C., 2018b. Progress in modelling agricultural impacts of and adaptations to climate change. Curr. Opin. Plant Biol. doi: 10.1016/j.pbi.2018.05.009. 
Sattler, C., Nagel, U.J., Werner, A., Zander, P., 2010. Integrated assessment of agricultural production practices to enhance sustainable development in agricultural landscapes. Ecological Indicators 10 (2010) 49-61. doi: 10.1016/j.ecolind.2009.02.014.

Semenov, M.A., Stratonovitch, P., Alghabari, F., Gooding, M.J., 2014. Adapting wheat in Europe for climate change. Journal of Cereal Science 59 (2014) 245-256. doi: 10.1016/j.jcs.2014.01.006.

Sennhenn, A., Njaruni, D.M.G., Maas, L., and Whitbread, A.M., Exploring niches for shortseason grain legumes in semi-arid eastern Kenya - coping with the impacts of climate variability. Frontiers in plant science. doi: 10.3389/fpls.2017.00699.

Streit, J. Meinen, C., Nelson, W.C.D., Siebrecht-Schöll, D., Rauber, R., 2018. Above- and belowground biomass in a mixed cropping system with eight novel winter faba bean genotypes and winter wheat using FTIR spectroscopy for root species discrimination. Plant and Soil. doi: 10.1007/s11104-018-03904-y.

Thornton, P.K., Jones, P.G., Ericksen, P.J., and Challinor, A.J., 2011. Agriculture and food systems in sub-Saharan Africa in a $4 C^{\circ}+$ world. Phil. Trans. R. Soc. A (2011) 369, 117-136. doi: 10.1098/rsta.2010.02.0246.

Tilman, D., K.G. Cassman, P.A. Matson, R. Naylor, and S. Polasky, 2002. Agricultural sustainability and intensive production practices. Nature 418, 671-677. doi: 0.1038/nature01014.

Trnka, M. Kocmánková, E., Balek, J., Eitzinger, J., Ruget, F., Formayer, H., Hlavinka, P., Schaumberger, A., Horáková, V., Možný, M., Žalud, Z., 2010. Simple snow cover model for agrometeorological applications. Agricultural and Forest Meteorology 150 (2010) 1115-1127. doi: 10.1016/j.agrformet.2010.04.012.

Trnka, M., Rötter, R.P., Ruiz-Ramos, M., Kersebaum, K.C., Olesen, J.E., Zalud, Z., Semenov, M.A., 2014. Adverse weather conditions for European wheat production will become more frequent with climate change. Nature Climate Change 4, 637-643. doi: $10.1038 /$ nclimate2242.

Tsubo, M., Walker, S., Ogindo, H.O., 2005. A simulation model of cereal-legume intercropping systems for semi-arid regions I. Model development. F. Crop. Res. 93 (2005) 10-22. doi: 10.1016/j.fcr.2004.09.002.

Vandermeer, J., van Noordwijk, M., Anderson, J., Ong, C., Perfecto, I., 1998. Global change and multi-species agroecosystems: concepts and issues. Agr Ecosyst Environ 67:122. doi: 10.1016/S0167-8809(97)00150-3.

Varshney, R.K., Thundi, M., Pandey, M.K., Tardieu, F., Ojiewo, C., Vadez, V., Whitbread, A.M., Siddique, K.H.M., Nguyen, H.T., carberry, P.S., and Bergvinson, D., 2018. Accelerating genetic gains in legumes for the development of prosperous smallholder agriculture: integrating genomics, phenotyping, systems modelling and agronomy. Journal of Experimental Botany, Vol. 69, No. 13 pp. 3293-3312, 2018. doi: $10.1093 / \mathrm{jxb} / \mathrm{ery} 088$.

Vera, C.L., Duguid, S.D., Fox, S.L., Rashid, K.Y., Dribnenki, J.C.P., and Clarke, F.R., 2012. Short Communication: Comparative effect of lodging on seed yield of flax and wheat. Can. J. Plant Sci. (2012) 92: 39-43. doi: 10.4141/CJPS2011-031.

van Vugt, D., Franke, A.C., and Giller, K.E., 2018. Understanding variability in the benefits of N2-fixation in soybean-maize rotations on smallholder farmers' fields in Malawi. 
Agriculture, Ecosystems and Environment 261 (2018) 241-250. doi: 10.1016/j.agee.2017.05.008.

Watson, C.A., Reckling, M., Preissel, S., Bachinger, J., Bergkvist, G., Kuhlman, T., Lindstrom, K., Nemecek, T., Topp, C.F.E., Vanhatalo, A., Zander, P., MurphyBokern, D., and Stoddard, F.L., 2017. Grain Legume Production and use in European Agricultural Systems. Advances in Agronomy, May 2017. doi: 10.1016/bs.agron.2017.03.003.

Webber, H., Gaiser, T., Ewert, F., 2014. What role can crop models play in supporting climate change adaptation decisions to enhance food security in Sub-Saharan Africa? Agriucultural Systems 127 (2014) 161-177. doi: 10.1016/j.agsy.2013.12.006.

Whitbread, A.M., Hoffmann, M.P., Davoren, C.W., Mowat, D., Baldock, J.A., 2018. Measuring and Modeling the Water Balance in Low-Rainfall Cropping Systems. Trans. ASABE 60, 2097-2110. doi:10.13031/trans.12581. 


\section{SUMMARY}

Intercropping has long been a key crop production strategy for low input farming systems, such as those of smallholders, and organic farmers, where two or more crops are used to allow for the complementary use of resources, such as light, water, and nutrients. Although some intercropping systems have shown success, our understanding of them is not fully complete. The increasing need to utilise ecosystem resources as efficiently as possible demands a more comprehensive understanding, in particular as large-scale, high production farming systems begin to show interest in mixed specie crop production. A more site-specific approach is required, which looks at management aspects, such as planting practices, fertiliser and irrigation use, soil type, weather conditions, and cultivar choice. This thesis looks at cereal-legume row intercropping with very different management and environmental conditions in India and Germany. A major challenge with intercropping research is to efficiently investigate all potential scenarios using traditional experimentation. Process-based agro-ecosystem modelling is explored and used to conduct virtual experiments using the crop simulation model (CSM) APSIM. The general discussion develops overall conclusions for intercropping strategies and the scope of their future use.

Chapters two and three are based on the use of intercropping as part of a climate resilient, risk reducing cropping strategy in semi-arid regions. As there is little knowledge of how and to what extent intercropping can be a viable option under future conditions, a field experiment in the dry season offered an opportunity to test this system under extreme but real-world conditions. Consequently, a field trial was run in semi-arid India over a twoyear period (2015 and 2016) in the dry and hot (summer) season. These trials were set up as a split-split-plot experiment with four replicates to assess the performance of simultaneously sown sole versus intercropped stands of pearl millet and cowpea, with two densities (30 cm and $60 \mathrm{~cm}$ spacing between rows - both with $10 \mathrm{~cm}$ spacing within rows), and three drip irrigation treatments (severe stress, partial stress, and well-watered). Results showed that intercropping pearl millet led to a significantly lower total grain yield in comparison to the sole equivalent. Pearl millet's highest yields were $1,350 \mathrm{~kg} / \mathrm{ha}$ when intercropped and 2,970 kg/ha when grown as a sole crop; for cowpea, $990 \mathrm{~kg} / \mathrm{ha}$ when intercropped, and $1,150 \mathrm{~kg} / \mathrm{ha}$ as a sole crop. Interestingly, even when maximum daily temperatures reached up to $42.2{ }^{\circ} \mathrm{C}$ (julian day 112 in 2016), well-watered, pearl millet produced reasonable yields. We conclude that sole as opposed to intercropping systems could be a more efficient and therefore suitable practice under similar temperature regimes. However, more research would be needed to identify a suitable cowpea genotype and 
planting density that could allow for higher intercropped pearl millet yields. Clearly, despite the bulk of the literature promoting the benefits of intercropping, the system per se is not a 'silver bullet' solution to agricultural production and sustainability needs.

We believe it is important to link such detailed experimental data with models to help reveal the mechanistic processes beneath system performance. This third chapter illustrates this approach using the data presented in chapter two, which was tested against APSIM simulations. After rigorous model calibration and validation, simulation experiments evaluated the manipulation of genetic traits, such as maximum plant height, i.e. 'ideotyping'. The model showed distinct interactions and our approach the ability to highlight insights into intercropping systems. For the pearl millet-cowpea intercrop simulations, the cereal was the driver of total intercrop yield. To achieve this, the cereal intercrop component had to be taller than the cowpea.

Chapter four of this thesis looked at a mechanised system using intercrop combinations of eight winter faba bean genotypes and three winter wheat varieties on two sites in temperate central Germany. Intercropping was higher yielding than sole crop equivalents, especially on the more marginal site and soil. Limited leaf area index and canopy height of faba bean are key traits for high yielding winter bean-wheat intercrops. Based on the genetic material used in this experiment, marginal sites are better cultivated with vigorous genotypes, while fertile sites require less vigorous ones. Mirrored in the simluation experiment of chapter three, this strategy works to ensure good cereal yields as excessive legume biomass growth must not out compete the cereal for light. Winter faba beans in particular should be bred to restrain from excess vegetative biomass development under more fertile conditions.

While intercropping can play a role in robust food production systems, further experimentation is needed to help design specific GxExM combinations of intercrop systems. This thesis finishes with a detailed discussion that looks not only into findings and discussion points of the core chapters, but also some of the challenges and ways forward for intercropping research and CSM. 


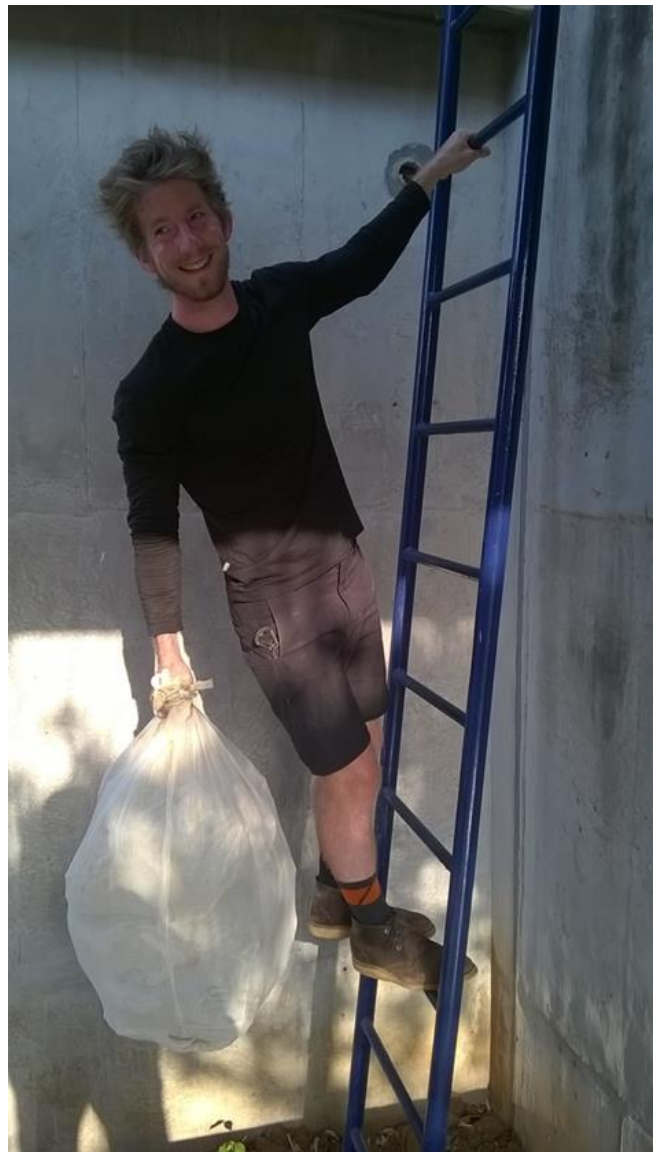

Photo credit: Anthony Whitbread, 2016.

My time as a $\mathrm{PhD}$ student has been extremely rewarding in many ways. I was given the chance to explore countries, people, my own limits and learning curves, and of course resource competition in intercropping :) For these opportunities I am hugely grateful to Anthony, who not only gave me the position, but who pushed and supported me. Field trips to India and Niger, a wonderful Indian field trial, and a 'surprise' workshop presentation I will never forget, would not have happened without your interest in our work, investment and trust in me. These were experiences that pushed me to grow thank you!

I thank Reimund, who not only accepted me as part of this team, but who saw potential in me and continues to support me. I continue to learn a great deal and am pleased to be able to contribute to your group between Göttingen and South Africa.

Vincent, thank you for welcoming me to your lab, for your constantly open door, creative mind, roast dinners, and valuable input to our work. You probably witnessed me at my most stressed, running a - then for me - ambitious field trial with little to no relevant prior experience. Thank you for your patience, flexibility, and trust.

Munir, from being your field assistant, to you 'showing me the APSIM ropes', it's been great working so closely with you, and this would not be half of what it is without your guidance and collaboration. Thank you for all the time and energy you've put into working with me. I'm pleased we will in some way collaborate in the next phase of our journeys, so I can help others with what you've helped me with, and in some way give back.

Thank you Johannes, for being an approachable, flexible and understanding figure as head of the IMPAC ${ }^{3}$ project. I 
very much look forward to the continued collaboration through SALLnet! Thank you for being my third examiner.

I am immensely grateful for my talented and generous friends, who have played a huge role in the development of my technical skills. Thank you, Susan, Purush, Pushpa, Anna and Holger, Alejandra (!!!), Marian, and Gennady. This learning curve is something that has brought me days/ weeks of frustration and joy - thank you!

Such detailed field work would not have been possible without the help of (in no particular order) Sala, James 'Beansies' Ellison, Birgit, Regina, Moira, Mitru, Mahenda, Purush, Susan, Jana, Rehka, Mahesh, and all of the GEMs team who so kindly helped me more than what was 'part of the job description'.

With so many people to thank, this has been a unique and unforgettable experience, which was certainly not achieved alone. This is the output of a collective network, many of which I hope to continue to work with. I also hope to put the energy invested and skills developed to good use.

Finally, I thank my family for supporting me, especially my partner Karina. You were a direct witness to all of the ups and downs (Gross Schneen; being the only woman on a night bus through India; me minus five kilos after 'that salad' in Niger, field-work, A1B1_inter!).
Thank you for motivating and supporting me!

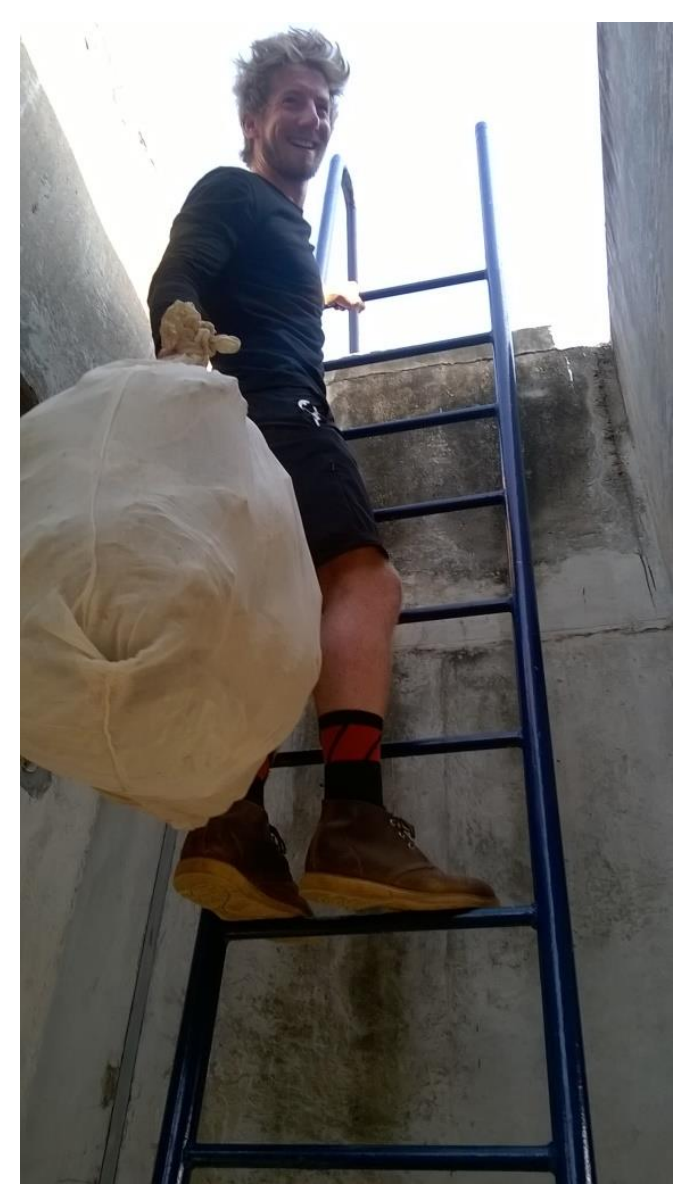

Photo credit: Anthony Whitbread, 2016. 